\title{
93
}

COSMOGENIC $^{32} \mathrm{P}$ AND ${ }^{33} \mathrm{P}$ IN THE ATMOSPHERE

AND OLIGOTROPHIC OCEAN AND APPLICATIONS

TO THE STUDY OF PHOSPHORUS CYCLING

by

\author{
Nathalie Anne Danielle Waser \\ B.S., Physical Chemistry \\ M.S., Oceanography \\ Université Pierre et Marie Curie
}

(1987)

Submitted in partial fulfillment of the requirements for the degree

of doctor of philosophy

at the

MASSACHUSETTS INSTITUTE OF TECHNOLOGY

and the

WOODS HOLE OCEANOGRAPHIC INSTITUTION

November 1992

Copyright Nathalie A. D. Waser 1992. All rights reserved.

The author hereby grants to MIT and WHOI permission to reproduce and distribute copies of this thesis document in whole or in part.

Signature of author_ $/$.

Joint Program in Oceanography

Massachusetts Institute of Technology/Woods Hole Oceanographic Institution

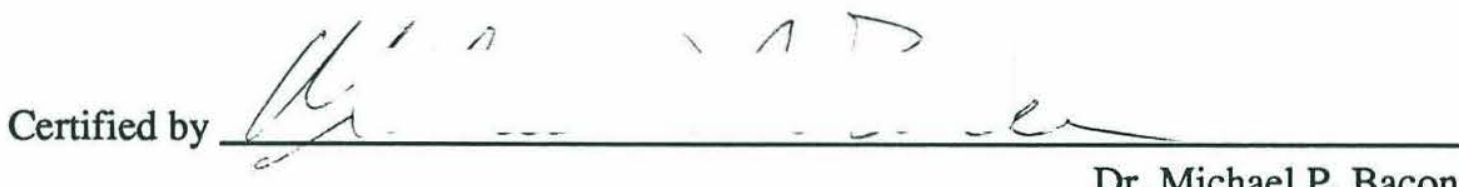

Dr. Michael P. Bacon
Thesis Supervisor

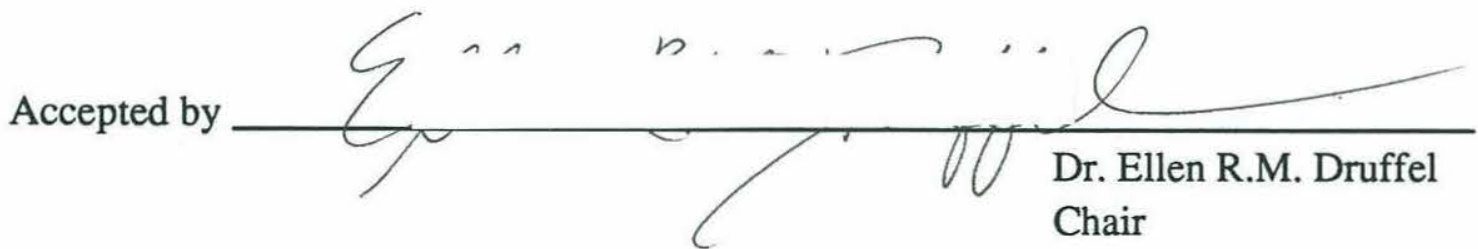

Joint Committee for Chemical Oceanography
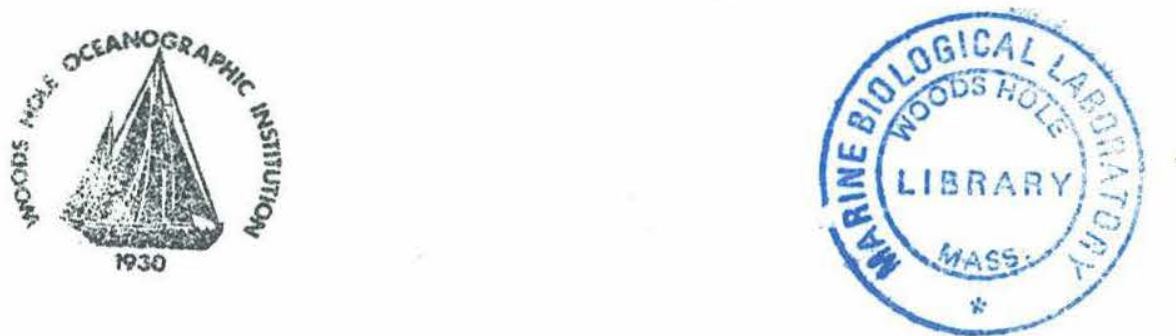


\section{COSMOGENIC $^{32}$ P AND $^{33}$ P IN THE ATMOSPHERE AND \\ OLIGOTROPHIC OCEAN AND APPLICATIONS \\ TO THE STUDY OF PHOSPHORUS CYCLING}

by

Nathalie Waser

ABSTRACT

Cosmogenic ${ }^{32} \mathrm{P}$ (14.28 days) and ${ }^{33} \mathrm{P}$ (25.3 days) are powerful tracers of upper ocean P cycling, when coupled with time-series of the atmospheric sources. A method was developed to determine the low-level beta activities in rainwater and plankton. The wet deposition rates of ${ }^{32} \mathrm{P}$ and ${ }^{33} \mathrm{P}$ were determined during 12 months at a marine site, at Bermuda, coinciding with measurements of the activities and activity ratio ${ }^{33} \mathrm{P} /{ }^{32} \mathrm{P}$ in suspended particles and plankton tows at BATS station. The in situ production rates of radiophosphorus in the upper ocean were estimated by measuring the activities induced in $\mathrm{Cl}, \mathrm{K}$ and $\mathrm{S}$ targets by cosmic rays. Knowledge of all the sources of radiophosphorus to the Sargasso Sea allowed the cycling of ${ }^{32} \mathrm{P}$ and ${ }^{33} \mathrm{P}$ in suspended particles and macrozooplankton to be studied. The study was based on the determination of the activity ratio ${ }^{33} \mathrm{P} /{ }^{32} \mathrm{P}$ in different particulate pools. The activity ratio was higher in particle collections dominated by higher levels in the food web. The increase in the ratio in plankton relative to rain allowed the determination of the turnover times of $\mathrm{P}$ in plankton and in situ grazing rates. 


\title{
COSMOGENIC $^{32} \mathrm{P}$ AND ${ }^{33} \mathrm{P}$ IN THE ATMOSPHERE AND OLIGOTROPHIC OCEAN AND APPLICATIONS \\ TO THE STUDY OF PHOSPHORUS CYCLING
}

\author{
by \\ Nathalie Waser
}

\begin{abstract}
Cosmic-ray produced ${ }^{32} \mathrm{P}\left(\mathrm{t}_{12}=14.28\right.$ days $)$ and ${ }^{33} \mathrm{P}\left(\mathrm{t}_{112}=25.3\right.$ days $)$ are power-
\end{abstract} ful tracers of upper ocean $\mathrm{P}$ cycling, when coupled with time-series estimates of the atmospheric sources. The cycle of $\operatorname{cosmogenic}{ }^{32} \mathrm{P}$ and ${ }^{33} \mathrm{P}$ in the atmosphere and euphotic zone of the ocean was investigated in the Sargasso Sea. A method was developed for the determination of the low-level beta activities of both nuclides in rainwater and marine particulate matter. The fallout rates of ${ }^{32} \mathrm{P}$ and ${ }^{33} \mathrm{P}$ by precipitation were determined over a period of 12 months at a marine site, at Bermuda, coinciding with measurements of the activities and activity ratio ${ }^{33} \mathrm{P} / \mathrm{P}$ in suspended particulate matter and plankton tows at the Bermuda Atlantic Time-series Study (BATS) station ( $\left.31^{\circ} 50^{\prime} \mathrm{N}, 64^{\circ} 10^{\prime} \mathrm{W}\right)$. The in situ production rates of ${ }^{32} \mathrm{P}$ and ${ }^{33} \mathrm{P}$ in the upper ocean were estimated by measuring the activities of ${ }^{32} \mathrm{P}$ and ${ }^{33} \mathrm{P}$ produced in $\mathrm{Cl}, \mathrm{K}$ and $\mathrm{S}$ targets exposed to cosmic rays at Woods Hole, on Mount Washington, and on l'Aiguille du Midi. Fallout by precipitation was found to be the major source of radiophosphorus to the ocean; in situ production in the upper ocean was found to account for $5 \%$ for ${ }^{32} \mathrm{P}$ and $1 \%$ for ${ }^{33} \mathrm{P}$ of the wet deposition rates. Knowledge of all the sources of radiophosphorus to the Sargasso Sea allowed the cycling of ${ }^{32} \mathrm{P}$ and ${ }^{33} \mathrm{P}$ in suspended particulate matter and macrozooplankton to be studied. The study was based on a new approach consisting of the determination of the activity ratio ${ }^{33} \mathrm{P} / 2 \mathrm{P}$ in the different pools of phosphorus. The activity ratios ${ }^{33} \mathrm{P} /{ }^{32} \mathrm{P}$ in suspended particulate matter and plankton tows ranged from 1.0 to 5.0 and were either equal to or higher than the activity ratio in rainwater. The monthly activity ratio in rain was remarkably constant and on average 0.96 . The increase in the ratio in plankton relative to rain can be interpreted as aging of the phosphorus in that pool or in the pool from which it is derived. This is because of differential radioactive decay rates of ${ }^{32} \mathrm{P}$ and ${ }^{33} \mathrm{P}$. The activity ratio was higher in particle collections dominated by higher levels in the ocean food web. The residence time of $P$ in macrozooplankton was estimated to range from 40 to 60 days. A grazing rate of macrozooplankton of 0.024 day $^{-1}$ was determined, allowing the determination of a grazing flux of $110 \mathrm{mg} \mathrm{C} / \mathrm{m}^{2} / \mathrm{d}$ and a flux of particulate carbon due to defecation of zooplankton of $30 \mathrm{mg} \mathrm{C} / \mathrm{m}^{2} / \mathrm{d}$. 


\section{ACKNOWLEDGEMENTS}

Certainly this work would not have been possible without the support, friendship and encouragements of my friends, familly and colleagues. I want first to thank my thesis advisor, Mike Bacon, for his continued support, encouragement and guidance throughout the past four years. I want also to acknowledge Professor Devendra Lal who has been, as well as his work, a great source of inspiration and enthousiasm.

I want to thank colleagues and friends in the laboratory, Alan Fleer and Terry Hammar, for their tremendous help in innumerable techniques ranging from pumping to the art of beta counting.

Collection of the rain and marine plankton samples would not have been possible without the generosity and support of Tony Michaels and the technicians working at the Bermuda Biological Station, Frances Howse, Ann Close, Kjell Gundersen and Jens Sorensen. As well I am indebted to Ollie Zafiriou for taking me along on board the Endeavor.

My committee members, Ken Buesseler, Tony Michaels, Devendra Lal and John Edmond, have provided strong support and encouragement and I want to thank them for that.

Thanks to my close friends with whom I have shared memorable moments at Woods Hole, Jessica Langsam, Ed Brook, Markku Santala, Catherine Villaret, Mike DeGrandpre, Maren Tracy, Ein-Fen Yu, Kathleen Ledyard. Thanks also to my friends and colleagues with whom I shared exciting and instructive discussions, Kathleen Ruttenberg, Ed Brook, Greg Ravizza, Brad Moran and Roger François.

Many thanks to the crew of R/V Weatherbird II, Captain Lee Black, Chief engineer Tony Sherriff, $2^{\text {nd }}$ engineer Maurice Woodmore and deckhand Chris Gibbons for their precious help. Thanks also to the cook Bruce Paynter for his warm support at times of low spirit due to "le mal de mer". Thanks also to the crew of the Endeavor and particularly to the chief engineer for his assistance. I want also to thank Jo White at the Mount Washington Observatory and Tom Trull at the Laboratoire des Isotopes Stables for their precious help in exposing salts to cosmic rays.

Finally I want to thank Jake Pierson and Abby Jackson for their finantial support and great involvement in the educational program.

Enfin, merci à toute ma famille, mes parents, Olivier et Raphaële, ainsi qu'à Patrice Klein pour son amitié. Un grand merci à Jean-François Minster pour m'avoir encouragée et supportée à venir faire ma thèse dans le Joint Program.

Funding for this research was provided by NSF (grants OCE-8800957, OCE8817836 and OCE-902284), DOE (grant DE-FG02-88ER60681), Woods Hole Oceanographic Institution, Ocean Venture Funding of Woods Hole Oceanographic Institution and Scurlock Funds of Mr Arch Scurlock to MIT/WHOI Joint Program. 


\section{TABLE OF CONTENTS}

\section{Page}

$\begin{array}{ll}\text { ABSTRACT } & 3\end{array}$

$\begin{array}{ll}\text { ACKNOWLEDGEMENTS } & 4\end{array}$

TABLE OF CONTENTS

LIST OF FIGURES $\quad 6$

LIST OF TABLES

$\begin{array}{ll}\text { INTRODUCTION } & 12\end{array}$

CHAPTER 1. Methods of measurement of ${ }^{32} \mathrm{P}$ and ${ }^{33} \mathrm{P} \quad 18$

CHAPTER 2. Determination of the fallout rates of ${ }^{32} \mathrm{P}$ and ${ }^{33} \mathrm{P}$ at Bermuda $\quad 43$

CHAPTER 3. In situ production of cosmogenic ${ }^{32} \mathrm{P}$ and ${ }^{33} \mathrm{P}$ in seawater 76

CHAPTER 4. Cosmogenic ${ }^{32} \mathrm{P}$ and ${ }^{33} \mathrm{P}$ recycling in plankton off Bermuda 96

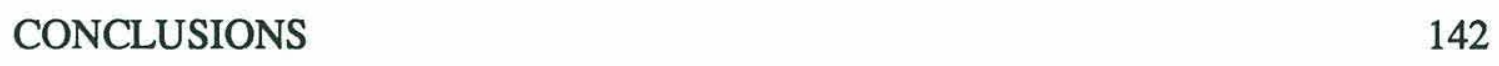

$\begin{array}{ll}\text { APPENDIX A } & 145\end{array}$ 


\section{LIST OF FIGURES}

Figure 1.1. Net count rate of ${ }^{32} \mathrm{P}$ as a function of external absorber

Figure 1.2. Net count rate of ${ }^{33} \mathrm{P}$ as a function of external absorber thickness

Figure 1.3. Net count rate of ${ }^{147} \mathrm{Pm}$ as a function of the external absorber thickness

Figure 1.4. Relative counting efficiency of ${ }^{33} \mathrm{P}$ as a function of source thickness

Figure 1.5. Relative counting efficiency of ${ }^{33} \mathrm{P}$ as a function of source thickness calculated for different values of the absorption coefficient $\mu$.

Figure 2.1. Activity ratio ${ }^{33} \mathrm{P} /{ }^{32} \mathrm{P}$ in precipitation events collected at BBSR from March 1991 to March 1992

Figure 2.2. Rainfall rates at St. David's, Bermuda, from January 1991 to March 1992

Figure 2.3. Monthly rainfall rates at St. David's, Bermuda, from January 1991 to March 1992

Figure 2.4. Activity ratio ${ }^{33} \mathrm{P} /{ }^{32} \mathrm{P}$ in rain at Bermuda averaged monthly from March 1991 to March 1992

Figure 2.5. Wet deposition rates of ${ }^{32} \mathrm{P}$ and ${ }^{33} \mathrm{P}$ averaged monthly at Bermuda from March 1991 to March 1992

Figure 2.6. Predicted ${ }^{33} \mathrm{P} /{ }^{32} \mathrm{P}$ activity ratio in rain as a function of the residence time of tropospheric aerosols

Figure 2.7. Residence time of tropospheric aerosols computed for each rain sample from the non-steady-state model and values of $R_{0}$ of 0.6 and 0.7

Figure 2.8 Monthly ${ }^{90} \mathrm{Sr}$ concentrations in $\mathrm{pCi} / \mathrm{l}$ in precipitation at Bermuda from 1967 to 1974 (HASL-315, 1977) 
Figure 3.1 Logarithm of the production rates of ${ }^{32} \mathrm{P}$ and ${ }^{33} \mathrm{P}$ (atom/ $\mathrm{min} / \mathrm{mol} \mathrm{Cl}$ ) in chlorine. The least-squares of the logarithm of the production rates are computed. The equations of the least-square fit are: $\ln { }^{32} \mathrm{P}=(1 / 155) \mathrm{X}+0.76$ and $\operatorname{Ln}^{33} \mathrm{P}=(1 / 195) \mathrm{X}-1.3$

Figure 3.2 Forty-year record of the neutron count rate recorded by the neutron detector at the Mount Washington Observatory (from J. Lockwood)

Figure 4.1 Specific activities of ${ }^{32} \mathrm{P}$ and ${ }^{33} \mathrm{P}(\mathrm{dpm} / \mathrm{mg} \mathrm{P})$ in surface suspended particles ( $>3$ or $8 \mu \mathrm{m}$ ) during BATS 34 (15-19 July 1991), BATS 38 (11-15 November 1991), BATS 41A (24-26 February 1992) and EN 235 (25-26 April 1992) at BATS Station

Figure 4.2 Profile of ${ }^{32} \mathrm{P}$ specific activity (dpm/mg P) in suspended particles (>3 $\mu \mathrm{m}$ ) during EN 235, 25-26 April 1992, at BATS Station

Figure 4.3 Profile of ${ }^{33} \mathrm{P}$ specific activity $(\mathrm{dpm} / \mathrm{mg} \mathrm{P})$ in suspended particles ( $>3 \mu \mathrm{m}$ ) during EN 235, 25-26 April 1992, at BATS Station

Figure 4.4a, b Activity ratio of ${ }^{33} \mathrm{P} / 2 \mathrm{P}$ in suspended particles and plankton tows collected with nets $(67,300 \mu \mathrm{m}$-mesh size net) during May and July 1991 at BATS station

Figure 4.4c Activity ratio of ${ }^{33} \mathrm{P} /{ }^{32} \mathrm{P}$ in suspended particles and plankton tows collected with nets $(67,300 \mu \mathrm{m}$-mesh size net) during November 1991 at BATS Station

Figure 4.4d, e Activity ratio of ${ }^{33} \mathrm{P} /{ }^{32} \mathrm{P}$ in suspended particles and plankton tows collected with nets $(67,150$ and $500 \mu \mathrm{m}$-mesh size net) during February and April 1992 at BATS Station

Figure 4.5 Monthly activity ratio ${ }^{33} \mathrm{P} /{ }^{32} \mathrm{P}$ in rainwater from March 1991 to March 1992, and activity ratio in surface suspended particles and plankton tows for May, July and November 1991, and February and April 1992

Figure 4.6 Profile of the activity ratio ${ }^{33} \mathrm{P} /{ }^{32} \mathrm{P}$ in suspended particles $(>3 \mu \mathrm{m}$ ) during EN 235, 25-26 April 1992, at BATS Station

Figure 4.7a. T profile for BATS 29A, 27 Feb to 1 March 1991 
Figure 4.7b. $\mathrm{PO}_{4}$ profile for BATS 29A, $27 \mathrm{Feb}$ to 1 March 1991

Figure 4.7c. $\mathrm{NO}_{3}$ profile for BATS 29A, $27 \mathrm{Feb}$ to 1 March 1991

$\begin{array}{lll}\text { Figure 4.8a. } & \text { T profile for BATS 31, 15-19 April } 1991 & 127\end{array}$

$\begin{array}{lll}\text { Figure 4.8b. } \mathrm{PO}_{4} \text { profile for BATS 31, 15-19 April } 1991 & 127\end{array}$

$\begin{array}{lll}\text { Figure 4.8c. } \mathrm{NO}_{3} \text { profile for BATS 31, 15-19 April } 1991 & 127\end{array}$

$\begin{array}{lll}\text { Figure 4.9a. T profile for BATS 34, 15-19 July } 1991 & 128\end{array}$

$\begin{array}{lll}\text { Figure 4.9b. } \mathrm{PO}_{4} \text { profile for BATS 34, 15-19 July } 1991 & 128\end{array}$

$\begin{array}{lll}\text { Figure 4.9c. } \quad \mathrm{NO}_{3} \text { profile for BATS 34, 15-19 July } 1991 & 128\end{array}$

$\begin{array}{lll}\text { Figure 4.9d. Chl a profile for BATS 34, 15-19 July } 1991 & 128\end{array}$

Figure 4.10a. T profile for BATS 38, 11-15 November 1991

Figure 4.10b. $\mathrm{PO}_{4}$ profile for BATS 38, 11-15 November 1991

Figure 4.10c. $\mathrm{NO}_{3}$ profile for BATS 38, 11-15 November 1991

Figure 4.10d. Chl a profile for BATS 38, 11-15 November 1991

Figure 4.11a. T profile for BATS 41A, 24-26 February 1992

Figure 4.11b. $\mathrm{PO}_{4}$ profile for BATS 41A, 24-26 February 1992

Figure 4.11c. $\mathrm{NO}_{3}$ profile for BATS 41A, 24-26 February 1992

Figure 4.11d. Chl a profile for BATS 41A, 24-26 February 1992

Figure 4.12a Temperature profiles for EN 235, 23 April 1992, at BATS station

Figure 4.12b. $\mathrm{NO}_{3}$ profiles for EN 235, 23, 25 and 26 April 1992, at BATS station 


\section{LIST OF TABLES}

Page

Chapter Two

Table 2.1. Activities of ${ }^{32} \mathrm{P}$ and ${ }^{33} \mathrm{P}\left(\mathrm{A}_{3}{ }_{2}\right.$ and $\left.\mathrm{A}_{3}{ }_{3}\right)$ and activity ratio ${ }^{33} \mathrm{P} /{ }^{32} \mathrm{P}(\mathrm{R})$ in rain samples obtained from the roof of a building at BBSR

Table 2.2. Activities of ${ }^{32} \mathrm{P}$ and ${ }^{33} \mathrm{P}\left(\mathrm{A}_{32}\right.$ and $\left.\mathrm{A}_{3}{ }_{3}\right)$ and activity ratio ${ }^{33} \mathrm{P} /{ }^{32} \mathrm{P}(\mathrm{R})$ in rain samples obtained from a $3 \mathrm{~m}^{2}$ rain collector situated on the roof of Clark Building

Table 2.3. Seasonal averages of the activity ratio ${ }^{33} P /{ }^{32} P(R)$ in rain and associated residence times of tropospheric aerosols at Bermuda for two different values of $R_{0}$

Table 2.4. Monthly averages of the activities of ${ }^{32} \mathrm{P}$ and ${ }^{33} \mathrm{P}\left(\mathrm{A}_{32}\right.$ and $\left.A_{3} 3\right)$, rainfall rate $(r)$ and wet deposition rates of ${ }^{32} P$ and ${ }^{33} P\left(W_{3} 2\right.$ and $\mathrm{W}_{33}$ ) at Bermuda in 1991 and 1992

Table 2.5. Seasonal wet deposition rates of ${ }^{32} \mathrm{P}$ and ${ }^{33} \mathrm{P}\left(\mathrm{W}_{32}\right.$ and $\left.\mathrm{W}_{32}\right)$, seasonal activities $\left(A_{3} 2\right.$ and $\left.A_{3} 3\right)$ and seasonal rainfall rates (r)

Table 2.6. Residence time $(\tau)$ derived from the activity ratio ${ }^{33} \mathrm{P} /{ }^{32} \mathrm{P}$ $(\mathrm{R})$ in each precipitation event sampled

Chapter three

Table 3.1. Nuclear reactions occurring in nucleonic spallation reactions in $\mathrm{Cl}, \mathrm{S}$ and $\mathrm{K}$

Table 3.2. Production rates of ${ }^{32} \mathrm{P}$ and ${ }^{33} \mathrm{P}$ in $\mathrm{Cl}, \mathrm{S}$ and $\mathrm{K}$ targets at l'Aiguille du Midi, Mount Washington and Woods Hole

Table 3.3. Comparison of production rates of ${ }^{32} \mathrm{P}$ and ${ }^{33} \mathrm{P}$ in $\mathrm{Cl}, \mathrm{S}$ and $\mathrm{K}$ at sea level

Table 3.4. In situ production rates of ${ }^{32} \mathrm{P}$ and ${ }^{33} \mathrm{P}$ in $\mathrm{Cl}, \mathrm{S}$ and $\mathrm{K}$ targets. The production rates are calculated for the upper ocean and geomagnetic latitude of Bermuda $\left(\lambda=43.6^{\circ} \mathrm{N}\right)$

Table 3.5. In situ oceanic production rates of ${ }^{32} \mathrm{P}$ and ${ }^{33} \mathrm{P}$ 
Chapter Four

Table 4.1. Specific activities of ${ }^{32} \mathrm{P}$ and ${ }^{33} \mathrm{P}$ and activity ratio ${ }^{33} \mathrm{P} /{ }^{32} \mathrm{P}$ in plankton tows collected with a $67-\mu \mathrm{m}$ plankton net in March 1991 at BATS station

Table 4.2. Specific activities of ${ }^{32} \mathrm{P}$ and ${ }^{33} \mathrm{P}$ and activity ratio ${ }^{33} \mathrm{P} /{ }^{32} \mathrm{P}$ in plankton tows collected with a 300- $\mu \mathrm{m}$ mesh net, 29 April-1 May 1991 at BATS station

Table 4.3. Specific activities of ${ }^{32} \mathrm{P}$ and ${ }^{33} \mathrm{P}$ and activity ratio ${ }^{33} \mathrm{P} /{ }^{32} \mathrm{P}$ in suspended particles $(>8 \mu \mathrm{m})$ and in plankton tows $(67-\mu \mathrm{m}$ mesh size net) collected during BATS 34, 15-19 July 1991

Table 4.4. Specific activities of ${ }^{32} \mathrm{P}$ and ${ }^{33} \mathrm{P}$ and activity ratio ${ }^{33} \mathrm{P} /{ }^{32} \mathrm{P}$ in plankton tows and suspended particulate $(>3 \mu \mathrm{m})$ samples collected during BATS 38, 11-15 November 1991

Table 4.5. Specific activities of ${ }^{32} \mathrm{P}$ and ${ }^{33} \mathrm{P}$ and activity ratio ${ }^{33} \mathrm{P} /{ }^{32} \mathrm{P}$ in plankton tows and suspended particulate $(>3 \mu \mathrm{m})$ samples collected during BATS 41A, 24-25 February 1992

Table 4.6. Specific activities of ${ }^{32} \mathrm{P}$ and ${ }^{33} \mathrm{P}$ and activity ratio ${ }^{33} \mathrm{P} /{ }^{32} \mathrm{P}$ in suspended particles $(>3 \mu \mathrm{m})$ and in plankton tows collected during EN 235 in April 1992 at BATS station

Table 4.7. Activities of ${ }^{32} \mathrm{P},{ }^{33} \mathrm{P}$ and concentrations of $\mathrm{P}$ in suspended matter $(>3-8 \mu \mathrm{m})$ at BATS station

Table 4.8. Mass balance of ${ }^{32} \mathrm{P}$ and ${ }^{33} \mathrm{P}$ in the euphotic zone. The activities (i.e., $A_{32}$ and $A_{3} 3$ ), the radioactive decay terms (i.e., $\lambda_{32} A_{32}$ and $\left.\lambda_{3}{ }_{3} A_{3} A_{3}\right)$ and wet deposition rates in the euphotic zone are computed

\section{List of tables in appendix A}

Table A.1. Total net count rates (Nt) and count rates with absorber (Na) for the rain samples collected at Woods Hole (first three rows) and at BBSR during 1990, 1991 and 1992

Table A.2. Net count rates of the source with absorber (Na) and without (Nt) as a function of time, for particle samples collected at the Bermuda Atlantic Time-series (BATS) station in 1991 and 1992 
Table A.3. Thickness (d), yield (Y), counting efficiencies ( $\varepsilon_{32}$ and $\left.\varepsilon_{33}\right)$, volume of rain water $(\mathrm{V})$ and net count rates at the time of collection $\left(\mathrm{N}_{3}{ }_{2}\right.$ and $\left.\mathrm{N}_{3}{ }_{3}\right)$ of rain samples collected at Woods Hole (first 3 rows) and at BBSR

Table A.4. Thickness (d), yield (Y), counting efficiencies $\left(\varepsilon_{32}\right.$ and $\left.\varepsilon_{33}\right)$ and net count rates at the time of collection $\left(\mathrm{N}_{3} 2\right.$ and $\left.\mathrm{N}_{3}{ }_{3}\right)$ in plankton tow samples collected with a 67- $\mu \mathrm{m}$ plankton net in March 1991

Table A.5. Thickness (d), yield (Y), counting efficiencies $\left(\varepsilon_{32}\right.$ and $\left.\varepsilon_{33}\right)$ and net count rates at the time of collection $\left(\mathrm{N}_{3} 2\right.$ and $\left.\mathrm{N}_{3}{ }_{3}\right)$ in plankton tows collected with a 300- $\mu$ m net on 29 April-1 May 1991

Table A.6. Thickness (d), yield (Y), counting efficiencies $\left(\varepsilon_{32}\right.$ and $\left.\varepsilon_{33}\right)$ and net count rates at the time of collection $\left(\mathrm{N}_{3}{ }_{2}\right.$ and $\left.\mathrm{N}_{3}{ }_{3}\right)$ in suspended particles and in plankton tows collected with a $67-\mu \mathrm{m}$ net during BATS 34 , 15-19 July 1991

Table A.7. Thickness (d), yield (Y), counting efficiencies $\left(\varepsilon_{32}\right.$ and $\left.\varepsilon_{33}\right)$ and net count rates at the time of collection $\left(\mathrm{N}_{3} 2\right.$ and $\mathrm{N}_{3} 3$ ) in plankton tow and suspended particulate samples ( $3-\mu \mathrm{m}$ mesh size) collected during BATS 38, 11-15 November 1991

Table A.8. Thickness (d), yield (Y), counting efficiencies ( $\varepsilon_{32}$ and $\varepsilon_{33}$ ) and net count rates at the time of collection $\left(\mathrm{N}_{3} 2_{2}\right.$ and $\left.\mathrm{N}_{3}{ }_{3}\right)$ in plankton tows and suspended particulate samples (Millipore 3- $\mu \mathrm{m}$ ) samples collected during BATS 41A, 24-25 February 1992

Table A.9. Thickness (d), yield (Y), counting efficiencies $\left(\varepsilon_{32}\right.$ and $\left.\varepsilon_{33}\right)$ and net count rates at the time of collection $\left(\mathrm{N}_{3} 2\right.$ and $\left.\mathrm{N}_{3} 3\right)$ in suspended particles and in plankton tows collected during EN 235 in April 1992 at BATS station

Table A.10. Thickness (d), yield (Y), counting efficiencies $\left(\varepsilon_{32}\right.$ and $\left.\varepsilon_{33}\right)$ and net count rates at the time of collection $\left(\mathrm{N}_{3}{ }_{2}\right.$ and $\left.\mathrm{N}_{3}{ }_{3}\right)$ of the samples exposed to cosmic rays in Woods Hole $\left(\lambda=53^{\circ} \mathrm{N}\right)$, Mt. Washington $\left(\lambda=55.7^{\circ} \mathrm{N}\right)$ and l'Aiguille du Midi $\left(\lambda=47^{\circ} \mathrm{N}\right)$ 


\section{INTRODUCTION}

In order to understand the magnitude and variations of primary productivity in the oligotrophic Sargasso Sea, as in any other oceanic province, it is essential to study the factors that control productivity. Primary productivity in the Sargasso Sea is likely regulated by the supply of nutrients into the euphotic zone during deep winter mixing (Menzel and Ryther, 1961; Marra et al., 1990) and by the rate of nutrient recycling (Goldman, 1988). Time-series measurements near Bermuda reveal correlations between the export flux of carbon, the flux of particle-reactive radionuclides in the deep ocean and primary productivity in the euphotic zone with a time-lag consistent with the sinking speed of large particles (Deuser and Ross, 1980; Bacon et al., 1985; Deuser, 1986; Asper et al., 1992). The study of nutrient cycles in the upper ocean remains a central issue for a complete understanding of the biological pump and its effect on the deep ocean.

There is recent evidence that primary productivity in the Sargasso Sea is higher than previously estimated with ${ }^{14} \mathrm{C}$ incubation techniques (Jenkins and Goldman, 1985; Jenkins, 1988). Recent primary productivity estimates (Michaels et al., 1992) at the Bermuda Atlantic Time-series Study (BATS) station are two-fold higher than the historical rate, possibly reflecting the use of cleaner techniques (Fitzwater et al., 1982). The fundamental processes that govern both the rate of carbon fixation and its export to the deep ocean remain poorly understood. Recent studies of photosynthesis-irradiance relationships suggest that there is a direct physiological control by nutrients on primary productivity in the North Sargasso Sea (Platt et al., 1992; Falkowski et al., 1992). 
Overall, the exact relationship between new production, primary production and nutrients, particularly which nutrient is limiting productivity, remain in doubt.

Among the processes that are most important in nutrient cycles and their relation to ocean productivity are uptake and regeneration rates and thus the fate and pathways of nutrients from the autotrophs to the higher trophic levels. The amount of C, $\mathrm{N}$ and $\mathrm{P}$ export to the deep ocean depends not only on the amount of nutrients being supplied to the euphotic zone, but also on the efficiency of the transfer of C, N and P to higher trophic levels (Eppley and Peterson, 1979; Goldman, 1988; Michaels and Silver, 1988). Therefore, it is important to determine the uptake rates, regeneration rates and turnover times of nutrients in the euphotic zone, because they directly determine the extent of new production versus primary production (Eppley and Peterson, 1979).

Phosphorus is one of the fundamental building blocks of all forms of living aquatic organisms. Its study has been neglected in favor of the cycles of nitrogen and carbon. It is a widespread view among biologists that $\mathrm{N}$ is the limiting nutrient in ocean ecosystems as opposed to P limitation in freshwater ecosystems (Perry and Eppley, 1981). Recently the role of $P$ in the oligotrophic ocean has received renewed interest (Fanning, 1989; Michaels et al., 1992; Karl et al., 1992; Fanning, 1992). With the results of the time-series studies of two oligotrophic oceans, the Sargasso Sea and the North Pacific Sub-tropical Gyre, the role of $\mathrm{P}$ in the marine environment has been reexamined (Karl et al., 1992; Michaels et al., 1992). Fanning (1992) recently reported puzzlingly high ratios of dissolved inorganic nitrogen to dissolved inorganic phosphorus (DIN/DIP) in the North Atlantic Ocean in contrast to all other oceans, raising the question of the relative role of $\mathrm{N}$ and $\mathrm{P}$ as limiting nutrients. DIN/DIP ratios below the euphotic zone down to $800 \mathrm{~m}$ at BATS are high, sometimes up to 40 (mole ratio), and always higher than the Redfield ratio of 16 (Knap et al., 1991; Knap et al., 1992; Michaels et al., 1992). Unfortunately, dissolved organic nitrogen (DON) and dissolved organic phosphorus 
(DOP) data are not measured routinely at BATS, so total dissolved nitrogen (TDN) and total dissolved phosphorus (TDP) cannot be compared. The high DIN/DIP regenerated below the euphotic zone might be indicative of P-depleted particles being regenerated or another source of nitrogen. These results are very puzzling and might be explained by (1) nitrogen fixation (Karl et al., 1992; Fanning, 1992), (2) high atmospheric supply of nitrogen relative to phosphorus due to polluted air (Fanning, 1989), or (3) blooms dominated by coccolithophorids (Fanning, 1992). These observations have pointed out the weakness of the current understanding of $\mathrm{P}$ and $\mathrm{N}$ cycles and their coupling in the oligotrophic ocean. If nitrogen fixation is truly an important process supplying $\mathrm{N}$ to phytoplankton in the ocean, then P should be the ultimate limiting nutrient.

The subject of this thesis is the study of the phosphorus cycle in the Sargasso Sea using two naturally produced radioisotopes of phosphorus. Cosmogenic ${ }^{32} \mathrm{P}\left(\mathrm{t}_{1 / 2}=\right.$ $\left.14.28 \mathrm{~d} ; \mathrm{E}_{\text {max }}=1.71 \mathrm{MeV}\right)$ and ${ }^{33} \mathrm{P}\left(\mathrm{t}_{1 / 2}=25.3 \mathrm{~d} ; \mathrm{E}_{\max }=0.249 \mathrm{MeV}\right)$ are beta emitters produced by spallation reactions in $\mathrm{Ar}$, in the atmosphere, and by spallation in $\mathrm{Cl}, \mathrm{S}, \mathrm{Ca}$ and $\mathrm{K}$ in the ocean. Very recently the first measurements of the minute activities of ${ }^{32} \mathrm{P}$ and ${ }^{33} \mathrm{P}$ in seawater were obtained (Lal and Lee, 1988; Lal et al., 1988). More extensive measurements of ${ }^{32} \mathrm{P}$ were made in TDP, DIP, DOP and plankton tows (Lal et al., 1988; Lee et al., 1991; Lee et al., 1992) demonstrating the feasibility of applying ${ }^{32} \mathrm{P}$ and perhaps ${ }^{33} \mathrm{P}$ to the study of the $\mathrm{P}$ cycle in the upper ocean. There were very few data on ${ }^{33} \mathrm{P}$ because ${ }^{33} \mathrm{P}$ is a weak beta emitter and thus hard to detect. The approach of this thesis consists of utilizing ${ }^{32} \mathrm{P}$ and ${ }^{33} \mathrm{P}$ and the ratio ${ }^{33} \mathrm{P} /{ }^{32} \mathrm{P}$ to determine the residence time of $\mathrm{P}$ in plankton and in the euphotic zone and the export of $\mathrm{P}$ out of the euphotic zone at the Bermuda Atlantic Time-series Study (BATS) station $\left(31^{\circ} 50^{\prime} \mathrm{N}, 64^{\circ} 10^{\prime} \mathrm{W}\right)$ in different seasons. In order to determine the turnover times of $\mathrm{P}$ in particles and in the total dissolved phosphorus, the mass balances of ${ }^{32} \mathrm{P}$ and ${ }^{33} \mathrm{P}$ in the euphotic zone need to be accurately constrained. The fallout rates of ${ }^{32} \mathrm{P}$ and ${ }^{33} \mathrm{P}$ by 
precipitation at Bermuda and the in situ production rates in seawater have thus been determined. The wet deposition rates of ${ }^{32} \mathrm{P}$ and ${ }^{33} \mathrm{P}$ have not been previously estimated at Bermuda, and it is important to document the variability of the supply of these short-lived nuclides at the study site. The in situ production of ${ }^{32} \mathrm{P}$ and ${ }^{33} \mathrm{P}$ has been estimated previously (Lal et al., 1988) but not measured directly in all of the possible targets in sea salt. 


\section{Bibliography}

Asper, V.L., W.G. Deuser, G.A. Knauer and S.E. Lohrenz, 1992. Rapid coupling of sinking particle fluxes between surface and deep ocean waters. Nature 357:670-672.

Bacon, M.P., C. Huh, A.P. Fleer and W.G. Deuser. 1985. Seasonality in the flux of natural radionuclides and plutonium in the deep Sargasso Sea. Deep Sea Res. 32:273285.

Deuser, W.G. 1986. Seasonal and interannual variations in deep-water particle fluxes in the Sargasso Sea and their relation to surface hydrography. Deep Sea Res. 33:225-246.

Deuser, W.G. and E.H. Ross. 1980. Seasonnal changes in the flux of organic carbon to the deep Sargasso Sea. Nature 283:364-365.

Eppley, R.W., and B.J. Peterson, 1979. Particulate organic matter flux and planktonic new production in the deep ocean. Nature 282:677-680.

Falkowski, P.G., R.M. Greene and, R.J. Geider. 1992. Physiological limitations on phytoplankton productivity in the ocean. Oceanogr. 5(2): 84-91.

Fanning, K.A., 1992. Influence of atmospheric pollution on nutrient limitation in the ocean. Nature, 339:460-

Fanning, K.A., 1992. Nutrient provinces in the sea: concentration ratios, reaction rate ratios, and ideal covariation. J. Geophys. Res. 97:5693-5712.

Fitzwater, S.E., G.A. Knauer and J.H. Martin, 1982. Metal contamination and its effect on primary production measurements. Limnol. Oceanogr., 27: 544-551.

Goldman, J. C., 1988. Spatial and temporal discontinuities of biological processes in pelagic surface waters. In: B.J. Rothschild (ed), Toward a theory on biological-physical interactions in the world ocean. Kluwer Academic Publisher, pp 273-296.

Karl, D.M., R. Letelier, D.V. Hebel, D.F. Bird and C.D. Winn. 1992. Trichodesmium blooms and new nitrogen in the North Pacific gyre. In: E.J. Carpenter, D.G. Capone and J.G. Rueter (eds.), Biology and ecology of diazotrophic marine organisms: trichodesmium and other species. Kluwer Academic Publishers, pp 1-19.

Knap, A. H., Michaels, A.F., R.L. Dow, R.J. Johnson, K. Gundersen, J. Sorensen, and A. Close, M. Hammer, G.A. Knauer, S.E. Lohrenz, V.A. Asper, M. Tuel, H Ducklow, H. 
Quinby, P. Brewer and R. Bidigare, 1992. U.S. Joint Global Ocean Flux Study, Bermuda Atlantic Time-series Study. BATS Data Report B-2, 1992.

Knap, A. H., Michaels, A.F., R.L. Dow, R.J. Johnson, K. Gundersen, G.A. Knauer, S.E. Lohrenz, V.A. Asper, M. Tuel, H Ducklow, H. Quinby and P. Brewer 1992. U.S. Joint Global Ocean Flux Study, Bermuda Atlantic Time-series Study. BATS Data Report B1A, 1991.

Lal, D. and T. Lee, 1988, Cosmogenic ${ }^{32} \mathrm{P}$ and ${ }^{33} \mathrm{P}$ used as tracers to study phosphorus recycling in the ocean. Nature 333:752-754.

Lal, D., Chung, Y., Platt, T. and T. Lee, 1988, Twin cosmogenic radiotracer studies of phosphorus cycling and chemical fluxes in the upper ocean. Limnol. Oceanogr. 33:15591567.

Lee, T., E. Barg and D. Lal, 1991. Studies of vertical mixing in the Southern California Bight using cosmogenic radionuclides ${ }^{32} \mathrm{P}$ and ${ }^{7} \mathrm{Be}$, Limnol. Oceanogr. 36:1044-1053.

Lee, T., E. Barg and D. Lal, 1992. Techniques for extraction of dissolved inorganic and organic phophorus from large volumes of seawater. Anal. Chim. Acta 260:113-121.

Marra, J., R.R. Bidigare and T.D. Dickey, 1990. Nutrients and mixing, chlorophyll and phytoplankton growth. Deep Sea Res., 37:127-143.

Menzel, D.W. and J.H. Ryther, 1961. Annual variations in primary production of the Sargasso Sea off Bermuda. Deep Sea Res., 7:282-288.

Michaels, A.F., A.H. Knap, R.L. Dow, K. Gundersen, R.J. Johnson, J. Sorensen, A. Close, G.A. Knauer, S.E. Lohrenz, V.A. Asper, M. Tuel and R. Bidigare, 1992. Ocean time-series measurements off Bermuda: The first two years of US JGOFS Bermuda Atlantic Time-series Study. Deep Sea Res., in press.

Michaels, A.F and M.W. Silver, 1988. Primary production, sinking fluxes and the microbial food web. Deep Sea Res., 35:473-490.

Perry, M. J. and R. W. Eppley, 1981. Phosphate uptake by phytoplankton in the central North Pacific Ocean. Deep Sea Res., 28A:39-49.

Platt, T., S. Sathyendranath, O. Ulloa, W. Harrison, N. Hoepffner and J. Goes. 1992. Nutrient control of phytoplankton photosynthesis in the Western North Atlantic. Nature $356: 229-231$. 


\section{Chapter One}

\section{METHODS OF MEASUREMENT OF ${ }^{32} \mathrm{P}_{\text {AND }}{ }^{33} \mathrm{P}$}

\section{INTRODUCTION}

Activities of ${ }^{32} \mathrm{P}\left(\mathrm{t}_{1 / 2}=14.28\right.$ days $)$ and ${ }^{33} \mathrm{P}\left(\mathrm{t}_{1 / 2}=25.3\right.$ days $)$ in seawater have only been measured very recently (Lal et al., 1988; Lal and Lee, 1988; Lee et al., 1991; Lee et al., 1992). In spite of their tremendous potential for tracing processes involving phosphorus in the environment, the very low activities in nature have impeded their use in biogeochemistry. Very low counting backgrounds and, more importantly, high specific activities are essential to their detection by low-level $\beta$ counting. The background can be reduced by the use of an anticoincidence system surrounding the primary detector. High activities can be obtained by preconcentration in the field. Preconcentration of the activity in rainwater is achieved here by concentrating the activity of the dissolved phase on alumina, a specific adsorbent of phosphate, in a system similar in principle to the one used by Silker $(1969,1971)$. Large volume filtration is utilized to collect suspended particulate matter. To separate ${ }^{32} \mathrm{P}$ and ${ }^{33} \mathrm{P}$ a nuclear technique has to be sought. The two isotopes are distinguished by their half-lives and by the very distinct energy spectrum of the electrons emitted in the decay. Their half-lives are not different enough to enable their separation by decay-curve analysis. In contrast, ${ }^{32} \mathrm{P}\left(\mathrm{E}_{\max }=1.71 \mathrm{MeV}\right)$ is a much more energetic emitter than ${ }^{33} \mathrm{P}\left(\mathrm{E}_{\max }=0.249 \mathrm{MeV}\right)$. As a consequence, the absorption characteristics of the two isotopes differ enough that an external absorber of a given thickness will absorb all the radiation from ${ }^{33} \mathrm{P}$ but only a small fraction of the radiation from ${ }^{32} \mathrm{P}$. I have used this absorber method to separate ${ }^{32} \mathrm{P}$ and ${ }^{33} \mathrm{P}$. 


\section{COLLECTION AND EXTRACTION OF RADIOPHOSPHORUS}

\section{1- Principle}

The preconcentration of dissolved ${ }^{32} \mathrm{P}$ and ${ }^{33} \mathrm{P}$ from rainwater has been achieved by extracting the radiophosphorus on alumina. The sorption properties of alumina with respect to orthophosphate have been well studied. Sorption studies have been carried out at different $\mathrm{pHs}, \mathrm{PO}_{4}$ concentration, and in the presence of inorganic and organic species (Chen et al., 1973; Huang, 1975; Stumm et al., 1980; Morel, 1983). The process by which $\mathrm{PO}_{4}$ binds to the surface has been described as a ligand exchange reaction in which $\mathrm{PO}_{4}$ replaces a hydroxide group at the surface (Stumm et al. 1980). In addition, my own experiments have shown faster removal of $\mathrm{PO}_{4}$ from solution on freshly precipitated aluminum hydroxides than on freshly precipitated ferric hydroxides in the absence of other inorganic or organic species at $\mathrm{pH} 7$. For this reason, alumina was the adsorbent of choice for this study.

\section{2- Rain sampling}

Rain samples were collected from the roof of a building at the Bermuda Biological Station for Research (BBSR) and from a collector situated on the roof of Clark building in Woods Hole. The collectors enabled the collection of the 10 to $60 \mathrm{l}$ of rainwater necessary to detect radiophosphorus. The rainwater was spiked with $100 \mu$ moles of stable $\mathrm{KH}_{2} \mathrm{PO}_{4}$, which served as carrier and enabled the yield of the extraction and purification procedures to be determined. The rainwater was left to equilibrate for 4-6 hours. The sample was then pumped (with a peristaltic pump) through a plexiglass unit containing about $7 \mathrm{~g}$ of alumina (Activated alumina, 98\% powder, Matheson Coleman and Dell) packed between two porous polyethylene filters $(3.5 \mathrm{~cm}$ in diameter). The extraction efficiency of $\mathrm{PO}_{4}$ was better than $98 \%$ for a volume of $60 \ell$ of rainwater and flow rates of $5 \ell / \mathrm{min}$ or less. This efficiency was confirmed by laboratory experiments. 
In the laboratory, $50-140 \ell$ of distilled water and filtered seawater $(0.2 \mu \mathrm{m})$ from Vineyard Sound were spiked with stable phosphate. Phosphate was extracted on alumina with efficiencies higher than $98 \%$ in the case of distilled water. In the experiment with filtered seawater, the efficiencies decreased from 100 to $90 \%$ during the course of the extraction. Once the extraction was completed, the resin was sent by Federal Express to WHOI, where the alumina was processed in the laboratory.

\section{3- Particulate sampling}

Different size fractions of particles were sampled. Particles were collected using 293-mm diameter Millipore ${ }^{\mathrm{TM}}$ filters ( 3 or $8 \mu \mathrm{m}$ mesh size). These samples were collected with a simple filtration system which consisted of either an impeller pump or a diaphragm pump connected to a $293-\mathrm{mm}$ filter holder. The pump was placed upstream of the filter holder. For surface samples a vacuum hose was lowered to a depth of 3-5 meters over the side of the ship. For deep samples the vacuum hose was attached to a weight on the hydrowire, and the rest of the hose was allowed to float freely at the surface. With this system I could pump $1,000 \ell$ at 10 to $45 \mathrm{psi}$ in about 1 hour. The filter clogged fast and was changed as soon as the flow rate started to decrease, which was about every hour. The filters were immediately frozen to avoid release of phosphorus compounds (Collier and Edmond, 1984). Particles larger than 67, 150, 300 and $500 \mu \mathrm{m}$ were harvested with plankton nets. The particles were sampled at the surface and at depth. Samples were recovered from the cod end and gravity filtered on Whatman filters and immediately frozen.

\section{RADIOCHEMICAL PURIFICATION}

\section{1- Rain samples}


The $\mathrm{Al}_{2} \mathrm{O}_{3}$ was removed from the filter holders and slurried in $1 \mathrm{~N} \mathrm{NaOH}$. $\mathrm{NaOH}$ has been reported to be efficient at releasing $\mathrm{PO}_{4}$ adsorbed by aluminum oxides and hydroxides (Dickman and Bray, 1940; Turner and Rice, 1954). NaOH (1N) removed adsorbed $\mathrm{P}$ from $\mathrm{Al}_{2} \mathrm{O}_{3}$, but large volumes of it were necessary to get good recoveries (> $50 \%$ ). Typically for rain samples $800 \mathrm{~m} \ell$ to $1 \ell$ of $1 \mathrm{~N} \mathrm{NaOH}$ was used and boiled down to about $200 \mathrm{~m}$. The alkaline solution was then poured gradually into a $6 \mathrm{~N} \mathrm{HNO}_{3}$ solution. The $\mathrm{pH}$ of the solution was kept below 2 to avoid formation of massive amounts of aluminum hydroxide colloids.

\section{2- Particulate samples}

The frozen Millipore ${ }^{\mathrm{TM}}$ filters and the zooplankton samples were refluxed for a few hours in concentrated $\mathrm{HNO}_{3}$ until the solution was clear. If refractory particles were present, the solution was filtered. The solution was then taken down to a small volume and diluted to about $1 \mathrm{~N} \mathrm{HNO}_{3}$ with distilled water. At this point, an aliquot of the solution was analysed for phosphate, i.e. the yield monitor, by the classic molybdenum blue method (Murphy and Riley, 1962; Koroleff, 1983).

\section{3- Radiochemical procedure}

The chemical purification of phosphorus is based on a series of specific phosphate precipitations, which have been described in the classic chemistry and radiopurification methods (Hillebrand et al., 1959; Mullins and Leddicotte, 1962; Volchock and De Planque, 1983; Whaley and Ferrara, 1972). The sample solution in $\mathrm{HNO}_{3}$ was heated, and an excess of ammonium molybdate was added. This solution was heated to about 30$40{ }^{\circ} \mathrm{C}$ and stirred until a yellow precipitate of ammonium phosphomolybdate $\left(\mathrm{NH}_{4}\right)_{3} \mathrm{PO}_{4}\left(\mathrm{MOO}_{3}\right)_{12}$ appeared. The ammonium phosphomolybdate precipitation is a preliminary separation which reduces the amount of heavy metals, particularly $\mathrm{Fe}, \mathrm{Co}$, $\mathrm{Ni}, \mathrm{Cr}, \mathrm{Ti}$ and $\mathrm{Zr}$ (Mullins and Leddicotte, 1962). Heating of the solution was stopped 
while stirring was maintained and the precipitation process allowed to continue. If heating was continued too long (at temperatures higher than $50^{\circ} \mathrm{C}$ ), molybdic acid would start to precipitate, and the precipitate would be contaminated with $\mathrm{Si}$, As and V (Hillebrand et al., 1959). After about one hour the precipitate was vacuum filtered through a Millipore ${ }^{\mathrm{TM}} \mathrm{HA}$ filter $(0.45 \mu \mathrm{m}, 47 \mathrm{~mm}$ in diameter $)$ and washed with $1 \mathrm{~N}$ $\mathrm{HNO}_{3}$. Sometimes the precipitate was so fine that a $0.2 \mu \mathrm{m}$ Millipore ${ }^{\mathrm{TM}}$ filter had to be used. The precipitate was dissolved with $\mathrm{NH}_{4} \mathrm{OH}$ and the solution acidified to $1 \mathrm{~N}$ $\mathrm{HNO}_{3}$. Ammonium phosphomolybdate was precipitated a second time and redissolved with ammonia. The $\mathrm{pH}$ of the solution was then lowered to about 7 with $\mathrm{HCl}$. The solution was cooled in an ice bath. A reagent containing $\mathrm{MgCl}_{2}$ and $\mathrm{NH}_{4} \mathrm{Cl}$ was added to the cold solution. Drops of $\mathrm{NH}_{4} \mathrm{OH}$ were added while stirring. A white crystalline precipitate of ammonium magnesium phosphate formed. An excess of concentrated $\mathrm{NH}_{4} \mathrm{OH}$ was added. The $\mathrm{NH}_{4} \mathrm{MgPO}_{4} \cdot 6 \mathrm{H}_{2} \mathrm{O}$ precipitate in solution was stirred for 15 min and cooled for half an hour in an ice bath. This step is not a separation, since there is a large number of interferences with the precipitation. The advantage of the $\mathrm{NH}_{4} \mathrm{MgPO}_{4} \cdot 6 \mathrm{H}_{2} \mathrm{O}$ precipitate is that it can be dissolved in $\mathrm{HCl}$ while $\left(\mathrm{NH}_{4}\right)_{3} \mathrm{PO}_{4}\left(\mathrm{MoO}_{3}\right)_{12}$ cannot. The $\mathrm{NH}_{4} \mathrm{MgPO}_{4} \cdot 6 \mathrm{H}_{2} \mathrm{O}$ precipitate was vacuum filtered through a Millipore HA filter $(0.45 \mu \mathrm{m}, 47 \mathrm{~mm}$ in diameter), washed with dilute $\mathrm{NH}_{4} \mathrm{OH}$, and dissolved in $9 \mathrm{~N} \mathrm{HCl}$. A cation exchange column of AG-50W-X8 Cl, 100200 (Analytical grade resin from Biorad Laboratory) mesh was conditioned with 3 volumes of $9 \mathrm{~N} \mathrm{HCl}$. The solution was loaded on the column and 1 volume of $9 \mathrm{~N} \mathrm{HCl}$ was passed through to rinse. The cation exchange resin allows separation of $\mathrm{Ca}, \mathrm{K}, \mathrm{Fe}$, $\mathrm{Al}, \mathrm{V}, \mathrm{W}, \mathrm{Zn}, \mathrm{Zr}$ and $\mathrm{Ti}$, which will interfere with the final $\mathrm{MgNH}_{4} \mathrm{PO}_{4} .6 \mathrm{H}_{2} \mathrm{O}$ precipitation (Hillebrand et al., 1959; Mullins and Leddicotte, 1962; Whaley and Ferrara, 1972). Concentrated $\mathrm{NH}_{4} \mathrm{OH}$ was added to make the $\mathrm{pH}$ neutral, and the solution was put again in an ice bath prior to the last precipitation. $\mathrm{MgNH}_{4} \mathrm{PO}_{4} .6 \mathrm{H}_{2} \mathrm{O}$ was precipitated as described previously and vacuum filtered on a preweighed Millipore HA filter $(0.45 \mu \mathrm{m}$, 
$25 \mathrm{~mm}$ in diameter). The area of the precipitate was $2.75 \mathrm{~cm}^{2}$. The precipitate was hygroscopic and it was thus dried carefully until the weight was constant. It was then mounted face down on a film of Mylar ${ }^{\mathrm{TM}}$ (thickness $=0.9 \mathrm{mg} / \mathrm{cm}^{2}$ ). The film of Mylar was supported by a white Delrin ring. A silver planchet $\left(140 \mathrm{mg} / \mathrm{cm}^{2}\right)$ was placed on top of the filter, and the source was sealed with tape to ensure no change in the weight of the precipitate. The source was counted on an anticoincidence low-level $\beta$ counter.

\section{LOW-LEVEL BETA COUNTING}

A thin-wall anticoincidence counter was used for low-level beta counting. The basic feature of low-level $\beta$ counting that distinguishes it from ordinary $\beta$ counting is the use of an anticoincidence guard detector next to the primary detector. The primary detector used here was similar in design to that of Lal and Schink (1960). The detector is a gasflow counter and operates in the Geiger-Muller region. The plateau starts at 820-860 Volts. The detector was operated at a voltage centered on the plateau. Q-gas $(98.7 \%$ Helium and $1.3 \%$ isobutane) flows continously through the sealed counter chamber. The $2.54 \mathrm{~cm}$ window is a thin $0.9 \mathrm{mg} / \mathrm{cm}^{2}$ aluminized Mylar. The background of the detector is significantly reduced by the guard detectors. Typically the background is about $0.25-$ $0.5 \mathrm{cpm}$ with an error of $0.02 \mathrm{cpm}$. This background is about 50 times lower than that of a detector without the guard detectors. The counting system is usually stable (no change in the background) for periods of 30 days or more. The detector measures beta radiation in pulse-type mode. The pulses from the source and the guard detectors are first amplified by Pelagic Electronics Model 7030-2 preamplifiers. They are further amplified by a Canberra Model 2012 amplifier. Pulses from the guard detector are sent to a Pelagic Electronics Model 7030-4 gate driver. Pulses from the source are sent to a Canberra Model 2032 dual discriminator, which is coupled to a Gate Driver and further through a Canberra Model 2035A single-channel analyzer and a Canberra Model 1476A scaler. 
V SEPARATION OF ${ }^{33} \mathrm{P}$ AND ${ }^{32} \mathrm{P}$

A nuclear method was used to separate the two radioisotopes of $\mathrm{P}$ based on the difference in energy of the beta particles emitted in their decay. Phosphorus-32 is a hard $\beta$ emitter with an end-point energy, $\mathrm{E}_{\max }=1.71 \mathrm{MeV}$, while ${ }^{33} \mathrm{P}$ is a soft $\beta$ emitter with $\mathrm{E}_{\max }=0.249 \mathrm{MeV}$. This difference in energy between the two isotopes results in different absorption characteristics for the $\beta$ particles. The interaction of $\beta$ particles with matter is described by the experimental half-thickness of absorption $x_{1 / 2}$ which is the thickness of a solid material between the source and the detector that will absorb half of the emitted radiation. The intensity of a source $\mathrm{I}$ as a function of the external absorber thickness $\mathrm{x}$ is simply approximated by: $I=I_{0} \exp \left(-\ln 2 \times / x_{1 / 2}\right)$, where $I_{0}$ is the intensity of the source with no external absorber (Libby, 1947). I have found that the activity of ${ }^{32} \mathrm{P}$ is decreased by a factor of 2 when an aluminum foil of $71.6 \pm 2 \mathrm{mg} / \mathrm{cm}^{2}$ is placed between the source and the detector (Figure 1.1). The mass absorption coefficient $\mu\left(\mu=\ln 2 / \mathrm{x}_{1 / 2}\right)$ was thus calculated to be $9.7 \pm 0.3 \mathrm{~cm}^{2} / \mathrm{g}$. These experimental values are comparable to some previous studies. An empirical formula relates $\mu$ and the maximum $\beta$ energy as follows: $\mu=22 / \mathrm{E}_{\max }^{1.33}$ for $0.5 \leq \mathrm{E}_{\max } \geq 6 \mathrm{MeV}$. For $\mathrm{E}_{\max }=1.71 \mathrm{MeV}$ the calculated $\mu$ is $10.8 \mathrm{~cm}^{2} / \mathrm{g}$ (Price et al., 1958) which is very close to the value of $9.7 \mathrm{~cm}^{2} / \mathrm{g}$ found in this study. Libby (1957) reported a different relationship, i.e. $1 / \mu=55 \mathrm{E}^{3 / 2}$, which yields a lower $\mu$ and a higher $\mathrm{x}_{1 / 2}$ of $84 \mathrm{mg} / \mathrm{cm}^{2}$. For the range of absorber used in my separation method, i.e. 6 to $40 \mathrm{mg} / \mathrm{cm}^{2}$, the two extreme half-thicknesses 72 and $84 \mathrm{mg} / \mathrm{cm}^{2}$ yield activities which differ by $1 \%$ to $5 \%$. In the case of ${ }^{33} \mathrm{P}$, a foil of only $4.3 \pm 0.1$ $\mathrm{mg} / \mathrm{cm}^{2}$ blocks $50 \%$ of the $\beta$ radiation (Figure 1.2 ). 


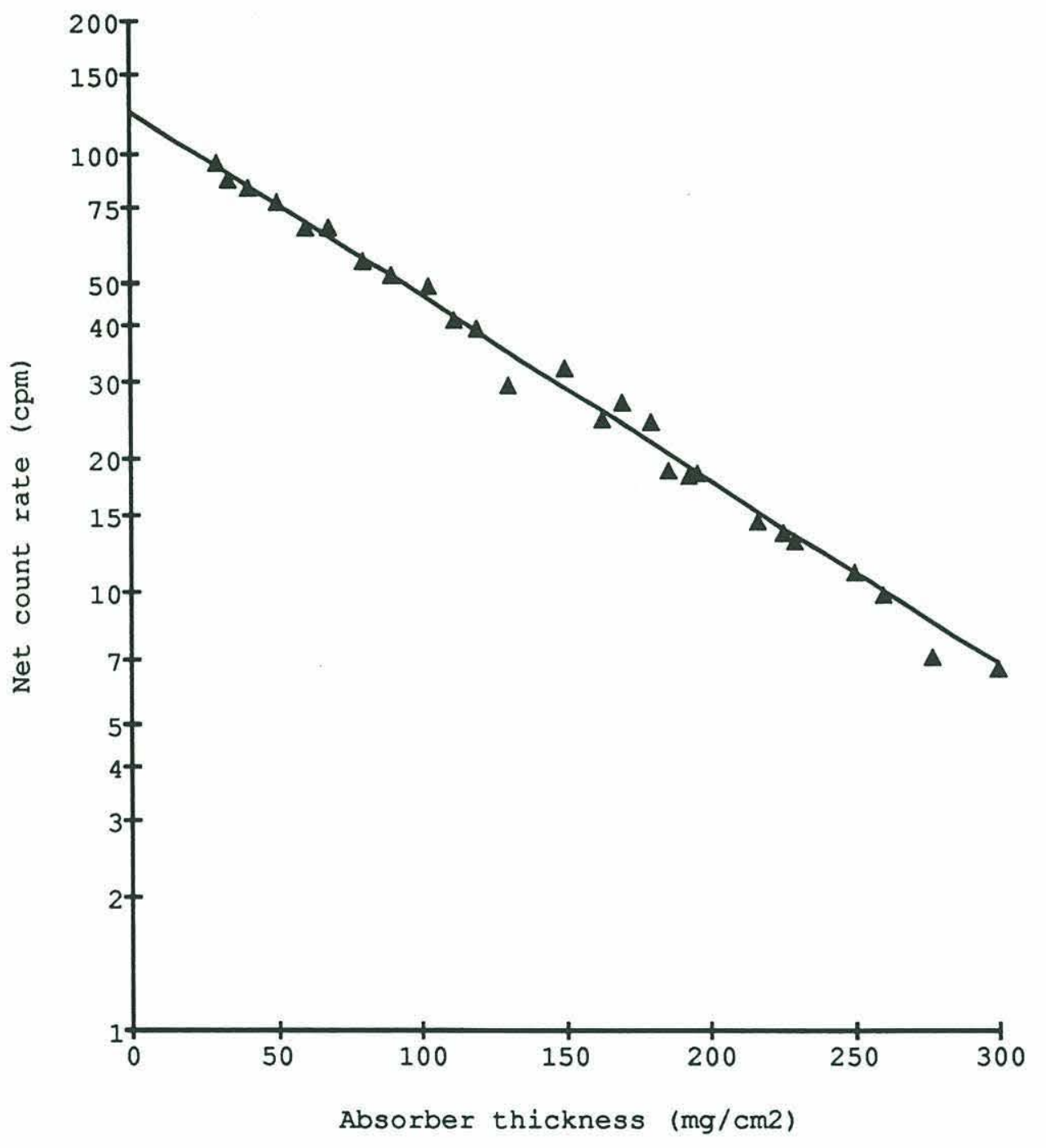

Figure 1.1. Net count rate of ${ }^{32} \mathrm{P}$ as a function of external absorber thickness. 


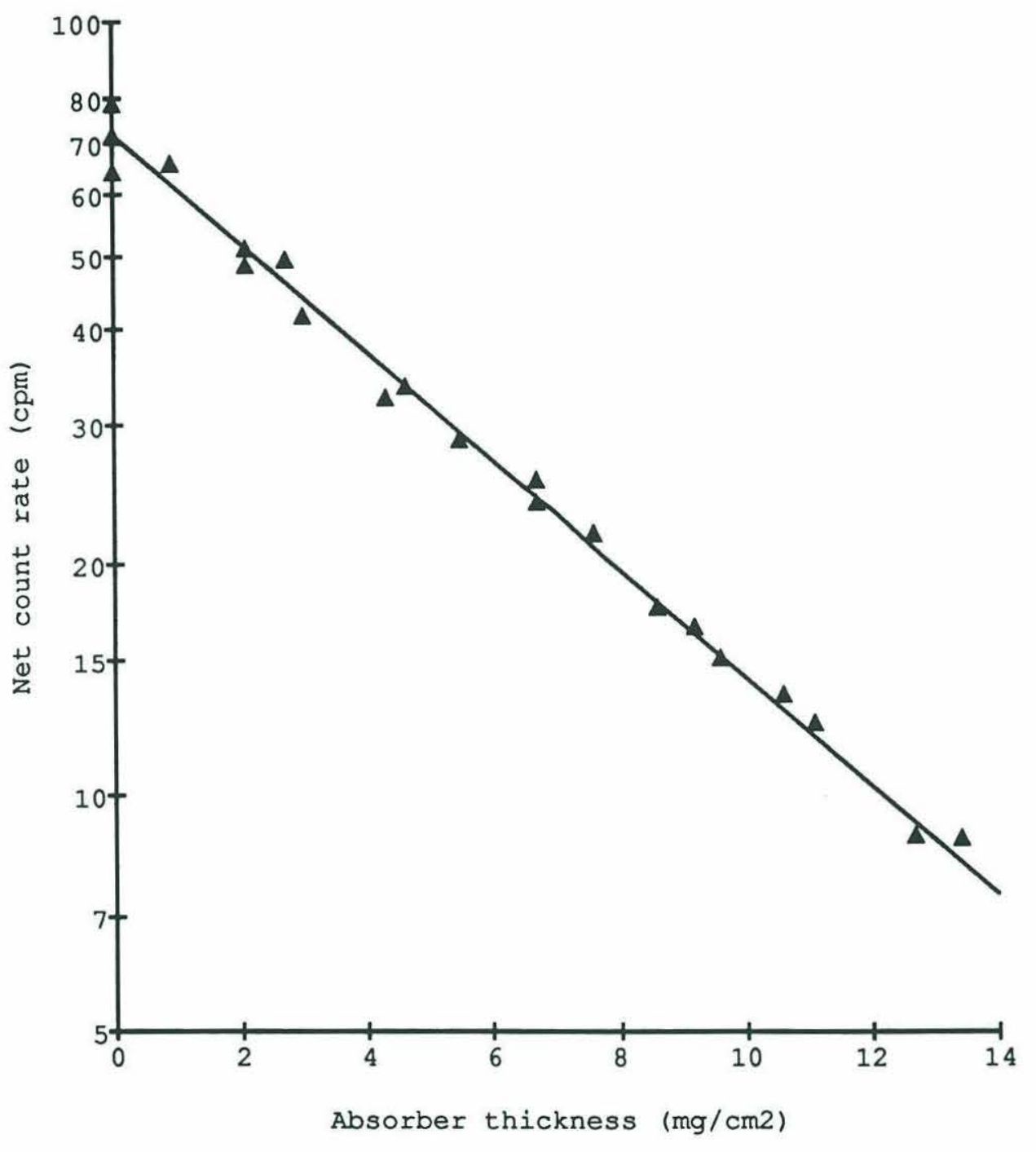

Figure 1.2. Net count rate of ${ }^{33} \mathrm{P}$ as a function of external absorber thickness. 
This half-thickness is in close agreement with $\mathrm{x}_{1 / 2}$ of $4.9 \mathrm{mg} / \mathrm{cm}^{2}$ found for ${ }^{45} \mathrm{Ca}$ $\left(\mathrm{E}_{\max }=0.255 \mathrm{MeV}\right)$ in $\mathrm{Al}$ (Libby, 1957). Thus from the absorption curves of ${ }^{32} \mathrm{P}$ and ${ }^{33} \mathrm{P}$ one can choose a thickness of aluminum that will block essentially all the radiation from ${ }^{33} \mathrm{P}$ and decrease the radiation from ${ }^{32} \mathrm{P}$ by a known small amount. The thickness of aluminum was chosen so that the estimated activity of ${ }^{33} \mathrm{P}$ in the source would be decreased to less than $0.02 \mathrm{cpm}$ when the source was counted with the absorber.

In order to separate ${ }^{32} \mathrm{P}$ and ${ }^{33} \mathrm{P}$ the samples were counted repeatedly in time with and without external absorber. The time-dependent curve generated without absorber represents the total activity of the sample. The curve with absorber represents the activity of ${ }^{32} \mathrm{P}$, decreased slightly due to the absorption of $\beta$ particles in the absorbing material. The initial net count rates ${ }^{32} \mathrm{~N}^{0}$ and ${ }^{33} \mathrm{~N}^{0}$ of ${ }^{32} \mathrm{P}$ and ${ }^{33} \mathrm{P}$, i.e., the net count rates at the time the sample was first counted, are then determined by the difference of the two time-dependent curves. The activities at the time the sample was collected were calculated from the known decay rates of ${ }^{32} \mathrm{P}$ and ${ }^{33} \mathrm{P}$. The equations describing the total gross count rates without absorber $\mathrm{G}_{\mathrm{t}}$ and with absorber $\mathrm{G}_{\mathrm{a}}$ at a given time are the following :

$$
\mathrm{G}_{\mathrm{t}}=\mathrm{N}_{\mathrm{t}}+\mathrm{B}={ }^{32} \mathrm{~N}+{ }^{33} \mathrm{~N}+\mathrm{B}=\mathrm{N}_{\mathrm{t}}^{0} \exp (-\lambda \mathrm{t})+\mathrm{B}
$$

$$
\mathrm{G}_{\mathrm{a}}=\mathrm{N}_{\mathrm{a}}+\mathrm{B}={ }^{32} \mathrm{~N}^{32} \beta+{ }^{33} \mathrm{~N}^{33} \beta+\mathrm{B}={ }^{32} \mathrm{~N}^{0}{ }^{32} \beta \exp \left(-{ }^{32} \lambda \mathrm{t}\right)+\mathrm{B}
$$

where

$\mathrm{N}_{\mathrm{t}}$ : total net count rate in cpm

$\mathrm{N}_{\mathrm{a}}$ : net count rate with absorber in cpm

$\mathrm{B}$ : background count rate

${ }^{32} \mathrm{~N}$ : net count rate of ${ }^{32} \mathrm{P}$ in cpm

${ }^{33} \mathrm{~N}$ : net count rate of ${ }^{33} \mathrm{P}$ in cpm 
${ }^{32} \beta$ : fraction of ${ }^{32} \mathrm{P}$ transmitted through the absorber.

${ }^{32} \beta=\exp (-\ln 2 x / 71.6)$.

$\mathrm{x}$ : thickness of the absorber, in $\mathrm{mg} / \mathrm{cm}^{2}$.

${ }^{33} \beta$ : fraction of ${ }^{33} \mathrm{P}$ transmitted through the absorber.

${ }^{33} \beta=\exp (-\ln 2 x / 4.3)$.

${ }^{32} \lambda$ : decay constant of ${ }^{32} \mathrm{P}$.

In practice each sample was counted long enough to obtain $8 \%$ or less counting error both with the external absorber and without. Typically the thickness of the absorber ranged from 6 to $40 \mathrm{mg} / \mathrm{cm}^{2}$ for the low count rate (plankton samples) to the high count rate samples (rainwater samples), respectively. $\mathrm{N}_{a}$ (i.e., ${ }^{32} \mathrm{~N}^{32} \beta+{ }^{33} \mathrm{~N}^{33} \beta$ ) was usually approximated by ${ }^{32} \mathrm{~N}^{32} \beta$, since the absorber was chosen to allow absorbtion of essentially all the radiation of ${ }^{33} \mathrm{P}$ so that ${ }^{33} \mathrm{~N}^{33} \beta<0.02 \mathrm{cpm}$. This approximation was verified when ${ }^{32} \mathrm{~N}^{0}$ and ${ }^{33} \mathrm{~N}^{0}$ were determined, by calculating ${ }^{33} \mathrm{~N}^{0}{ }^{33} \beta$. The two curves $\mathrm{N}_{t}(\mathrm{t})$ and $\mathrm{N}_{\mathrm{a}}(\mathrm{t})$ were then fitted by least squares. The source was counted repeatedly over 30 to 60 days, allowing a minimum of 10 points on $\mathrm{N}_{t}$ and 5 on $\mathrm{N}_{\mathrm{a}}$. The general equations used for the fit are:

$$
\begin{aligned}
& N_{t}=a \exp (-\alpha t) \\
& N_{a}=b \exp \left(-{ }^{32} \lambda t\right)
\end{aligned}
$$

The values of the initial net count rates ${ }^{32} \mathrm{~N}^{0}$ and ${ }^{33} \mathrm{~N}^{0}$ were determined by the intercepts, $a$ and $b$, of the two curves with y axes. At this point the term ${ }^{3}{ }^{3} \mathrm{~N}^{0}{ }^{33} \beta$ was computed to verify that ${ }^{33} \mathrm{~N}^{0}{ }^{33} \beta$ was smaller than $0.02 \mathrm{cpm}$. For samples of extremely low total activity, there was sometimes a remaining activity of ${ }^{33} \mathrm{P}$ in the absorber curve $\left({ }^{33} \mathrm{~N}^{33} \beta>0.02 \mathrm{cpm}\right)$ which was corrected for by substracting the estimated activity of ${ }^{33} \mathrm{P}$ from the curve with absorber. The correction was iterated until the calculated values ${ }^{32} \mathrm{~N}^{0}$ and ${ }^{33} \mathrm{~N}^{0}$ converged to constant values. 


\section{DETERMINATION OF ABSOLUTE ACTIVITIES}

The initial net count rates, ${ }^{32} \mathrm{~N}^{0}$ and ${ }^{33} \mathrm{~N}^{0}$, were converted into absolute activities ${ }^{32} \mathrm{~A}^{0}$ and ${ }^{33} \mathrm{~A}^{0}$ by taking into account the counting efficiency, $\varepsilon$, and the yield of the procedure, $y$. The absolute activities were calculated as follows :

$$
\mathrm{A}^{0}=\mathrm{N}^{0} / \mathrm{y} \varepsilon
$$

The absolute activity at the time of collection is:

$$
A_{c}{ }^{0}=A^{0} \exp (\lambda t)
$$

where, $t$ is the time elapsed between collection and initial counting time, and $\lambda$ is the decay constant. The activity ratio $r$ of ${ }^{33} \mathrm{P}$ to ${ }^{32} \mathrm{P}$ is :

$$
\mathrm{r}={ }^{33} \mathrm{~A}^{0} / /^{32} \mathrm{~A}^{0}={ }^{33} \mathrm{~N}^{0}{ }^{32} \varepsilon / /^{32} \mathrm{~N}^{0}{ }^{33} \varepsilon
$$

The counting efficiency, $\varepsilon$, for a given radioisotope varies with the thickness of the source according to the following relationship (Libby, 1947):

$$
\text { (1.3) } \varepsilon / \varepsilon_{0}=(1-\exp (-\mu d)) /(\mu d)
$$

where

$$
\begin{aligned}
& \mu \text { : self-absorption coefficient in } \mathrm{cm}^{2} / \mathrm{mg} \\
& \mathrm{d} \text { : thickness of the source in } \mathrm{mg} / \mathrm{cm}^{2} \\
& \varepsilon \text { : counting efficiency for a source of thickness d } \\
& \varepsilon_{0} \text { : counting efficiency for an infinitely thin source }
\end{aligned}
$$

Typically, the thicknesses of the samples, d, varied from 2 to $12 \mathrm{mg} / \mathrm{cm}^{2}$. Selfabsorption and scattering processes in the source, absorption in the air and window and backscattering processes on the backing material were all included in one parameter: $\varepsilon_{0}$, the counting efficiency for an infinitely thin source. The thickness of the backing material is chosen to be the thickness of saturation (or close to it) to allow maximum backscattering. Experiments have shown that saturation is reached for a thickness of about $20 \%$ of the range of a nuclide (Price et al., 1958; Wang et al., 1975; Choppin and 
Rydberg, 1980). The ranges in aluminum are $800 \mathrm{mg} / \mathrm{cm}^{2}$ for ${ }^{32} \mathrm{P}$ and $60 \mathrm{mg} / \mathrm{cm}^{2}$ for ${ }^{33} \mathrm{P}$, and the saturation thicknesses are $12 \mathrm{mg} / \mathrm{cm}^{2}$ for ${ }^{33} \mathrm{P}$ and $160 \mathrm{mg} / \mathrm{cm}^{2}$ for ${ }^{32} \mathrm{P}$ (Choppin and Rydberg, 1980). The fraction of the electrons backscattered increases with the atomic number of the backing material. Silver $(A=47)$ was chosen and gives a factor of 1.65 increase in the counting efficiency at saturation backscattering for ${ }^{32} \mathrm{P}$ (Choppin and Rydberg, 1980). For ${ }^{33} \mathrm{P}$, absorption in air and in the window of the detector eliminates some of the backscattered particles, and therefore the factor is lower, about 1.35. The thickness of the silver planchet used for backing material was about 140 $\mathrm{mg} / \mathrm{cm}^{2}$, which is well beyond the saturation thickness of ${ }^{33} \mathrm{P}$ and very close to the saturation thickness of ${ }^{32} \mathrm{P}$.

\section{1- Counting efficiency}

The overall counting efficiencies ${ }^{32} \varepsilon$ and ${ }^{33} \varepsilon$ were experimentally obtained by counting sources of constant activity and of varying thickness. Previous studies by Nervik and Stevenson (1952) have shown that the efficiency curves are not simply described by equation (1.3), which models the effect of self-absorption only, because selfscattering in thin sources can also be an important process. Their study showed that the shape of the efficiency curve is a function of the composition of the source (nature of the precipitate) and the energy of the beta emitter. For the weak emitters ${ }^{35} \mathrm{~S} \underset{\max }{\mathrm{E}}=0.167$ $\mathrm{MeV})$ and ${ }^{14} 7 \mathrm{Pm}\left(\mathrm{E}_{\max }=0.244 \mathrm{MeV}\right)$ the efficiency curves exhibit a maximum for very thin sources (about $1-2 \mathrm{mg} / \mathrm{cm}^{2}$ ) followed by an exponential decrease with thickness. For the high energy emitters ${ }^{32} \mathrm{P}$ and ${ }^{90} \mathrm{Y}\left(\mathrm{E}_{\max }=2.28 \mathrm{MeV}\right)$, the curves increase slightly initially and reach a plateau (Nervik and Stevenson, 1952). The transition in the curve for both hard and soft beta emitters is due to the relatively higher importance of selfscattering versus self-absorption in the thin sources. The transition is also dependent on the composition of the source. The exponential decrease is due to self-absorption only and can be described by equation (1.3). 


\section{a)- Counting efficiency of ${ }^{32} \mathrm{P}$}

Phosphorus-32 was commercially available from DuPont in a solution of $\mathrm{KH}_{2} \mathrm{PO}_{4}$. The ${ }^{32} \mathrm{P}$ purchased was not a standard and had to be standardized. Verification of the purity of the tracer was obtained by determining the half-life and the half-thickness of absorption on the low level beta counting system. The half-life was, within the error, 14.28 days and the half-thickness was $71.6 \mathrm{mg} / \mathrm{cm}^{2}$. The solution was then standardized by counting a thin source of ${ }^{32} \mathrm{P}$, evaporated on a stainless steel planchet on a $2 \Pi$ gas-flow proportional counter (Nuclear Measurements Corporation, model PCC_11T). The counter had been calibrated by the manufacturer with sources of beta emitters of different $\mathrm{E}_{\max }$ on stainless steel, and I recalibrated it with standards of ${ }^{234} \mathrm{Th}$ and ${ }^{147} \mathrm{Pm}$ (Amersham). A standard of ${ }^{234} \mathrm{Th}$ was prepared by separation from a high purity $\mathrm{U}_{3} \mathrm{O}_{8}$ standard solution (NBS 950A) in which ${ }^{234}$ Th had grown into radioactive equilibrium (Fleer, 1991). My calibration agreed with that of the manufacturer and a 72 $\%$ counting efficiency was determined for ${ }^{32} \mathrm{P}$ on the $2 \Pi$ gas-flow proportional counter. The standardization of the ${ }^{32} \mathrm{P}$ in $\mathrm{KH}_{2} \mathrm{PO}_{4}$ solution from DuPont could then be done.

A known amount of activity of ${ }^{32} \mathrm{P}$ was precipitated as $\mathrm{NH}_{4} \mathrm{MgPO}_{4} \cdot 6 \mathrm{H}_{2} \mathrm{O}$ with varying amounts of stable $\mathrm{PO}_{4}$. The sources were dried until the weight was constant then sealed and counted. Phosphorus-32 is a hard beta emitter and the efficiency was almost constant in the range of thicknesses encountered in all the samples. The efficiency for an infinitely thin source, $\varepsilon_{0}$, was calculated by evaporating drops of a standard solution of ${ }^{32} \mathrm{P}$ on an area of $2.75 \mathrm{~cm}^{2}$ centered on the Mylar film. This was to ensure that all the activity was distributed on an area equal in size to the area of the precipitate, because the counting efficiency is not the same in all the area of the source (Lal and Schink, 1960). A Millipore ${ }^{\mathrm{TM}}$ filter and a silver planchet were placed on top of the source. The efficiency for an infinitely thin source and for all thicknesses from 2 to $8 \mathrm{mg} / \mathrm{cm}^{2}$ was $49 \%$. 
b)- Counting efficiency of ${ }^{33} \mathrm{P}$

A solution of $\mathrm{KH}_{2} \mathrm{PO}_{4}$ of unknown activity of ${ }^{33} \mathrm{P}$ was obtained from DuPont. A standard of ${ }^{147} \mathrm{Pm}$ was available from Amersham and was used as an analogue of ${ }^{33} \mathrm{P}$. ${ }^{14}{ }^{7} \mathrm{Pm}\left(\mathrm{t}_{1 / 2}=2.6234 \mathrm{y}\right)$ has an end point energy of $0.224 \mathrm{MeV}$ which is extremely close to that of ${ }^{33} \mathrm{P}\left(\mathrm{E}_{\max }=0.249 \mathrm{MeV}\right)$. It is therefore expected that the two radioisotopes will have a similar half-thickness of absorption. $A{ }^{147} \mathrm{Pm}$ standard was evaporated on a silver planchet and its absorption curve was generated (Figure 1.3). The exponent of that curve is $0.156 \mathrm{~cm}^{2} / \mathrm{mg}$ and the half-thickness of absorption is $4.4 \pm 0.1$ $\mathrm{mg} / \mathrm{cm}^{2}$. Within experimental errors it is identical to $4.3 \pm 0.1 \mathrm{mg} / \mathrm{cm}^{2}$, the halfthickness of ${ }^{33} \mathrm{P}$. Thus ${ }^{147} \mathrm{Pm}$ and ${ }^{33} \mathrm{P}$ were considered to be equivalent with respect to their properties of interaction with matter. A known activity of ${ }^{147} \mathrm{Pm}$ was evaporated on a Mylar film. A filter and a silver planchet were put on top so that this standard was as similar to the sample as possible. The ratio of the net count rate to the activity of this standard was the counting efficiency of ${ }^{33} \mathrm{P},{ }^{33} \varepsilon_{0}$, for an infinitely thin source. To calculate ${ }^{33} \varepsilon$ for all thicknesses, a carrier free unknown activity of ${ }^{33} \mathrm{PO}_{4}$ was precipitated as $\mathrm{MgNH}_{4} \mathrm{PO}_{4} .6 \mathrm{H}_{2} \mathrm{O}$ with increasing amounts of stable $\mathrm{PO}_{4}$. A curve was generated of the net count rate as a function of thickness. The expected decreasing curve was regressed with a least square method and the intercept at $0 \mathrm{mg} / \mathrm{cm}^{2}$ was determined. That intercept was assumed to be the net count rate for an infinitely thin source, ${ }^{33} \varepsilon_{0}$. Since from our ${ }^{147} \mathrm{Pm}$ standard ${ }^{33} \varepsilon_{0}$ was already known (i.e. $26 \%$ ) the rest of the curve could then be calibrated. The curve did not exhibit any maximum, possibly because (1) I could not make sources thinner than $1 \mathrm{mg} / \mathrm{cm}^{2}$ or (2) self-scattering is small in $\mathrm{MgNH}_{4} \mathrm{PO}_{4} .6 \mathrm{H}_{2} \mathrm{O}$. I concluded that the efficiencies might be underestimated by up to $3 \%$ when using equation (1.3) to calculate the efficiency of ${ }^{33} \mathrm{P}$. Figure 1.4 shows the counting efficiency, ${ }^{3} \varepsilon$, as a function of sample thickness. The counting efficiencies for an infinitely thin source, ${ }^{33} \varepsilon_{0}$, were the same within $1 \%$ for all 4 counters. The relative efficiency curve was fitted by the function given in equation (1.3). 


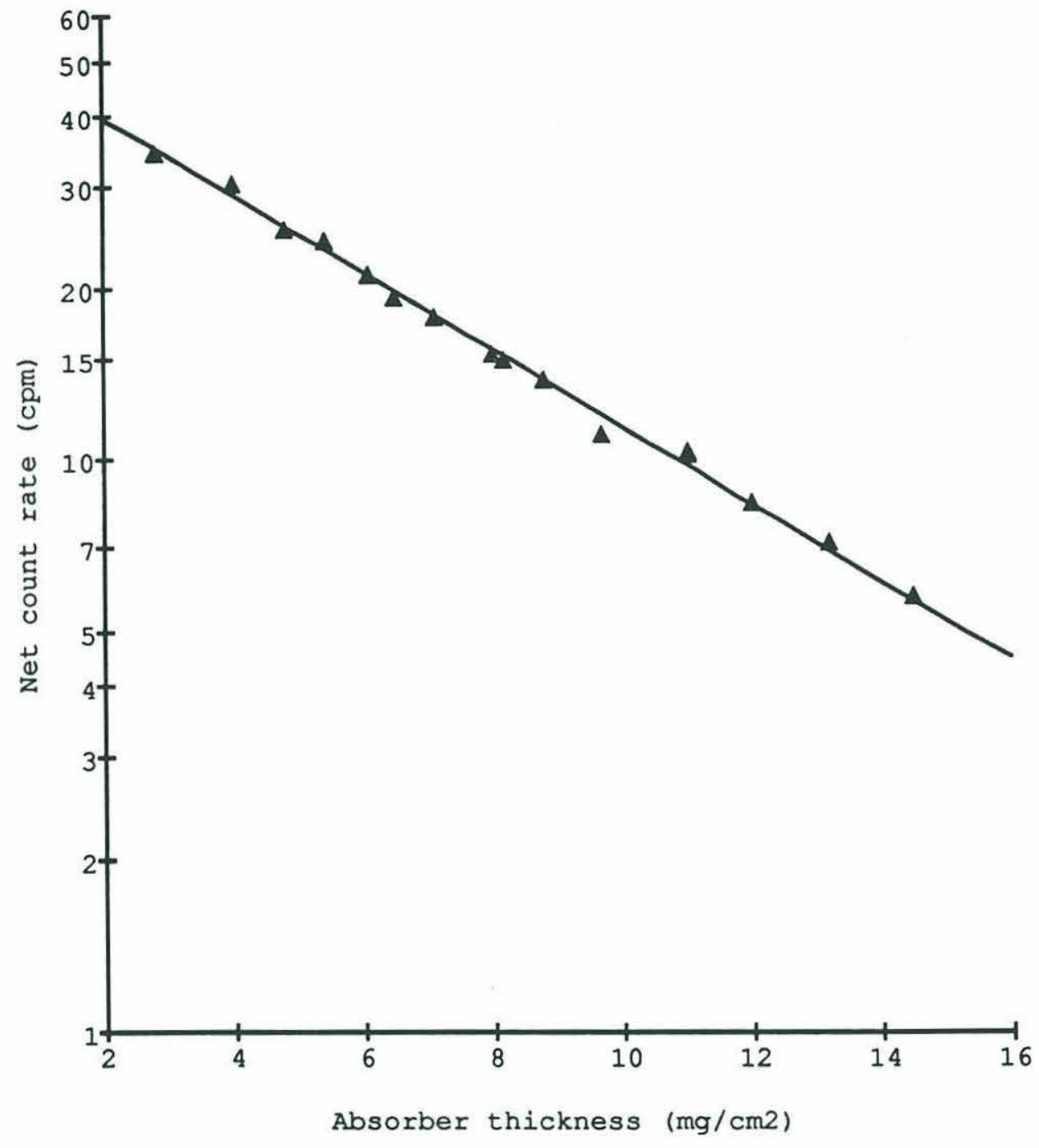

Figure 1.3. Net count rate of ${ }^{147} \mathrm{Pm}$ as a function of external absorber thickness. 


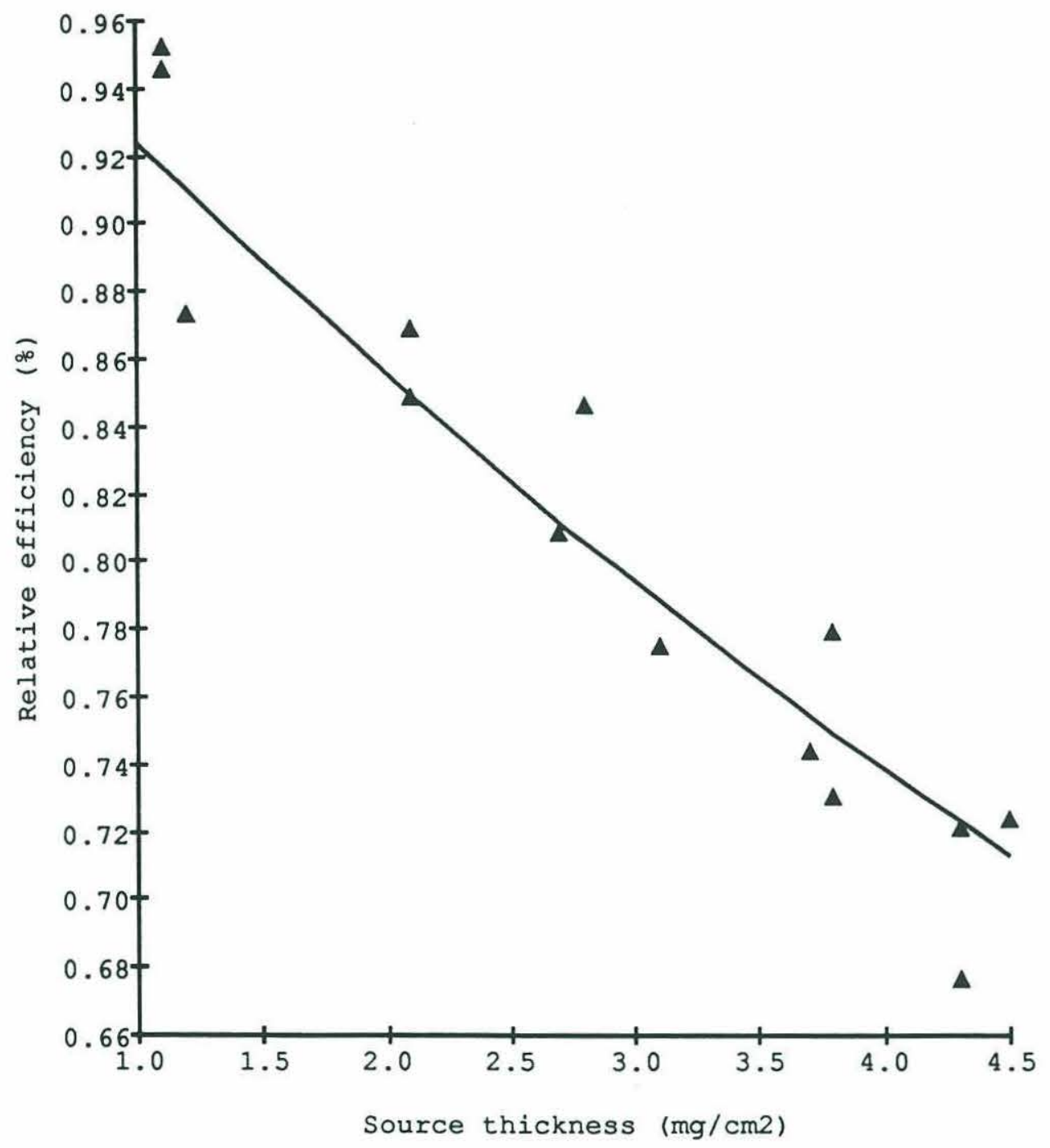

Figure 1.4. Relative counting efficiency of ${ }^{33} \mathrm{P}$ as a function of source thickness. 
The exponent $\mu$ of the curve was determined for each detector. It varied from 0.145 to 0.160 and averaged $0.150 \pm 0.01 \mathrm{~cm}^{2} / \mathrm{mg}$. These values all agreed within the error of the regression. Figure 1.5 shows the effect of a change in $\mu$ on the relative efficiency. The error on the absolute efficiency is estimated to be less than $2 \%$ for an error of $0.01 \mathrm{~cm}^{2} / \mathrm{mg}$ on $\mu$. The counter efficiency $\varepsilon$ (expressed in \%) for a sample of thickness $\mathbf{x}$ (expressed in $\mathrm{mg} / \mathrm{cm}^{2}$ ) is calculated from the experimental relationship:

$$
\text { (1.4) } \varepsilon=26(1-\exp (-0.150 \mathrm{x})) /(0.150 \mathrm{x})
$$

\section{2- Yield of procedure}

The chemical yield was calculated as the ratio of the amount of stable $\mathrm{P}$ in the source relative to the amount of stable $\mathrm{P}$ initially present. The determination of the yield was different according to the sample type. For rainwater samples $100 \mu$ moles $\mathrm{KH}_{2} \mathrm{PO}_{4}$ were added to the rainwater. The amount of $\mathrm{PO}_{4}$ present in the final $\mathrm{NH}_{4} \mathrm{MgPO}_{4} .6 \mathrm{H}_{2} \mathrm{O}$ precipitate was determined colorimetricaly with the classic molybdenum blue method (Murphy and Riley, 1962; Koroleff, 1983). This procedure was used because the amount of phosphate in the source could not be precisely determined from the weight of the precipitate. This was because the precipitate is hygroscopic and the stoichiometry is not always $6 \mathrm{H}_{2} \mathrm{O}$. For plankton and suspended particulate samples, the initial amount of $\mathrm{PO}_{4}$ was measured colorimetrically after digestion with nitric acid. In the case where the amount of phosphate exceeded $100 \mu$ moles, the sample was split so that thin sources

could be obtained to minimize self-absorption of ${ }^{33} \mathrm{P}$ in the source. Experience showed that 50-100 $\mu$ moles of stable $\mathrm{P}$ in the source optimized the total net count rate and minimized self-absorption of ${ }^{33} \mathrm{P}$ for samples collected in the Sargasso Sea. Usually, for plankton samples obtained from 15-20-minute tows, the initial amount of stable $\mathrm{P}$ 


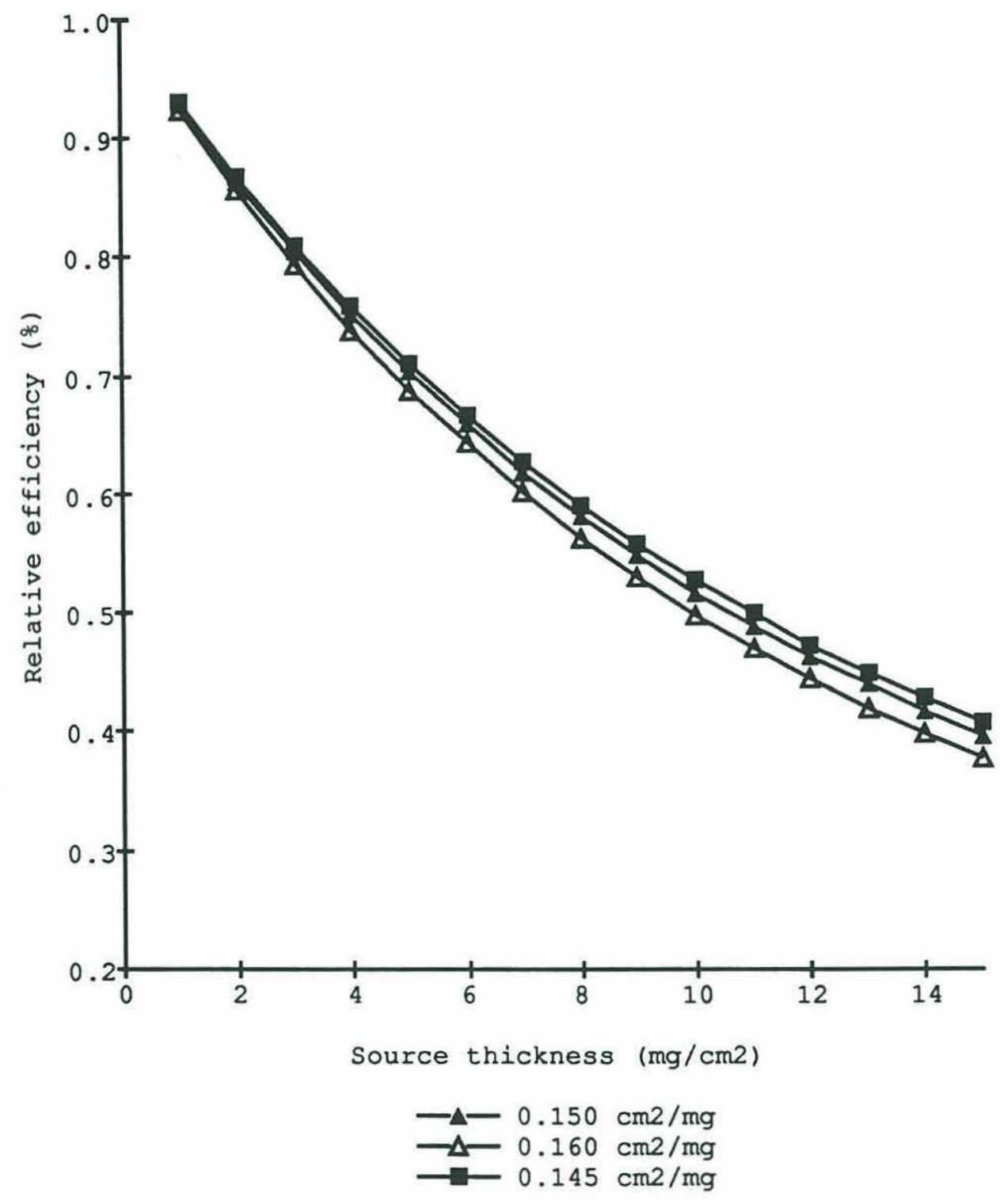

Figure 1.5. Relative counting efficiency as a function of source thickness calculated for different values of the absorption coefficient $\mu$. 
exceeded $100 \mu$ moles and the sample was split. For suspended particles, the samples had typically 30-60 $\mu$ moles of $\mathrm{PO}_{4}$ initially and were thus never split.

The data for all the rain samples and plankton samples are listed in Appendix A. The data include the equations of the regressions of the curves $\mathrm{Nt}$ and $\mathrm{Na}$ in tables A.1 (rain samples) and in table A.2 (plankton samples). The thickness, $d$, the yield, $y$, the counting efficiencies, ${ }^{32} \varepsilon$ and ${ }^{33} \varepsilon$, and the counting rates at the time of sampling ${ }^{32} \mathrm{~N}$ and ${ }^{33} \mathrm{~N}$ are given, for all the samples, in appendix $\mathrm{A}$ in tables $\mathrm{A} .3$ for the rain samples, in tables A.4 to A.9 for the plankton samples and in table A.10 for the salt samples (see chapter 3).

\section{COUNTING STATISTICS AND ERROR ANALYSIS}

The errors on the absolute initial activities ${ }^{32} \mathrm{~A}^{0}$ and ${ }^{33} \mathrm{~A}^{0}$ were computed for the time the sample was put in the counter. These activities are derived from the two experimental curves $G_{t}(t)$ and $G_{a}(t)$ of the gross count rate of the source as a function of time expressed in equations (1.1) and (1.2).

\section{1- Error on the net count rates}

The curves $N_{t}(t)$ and $N_{a}(t)$ were fitted with a least square method and the 2 intercepts $\mathrm{N}_{\mathrm{a}}{ }^{0}$ and $\mathrm{N}_{\mathrm{t}}{ }^{0}$ were determined. The errors were given by the non-weighted least squares fit (samples are counted in time typically until each count in time is 300 or 500 for low count rate samples and 1000 or more for rain samples). ${ }^{32} \mathrm{~N}^{0}$ is equal to $\left(\mathrm{G}^{0}{ }_{\mathrm{a}}{ }^{-}\right.$ B) $/{ }^{32} \beta$ or $\mathrm{N}_{\mathrm{a}}^{0} /{ }^{32} \beta$. The error on ${ }^{32} \mathrm{~N}^{0}, \sigma_{32} \mathrm{~N}^{0}$ was deduced from the propagation theory (Friedlander et al.,1981). ${ }^{32} \mathrm{~N}^{0}$ is a function of ${ }^{32} \beta, \mathrm{Ga}$ and B. Thus the standard error is given by:

$$
\sigma_{32} N^{0}{ }^{2}=\sigma_{32}^{2} \beta^{*}\left(\partial^{32} N^{0} / \partial^{32} \beta\right)^{2}+\sigma_{G a^{0}}^{2} *\left(\partial^{32} N^{0} / \partial G_{a}{ }^{0}\right)^{2}
$$




$$
+\sigma_{B}^{2} *\left(\partial^{32} N^{0} / \partial B\right)^{2}
$$

Both the background and ${ }^{32} \beta$ are well known, and the errors associated with these quantities are small. It follows that:

$$
\sigma_{32} N^{0}{ }^{2}=\sigma_{G_{a}^{0}}{ }^{*}\left(\partial^{32} N^{0} / \partial G_{a}^{0}\right)^{2}=\sigma_{N^{0}}^{2} *\left(\partial^{32} N^{0} / \partial N^{0}\right)^{2}
$$

or

$$
\sigma_{32} \mathrm{~N}^{0}=1 \beta^{32} \beta * \sigma_{\mathrm{N}^{0}}
$$

Since $\mathrm{N}_{\mathrm{t}}^{0}={ }^{32} \mathrm{~N}^{0}+{ }^{33} \mathrm{~N}^{0}$, then $\mathrm{N}_{\mathrm{t}}^{0}=\mathrm{N}_{\mathrm{a}}^{0} /^{32} \beta+{ }^{33} \mathrm{~N}^{0}$. Therefore:

$$
{ }^{33} \mathrm{~N}^{0}=\mathrm{N}_{\mathrm{t}}^{0}-\mathrm{N}^{0}{ }_{\mathrm{a}}{ }^{32} \beta .
$$

Applying the theory of propagation of error to ${ }^{33} \mathrm{~N}^{0}$ we obtain:

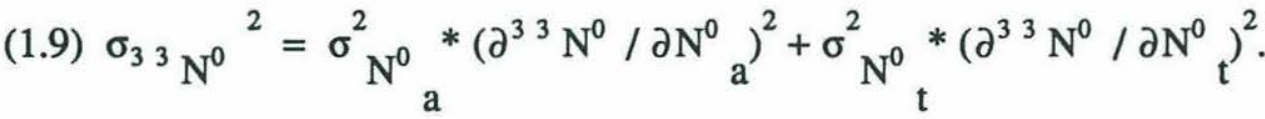

Thus:

$$
\text { (1.10) } \sigma_{33} \mathrm{~N}^{0}=\left(1 \beta^{2} \beta\right)^{2} * \sigma^{2}{ }_{\mathrm{N}^{0}}+\sigma^{2}{ }_{\mathrm{N}^{0}}
$$

The standard errors $\sigma_{32} \mathrm{~N}^{0}$ and $\sigma_{33} \mathrm{~N}^{0}$ were therefore calculated from equations (1.7) and (1.10) and depend only on the errors $\sigma_{\mathrm{N}^{0}}$ and $\sigma_{\mathrm{N}^{0}}$ which were determined by the fit of the time-dependent curves $\mathrm{N}_{\mathrm{t}}$ and $\mathrm{N}_{\mathrm{a}}$.

\section{2- Error on the absolute activities}

$$
\begin{aligned}
& { }^{32} \mathrm{~A}^{0}={ }^{32} \mathrm{~N}^{0} / \mathrm{y}^{* 32} \varepsilon \\
& { }^{33} \mathrm{~A}^{0}={ }^{33} \mathrm{~N}^{0} / \mathrm{y}{ }^{33} \varepsilon \\
& \mathrm{R}={ }^{33} \mathrm{~A}^{0} / /^{32} \mathrm{~A}^{0}=\left({ }^{33} \mathrm{~N}^{0} / /^{32} \mathrm{~N}^{0}\right) *\left({ }^{32} \varepsilon / /^{33} \varepsilon\right)
\end{aligned}
$$

From the propagation theory it is straightforward to derive the errors on ${ }^{32} A^{0},{ }^{33} A^{0}$ and $\mathbf{R}$. The errors are given by:

$$
\begin{gathered}
\sigma_{32} \mathrm{~A}^{0}=\left(1 / \mathrm{y}^{*^{32}} \varepsilon\right)^{2}{ }^{2} \sigma_{32} \mathrm{~N}^{0}+\left({ }^{32} \mathrm{~N}^{0} / \mathrm{y}^{2} *^{32} \varepsilon\right)^{2}{ }^{2} \sigma_{\mathrm{y}}{ }^{2}+ \\
\left({ }^{32} \mathrm{~N}^{0} / \mathrm{y}^{32} \varepsilon^{2}\right)^{2} * \sigma_{32}{ }_{\varepsilon}
\end{gathered}
$$




$$
\begin{gathered}
\sigma_{33} A^{0}=\left(1 / y^{*^{33}} \varepsilon\right)^{2} * \sigma_{33} N^{0}+\left({ }^{33} N^{0} / y^{2} *^{33} \varepsilon\right)^{2} * \sigma_{y}{ }^{2}+ \\
\left({ }^{33} N^{0} / y^{* 33} \varepsilon^{2}\right)^{2} * \sigma_{33}{ }^{2}
\end{gathered}
$$

$$
\begin{aligned}
& \sigma_{\mathrm{R}}{ }^{2}=\left({ }^{32} \varepsilon /^{32} \mathrm{~N}^{0} *^{33} \varepsilon\right)^{2} * \sigma_{33} \mathrm{~N}^{0}+\left({ }^{33} \mathrm{~N}^{0} \beta^{33} \varepsilon^{*^{3}{ }^{2} \mathrm{~N}^{0}}\right)^{2} * \sigma_{32}{ }^{2}+ \\
& \left({ }^{33} \mathrm{~N}^{0} *^{32} \varepsilon /^{32} \mathrm{~N}^{0} *^{33} \varepsilon^{2}\right)^{2} * \sigma_{33} \varepsilon^{2}+\left({ }^{33} \mathrm{~N}^{0} *^{32} \varepsilon /^{33} \varepsilon^{*^{32}} \mathrm{~N}^{0}\right)^{2} * \sigma_{32} \mathrm{~N}^{0}
\end{aligned}
$$

In practice, the errors were given by equations (1.11), (1.12) and (1.13). For the rain samples the errors associated with the counting statistic were small (usually $<2 \%$ ), and thus the errors on the initial activities, ${ }^{32} \mathrm{~A}^{0}$ and ${ }^{33} \mathrm{~A}^{0}$, and the ratio, $\mathrm{R}$, were dominated by the errors on the counting efficiencies. For plankton samples the errors were often equally dominated by both counting statistics and counting efficiencies.

\section{CONCLUSION}

The method described in this chapter allows the measurement of $\operatorname{cosmogenic}^{32} \mathrm{P}$ and ${ }^{33} \mathrm{P}$ in rainwater (10 to $60 \mathrm{\ell}$ ), suspended particulate matter filtered from 2,000 to $5,000 \mathrm{l}$ of seawater, and 15 to 20 minute plankton tows in an oligotrophic ocean. The activities of ${ }^{32} \mathrm{P}$ and ${ }^{33} \mathrm{P}$ in rainwater can be determined within $10 \%-20 \%$. The specific activities in both suspended particles and plankton tows can be determined within 10\%$30 \%$. The activity ratio ${ }^{33} \mathrm{P} /{ }^{32} \mathrm{P}$ was measured within $10 \%$ in rainwater and $20-30 \%$ in

particles. The successful measurement of the weak emitter, ${ }^{33} \mathrm{P}$, in particulate phases was due to the low amount of stable $\mathrm{P}$ in the samples collected off Bermuda. Low amounts of stable phosphate are essential to minimize self-absorption, in the source, of the low energy $\beta$ particles emitted by ${ }^{33} \mathrm{P}$. The accuracy of the measurements is limited by the accuracy of the determination of the counting efficiencies. The precision of the measurements is limited by the precision of the counting efficiencies, the chemical yield and the counting statistics for the low activity samples. 


\section{Bibliography}

Chen, Y. R., J. N. Butler and W. Stumm, 1973. Adsorption of phosphate on alumina and kaolinite from dilute aqueous solutions. J. of Colloid and Interface Sci., 43:421-436.

Choppin, G. R. and J. Rydberg, 1980. Nuclear Chemistry Theory and Applications, Pergamon Press.

Collier, R. W. and J. Edmond, 1984. The trace element geochemistry of marine biogenic particulate matter. Prog. Oceanogr., 13:113-199.

Dickman S. R. and R. H. Bray. 1941. Replacement of adsorbed phosphate from kaolinite by fluoride. Soil Sci., 52:263-273.

Fleer, A.P., 1991. Updated determination of particulate and dissolved thorium-234. In: D.C. Hurd and D.W. Spencer (eds.), Marine Particles: Analysis and Characterization, Geophysical Monograph 63, pp 227-228.

Friedlander, G., Kennedy, J., Macias, E. and J. Miller, 1981. Nuclear and Radiochemistry, John Wiley and Sons, Inc..

Hillebrand, W. F., G. E. F. Lundell, H. A. Bright and J. I. Hoffman (eds.), 1959. Applied Inorganic Analysis, 2nd. Edition, John Wiley, pp694-710.

Huang, C. P. 1975. Adsorption of phosphate on the hydrous $\gamma \mathrm{Al}_{2} \mathrm{O}_{3}$ / electrolyte interface. J. colloid Interface Sci., 53:178-186.

Koroleff, F., 1983. Determination of phosphorus. In: K. Grasshoff, M. Ehrhard and K. Kremling (eds.), Methods of Seawater Analysis, 2nd Edn., Verlag Chemie, Weinheim, pp125-135.

Lal, D. and T. Lee, 1988. Cosmogenic ${ }^{32} \mathrm{P}$ and ${ }^{33} \mathrm{P}$ used as tracers to study phosphorus recycling in the upper ocean. Nature, 333:752-754.

Lal, D., Chung, Y., Platt, T. and T. Lee, 1988. Twin cosmogenic radiotracer studies of phosphorus cycling and chemical fluxes in the upper ocean. Limnol. Oceanogr., 33:15591567.

Lal, D. and D. S. Schink, 1960. Low background thin-wall flow counters for measuring beta activity of solids. Rev. Sci. Instr., 31:395-398. 
Lee, T., E. Barg and D. Lal, 1991. Studies of vertical mixing in the Southern California Bight using cosmogenic radionuclides ${ }^{32} \mathrm{P}$ and ${ }^{7} \mathrm{Be}$, Limnol. Oceanogr., 36:1044-1053.

Lee, T., E. Barg and D. Lal, 1992. Techniques for extraction of dissolved inorganic and organic phophorus from large volumes of seawater. Anal. Chim. Acta, 260:113-121.

Libby, W.F., 1957. Simple absolute measurement technique for beta radioactivity. Anal. Chem., 29:1566-1570.

Libby, W.F., 1947. Measurement of radioactive tracers, particularly ${ }^{14} \mathrm{C},{ }^{35} \mathrm{~S}, \mathrm{~T}$, and other longer-lived low-energy activities. Anal. Chem., 19:2-6.

Morel, F. M. 1983. Reactions on solid surfaces. In: Principles of Aquatic Chemistry. John Wiley and Sons, pp377-433.

Mullins W. T. and G. W. Leddicotte, 1962. The Radiochemistry of Phosphorus. NASNS-3056, Oak Ridge national Laboratory.

Murphy, J. and J. P. Riley, 1962. A modified single solution method for the determination of phosphate in natural waters. Anal. Chim. Acta, 27:31-36.

Nerwik, W. E. and P. C. Stevenson, 1952. Self-scattering and self-absorption of betas by moderately thick samples. Nucleonics, 10(3):18-22.

Price, W.J., 1958. Properties of nuclear radiation. In: Nuclear radiation detection, McGraw-Hill, New York, pp1-41.

Silker W. B. and H. G. Rieck, 1969. Radionuclide collection efficiencies from ocean water with alumina. BNWL-1051. Part 2.

Silker W. B., R. W. Perkins and H. G. Rieck, 1971. A sampler for concentrating radionuclides from natural waters. Ocean Engng., 2:49-55.

Stumm W., Kummert R. and L. Sigg, 1980. A ligand exchange model for the adsorption of inorganic and organic ligands at hydrous oxide interfaces. Croat. Chem. Acta., 53:291312.

Turner R. L. and H. M. Rice. 1954. Role of fluoride ion in release of phosphate adsorbed by $\mathrm{Al}$ and fe hydroxide. Soil Sci., 74:141-148. 
Volchok H. L. and G. De Planque (eds.), 1987. Environmental Measurement Procedures Manual. 26th Edition. Environmental Measurements laboratory, U. S. department of energy, HASL-300.

Wang, C. H., D. L. Willis and W. D. Loveland, 1975. Radiotracer Methodology in the Biological Environment and Physical Sciences, Prentice-Hall, Inc.

Whaley, T. P. and L. W. Ferrara, 1972. Gravimetric Analysis of Phosphorus Compounds. In: Griffith, Beeton, Spencer and Mitchell (eds.), Environmental Phosphorus Handbook, John Wiley and Sons, pp313-326. 
Chapter Two

\section{DETERMINATION OF THE FALLOUT RATES OF ${ }^{32}$ P AND ${ }^{33}$ P AT BERMUDA}

\section{INTRODUCTION}

In order to understand the pathways, concentrations and transformations of ${ }^{33} \mathrm{P}$ and ${ }^{32} \mathrm{P}$ in the upper ocean it is necessary to know the supply to the ocean. Following their production by spallation in $\mathrm{Ar},{ }^{32} \mathrm{P}$ and ${ }^{33} \mathrm{P}$ are believed to be rapidly oxidized to phosphate and scavenged by sub-micrometer aerosols. The aerosols are ultimately removed from the troposphere by precipitation. Wet deposition is believed to be the primary removal mechanism of ${ }^{32} \mathrm{P}$ and ${ }^{33} \mathrm{P}$ (Lal et al., 1957; Goel et al., 1959; Lal et al., 1960). Therefore, in order to quantify the deposition rates of ${ }^{32} \mathrm{P}$ and ${ }^{3} 3 \mathrm{P}$ at a particular site, it is necessary to study the activities of ${ }^{32} \mathrm{P}$ and ${ }^{3} 3 \mathrm{P}$ in rainwater at that site.

A year-long record of the activities of ${ }^{32} \mathrm{P}$ and ${ }^{33} \mathrm{P}$ and of the activity ratio ${ }^{33} \mathrm{P} /{ }^{32} \mathrm{P}$ in individual precipitation events was acquired at Bermuda $\left(32^{0} 30^{\prime} \mathrm{N} ; 64^{0}\right.$ $\left.40^{\prime} \mathrm{W}\right)$. In conjunction with those data a few individual rain samples were collected at Woods Hole ( $\left.41^{0} 31^{\prime} \mathrm{N} ; 70^{\circ} 40^{\prime} \mathrm{W}\right)$. The activities of ${ }^{32} \mathrm{P}$ and ${ }^{33} \mathrm{P}$ measured in rainwater and the measured rainfall rates allowed computation of the wet deposition rates of ${ }^{32} \mathrm{P}$ and ${ }^{33} \mathrm{P}$ from March 1991 to March 1992 at Bermuda. 


\section{BACKGROUND}

Cosmogenic ${ }^{32} \mathrm{P}$ and ${ }^{33} \mathrm{P}$ are continuously produced by cosmic-ray spallation of argon within the earth's atmosphere. The production rates vary notably with altitude and latitude (Lal et al., 1958; Lal and Peters, 1967). The production rates of both ${ }^{32} \mathrm{P}$ and ${ }^{33} \mathrm{P}$ increase by two orders of magnitude from ground level to the top of the troposphere and are much higher in the stratosphere than in the troposphere (Lal and Peters, 1967). The global tropospheric production rates of ${ }^{32} \mathrm{P}$ and ${ }^{33} \mathrm{P}$ are almost independent of latitude. This is in contrast with the global stratospheric production rates, which are an order of magnitude higher at a latitude of $90^{\circ}$ than at $0^{\circ}$ (Lal and Peters, 1967). The ratio of the production rates of the two isotopes is approximately constant with time, latitude and altitude (Lal and Peters, 1967). The atom ratio ${ }^{33} \mathrm{P} /{ }^{32} \mathrm{P}$ of the production rates has been determined experimentally in argon to be 0.8 (Lal et al., 1960a).

Following their production ${ }^{33} \mathrm{P}$ and ${ }^{32} \mathrm{P}$ are believed to be rapidly oxidized to phosphate. Cosmogenic ${ }^{32} \mathrm{P},{ }^{33} \mathrm{P}$ as well as ${ }^{7} \mathrm{Be}\left(\mathrm{t}_{1 / 2}=53.3 \mathrm{~d}\right)$, another cosmogenic nuclide with similar source and pattern of production as ${ }^{32} \mathrm{P}$ and ${ }^{33} \mathrm{P}$, are believed to be rapidly scavenged by sub-micrometer particles in the atmosphere. Tropospheric aerosols become condensation nuclei and the radionuclides are ultimately deposited by precipitation. Dry deposition of both short-lived and particle-reactive radionuclides, i.e. ${ }^{32} \mathrm{P},{ }^{33} \mathrm{P}$ and ${ }^{7} \mathrm{Be}$, has generally been assumed to be small relative to wet deposition (Lal and Peters, 1967; Young and Silker, 1974; Turekian et al., 1983). Recent studies have shown that dry deposition of ${ }^{7} \mathrm{Be}$ is only $10 \%$ of the total deposition rate (Brown et al., 1989). Wet deposition rates and total deposition rates of ${ }^{7} \mathrm{Be}$ have been measured extensively (Rama Thor and Zutshi, 1958; Goel et al., 1959; Lal et al., 1960b; Walton and Fried, 1962; Schumann and Stroeppler, 1963; Young and Silker, 1974; Lal et al., 1979; Young and Silker, 1980; Krishnaswami et al., 1980; Crecelius, 1981; Turekian et al., 1983; Olsen et al., 1985, 1986; Dibb, 1989). This is in contrast with the small amount of data 
on the fallout of ${ }^{32} \mathrm{P}$ (Lal et al., 1957; Goel et al., 1959; Lal et al., 1960) and even fewer data for ${ }^{3} 3$ P fallout rates (Lal et al., 1957; Goel et al., 1959). The lack of data on the deposition rates of ${ }^{32} \mathrm{P}$ and of ${ }^{33} \mathrm{P}$ is due primarily to the difficulty of the measurements. It results in a poor latitudinal coverage of the wet deposition rates of ${ }^{32} \mathrm{P}$ and ${ }^{33} \mathrm{P}$. There have been more extensive measurements of ${ }^{32} \mathrm{P}$ activities in surface air relative to rainwater, and it has been used as a tracer of atmospheric circulation, usually in conjunction with ${ }^{7} \mathrm{Be}$ and sometimes with ${ }^{33} \mathrm{P}$ (Rama and Honda, 1961; Aegerter et al., 1966; Luyanas et al., 1970; Bhandari et al., 1970; Reiter et al., 1971; Reiter et al., 1975; Sanak et al., 1985).

Cosmogenic ${ }^{7} \mathrm{Be}$ has been widely studied. The studies of its distribution in air, scavenging rates, and seasonal and latitudinal variability can be useful for the study of ${ }^{32} \mathrm{P}$ and ${ }^{33} \mathrm{P}$ and those studies are thus reviewed. The strong dependence of ${ }^{7} \mathrm{Be}$ concentrations in surface air on latitude and season is now well established. It has been attributed to latitudinal and seasonal variations in the exchange between the troposphere and the stratosphere (Parker, 1962; Schumann and Stroeppler, 1963; Peirson, 1963; Rangarajan and Gopalakrishnan, 1970; Reiter et al., 1971; Viezee and Singh, 1980; Dutkiewicz and Husain, 1985; Dibb, 1989). Maximum ${ }^{7}$ Be concentrations in surface air and maximum deposition rates have been reported at mid-latitude $\left(40-50{ }^{\circ} \mathrm{N}\right)$ in late spring/summer (Parker, 1962; Schumann and Stroeppler, 1963; Viezee and Singh, 1980; Dibb 1989); at low latitudes $\left(20-30^{\circ} \mathrm{N}\right)$ in spring (Rangarajan and Gopalakrishnan, 1970; Viezee and Singh, 1980); and at polar latitudes during austral summer (Feely et al., 1977; Maenhaut et al., 1979; Sanak et al., 1985). Anomalously high deposition rates of ${ }^{7} \mathrm{Be}$ in the intertropical convergence zone (ITCZ) have been reported north of the ITCZ (10$20^{\circ} \mathrm{N}$ ) by Young and Silker (1974). They explain these high deposition rates not by stratospheric intrusion per se, but by the intrusion of tropospheric cumulus and cumulonimbus clouds into the stratosphere and scavenging of the stratospheric aerosols. 
At low latitudes $\left(20-30^{\circ}\right)$ and mid-latitudes $\left(40-50^{\circ}\right)$ the exchanges have been attributed to low-pressure troughs associated with a folding of the tropopause (Danielson and Mohnen, 1977; Viezee and Singh, 1980). These areas of exchange are found in the vicinity of the jet streams which are typically located at $30^{\circ}$ and $60^{\circ}$ in both hemispheres (Hasse, 1983). The process of exchange in the jet stream is due to large-scale eddy transport (Reiter, 1975). At polar latitudes the stratospheric contribution could be considerable because of (1) the much higher production rates of ${ }^{7} \mathrm{Be}$ in the stratosphere at high latitudes than at low latitudes (Lal and Peters, 1967) (2) substantial and continual fluctuations of the height of the tropopause at the poles (Sanak et al., 1985) and (3) breakup of the polar vortex in the winter and spring (Martell and Drevinsky, 1960).

During the time of atmospheric testing of nuclear weapons, the distributions of the bomb-produced radioisotopes ${ }^{90} \mathrm{Sr},{ }^{137} \mathrm{Cs},{ }^{238} \mathrm{Pu},{ }^{239} \mathrm{Pu}$ and ${ }^{240} \mathrm{Pu}$ were similar to the distribution of ${ }^{32} \mathrm{P},{ }^{33} \mathrm{P}$ and ${ }^{7} \mathrm{Be}$, because they were injected primarily into the stratosphere and at high latitudes. The tropospheric contribution of the tests was small, because; (1) the tropospheric tests were low yield (Perkins and Thomas, 1980), and (2) the tropospheric radioactivity so produced was removed rapidly after the tests. The bombproduced radioisotopes were thus good tracers of stratospheric air. The concentrations of the bomb-produced nuclides in surface air and their transport to the troposphere exhibited strong latitudinal and seasonal variations (Rangarajan and Gopalakrishnan, 1970; Silker, 1972; Perkins and Thomas, 1980; Staley, 1982; Dutkiewicz and Husain, 1985). The concentrations of ${ }^{137} \mathrm{Cs}$ in surface air were highest in the spring at low and mid-latitudes (Rangarajan and Gopalakrishnan, 1970; Silker, 1972). The fallout rate of ${ }^{90} \mathrm{Sr}$ and its concentration in surface air were found to be highest (1) in late-winter and spring at low latitudes (Machta, 1959; Staley, 1982) and (2) in summer at mid-latitudes (Schumann and Stoeppler, 1963; Staley, 1982).

Most of the exchange processes between the stratosphere and the troposphere evidenced with radionuclides are due to large-scale eddy transport across the tropopause 
in the jet stream region. This process has been widely reported to have a very strong seasonality. Nevertheless, there are also other exchange mechanisms, in particular the adjustment of the height of the tropopause (Reiter, 1975). This adjustment is continuous during the year and occurs at all latitudes. It is characterized by a general drop of the tropopause from spring to fall and a general rise from fall to spring.

\section{METHODS}

Rain water was collected from the roof of Hansen Hall at the Bermuda Biological Station for Research. The roof (area of about $30 \mathrm{~m}^{2}$ ) thus collected particles in addition to rainwater. Two 60 -liter barrels were connected to the gutter and could be alternately filled. Usually only major rain events (rainfall rate $>1 \mathrm{~cm} / \mathrm{d}$ ) were sampled because of the large minimum volume required (10-20 $\ell$ ). The rainwater was spiked with stable $\mathrm{P}\left(\mathrm{KH}_{2} \mathrm{PO}_{4}\right)$ as carrier phase and yield monitor. Phosphate was efficiently extracted on alumina, and the sample was analysed as described in Chapter One. In addition, rainwater samples were collected from a $4 \mathrm{~m}^{2}$ rain collector placed on the roof of the Clark Building at Woods Hole in the winter/spring of 1990 and 1991. The collection procedure used was identical to the one described above.

\section{RESULTS}

A year-long record of the concentrations of ${ }^{32} \mathrm{P}$ and ${ }^{33} \mathrm{P}$ and of the activity ratio ${ }^{33} \mathrm{P} /{ }^{32} \mathrm{P}$ in single precipitation events was acquired at Bermuda $\left(32^{0} 30^{\prime} \mathrm{N} ; 64^{0}\right.$ 40' W). Figure 2.1 shows the record of the ratio from March 1991 to March 1992. Figure 2.2 shows the daily rainfall rates measured from January 1991 to March 1992 at Saint Davids, situated at the eastern tip of the island. The distribution of the monthly averaged rainfall rate during that period shows high rates in February, March, September 
of 1991 and January, February of 1992 (Figure 2.3). The activities of ${ }^{32} \mathrm{P}$ and ${ }^{33} \mathrm{P}$ and the activity ratios ${ }^{33} \mathrm{P} /{ }^{32} \mathrm{P}$ of all the individual rain samples collected in 1990-92 at Woods Hole and Bermuda are presented in tables 2.1 and 2.2. The activities of ${ }^{32} \mathrm{P}$ and ${ }^{3}{ }^{3} \mathrm{P}$ vary from 0.15 to $3.5 \mathrm{dpm} / 1$ for ${ }^{32} \mathrm{P}$ and from 0.14 to $3.0 \mathrm{dpm} / 1$ for ${ }^{33} \mathrm{P}$ at Bermuda and from 0.4 to $0.9 \mathrm{dpm} / 1$ for ${ }^{32} \mathrm{P}$ and from 0.5 to $0.98 \mathrm{dpm} / 1$ for ${ }^{33} \mathrm{P}$ at Woods Hole. In contrast to the wide range in activities, the range in the ratio is smaller: 0.66 to 1.20 in the Bermuda samples and clustering around 1.10 at Woods Hole. The activities of ${ }^{32} \mathrm{P}$ and ${ }^{3}{ }^{3} \mathrm{P}$ in rainwater are extremely variable, because they depend on the residence time of aerosols, the activities of ${ }^{32} \mathrm{P}$ and ${ }^{33} \mathrm{P}$ in air and the rate of scavenging of ${ }^{32} \mathrm{P}$ and ${ }^{33} \mathrm{P}$ by aerosols. In contrast, the activity ratio ${ }^{33} \mathrm{P} /{ }^{32} \mathrm{P}$ in rain depends only on the history and pathways of the air mass. The highest activities of ${ }^{32} \mathrm{P}$ and ${ }^{33} \mathrm{P}$ in Bermuda rain are found in March 1991, and they are associated with high ratios averaging 1.0 in March 1991. The June-November 1991 period is characterized by a higher frequency of low activity ratios ${ }^{33} \mathrm{P} /{ }^{32} \mathrm{P}$ than the March-April 1991 and January-March 1992 periods. At the same time, ratios as high as 1.0-1.2 are observed during the period.

An important feature of the Bermuda data set is the systematic variation in the activity ratio ${ }^{33} \mathrm{P} /{ }^{3} \mathrm{P}$ about the annual mean of 0.96 (Figure 2.4). Higher ratios were observed in April 1991 and January-February 1992, and lower ratios were observed in September-October 1991. The activity ratio was on average $1.01 \pm 0.04$ in the late winter/spring period (i. e., March to June 1991), $0.88 \pm 0.03$ and $0.90 \pm 0.06$ in summer and fall 1991 and $1.03 \pm 0.05$ in the winter of 1992 (Table 2.3). The variations might be due to stratospheric input in spring and winter at Bermuda. It might also be due to increased mixing between the upper and lower troposphere in summer and fall relative to spring and winter. 


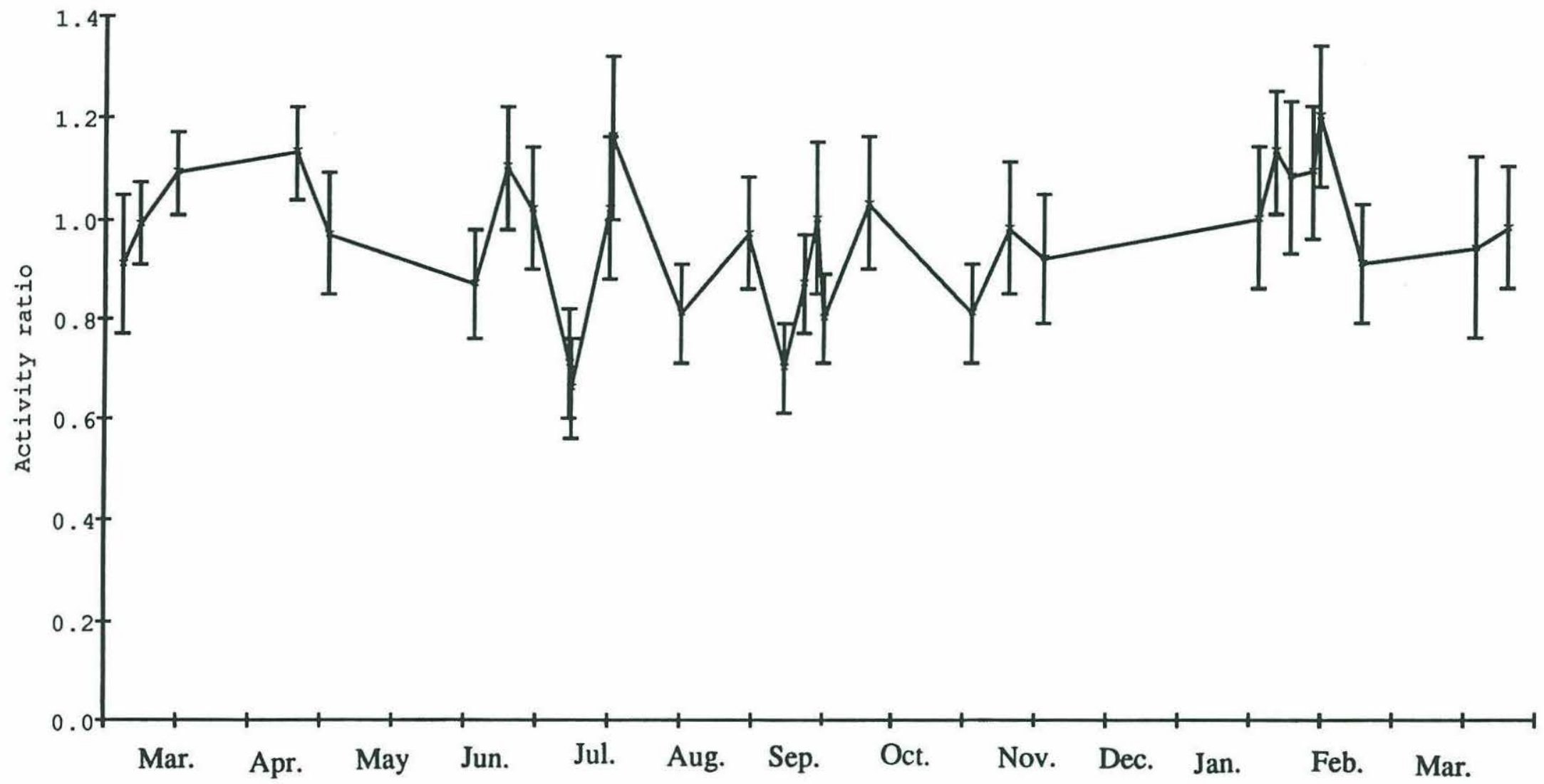

Figure 2.1. Activity ratio ${ }^{33} \mathrm{P} /{ }^{32} \mathrm{P}$ in major precipitation events collected at Bermuda Biological Station for Research (BBSR) from March 1991 to March 1992. 


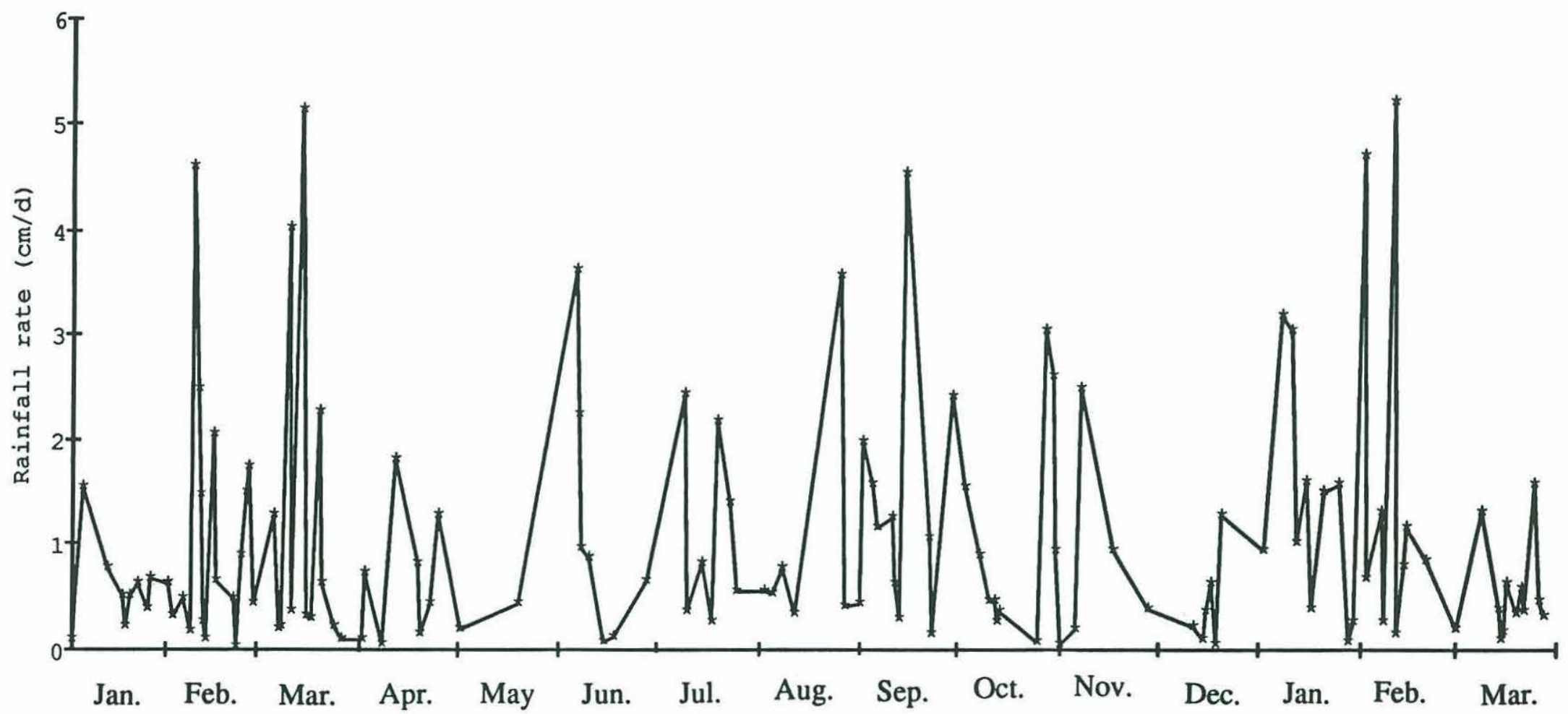

Figure 2.2. Rainfall rate at Saint Davids, Bermuda, from January 1991 to March 1992, for rates higher than $0 \mathrm{~cm} /$ day. 


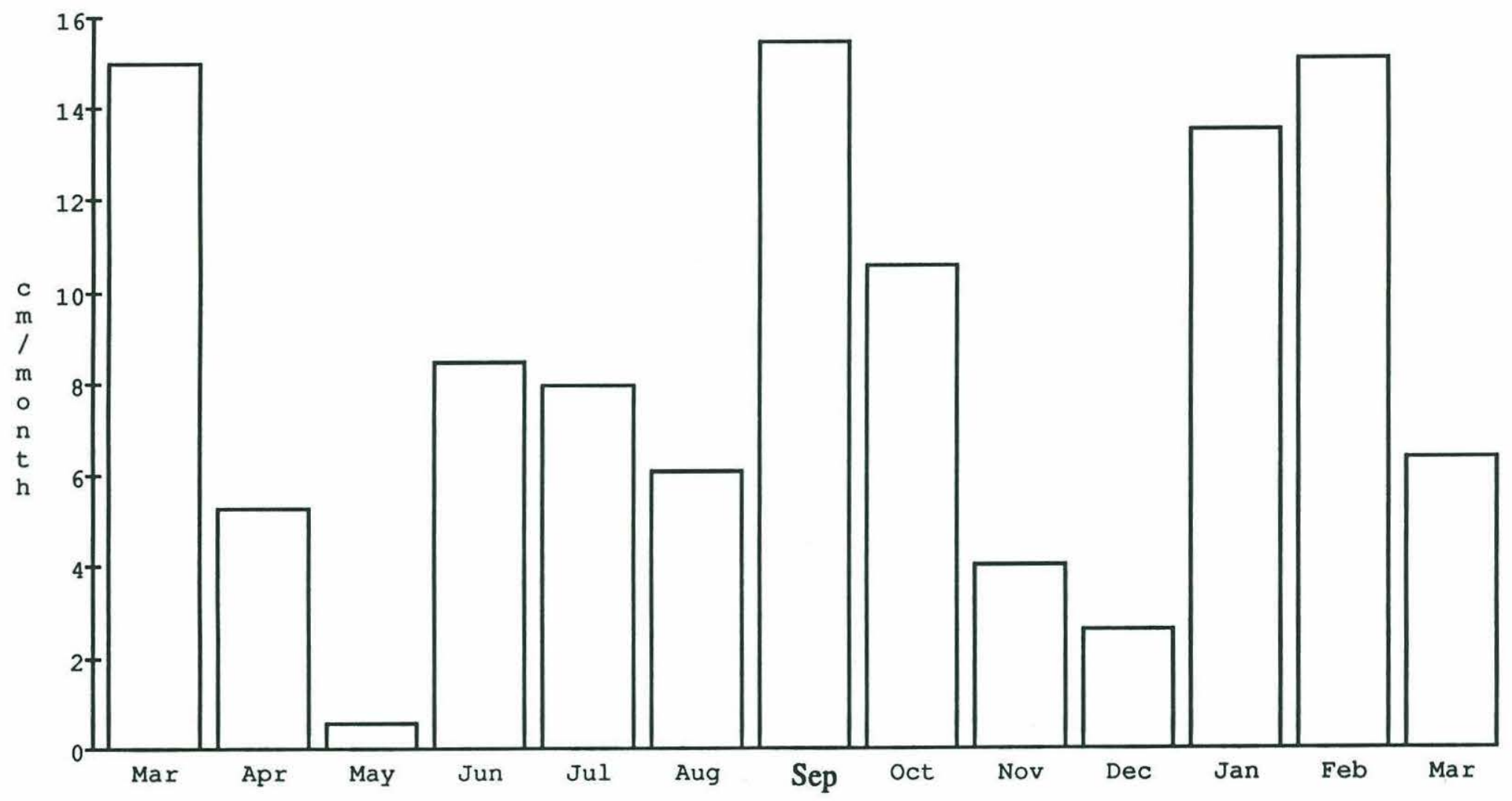

Figure 2.3. Monthly rainfall rates at Saint Davids, Bermuda, from January 1991 to March 1992. 
Table 2.1. Activities of ${ }^{32} \mathrm{P}$ and ${ }^{33} \mathrm{P}\left({ }^{32} \mathrm{~A}\right.$ and $\left.{ }^{33} \mathrm{~A}\right)$ and activity ratio ${ }^{33} \mathrm{P} /{ }^{32} \mathrm{P}(\mathrm{R})$ in rain samples collected during 1991 and 1992 at the Bermuda biological Station.

\begin{tabular}{|c|c|c|c|}
\hline date & $\begin{array}{l}{ }_{\mathrm{dpm} / \ell}^{32} \\
\mathrm{~A}\end{array}$ & $\begin{array}{c}{ }^{33} \mathrm{~A} \\
\mathrm{dpm} / \mathrm{l}\end{array}$ & $\underset{\mathrm{dpm} / \mathrm{dpm}}{\mathrm{R}}$ \\
\hline 05-Mar-91 & $0.41 \pm 0.07$ & $0.37 \pm 0.06$ & $0.91 \pm 0.14$ \\
\hline 10-Mar-91 & $1.92 \pm 0.30$ & $2.12 \pm 0.29$ & $1.10 \pm 0.12$ \\
\hline 10-Mar-91 & $3.46 \pm 0.16$ & $3.02 \pm 0.46$ & $0.87 \pm 0.10$ \\
\hline 20-Mar-91 & $1.05 \pm 0.19$ & $1.13 \pm 0.14$ & $1.08 \pm 0.12$ \\
\hline 20-Mar-91 & $1.55 \pm 0.3$ & $1.69 \pm 0.20$ & $1.09 \pm 0.11$ \\
\hline 22-Apr-91 & $1.02 \pm 0.11$ & $1.06 \pm 0.14$ & $1.04 \pm 0.12$ \\
\hline 22-Apr-91 & $0.55 \pm 0.07$ & $0.67 \pm 0.11$ & $1.22 \pm 0.14$ \\
\hline 01-May-91 & $0.75 \pm 0.10$ & $0.73 \pm 0.10$ & $0.97 \pm 0.12$ \\
\hline 11-Jun-91 & $0.60 \pm 0.09$ & $0.58 \pm 0.10$ & $0.96 \pm 0.13$ \\
\hline 11-Jun-91 & $0.38 \pm 0.06$ & $0.29 \pm 0.06$ & $0.78 \pm 0.14$ \\
\hline 20-Jun-91 & $0.58 \pm 0.06$ & $0.64 \pm 0.08$ & $1.10 \pm 0.12$ \\
\hline 27-Jun-91 & $0.49 \pm 0.06$ & $0.50 \pm 0.07$ & $1.02 \pm 0.12$ \\
\hline 07-Jul-91 & $1.39 \pm 0.17$ & $0.98 \pm 0.14$ & $0.71 \pm 0.11$ \\
\hline 08-Jul-91 & $1.31 \pm 0.13$ & $0.86 \pm 0.11$ & $0.66 \pm 0.10$ \\
\hline 18-Jul-91 & $0.72 \pm 0.07$ & $0.73 \pm 0.10$ & $1.02 \pm 0.14$ \\
\hline 19-Jul-91 & $0.60 \pm 0.07$ & $0.70 \pm 0.10$ & $1.16 \pm 0.16$ \\
\hline 07-Aug-91 & $1.05 \pm 0.09$ & $0.86 \pm 0.14$ & $0.81 \pm 0.10$ \\
\hline 26-Aug-91 & $0.77 \pm 0.09$ & $0.75 \pm 0.10$ & $0.97 \pm 0.11$ \\
\hline 05-Sep-91 & $1.04 \pm 0.13$ & $0.78 \pm 0.14$ & $0.70 \pm 0.09$ \\
\hline 11-Sep-91 & $0.67 \pm 0.09$ & $0.59 \pm 0.09$ & $0.87 \pm 0.10$ \\
\hline 14-Sep-91 & $0.26 \pm 0.03$ & $0.26 \pm 0.04$ & $1.00 \pm 0.15$ \\
\hline 16-Sep-91 & $0.90 \pm 0.09$ & $0.72 \pm 0.09$ & $0.80 \pm 0.09$ \\
\hline 29-Sep-91 & $0.47 \pm 0.05$ & $0.48 \pm 0.04$ & $1.03 \pm 0.13$ \\
\hline 28-Oct-91 & $0.79 \pm 0.09$ & $0.62 \pm 0.08$ & $0.78 \pm 0.10$ \\
\hline 28-Oct-91 & $0.26 \pm 0.04$ & $0.22 \pm 0.03$ & $0.84 \pm 0.15$ \\
\hline 07-Nov-91 & $0.79 \pm 0.09$ & $0.77 \pm 0.09$ & $0.98 \pm 0.13$ \\
\hline 17-Nov-91 & $0.88 \pm 0.10$ & $0.81 \pm 0.09$ & $0.92 \pm 0.13$ \\
\hline 16-Jan-92 & $0.31 \pm 0.03$ & $0.31 \pm 0.05$ & $1.00 \pm 0.14$ \\
\hline 21-Jan-92 & $1.26 \pm 0.15$ & $1.42 \pm 0.17$ & $1.13 \pm 0.12$ \\
\hline 25-Jan-92 & $0.36 \pm 0.04$ & $0.39 \pm 0.06$ & $1.08 \pm 0.15$ \\
\hline 31-Jan-92 & $0.67 \pm 0.09$ & $0.74 \pm 0.09$ & $1.09 \pm 0.13$ \\
\hline 02-Feb-92 & $0.31 \pm 0.03$ & $0.38 \pm 0.04$ & $1.20 \pm 0.14$ \\
\hline 14-Feb-92 & $0.69 \pm 0.09$ & $0.63 \pm 0.1$ & $0.91 \pm 0.12$ \\
\hline 17-Mar-92 & $0.15 \pm 0.02$ & $0.14 \pm 0.03$ & $0.94 \pm 0.18$ \\
\hline 26-Mar-92 & $0.54 \pm 0.08$ & $0.56 \pm 0.09$ & $1.02 \pm 0.19$ \\
\hline 26-Mar-92 & $0.65 \pm 0.12$ & $0.60 \pm 0.12$ & $0.93 \pm 0.15$ \\
\hline
\end{tabular}


Table 2.2. Activities of ${ }^{32} \mathrm{P}$ and ${ }^{33} \mathrm{P}\left({ }^{32} \mathrm{~A}\right.$ and $\left.{ }^{33} \mathrm{~A}\right)$ and activity ratio ${ }^{33} \mathrm{P} \mathrm{P}^{32} \mathrm{P}(\mathrm{R})$ in rain samples collected at Woods Hole.

\begin{tabular}{|c|c|c|c|}
\hline date & $\begin{array}{l}{ }_{\mathrm{dpm} / \ell}^{32} \mathrm{~A} \\
\text { d }\end{array}$ & $\begin{array}{l}{ }_{\mathrm{dpm} / \mathrm{l}}^{33} \\
\text { A }\end{array}$ & $\begin{array}{l}\mathrm{R} \\
\mathrm{dpm} / \mathrm{dpm}\end{array}$ \\
\hline 27-Dec-90 & $0.82 \pm 0.09$ & $0.98 \pm 0.10$ & $1.21 \pm 0.09$ \\
\hline 16-Jan-91 & $0.41 \pm 0.04$ & $0.51 \pm 0.06$ & $1.24 \pm 0.11$ \\
\hline 21-Apr-91 & $0.90 \pm 0.10$ & $0.74 \pm 0.10$ & $0.82 \pm 0.13$ \\
\hline
\end{tabular}

Table 2.3. Seasonal averages of the activity ratio ${ }^{33} \mathrm{P} /{ }^{32} \mathrm{P}(\mathrm{R})$ in rain and associated residence times of tropospheric aerosols at Bermuda for two different values of $\mathrm{R}_{0}$.

\begin{tabular}{lcll}
\hline Season & $\begin{array}{c}\mathrm{R} \\
\mathrm{dpm} / \mathrm{dpm}\end{array}$ & $\begin{array}{c}\tau \\
\text { days } \\
\mathrm{R}_{0}=0.7\end{array}$ & $\begin{array}{c}\tau \\
\text { days } \\
\mathrm{R}_{0}=0.6\end{array}$ \\
\hline Spring and March 1991 & $1.01 \pm 0.04$ & $50 \pm 10$ & $110 \pm 25$ \\
Spring 1991 & $1.02 \pm 0.05$ & $52 \pm 10$ & $115 \pm 35$ \\
Summer 1991 & $0.88 \pm 0.03$ & $25 \pm 5$ & $52 \pm 10$ \\
Fall 1991 & $0.90 \pm 0.06$ & $30 \pm 7$ & $57 \pm 10$ \\
Winter 1992 & $1.03 \pm 0.05$ & $55 \pm 12$ & $95-290$ \\
\hline Annual average & $0.96 \pm 0.02$ & $40 \pm 7$ & $80 \pm 15$ \\
\hline
\end{tabular}


The average wet deposition rates were determined by multiplying the monthly average activities of ${ }^{32} \mathrm{P}$ and ${ }^{33} \mathrm{P}$ (Figure 2.5 ) by the monthly average rainfall rates. Monthly, seasonal and yearly averages of the wet deposition rates are shown in tables 2.4 and 2.5. The monthly mean wet deposition rates of ${ }^{32} \mathrm{P}$ and ${ }^{33} \mathrm{P}$ show significant differences from one month to another, mostly due to the difference in rainfall rates. The monthly averages vary from 0.059 to $0.266 \mathrm{dpm} / \mathrm{cm}^{2} / \mathrm{yr}$ for ${ }^{32} \mathrm{P}$ and from 0.058 to 0.264 $\mathrm{dpm} / \mathrm{cm}^{2} / \mathrm{yr}$ for ${ }^{33} \mathrm{P}$. The extreme upper and lower values occurred in March and May 1991 (Table 2.4). For the 9 other months, the average wet deposition rates were much more constant and averaged $0.074 \pm 0.04 \mathrm{dpm} / \mathrm{cm}^{2} / \mathrm{yr}$ for ${ }^{32} \mathrm{P}$ and $0.073 \pm 0.05$ $\mathrm{dpm} / \mathrm{cm}^{2} / \mathrm{yr}$ for ${ }^{33} \mathrm{P}$. The extremes in March and May were caused by (1) a low precipitation rate in May 1991, resulting in a low fallout rate for that month, and (2) very high concentrations of ${ }^{32} \mathrm{P}$ and ${ }^{33} \mathrm{P}$ in rain and high rainfall rates in March 1991. The seasonal averaged wet deposition rates range from $3.610^{-2}$ to $10.210^{-2} \mathrm{dpm} / \mathrm{cm}^{2} / \mathrm{yr}$ for ${ }^{32} \mathrm{P}$ and $3.710^{-2}$ to $11.310^{-2} \mathrm{dpm} / \mathrm{cm}^{2} / \mathrm{yr}$ for ${ }^{33} \mathrm{P}$ (Table 2.5). The annual averages are $8.610^{-2}$ and $8.210^{-2} \mathrm{dpm} / \mathrm{cm}^{2} / \mathrm{yr}$ or $4.910^{-3}$ and $8.210^{-3}$ atom/ $/ \mathrm{cm}^{2} / \mathrm{min}$. Assuming a 40 day residence time of tropospheric aerosols, Lal and Peters (1967) estimated global mean tropospheric fallout rates of $5.810^{-3}$ atom $/ \mathrm{cm}^{2} / \mathrm{min}$ for ${ }^{32} \mathrm{P}$ and $6.910^{-3}$ atom/ $/ \mathrm{cm}^{2} / \mathrm{min}$ for ${ }^{33} \mathrm{P}$ with uncertainties of 20 to $30 \%$. These values agree within the uncertainties of each estimation.

\section{MODEL OF AEROSOL RESIDENCE TIMES}

In this section, I explain how the residence time of sub-micrometer aerosols in the troposphere can be derived from the ratio ${ }^{33} \mathrm{P} /{ }^{32} \mathrm{P}$ in individual rain events. The ratio ${ }^{33} \mathrm{P} /{ }^{3} \mathrm{P}$ in air increases between the time the nuclides are produced and the time the aerosols are scavenged by precipitation because of the differential decay rates of ${ }^{33} \mathrm{P}$ and ${ }^{32} \mathrm{P}$. If one assumes that there is no fractionation during the condensation process, 
then the increase in the ratio in the air will be exactly reflected in the rainwater. The determination of the residence time is model-dependent. Both a non-steady-state and a steady-state model were investigated. A non-steady-state model has been previously applied to cosmogenic ${ }^{7} \mathrm{Be}$ (Lal and Peters, 1967; Shapiro and Forbes-Resha, 1976; Bleichrodt, 1978) and to the ratio of two cosmogenic radioisotopes: $(1)^{33} \mathrm{P} /{ }^{2} \mathrm{P}$ (Lal et al., 1957; Goel et al. 1959; Luyanas et al., 1979; Rama and Honda, 1961) and (2) ${ }^{7} \mathrm{Be} /{ }^{2}$ P (Goel et al., 1959; Lal et al., 1960; Rama and Honda, 1961; Walton and Fried, 1962; Bhandari et al., 1970).

\section{a) Non steady-state model}

The mass-conservation equation for a radionuclide in a parcel of air is the following:

(2.1) $d C / d t=\partial C / \partial t+u \partial C / \partial x+v \partial C / \partial y+w \partial C / \partial z=F-\lambda C$

Where $\mathrm{C}$ is the mean concentration, $\lambda$ is the decay constant, $\mathrm{u}, \mathrm{v}$ and $\mathrm{w}$ are the mean advective velocities in the $\mathrm{x}, \mathrm{y}$ and $\mathrm{z}$ dimensions, and $\mathrm{F}$ is the mean production rate in the troposphere. Equation (2.1) assumes that the radionuclides are continually produced and lost by decay in the air mass. No removal term by precipitation is included, because precipitation is a discontinuous process and will be treated as such. The model assumes no mixing of the air mass with surrounding air. The solution of (2.1) is:

(2.2) $\mathrm{C}=\mathrm{F} / \lambda-\left(\mathrm{F} / \lambda-\mathrm{C}^{0}\right) \exp (-\lambda \mathrm{t})$

Where $\mathrm{C}=\mathrm{C}^{0}$ at $\mathrm{t}=0$. Furthermore it is assumed that at $\mathrm{t}=0$ both radioisotopes were efficiently removed by washout. Thus $\mathrm{C}^{0}=0$ and equation (2.2) becomes:

(2.3) $\quad C=F / \lambda(1-\exp (-\lambda t))$ 


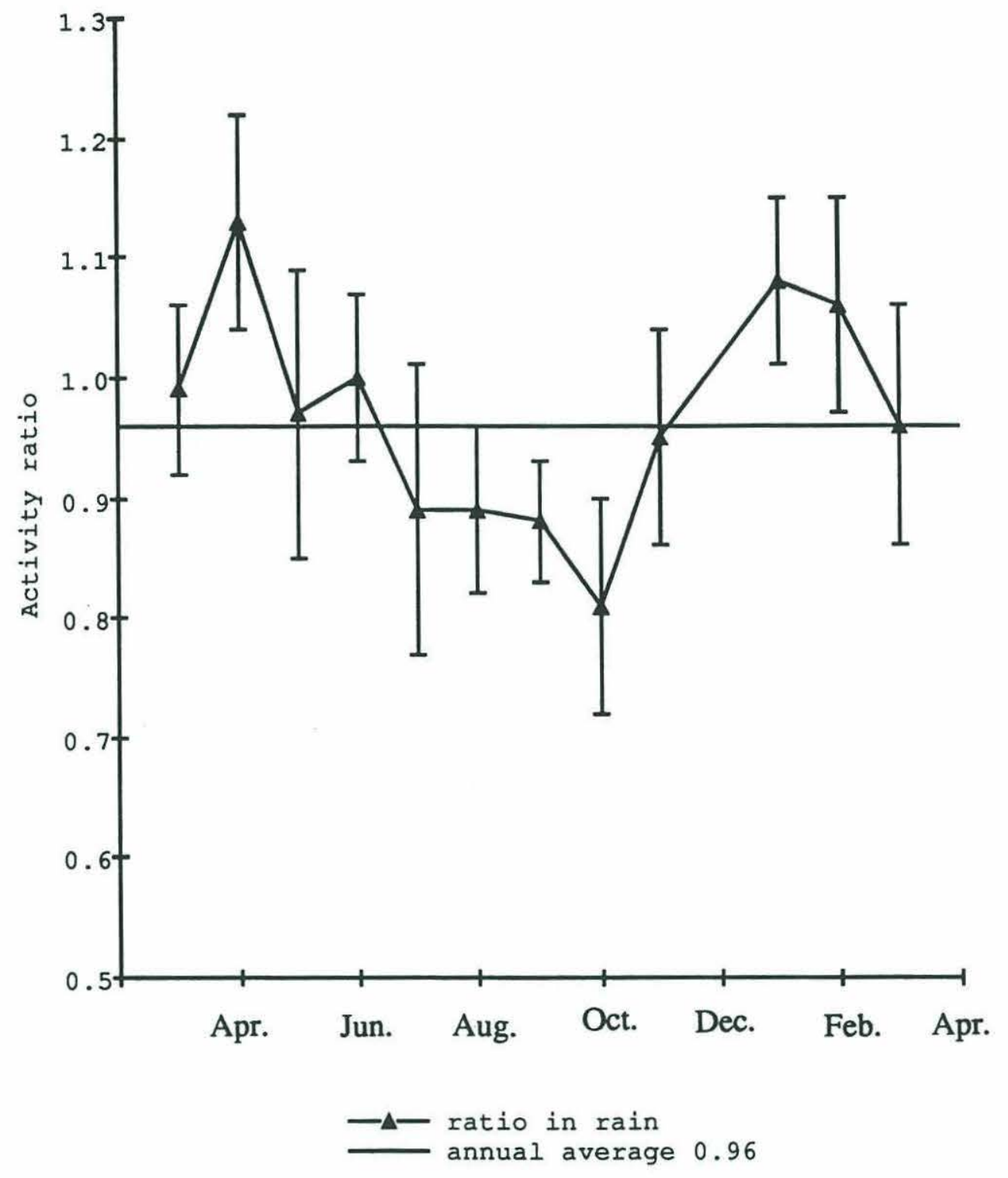

Figure 2.4. Activity ratio ${ }^{33} \mathrm{P} /{ }^{32} \mathrm{P}$ in rain at BBSR averaged monthly from March 1991 to March 1992. 


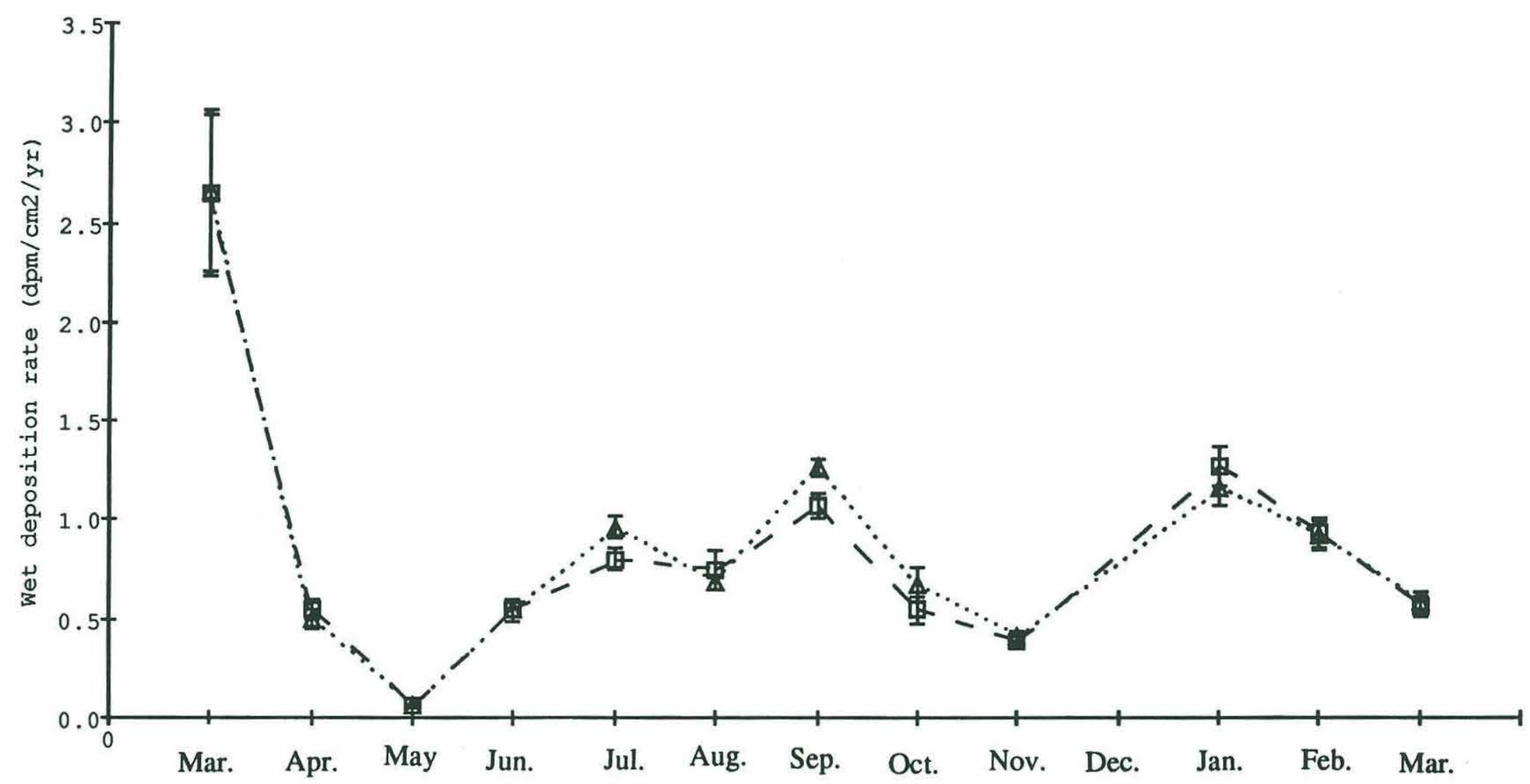

Figure 2.5. Wet deposition rates of ${ }^{32} \mathrm{P}$ and ${ }^{33} \mathrm{P}$ averaged monthly at Bermuda from March 1991 to March 1992. 
Table 2.4. Monthly averages of the activities of ${ }^{32} \mathrm{P}$ and ${ }^{33} \mathrm{P}\left({ }^{32} \mathrm{~A}\right.$ and $\left.{ }^{33} \mathrm{~A}\right)$, rainfall rate $(\mathrm{r})$ and wet deposition rates of ${ }^{32} \mathrm{P}$ and ${ }^{33} \mathrm{P}\left({ }^{32} \mathrm{~W}\right.$ and $\left.{ }^{33} \mathrm{~W}\right)$ at Bermuda in 1991 and 1992.

\begin{tabular}{llllll}
\hline Month & $\begin{array}{c}{ }^{32} \mathrm{~A} \\
\mathrm{dpm} / \ell\end{array}$ & $\begin{array}{c}{ }^{33} \mathrm{~A} \\
\mathrm{dpm} / \ell\end{array}$ & $\begin{array}{c}\mathrm{r} \\
10^{-4} \mathrm{~cm} / \mathrm{min}\end{array}$ & $\begin{array}{l}32 \mathrm{~W} \\
10^{-1} \mathrm{dpm} / \mathrm{cm}^{2} / \mathrm{yr}\end{array}$ \\
\hline Mar-91 & 1.46 & 1.45 & 3.47 & 2.66 & 2.64 \\
Apr-91+ & 0.78 & 0.86 & 1.23 & 0.50 & 0.55 \\
May-91* & 0.75 & 0.73 & 0.15 & 0.059 & 0.058 \\
Jun-91 & 0.53 & 0.52 & 1.97 & 0.55 & 0.54 \\
Jul-91 & 0.99 & 0.82 & 1.85 & 0.96 & 0.80 \\
Aug-91 & 0.91 & 0.81 & 1.42 & 0.68 & 0.75 \\
Sep-91 & 0.67 & 0.57 & 3.59 & 1.26 & 1.07 \\
Oct-91+ & 0.52 & 0.42 & 2.46 & 0.67 & 0.54 \\
Nov-91 & 0.83 & 0.79 & 0.94 & 0.41 & 0.39 \\
Jan-92 & 0.70 & 0.77 & 3.14 & 1.15 & 1.27 \\
Feb-92 & 0.50 & 0.51 & 3.49 & 0.92 & 0.93 \\
Mar-92 & 0.74 & 0.72 & 1.48 & 0.58 & 0.56 \\
& & & & & \\
\hline
\end{tabular}

* Averages based on one data point.

+ Averages based on duplicates of the same rain event.

Table 2.5. Seasonal wet deposition rates of ${ }^{32} \mathrm{P}$ and ${ }^{33} \mathrm{P}\left({ }^{32} \mathrm{~W}\right.$ and $\left.{ }^{33} \mathrm{~W}\right)$, seasonal activities $\left({ }^{32} \mathrm{~A}\right.$ and $\left.{ }^{33} \mathrm{~A}\right)$ and seasonal rainfall rates (r). Spring refers to April, May and June; summer refers to July, August and September; fall refers to October, November and December; and winter refers to January and February.

\begin{tabular}{|c|c|c|c|c|c|c|c|}
\hline season & ${ }^{32} \mathrm{~A}$ & ${ }^{33} \mathrm{~A}$ & $r$ & ${ }^{32} \mathrm{~W}$ & ${ }^{33} \mathrm{~W}$ & ${ }^{32} \mathrm{~W}$ & ${ }^{33} \mathrm{~W}$ \\
\hline & $\mathrm{dpm} / \mathrm{l}$ & $\mathrm{dpm} / \ell$ & $\mathrm{cm} / \mathrm{mon}$ & \multicolumn{2}{|c|}{$10^{-2} \mathrm{dpm} / \mathrm{cm}^{2} / \mathrm{yr}$} & \multicolumn{2}{|c|}{$10^{-3}$ atom $/ \mathrm{cm}^{2} / \mathrm{min}$} \\
\hline $\begin{array}{l}\text { Spring and } \\
\text { March } 91\end{array}$ & 0.94 & 0.94 & 7.38 & $8.4 \pm 2.2$ & $8.4 \pm 2.2$ & $4.7 \pm 1.2$ & $8.4 \pm 2.2$ \\
\hline Spring 91 & 0.62 & 0.63 & 4.80 & $3.6 \pm 0.8$ & $3.7 \pm 1.2$ & $2.0 \pm 0.5$ & $3.7 \pm 1.3$ \\
\hline Summer 91 & 0.85 & 0.72 & 9.86 & $10.2 \pm 2.2$ & $8.2 \pm 1.5$ & $5.8 \pm 1.2$ & $8.2 \pm 1.5$ \\
\hline Fall 91 & 0.73 & 0.67 & 5.77 & $5.1 \pm 1.2$ & $4.7 \pm 1.3$ & $2.9 \pm 0.6$ & $4.7 \pm 1.4$ \\
\hline Winter 92 & 0.58 & 0.65 & 14.33 & $10.1 \pm 2.0$ & $11.3 \pm 2.5$ & $5.7 \pm 1.1$ & $11.3 \pm 2.2$ \\
\hline $\begin{array}{l}\text { Annual } \\
\text { averages }\end{array}$ & 0.82 & 0.77 & 8.76 & $8.6 \pm 1.5$ & $8.2 \pm 2.1$ & $4.9 \pm 1.4$ & $8.2 \pm 2.2$ \\
\hline
\end{tabular}


Equation (2.3) describes the evolution of ${ }^{32} \mathrm{P}$ or ${ }^{33} \mathrm{P}$ attached to aerosols that are part of an air parcel and thus move with it. The ratio $\mathrm{R}$ is then simply given by:

$$
\text { (2.4) } \mathrm{R}=\mathrm{C}_{33_{3}} / \mathrm{C}_{32}=\left(\mathrm{F}_{33} / \mathrm{F}_{32}\right)\left(\lambda_{32} / \lambda_{33}\right)\left(1-\exp \left(-\lambda_{33} \mathrm{t}\right)\right) /\left(1-\exp \left(\begin{array}{ll}
-\lambda_{32} & \mathrm{t}
\end{array}\right)\right)
$$

$R$ is equal to $R_{0}=F_{33} / F_{32}$ at time to $=0$ and reaches a limiting value of $R_{e}=1.77$ $F_{33} / F_{32}$ in approximately 300 days. In the troposphere, since the residence time of air masses is shorter than 300 days (Lal and Perters, 1967; Poet et al., 1972; Moore et al., 1973; Martell and Moore, 1974; Shapiro and Forbes-Resha, 1976; Bleichrodt, 1978; Holloway and Hayes, 1982) the ratio ${ }^{33} \mathrm{P} /{ }^{32} \mathrm{P}$ in the air mass will increase until the aerosols are removed by condensation and ultimately by precipitation. Therefore, the ratio ${ }^{33} \mathrm{P} /{ }^{32} \mathrm{P}$ in an individual rain event is identical to the ratio in the tropospheric air scavenged by the rain, and equation (2.4) becomes the following:

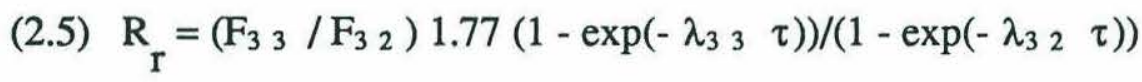

Where, $R_{r}$ is the ratio in a rain event, and $\tau$ is the average residence time of tropospheric aerosols in an air mass that is being washed out by a particular rain event.

To summarize, the assumptions of this model are: (1) the air masses are confined to the troposphere only; (2) the troposphere is well mixed; (3) no mixing occurs during the movement of an air mass; (4) at $\mathrm{t}_{0}, \mathrm{C}=0$; and (5) no fractionation of ${ }^{32} \mathrm{P}$ and ${ }^{33} \mathrm{P}$ occurs during condensation on the aerosols. The residence time calculated with equation (2.5) can be in error if any of the assumptions is violated. This will be the case, for example, if stratospheric air intrudes and mixes with the tropospheric air, or if the lower and upper troposphere are isolated or partly isolated from one another.

The most important feature of the Bermuda àata set, as stated previously, is the small variability of the activity ratio ${ }^{33} \mathrm{P} /{ }^{32} \mathrm{P}$, with values ranging from $0.66 \pm 0.10$ to $1.22 \pm 0.14$ (Table 2.1). According to the model, the ratio in rainwater should vary from 
an initial ratio $R_{0}$ to an equilibrium ratio $R e$ equal to 1.77 times $R_{0}$. The range of ratios observed at Bermuda is $0.66-1.22$. The highest and lowest ratios observed are in a ratio of 1.8 which is, within the error, identical to 1.77 . Thus the data exhibit, within the uncertainties of the measurements, the entire theoretical range, i.e. $R_{0}$ to $R_{e}$. In view of the fact that the errors on the measurements are around 0.1 , the theoretical range of the activity ratio could be 0.6 to 1.06 or 0.7 to 1.24 or any range in between that satisfies the relationship $\mathrm{R}_{\mathrm{e}} / \mathrm{R}_{0}=1.77$.

Equation (2.5) allows the calculation of the residence time $\tau$ of tropospheric aerosols for each activity ratio ${ }^{33} \mathrm{P}^{32} \mathrm{P}$ measured in individual rain events. Figure 2.6 is a plot of equation (2.5) for different values of $R_{0}: 0.60,0.65$ and 0.70 . It is seen in Figure 2.6 that the residence time of tropospheric aerosols cannot be determined precisely if it exceeds 80 days. The residence time calculated for the two extreme values of $R_{0}$ is shown in Figure 2.7 and Table 2.6. It is high on average in March-April 1991 and January-February 1992 and lower on average in August-October 1991. The activity ratios are also averaged over a season and the corresponding residence time calculated (table 2.3). From March to June of 1991 and January to February 1992, the residence time averaged $52 \pm 10$ days while from July to November 1991 it averaged $27 \pm 7$ days, assuming $R_{0}=0.7$. If one assumes that $R_{0}=0.6$ then the residence times are about 110 days and 55 days for the two periods. A value of $R_{0}=0.7$ gives residence times that are more consistent with previous estimate of 30-40 days (Beck and Kuroda, 1966; Lal and Peters, 1967; Shapiro and Forbes-Resha, 1976; Bleichrodt, 1978).

\section{b)- Global steady-state model}

Another method of estimating the residence time consists of establishing a steady-state mass balance for each isotope. The approach assumes that the mean production rate of an isotope in tropospheric air masses is balanced by the sum of its decay and its removal by precipitation: 


$$
\begin{array}{ll}
\text { (2.6) } & \mathrm{F}=\mathrm{W}+\lambda \mathrm{C} \\
\text { (2.7) } & \tau=(\mathrm{F}-\mathrm{W}) /(\lambda \mathrm{W})
\end{array}
$$

Where

W: mean wet deposition rate of ${ }^{32} \mathrm{P}$ or ${ }^{33} \mathrm{P}$ in atom $\mathrm{cm}^{-2} \mathrm{~min}^{-1}$;

F: tropospheric production rate of ${ }^{32} \mathrm{P}$ or ${ }^{33} \mathrm{P}$ in atom $\mathrm{cm}^{-2} \mathrm{~min}^{-1}$;

$\lambda$ : decay constant of ${ }^{32} \mathrm{P}$ or ${ }^{33} \mathrm{P}$ in $\min ^{-1}$;

C: mean ${ }^{32} \mathrm{P}$ or ${ }^{33} \mathrm{P}$ concentration in tropospheric air in atom/ $/ \mathrm{cm}^{2}$;

$\tau$ : mean residence time of aerosols in the troposphere, $\tau=\mathrm{C} / \mathrm{W}$.

The monthly mean wet deposition rates of ${ }^{32} \mathrm{P}$ and ${ }^{33} \mathrm{P}$ (i.e., $\mathrm{W}_{32}$ and $\mathrm{W}_{33}$ ) are given in table 2.4, and the seasonal means are given in table 2.5. Equation (2.7) allows computation of $\tau$ for each of the three particular periods late winter/spring of 1991 and late winter 1992 and summer/fall of 1991. It is assumed that, on these time-scales, there is a balance between the production, decay and removal by precipitation of ${ }^{32} \mathrm{P}$ and ${ }^{33} \mathrm{P}$. The average wet deposition rates are $5.2510^{-3}$ and $9.6510^{-3}$ atom/ $/ \mathrm{cm}^{2} / \mathrm{min}$ for ${ }^{32} \mathrm{P}$ and ${ }^{33} \mathrm{P}$, respectively, in late-winter/spring of 1991 and winter of 1992 . For summer and fall the wet deposition rates are $4.8610^{-3}$ and $7.310^{-3}$ atom/ $/ \mathrm{cm}^{2} / \mathrm{min}$ for ${ }^{32} \mathrm{P}$ and ${ }^{33} \mathrm{P}$, respectively. The global tropospheric production rates have been estimated by Lal et al. (1988) to be $1.610^{-2}$ and $1.310^{-2}$ atom $/ \mathrm{cm}^{2} / \mathrm{min}$ for ${ }^{32} \mathrm{P}$ and ${ }^{33} \mathrm{P}$, respectively corresponding to the years 1948-1949. Since the years 1992 and 1948/49 correspond to periods of low production rates in the 11-year cycle, the estimates of Lal et al., (1988) are used unmodified. The residence times are thus calculated for each isotope. For the period March to June 1991 and January to March 1992, the residence time calculated for ${ }^{32} \mathrm{P}$ and ${ }^{33} \mathrm{P}$ are $42 \pm 12$ days and $13 \pm 5$ days, respectively. For the period July to November 1991, the residence times are $47 \pm 15$ days and $28 \pm 10$ days for ${ }^{32} \mathrm{P}$ and ${ }^{33} \mathrm{P}$, respectively. The residence times calculated with the steady-state model are similar to the residence times calculated with the non steady-state model applied to the ratio ${ }^{33} \mathrm{P} /{ }^{3} \mathrm{P}$, suggesting that steady-state is a good approximation on a seasonal time-scale. 


\section{DISCUSSION}

In this section three aspects of the data will be discussed. First, the observations made both at Woods Hole and at Bermuda will be compared to previous data on ${ }^{32} \mathrm{P}$ and ${ }^{33} \mathrm{P}$ in air and rainwater samples. Second, the contrast between winter/spring and summer/fall of the wet deposition rates and the ratios will be compared to the general patterns found in previous studies of short-lived cosmogenic nuclides and artificial radionuclides. Third, the more detailed structures in the data on the ratio ${ }^{33} \mathrm{P} /{ }^{32} \mathrm{P}$ in rain will be discussed as well as the validity of the assumptions made in the non-steady state model.

A range of 0.66 to 1.24 was observed for the activity ratio ${ }^{33} \mathrm{P} /{ }^{32} \mathrm{P}$ in rainwater in the samples collected both at Bermuda and at Woods Hole. The observed ratios were somewhat lower than the ratios of 0.8 to 1.6 measured in rainwater by Goel et al. (1959) and higher than the ratios of 0.42-0.56 determined in 3 rainwater samples by Lal et al. (1957). Rama and Honda (1961) determined the ${ }^{33} \mathrm{P} /{ }^{32} \mathrm{P}$ activity ratio in air at different altitudes, both in the troposphere and stratosphere, and found ratios ranging from 0.46 to 1.1 , which are, within the uncertainties of the measurements, very close to my observed range of ratios. Luyanas et al. (1970) reported ratios that are significantly lower, ranging from 0.18 to 1.01 in surface air samples collected in 1967-1969. They argued that their lowest values $0.18-0.26$ were probably due to artificial sources of ${ }^{32} \mathrm{P}$ from weapon tests and that they should be neglected, bringing their range to 0.3-0.4 to 1.0. Lal and Peters (1962) estimated activity ratios in tropospheric air ranging from 0.46 to 0.81 using a different approach. They measured a ratio of the production rates ${ }^{3}{ }^{3} \mathrm{P} /{ }^{32} \mathrm{P}$ in $\mathrm{Ar}$ of 0.82 (atom ratio) or 0.46 (activity ratio) (Lal et al., 1960a). Their results suggest that the expected range of ratios is lower than what I have found at Woods Hole and Bermuda. The measurements of the production rates of ${ }^{33} \mathrm{P}$ and ${ }^{32} \mathrm{P}$ made by Lal et al. (1960a) 
differ from the calculation done earlier by Lal (1958) that predicted a ${ }^{33} \mathrm{P} /{ }^{32} \mathrm{P}$ production-rate ratio of 1.1 (atom ratio). This discrepancy might be due in part to the difficulty of measuring ${ }^{33} \mathrm{P}$, since very few direct measurements of the production rates of ${ }^{32} \mathrm{P}$ and ${ }^{33} \mathrm{P}$ were made. It appears that the measured ratios, either in air or rain, have a wider range than would be predicted by the non-steady-state model $\left(R_{0}\right.$ to $\left.1.77 R_{0}\right)$. It is probably due to difficulties in measuring ${ }^{32} \mathrm{P}$ and ${ }^{33} \mathrm{P}$. It might possibly be because the troposphere is not always well mixed but divided into upper and lower zones. It is conceivable that an air mass could spend a long time in the lower troposphere (which has small production rates of ${ }^{32} \mathrm{P}$ and ${ }^{33} \mathrm{P}$ ) before the aerosols are being scavenged by precipitation. Once the air mass is confined to the lower troposphere the ${ }^{33} \mathrm{P} /{ }^{32} \mathrm{P}$ ratio would exponentially increase and increase much faster than if the air mass was irradiated in the whole troposphere. This might explain why high ratios (i.e., higher than the ratios predicted from secular equilibrium) are observed.

A contrast that is possibly seasonal has been observed in the activity ratio ${ }^{3}{ }^{3} \mathrm{P} /{ }^{3} \mathrm{P}$ at Bermuda. High ratios were observed in March-June 1991 and JanuaryMarch 1992 at Bermuda. Ratios significantly higher than the annual average were observed in April 1991 and January-February 1992. Significantly lower ratios were observed in September-October 1991. Residence times based on the ratio were high in

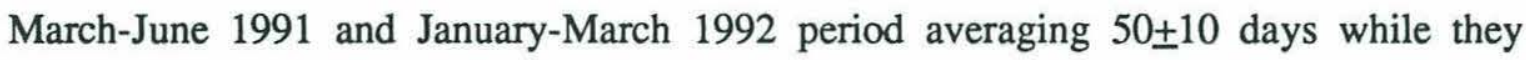
averaged $27 \pm 7$ days in the July-November 1991 period. The long apparent residence time of 50 days was higher than the estimates of 30-40 days (Beck and Kuroda, 1966; Lal and Peters, 1967; Shapiro and Forbes-Resha, 1976; Bleichrodt, 1978). The observations might be explained by a stratospheric input during that period, "apparently" increasing the residence time. Stratospheric air is characterized by high ${ }^{33} \mathrm{P} /{ }^{3} \mathrm{P}$ ratios because both radioisotopes are in equilibrium with their production rates due to the long residence time (about 14 months) of stratopheric air. The data suggest that the activity ratio ${ }^{3{ }^{3}} \mathrm{P} /{ }^{32} \mathrm{P}$ in 
stratospheric air is about 1.1-1.2. Intrusion of high ${ }^{33} \mathrm{P} /{ }^{32} \mathrm{P}$ air would explain the apparent old age of tropospheric air masses in March-June 1991 and January-March 1992. It might also explain the high ratios observed in individual rain samples in summer 1991. The observed high ratio in April 1991 is consistent with evidence of a seasonal stratospheric intrusion of ${ }^{90} \mathrm{Sr}$ in the spring at Bermuda (Health and Safety Laboratory, 1977). Figure 2.8 shows a 6-year record of ${ }^{90} \mathrm{Sr}$ in precipitation with a marked peak in the spring of every year. The high ratios and deposition rates observed in the winter and spring at Bermuda are due possibly to: (1) stratospheric intrusion at high latitudes (45-50 ${ }^{0} \mathrm{~N}$ ) and subsequent advection of that air to lower latitudes or (2) stratospheric intrusion at low latitudes $\left(20-30^{\circ} \mathrm{N}\right)$. The southward advection of high latitude, high altitude air masses is markedly visible in the distribution of ozone in the atmosphere of the northern hemisphere (Johnson and Viezee, 1981). It is furthermore confirmed by trajectory analysis which shows that in the winter most of the air masses traced 10 days before reaching Bermuda come from the American continent at both high latitudes and altitudes (J. Merrill; AEROCE meeting, 1991).

A change in the convective mixing in the troposphere can explain some of the contrast observed between the two periods. In the summer, convection is more efficient than in the winter, leading to more extensive mixing between the lower and upper troposphere. It is evidenced by ${ }^{210} \mathrm{~Pb}$ and ${ }^{22} \mathrm{Rn}$ determined on aerosols at the AEROCE site at Bermuda (western tip of the island). The ratio ${ }^{210} \mathrm{~Pb} /{ }^{22} \mathrm{Rn}$ is higher in the summer than in the winter because of increased convection in the summer delivering high activities of ${ }^{210} \mathrm{~Pb}$ to the lower troposphere (W. Graustein, personal commmunication at AEROCE meeting 1992). The magnitude of vertical mixing in the troposphere affects the activity ratio ${ }^{33} \mathrm{P} /{ }^{32} \mathrm{P}$. Increased mixing between the lower and upper troposphere, following a period of stable stratification, would decrease the residence time determined from the activity ratio ${ }^{33} \mathrm{P} /{ }^{32} \mathrm{P}$ in rainwater. 
The residence time of $27 \pm 7$ days estimated in the summer and fall 1991 at Bermuda is consistent with previous studies of short-lived radionuclides (Bleichrodt, 1978; Shapiro and Forbes-Resha, 1976; Lal and Peters, 1967) and artificial nuclides (Beck and Kuroda, 1966). It is in disagreement with most of the studies of the radon daughter nuclides which tend to show residence times on the order of a week (Poet et al., 1972; Moore et al., 1973; Martell and Moore, 1974; W. Graustein, personal communication at AEROCE meeting, 1992). The disagreement might be in part due to: (1) stratospheric input that tends to apparently increase the residence time as determined by the cosmogenic nuclides and/or: (2) poorly mixed troposphere with increasing residence times with altitude. The determination of $\tau$, as explained previously, is very sensitive to the choice of the initial ratio ${ }^{33} \mathrm{P} /{ }^{32} \mathrm{P}$. The estimate of 27 days assumes that $R_{0}$ is 0.7 . That estimate was also calculated from the average ratio ${ }^{33} \mathrm{P} /{ }^{32} \mathrm{P}$ in the rain in summer and fall 1991. It is observed in figure 3.1 that the ratio exhibits some high values in the summer and fall and that they could correspond to air originating in the stratosphere. Therefore, the residence time of 27 days determined in the summer could be overestimated if the peaks in the ratio are truly associated with stratospheric air intrusion. 


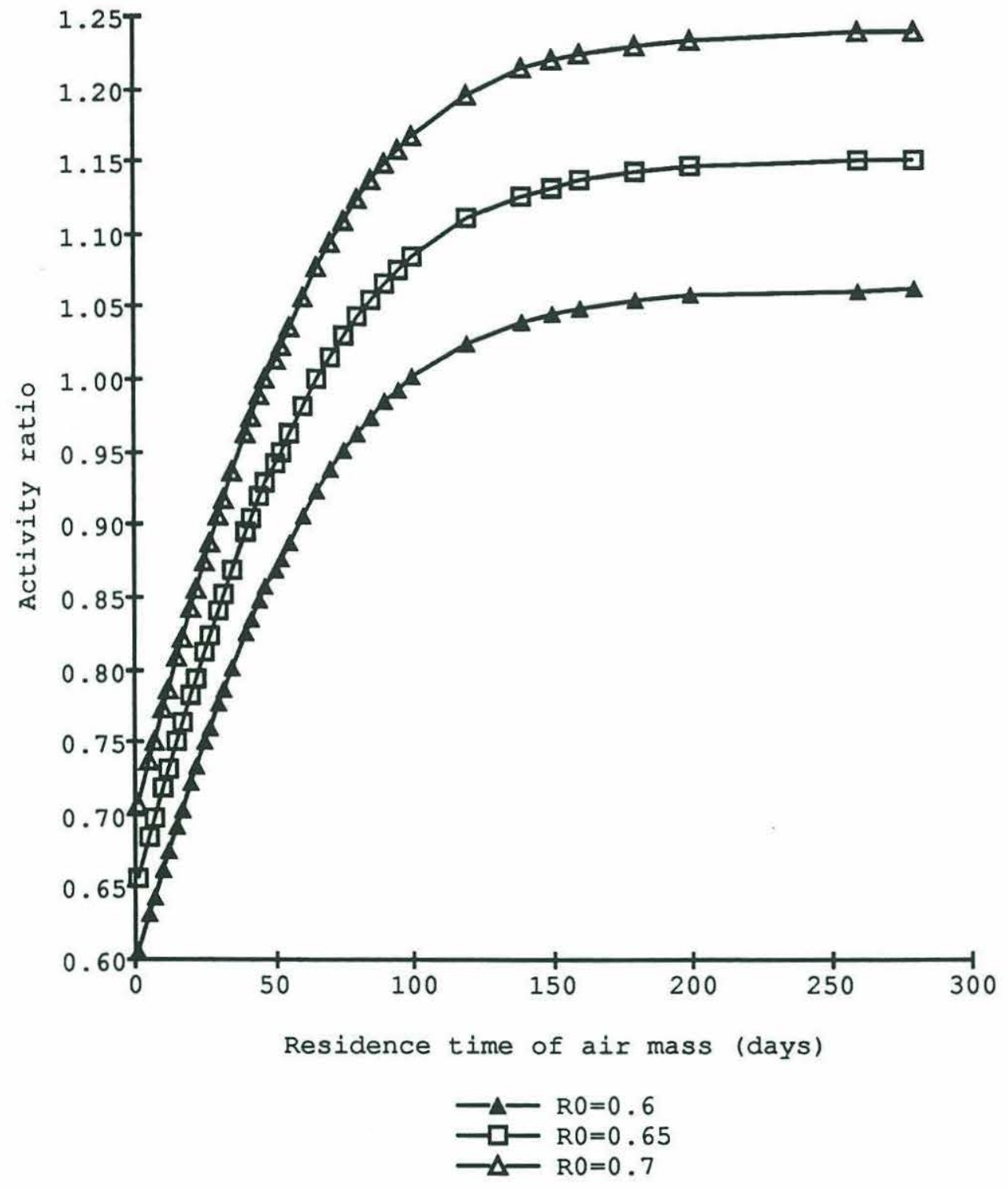

Figure 2.6. Predicted ${ }^{33} \mathrm{P} /{ }^{32} \mathrm{P}$ activity ratio in rain as a function of the residence time of tropospheric aerosols. 


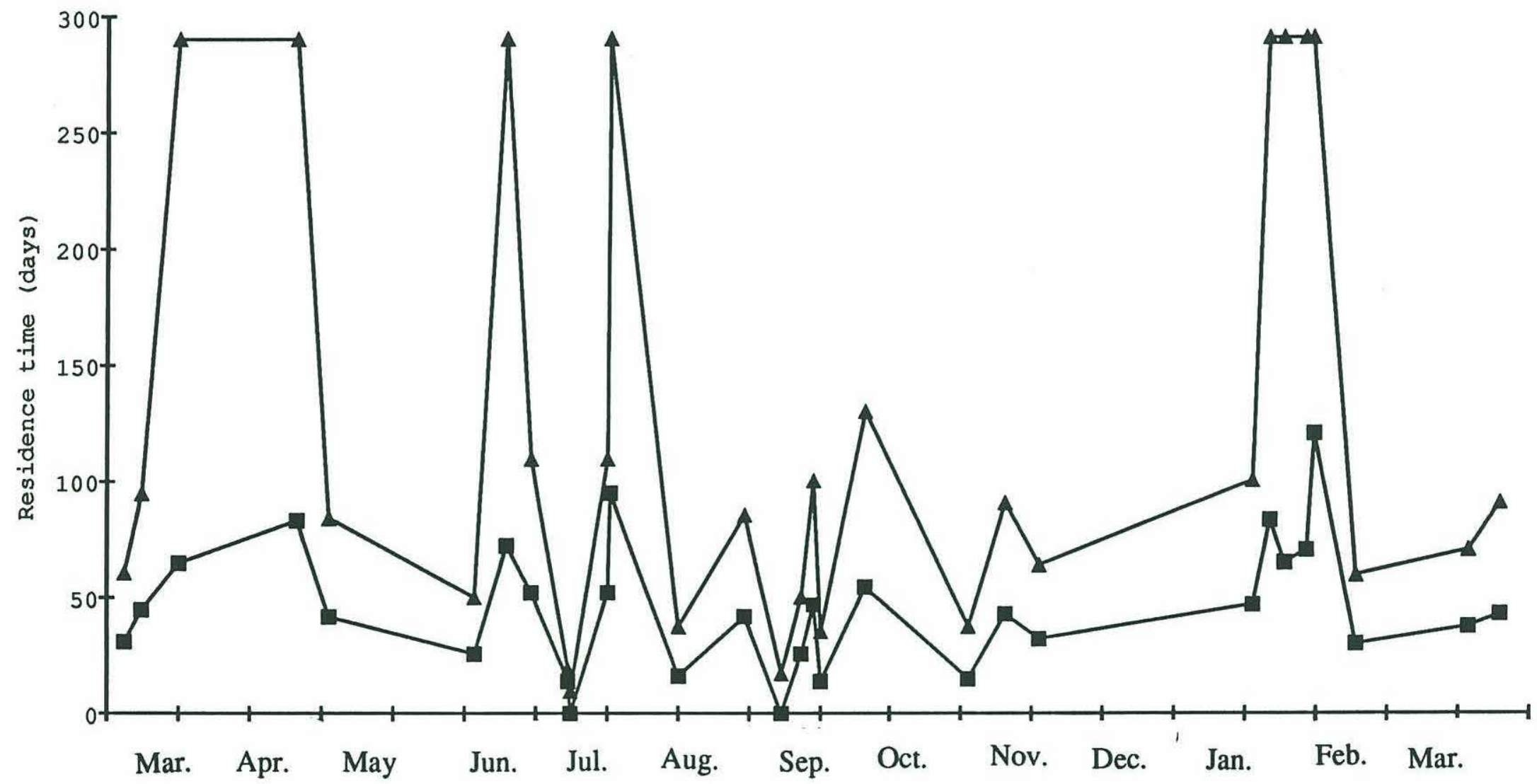

Figure 2.7. Residence time of air masses computed for each rain sample from the non-steadystate model and values of $R_{0}$ of 0.6 and 0.7 . 
Table 2.6. Residence time $(\tau)$ derived from the activity ratio ${ }^{33} \mathrm{P} /{ }^{32} \mathrm{P}(\mathrm{R})$ in each precipitation event sampled. Samples collected the same day were averaged. $\tau$ is calculated assuming that; (1) $R_{0}=0.7$; and (2) $R_{0}=0.6$.

\begin{tabular}{|c|c|c|c|c|c|}
\hline \multirow[t]{2}{*}{ date } & \multirow[t]{2}{*}{$\stackrel{\mathrm{R}}{\mathrm{dpm} / \mathrm{dpm}}$} & \multicolumn{3}{|c|}{$\begin{array}{l}\text { Residence time } \tau \\
\text { days }\end{array}$} & \multirow[b]{2}{*}{ range* } \\
\hline & & $R_{0}=0.7$ & range* & $\mathbf{R}_{0}=0.6$ & \\
\hline 05-Mar-91 & $0.91 \pm 0.14$ & 31 & $10-57$ & 61 & $30-160$ \\
\hline 10-Mar-91 & $0.99 \pm 0.08$ & 45 & $30-62$ & 95 & $60->290$ \\
\hline 20-Mar-91 & $1.08 \pm 0.08$ & 65 & $47-95$ & 290 & $>290$ \\
\hline 22-Apr-91 & $1.13 \pm 0.09$ & 83 & $56-150$ & 290 & $>290$ \\
\hline 01-May-91 & $0.97 \pm 0.12$ & 41 & $21-70$ & 85 & $45->290$ \\
\hline 11-Jun-91 & $0.87 \pm 0.11$ & 25 & $8-43$ & 50 & $27-90$ \\
\hline 20-Jun-91 & $1.10 \pm 0.12$ & 72 & $43-150$ & 290 & $>290$ \\
\hline 27-Jun-91 & $1.02 \pm 0.12$ & 52 & $28-85$ & 110 & $57->290$ \\
\hline 07-Jul-91 & $0.71 \pm 0.11$ & 14 & $0-32$ & 19 & $0-37$ \\
\hline 08-Jul-91 & $0.66 \pm 0.10$ & 0 & $0-8$ & 10 & $0-27$ \\
\hline 18-Jul-91 & $1.02 \pm 0.14$ & 52 & $26-95$ & 110 & $53->290$ \\
\hline 19-Jul-91 & $1.16 \pm 0.16$ & 95 & $47->290$ & 290 & $>290$ \\
\hline 07-Aug-91 & $0.81 \pm 0: 10$ & 16 & $1-31$ & 37 & $18-60$ \\
\hline 26-Aug-91 & $0.97 \pm 0.11$ & 42 & $23-65$ & 85 & $48->290$ \\
\hline 05-Sep-91 & $0.70 \pm 0.09$ & 0 & $0-12$ & 17 & $1-32$ \\
\hline 11-Sep-91 & $0.87 \pm 0.10$ & 25 & $10-42$ & 50 & $30-85$ \\
\hline 14-Sep-91 & $1.00 \pm 0.15$ & 47 & $22-90$ & 100 & $45->290$ \\
\hline 16-Sep-91 & $0.80 \pm 0.09$ & 14 & $2-27$ & 35 & $18-55$ \\
\hline 29-Sep-91 & $1.03 \pm 0.13$ & 54 & $28-95$ & 130 & $58->290$ \\
\hline 28-Oct-91 & $0.81 \pm 0.10$ & 15 & $4-27$ & 37 & $18-60$ \\
\hline 07-Nov-91 & $0.98 \pm 0.13$ & 43 & $22-75$ & 90 & $45->290$ \\
\hline 17-Nov-91 & $0.92 \pm 0.13$ & 32 & $12-58$ & 64 & $32-160$ \\
\hline 16-Jan-92 & $1.00 \pm 0.14$ & 47 & $23-85$ & 100 & $48->290$ \\
\hline 21-Jan-92 & $1.13 \pm 0.12$ & 83 & $50->290$ & 290 & $>290$ \\
\hline 25-Jan-92 & $1.08 \pm 0.15$ & 65 & $35-180$ & 290 & $>290$ \\
\hline 31-Jan-92 & $1.09 \pm 0.13$ & 70 & $40-150$ & 290 & $>290$ \\
\hline 02-Feb-92 & $1.20 \pm 0.14$ & 120 & $60->290$ & 290 & $>290$ \\
\hline $14-f e b-92$ & $0.91 \pm 0.12$ & 31 & $12-53$ & 60 & $32-130$ \\
\hline 17-Mar-92 & $0.94 \pm 0.18$ & 37 & $8-80$ & 70 & $27->290$ \\
\hline 26-Mar-92 & $0.98 \pm 0.12$ & 43 & $18-85$ & 90 & $48->290$ \\
\hline
\end{tabular}

* range: $R_{0}-\sigma$ to $R_{0}+\sigma$. 


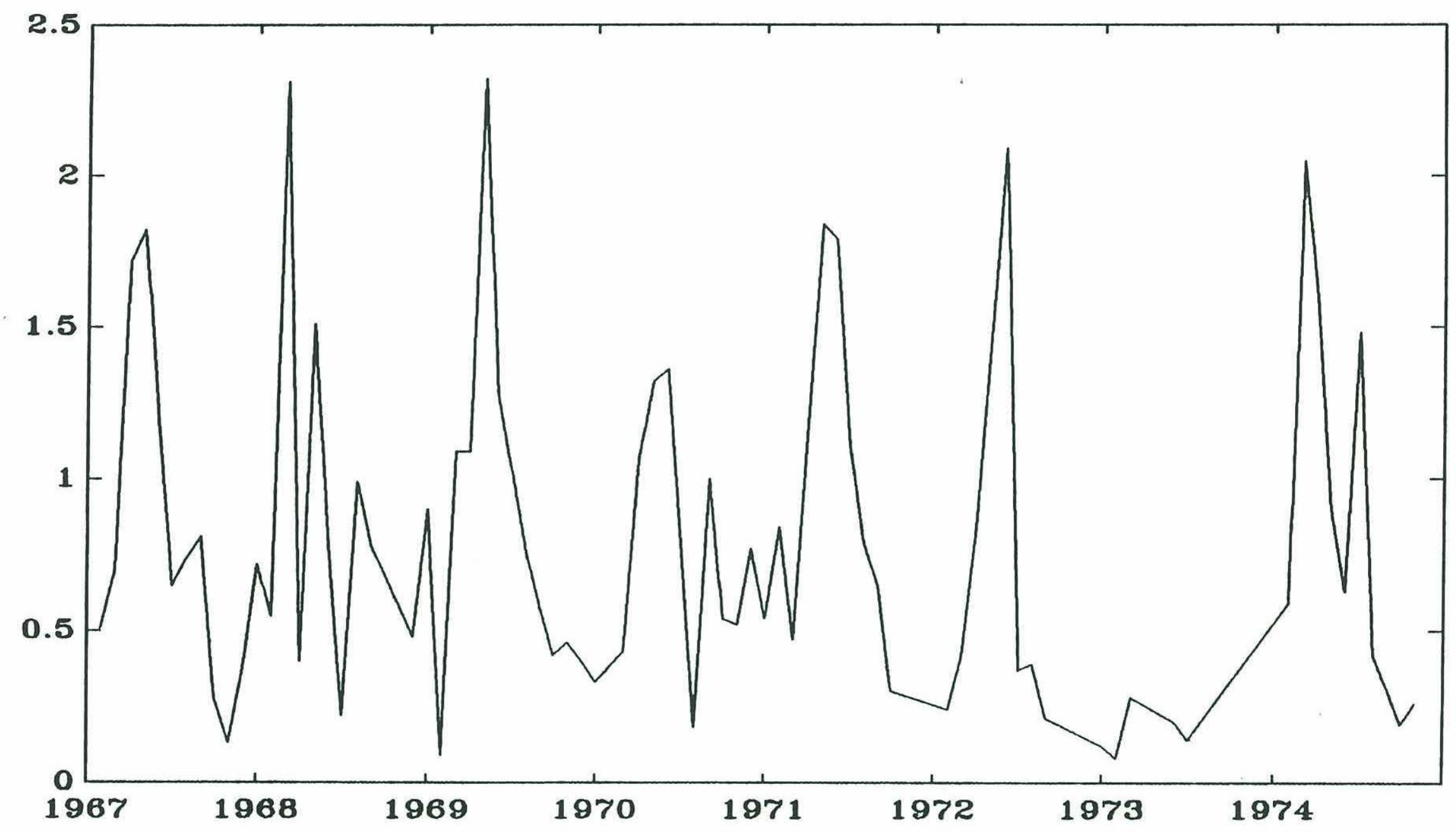

8

Figure 2.8. Monthly ${ }^{90} \mathrm{Sr}$ concentrations in $\mathrm{pCi} / \mathrm{l}$ in precipitations at Bermuda from 1967 to 1974 (Health and Safety Laboratory, HASL-315, 1977). 


\section{CONCLUSIONS}

1. A contrast was observed between March-June 1991/ January-March 1992 and July-November 1991, possibly suggesting a seasonal change in the atmospheric processes at Bermuda. Activity ratios ${ }^{33} \mathrm{P} /{ }^{2} \mathrm{P}$ higher than the annual average of 0.96 were observed in April 1991 and January and February 1992 at Bermuda. Lower-thanaverage activity ratios were observed in September and October 1991. The contrast might be due to seasonal changes in mixing of stratospheric air and/or changes in mixing between upper and lower troposphere. Injection of stratospheric air due to tropopause folding might explain the high ratio observed in April 1991 at Bermuda.

2. The calculated residence time of tropospheric aerosols of $27 \pm 7$ days could be overestimated if the high ratios observed in July to November 1991 are due to stratospheric air mixing with tropospheric air. The residence time would also be overestimated if the troposphere is not well mixed.

3. The range of activity ratios in rainwater suggests that the ${ }^{33} \mathrm{P} /{ }^{32} \mathrm{P}$ production-rate ratio is $1.06-1.24$ (atom ratio). 


\section{Bibliography}

Aegerter, S., N. Bhandari, Rama and A., S. Tamhane, 1966. ${ }^{7} \mathrm{Be}$ and ${ }^{32} \mathrm{P}$ in ground level air. Tellus XVIII, 212-215.

Beck J. N., and P.K. Kuroda, 1966. Radiostrontium fallout from the nuclear explosion of October 16, 1964. J. Geophys. Res., 71:2451-2456.

Bhandari, N., D. Lal and Rama, 1970. Vertical structure of the troposphere as revealed by radioactive tracer studies. J. Geophys. Res., 75:2974-2980.

Bleichrodt, J. F., 1978. Mean tropospheric residence time of cosmic ray-produced ${ }^{7} \mathrm{Be}$ at North temperate latitudes. J. Geophys. Res., 83:3058-3062.

Brown, L., G. J. Stensland, J. Klein and R. Middleton, 1989. Atmospheric deposition of

${ }^{7} \mathrm{Be}$ and ${ }^{10} \mathrm{Be}$. Geochim. Cosmochim. Acta, 53:135-142.

Crecelius, E., 1981. Prediction of marine atmospheric deposition rates using total ${ }^{7} \mathrm{Be}$ deposition velocities. Atmos. Envir., 15:579-582.

Danielson E.F. and V.A. Mohnen, 1977. Project duststorm report: Ozone transport, in situ measurements, and meteorological analyses of tropopause folding. J. Geophys. Res., 82:5867-5877.

Dibb, J. E., 1989. Atmospheric deposition of Beryllium 7 in the Chesapeake Bay Region. J. Geophys. Res., 94(D2):2261-2265.

Dutkiewicz, V. A. and L. Husain, 1985. Stratospheric and tropospheric components of ${ }^{7} \mathrm{Be}$ in surface air. J. Geophys. Res., 90, D3, 5783-5788.

Feely H.W., L.E. Toonkel and H. Schonberg, 1977. Radionuclides and lead in surface air. Rep. HASL-315, B1-B149, U.S. Energy Res. and Develop. Admin., Washington, DC.

Goel, P. S., Narasappaya, N., Prabhakara, C., Rama Thor and P.K. Zutshi, 1959. Study of cosmic ray produced short-lived ${ }^{32} \mathrm{P},{ }^{33} \mathrm{P},{ }^{7} \mathrm{Be}$, and ${ }^{35} \mathrm{~S}$ in tropical latitudes. Tellus, 1,91:100.

Hasse, L., 1983. Introductory meteorology and fluid dynamics. In: P. Liss and G. Slinn (Eds.), Air-sea exchange of gases and particles, NATO ASI Series, pp 1-51. 
Health and Safety Laboratory, 1977. Monthly fallout deposition of ${ }^{90} \mathrm{Sr}$ at Bermuda from 1967 to 1976. HASL-315, A169-A170.

Holloway, R.W. and D.W. Hayes, 1982. Mean residence time of plutonium in the troposphere. Environ. Sci. Technol., 16:127-129.

Johnson W.B. and W. Viezee, 1981. Stratospheric ozone in the lower troposphere. I. Presentation and interpretation of aircraft measurenments. Atmos. Envir., 15:1309-1323.

Krishnaswami S., L. K. Benninger, R. C. Aller and K. L. Von Damm, 1980. Atmospherically-derived radionuclides as tracers of sediment mixing and accumulation in near-shore marine and lake sediments: evidence from ${ }^{7} \mathrm{Be},{ }^{210} \mathrm{~Pb}$, and ${ }^{239},{ }^{240} \mathrm{Pu}$. Earth and Planet. Sci. Let., 47:307-318.

Lal D., V. Nijampurkar, G. Rajagopalan and B. L. Somayajulu, 1979. Annual fallout of ${ }^{32} \mathrm{Si},{ }^{2}{ }^{10} \mathrm{~Pb},{ }^{22} \mathrm{Na},{ }^{35} \mathrm{~S}$ and ${ }^{7} \mathrm{Be}$ in rains in India. Proc. Indian Acad. Sci., Vol. $88 \mathrm{~A}$, Part II, number 1, pp. 29-40

Lal, D. and B. Peters, 1967, Cosmic ray produced radioactivity on the earth. In Handbuch der Physics vol 46/2, edited by S. Flugge, Springer-Verlag, Berlin.

Lal, D., Arnold, J. R, and M. Honda, 1960a. Cosmic-ray production rates of ${ }^{7} \mathrm{Be}$ in oxygen, and ${ }^{32} \mathrm{P},{ }^{33} \mathrm{P},{ }^{35} \mathrm{~S}$ in argon at mountain altitudes. Phys. Rev., 118:1626-1632.

Lal, D, Rama and P. K. Zutshi, 1960b. Radioisotopes ${ }^{32} \mathrm{P},{ }^{7} \mathrm{Be}$, and ${ }^{35} \mathrm{~S}$ in the atmosphere. J. Geophys. Res., 65: 669-674.

Lal, D., Malhotra, P.K. and B. Peters, 1958, On the production of radioisotopes in the atmosphere by cosmic radiation and their application to meteorology. J. Atmos. Terres. Physics, 12:306-328.

Lal D., 1958. Investigations of nuclear interactions produced by cosmic rays. Tata Institute of Fundamental Research, Bombay, 90p.

Lal, D, Narasappaya, N, and P. K. Zutshi, 1957. Phosphorus isotopes ${ }^{32} \mathrm{P}$ and ${ }^{33} \mathrm{P}$ in rain water. Nuclear Physics, 3:69-75

Luyanas, V., R. Yu, Yasyulynis, D. A. Shopanskiene, and B. I. Styra, 1970, Cosmogenic ${ }^{2}{ }^{2} \mathrm{Na},{ }^{7} \mathrm{Be},{ }^{32} \mathrm{P}$ and ${ }^{33} \mathrm{P}$ in atmospheric dynamics research. J. Geophys. Res., 75:36653667. 
Machta, L., 1959. Transport in the stratosphere and through the tropopause. Advan. Geophys., 6:273-288.

Maenhaut, W., W. H. Zoller and D. G. Coles, 1979. Radionuclides in the South Pole Atmosphere. J. Geophys. Res., 84(C6):3131-3138.

Martell, E. A. and H. E. Moore, 1974. Tropospheric aerosol residence times, a critical review. J. Rech. Atmos., 8:903-910.

Martell, E. A. and P. J. Drevinsky, 1960. Atmospheric transport of artificial radioactivity. Science, 132:1523-1531.

Moore H.E., S.E. Poet, and E.A. Martell, 1973. ${ }^{222} \mathrm{Rn},{ }^{210} \mathrm{~Pb},{ }^{210} \mathrm{Bi}$, and ${ }^{210} \mathrm{Po}$ profiles and aerosols residence times versus altitude. J. of Geophys. Res., 78:7065-7075.

Olsen, C. R., I. L. Larsen, P. D. Lowry, and N. H. Cutshall, 1986. Geochemistry and deposition of ${ }^{7} \mathrm{Be}$ in river-estuarine and coastal waters. J. of Geophys. Res., 91(C1):896908.

Olsen, C. R., I. L. Larsen, P. D. Lowry, N. H. Cutshall, J. F. Todd, G. T. Wong, and W. $\mathrm{H}$. Casey, 1985. Atmospheric fluxes and marsh-soil inventories of ${ }^{7} \mathrm{Be}$ and ${ }^{210} \mathrm{~Pb} . J$. Geophys. Res., 90(D6):10487-10495.

Parker, R. P., 1962. Beryllium-7 and fission products in surface air. Nature, 193:967968.

Peirson, D. H., 1963. Beryllium 7 in air and rain. J. of Geophys. Res., 68:3831-3832.

Perkins, R. W. and C. W. Thomas, 1980. Worldwide fallout, in: Transuranic elements in the environment, W. C. Harson (Ed.), pp53-82.

Poet, S.E., Moore H.E., and E.A. Martell, 1972. Lead-210, bismuth 210 and polonium 210 in the atmosphere: accurate ratio measurement and application to aerosol residence time determination. J. Geophys. Res., 77:6515-6527.

Rama and Honda, 1961. Natural radioactivity in the atmosphere. J. Geophys. Res., 66:3227-3230.

Rama Thor and P. K. Zutshi, 1958. Annual Deposition of cosmic ray produced ${ }^{7} \mathrm{Be}$ at equatorial latitudes. Tellus, X :99-103. 
Rangarajan, C. and S. Gopalakrishnan, 1970. Seasonal variations of Beryllium-7 relative to Caesium-137 in surface air at tropical and sub-tropical latitudes. Tellus, 1:115-120.

Reiter, E. R., 1975. Stratospheric-tropospheric exchanges processes. Rev. Geophys. Space Phys., 13:459-474.

Reiter, E. R., W. Carnuth, H. Kanter, K. Potzl, R. Reiter and R. Sladkovic, 1975. Measurement of stratospheric residence times. Arch. Meteorol. Geophys. Bioklimatol., A, 24:41-51.

Reiter, R., R. Sladkovic, K. Potzl, W. Carnuth and H. Kanter, 1971. Studies on the influx of stratospheric air into the lower troposphere using cosmic-ray produced radionuclides and fallout. Arch. Meteorol. Geophys. Bioklimatol., Ser., A, 20:211-246.

Sanak, J., G. Lambert and B. Ardouin, 1985. Measurements of stratospheric-totroposphere exchange in Antarctica by using short-lived cosmonuclides. Tellus, 37B:109115.

Schumann, G. and M. Stoeppler, 1963. Beryllium 7 in the atmosphere. J. Geophys. Res., 68:3827-3830.

Shapiro, M. H. and J. L. Forbes-Resha, 1976. Mean residence time of ${ }^{7}$ Be-bearing aerosols in the troposphere. J. of Geophys. Res., 81:2647-2649.

Silker, W. B., 1972. Beryllium-7 and fission products in the Geosecs II water column and applications of their oceanic distributions. Earth Planet. Sci. Let., 16:131-137.

Staley D. O., 1982. Strontium-90 in surface air and the stratosphere: some interpretation of the 1963-1975 data. J. Atmos. Sci., 39:1571-1590.

Turekian, K.,K., Benninger, L., K., and E. P. Dion, $1983 .{ }^{7}$ Be and ${ }^{10}$ Be total deposition fluxes at New Haven, Connecticut and at Bermuda. J. Geophys. Res., 88:5411-5415.

Young, J. A. and W. B. Silker, 1974. The determination of air-sea exchange and oceanic mixing rates using ${ }^{7}$ Be during the Bomex Experiment. J. Geophys. Res., 79:4481-4489.

Young, J. A. and W. B. Silker, 1980. Aerosol deposition velocities on the Pacific and Atlantic oceans calculated from ${ }^{7}$ Be measurements. Earth Planet. sci. Let., 50:92-104.

Viezee, W. and H. B. Singh, 1980. The distribution of beryllium-7 in the troposphere: implications on stratospheric/tropospheric air exchange. Geophys. Res. Let., 7:805-808. 
Walton, A. and R. E. Fried, 1962. The deposition of ${ }^{7} \mathrm{Be}$ and ${ }^{32} \mathrm{P}$ in precipitation at north temperate latitudes. J. Geophys. Res., 67:5335-5340. 
Chapter Three

\section{IN SITU PRODUCTION OF COSMOGENIC ${ }^{32} P$ AND ${ }^{33} P$ IN SEAWATER}

\section{INTRODUCTION}

Cosmic rays are capable of inducing nuclear transmutations in the atmosphere, in the oceans and in rocks. These interactions result in the production of a suite of radionuclides. Spallation reactions on atmospheric Ar are believed to be the major mechanisms for the production of ${ }^{32} \mathrm{P}$ and ${ }^{33} \mathrm{P}$ on earth (Lal and Peters, 1967). In the ocean, it is believed that an additional source derives from spallation reactions on $\mathrm{Cl}, \mathrm{S}$ and $\mathrm{K}$ in seawater (Lal et al., 1988), but direct measurements of the production rates of both ${ }^{32} \mathrm{P}$ and ${ }^{33} \mathrm{P}$ are scarce, preventing accurate assessment of the importance of this process relative to the wet deposition of ${ }^{32} \mathrm{P}$ and ${ }^{33} \mathrm{P}$ produced in the atmosphere.

The purpose of this study was to investigate the in situ production of ${ }^{32} \mathrm{P}$ and ${ }^{33} \mathrm{P}$ in seawater relative to their fallout rates via wet deposition at Bermuda (geomagnetic latitude $\left.\lambda=43.6^{\circ} \mathrm{N}\right) . \mathrm{NaCl}, \mathrm{KNO}_{3}, \mathrm{MgSO}_{4}$ and $\mathrm{CCl}_{4}$ targets were exposed to cosmic rays at sites of different altitudes. The sites chosen were Mount Washington, New Hampshire $\left(\lambda=55.7^{\circ} \mathrm{N}\right.$, altitude $\left.=1917 \mathrm{~m}\right) ; \mathrm{l}^{\prime}$ Aiguille du Midi, France $\left(\lambda=47.4^{\circ} \mathrm{N}\right.$, altitude $=3840 \mathrm{~m})$; and Woods Hole, Massachusetts $\left(\lambda=53^{\circ} \mathrm{N}\right.$, altitude $\left.=0 \mathrm{~m}\right)$. 


\section{BACKGROUND}

Primary cosmic rays interact strongly with atmospheric nuclei giving rise to secondary cosmic rays. Pomerantz (1971) described 3 types of cosmic ray components: (1) the nucleonic or nuclear-active component (neutrons and protons), (2) the meson or hard component (pions and muons), and (3) the electromagnetic or soft component (electrons and $\gamma$-rays). Muons are weakly interactive particles and do not generally contribute significantly to the production of cosmogenic nuclides in the atmosphere, except in the case of ${ }^{39} \mathrm{Cl}$, for which muon capture by ${ }^{40} \mathrm{Ar}$ is the major production mechanism (Winsberg, 1956). In fact, the majority of the nuclear disintegrations are induced by neutron capture or nucleonic spallation reactions (Rossi, 1952; Lal and Peters, 1967). The nuclear disintegration rates and the production rates in the atmosphere are approximated by an exponential increase with altitude. In the atmosphere, the attenuation length of the production rates of most cosmogenic nuclides, e.g. ${ }^{7} \mathrm{Be},{ }^{32} \mathrm{P},{ }^{33} \mathrm{P},{ }^{36} \mathrm{Cl}$ (Rama and Honda, 1961; Mabuchi et al., 1971; Nakamura et al., 1972; Zreda et al., 1991), is identical to the attenuation length of neutrons in air (Rossi, 1952; Simpson and Fagot, 1953; Hess et al., 1959). The attenuation length of slow neutrons (neutrons responsible for the spallation reactions, typically with $\mathrm{E}>40 \mathrm{MeV}$ ) is a constant at a given latitude in the lower troposphere and was determined to be $145 \pm 5 \mathrm{~g} / \mathrm{cm}^{2}$ at geomagnetic latitudes of 40-55 ${ }^{\circ} \mathrm{N}$ (Simpson and Fagot, 1953; Yamashita et al., 1966; Lal, 1991). As a result of the neutron dependence, the production rates of nucleonic spallation products vary significantly with latitude. The magnitude increases substantially toward the poles, reflecting the higher neutron fluxes at high latitudes due to decreased shielding of cosmic rays at the poles (Rose et al., 1956; Lal and Peters, 1967).

The magnitude of nuclear disintegration rates and of the production rates of ${ }^{32} \mathrm{P}$

and ${ }^{33} \mathrm{P}$ have been estimated previously by two nuclear physics methods (Lal, 1958; Lal and Peters, 1967) and by direct measurements of the activities produced in a particular 
target (Lal et al., 1960; Bhandari et al., 1968). The nuclear physics methods refer to two distinct methods. The first method is a theoretical one and relies on the knowledge of the neutron flux and the cross section of interaction. The second method is experimental and consists of determining the nuclear disintegration rate and the yield of the spallation reaction. The direct measurements of the production rates of ${ }^{32} \mathrm{P}$ and ${ }^{33} \mathrm{P}$ in $\mathrm{Ar}$ gas have allowed independent verification of the calculations (Lal et al., 1960; Bhandari et al., 1968). The latitude and altitude coverage of the production rates of cosmogenic nuclides determined by direct measurement is very scarce. In contrast, the neutron flux has been measured extensively with neutron monitors and is relatively well known at all latitudes and altitudes. The wide coverage of the neutron monitors has allowed extrapolation of the few direct measurements of production rates to all latitudes and altitudes (Lal and Peters, 1967). The nuclear disintegration rate due to neutrons has been parameterized in the form of polynomials expressed as a function of altitude for particular latitudes between 0 and $90^{\circ} \mathrm{N}(\mathrm{Lal}, 1991)$. These polynomials serve as altitude and latitude scaling factors for any direct measurement.

In seawater, production of ${ }^{32} \mathrm{P}$ and ${ }^{33} \mathrm{P}$ can occur via nucleonic spallation reactions in $\mathrm{Cl}, \mathrm{S}$ and $\mathrm{K}$ due to the abundance of these targets. The in situ production rates have been estimated recently (Lal et al., 1988) based on the data of Rama and Honda (1961). The nucleonic spallation in ${ }^{32} \mathrm{~S}$ inducing ${ }^{32} \mathrm{P}$ has a well known cross section and thus the production rate of ${ }^{32} \mathrm{P}$ can be calculated fairly accurately. Otherwise, there have been a few direct measurements of the production rate of ${ }^{32} \mathrm{P}$ in $\mathrm{S}$ and $\mathrm{Cl}$ exposed to cosmic rays (Rama and Honda, 1961, Husain and Kuroda, 1968; Mabuchi et al., 1971) but none at all in $\mathrm{K}$. In the case of ${ }^{33} \mathrm{P}$, there has been one measurement of in situ production in $\mathrm{Cl}$ by Rama and Honda (1961). The nucleonic spallation reactions which are believed to occur in each target are given in table 3.1 . 
Although neutrons are the major cosmic ray component responsible for nuclear disintegrations in the atmosphere, at the earth's surface and below the neutron flux is substantially diminished. In contrast, the muon attenuation length is an order of magnitude larger than that of neutrons (Kurz, 1986; Lal, 1987; Bilokon et al., 1989). Although muons are weakly interactive particles, they can become the primary source of cosmogenic nuclides at depth below the surface (Rama and Honda, 1961; Tanaka et al., 1968; Takagi and Tanaka, 1968; Mabuchi et al., 1971; Hampel et al., 1975; Lal, 1988; Nishiizumi et al., 1989). For instance, Mabuchi et al. (1971) detected ${ }^{32} \mathrm{P}$ in $\mathrm{CS}_{2}$ exposed at sea level and underground and reported that a significant fraction of the production of ${ }^{32} \mathrm{P}$ at depth is due to muons according to the reaction ${ }^{32} \mathrm{~S}(\mu-, \gamma){ }^{32} \mathrm{P}$.

Variations in the neutron flux can occur over time, and it is important to examine the time scale of these variations with respect to the half-life of ${ }^{32} \mathrm{P}$ and ${ }^{33} \mathrm{P}$. It is well known that changes in the production rates occur due to changes in the solar magnetic activity. It is well established that solar activity modulates the intensity of cosmic rays, and by far the most pronounced effect is the 11-year solar cycle (O'Brien, 1979; Lal and Peters, 1967). Other shorter time-scale variations occur as well, like the reduction in cosmic ray intensity, i.e. Forbush effect (Lockwood, 1962) or the 27-day variations (Lal and Peters, 1967). Changes in the neutron flux associated with the 27-day cycle are small, and its effect on the production rates has usually been neglected (Lal and Peters, 1967). Solar flares can produce dramatic increases in the neutron flux by factors of 1 to 2 (Lockwood, 1962), but this effect is limited in time to a few hours up to a day and is thus generally neglected. Similarly the Forbush effect, which produces a decrease of the neutron flux, is limited in time to a few days and is also neglected (Lockwood, 1962). 
Table 3.1. Nuclear reactions occurring in nucleonic spallation of $\mathrm{Cl}, \mathrm{S}$ and $\mathrm{K}$.

\begin{tabular}{cc}
\hline Target & Reaction \\
\hline${ }^{35} \mathrm{Cl}$ & ${ }^{35} \mathrm{Cl}(\mathrm{n}, \alpha){ }^{32} \mathrm{P}$ \\
${ }^{35} \mathrm{Cl}$ & ${ }^{35} \mathrm{Cl}(\mathrm{n}, 2 \mathrm{pn}){ }^{33} \mathrm{P}$ \\
${ }^{37} \mathrm{Cl}$ & ${ }^{37} \mathrm{Cl}(\mathrm{n}, \alpha 2 \mathrm{n}){ }^{32} \mathrm{P}$ \\
${ }^{37} \mathrm{Cl}$ & ${ }^{37} \mathrm{Cl}(\mathrm{n}, \alpha \mathrm{n}){ }^{33} \mathrm{P}$ \\
${ }^{32} \mathrm{~S}$ & ${ }^{32} \mathrm{~S} \mathrm{(n,p)}{ }^{32} \mathrm{P}$ \\
${ }^{39} \mathrm{~K}$ & ${ }^{39} \mathrm{~K}(\mathrm{n}, 2 \alpha){ }^{32} \mathrm{P}$ \\
${ }^{39} \mathrm{~K}$ & ${ }^{39} \mathrm{~K}(\mathrm{n}, \alpha 2 \mathrm{pn}){ }^{33} \mathrm{P}$ \\
\hline
\end{tabular}




\section{Experimental procedure}

Salts of $\mathrm{NaCl}, \mathrm{MgSO}_{4}, \mathrm{KNO}_{3}$ as well as $\mathrm{CCl}_{4}$ were exposed on Mount Washington (geomagnetic latitude $55.7^{\circ} \mathrm{N}$, altitude $1917 \mathrm{~m}$ ), on l'Aiguille du Midi (47.4 $\left.{ }^{0} \mathrm{~N}, 3840 \mathrm{~m}\right)$ and at Woods Hole $\left(53^{\circ} \mathrm{N}, 10 \mathrm{~m}\right)$. The salts were packed in polyethylene bags and heat sealed. The carbon tetrachloride was exposed in 2.5 liter glass bottles. The targets were placed on the roofs of buildings at each site and away from obstacles (i.e., walls) to allow a $2 \Pi$ geometry. The targets were exposed for a minimum of 2 months, after which the activities produced should have been more than $95 \%$ and $83 \%$ of saturation exposure for ${ }^{32} \mathrm{P}$ and ${ }^{33} \mathrm{P}$ respectively. At Woods Hole and on $\mathrm{l}^{\prime}$ Aiguille du Midi a combination of salts was exposed. The salts consisted of $\mathrm{NaCl}, \mathrm{KCl}, \mathrm{CaCl}_{2} \cdot \mathrm{H}_{2} \mathrm{O}$ and $\mathrm{MgSO}_{4}$ mixed in the proportions as they occur in seawater (i.e., Cl: $19.35 \mathrm{~g} / \mathrm{kg}, \mathrm{SO}_{4}$ : $2.71 \mathrm{~g} / \mathrm{kg}, \mathrm{K}: 0.40 \mathrm{~g} / \mathrm{kg}$ and $\mathrm{Ca}: 0.41 \mathrm{~g} / \mathrm{kg}$ ). Chlorine is the most abundant target in seawater, and more experiments were pursued with that target than any other. The samples were generally processed within 4 days after the end of the exposure. The salts exposed on l'Aiguille du Midi were sent by air to WHOI (flight was approximately 6 hours at $10-11 \mathrm{~km}$ at $50-55^{\circ} \mathrm{N}$ ). On Mt. Washington, $\mathrm{NaCl}, \mathrm{KNO}_{3}, \mathrm{CCl}_{4}$ and $\mathrm{MgSO}_{4}$ were exposed separately for 68 days on top of the Observatory. The targets were brought quickly to WHOI and analyzed.

No corrections for initial activities were made for the high altitude exposure experiments, because exposure to cosmic rays was long enough (68 and 82 days) to ensure virtually complete decay of any initial activity of ${ }^{32} \mathrm{P}$. The production rate of ${ }^{33} \mathrm{P}$ is expected to be very low at sea level, so, in the small quantities of laboratory chemicals exposed at high altitudes, ${ }^{33} \mathrm{P}$ would be undetectable prior to exposure (activity below the error on the background of 0.01-0.02 cpm). For the exposure experiment at sea level, a blank of $1 \mathrm{~kg}$ of $\mathrm{NaCl}$ was run. No activities were detected in the blank within an error of 0.01-0.02 cpm associated with the background. At most the initial activity was $0.02 \mathrm{cpm}$ 
in $1 \mathrm{~kg}$ of $\mathrm{NaCl}$ or $0.2 \mathrm{cpm}$ in $10 \mathrm{~kg}$. After 64 days of exposure the activity of ${ }^{32} \mathrm{P}$ would be $4 \%$ of the initial activity (i.e., $0.006 \mathrm{cpm}$ ), and the activity of ${ }^{33} \mathrm{P}$ would be $17 \%$ of the initial activity (i.e., $0.008 \mathrm{cpm}$ ). It is thus assumed that no corrections for initial activity have to be made for any of the experiments.

After exposure the salts were dissolved in distilled water. The salts exposed at Woods Hole were dissolved in a 140-liter drum, while all the others were dissolved in 20liter cubitainers. Each solution was spiked with $\mathrm{KH}_{2} \mathrm{PO}_{4}$. An $\mathrm{FeCl}_{3}$ solution and then an excess of ammonia were added to each solution to precipitate $\mathrm{Fe}(\mathrm{OH})_{3}$. The precipitate of ferric hydroxide was allowed to settle. The supernatant was decanted and the precipitate was centrifuged, washed, and finally dissolved in $\mathrm{HCl}$. The solution was then boiled to a small volume. Nitric acid was added and the solution boiled until $\mathrm{HCl}$ was all removed. Finally the nitric acid solution was made $1 \mathrm{~N}$. The rest of the chemical separation procedure is explained in Chapter One.

Phosphate in the carbon tetrachloride phase was extracted into the aqueous phase in a two-liter separatory funnel. The $4 \ell$ of $\mathrm{CCl}_{4}$ were extracted $1 \ell$ at a time. For each extraction, $1 \ell$ of distilled water was spiked with $\mathrm{KH}_{2} \mathrm{PO}_{4}$. The two phases were shaken vigorously for 3 to 4 minutes and allowed to separate for half an hour. After each separation, the $\mathrm{PO}_{4}$ in the aqueous phase was measured by the classic molybdenum blue method (Murphy and Riley, 1962). $100 \%$ of the $\mathrm{KH}_{2} \mathrm{PO}_{4}$ added was recovered in the aqueous phase after each separation. Phosphorus was co-precipitated with $\mathrm{Fe}(\mathrm{OH})_{3}$. The rest of the procedure is identical to the one described for the salts.

\section{RESULTS AND DISCUSSION}

The production rates of ${ }^{32} \mathrm{P}$ and ${ }^{33} \mathrm{P}$ were calculated for each target at each site according to the following equation: 


$$
\text { (3.1) } \quad d C(t) / d t=F-\lambda C(t)
$$

The solution of equation (3.1) is:

$$
\text { (3.2) } \mathrm{C}(\mathrm{t})=\mathrm{F} / \lambda-\left(\mathrm{F} / \lambda-\mathrm{C}^{0}\right) \exp (-\lambda \mathrm{t})
$$

where

$\mathrm{C}(\mathrm{t})$ : concentration of ${ }^{32} \mathrm{P}$ or ${ }^{33} \mathrm{P}$ at time $\mathrm{t}$ (atom/mol target);

$\mathrm{C}^{0}$ : concentration of ${ }^{32} \mathrm{P}$ or ${ }^{33} \mathrm{P}$ at the beginning of exposure (atom/mol target);

F: production rate of ${ }^{32} \mathrm{P}$ or ${ }^{33} \mathrm{P}$ (atom/ $/ \mathrm{min} / \mathrm{mol}$ target);

$\lambda$ : decay constant of ${ }^{32} \mathrm{P}$ or ${ }^{33} \mathrm{P}\left(\mathrm{min}^{-1}\right)$;

It was assumed that $\mathrm{C}^{0} \ll \mathrm{F} / \lambda$ (no initial concentrations of ${ }^{32} \mathrm{P}$ or ${ }^{33} \mathrm{P}$ ), thus equation (3.2) becomes:

$$
\text { (3.3) } A(t)=C \lambda=F(1-\exp (\lambda t))
$$

where

$\mathrm{A}(\mathrm{t})$ : activity of ${ }^{32} \mathrm{P}$ or ${ }^{33} \mathrm{P}$ at time $\mathrm{t}$.

The activities of ${ }^{32} \mathrm{P}$ and ${ }^{33} \mathrm{P}$ produced in each target at the end of the exposure period were computed from the net count rates, the counting efficiencies and the chemical yield (Table A.10). Corrections for saturation exposure were done using equation (3.3). The production rates of ${ }^{32} \mathrm{P}$ and ${ }^{33} \mathrm{P}$ in $\mathrm{Cl}, \mathrm{S}$ and $\mathrm{K}$ at each site are presented in table 3.2. For the sample exposed on l' Aiguille du Midi and sent by air, no corrections were made to account for the in situ production of ${ }^{32} \mathrm{P}$ and ${ }^{33} \mathrm{P}$ during the 6 hour flight. The production rates at $10 \mathrm{~km}$ for an open exposure (not shielded by the aircraft structure) are estimated to add a $10 \%$ and $7 \%$ contribution to the production rates at $3840 \mathrm{~m}$ for ${ }^{32} \mathrm{P}$ and ${ }^{33} \mathrm{P}$, respectively. In reality there is shielding and the contribution during the flight is somewhat smaller than the calculation for open exposure.

The logarithm of the production rate of ${ }^{32} \mathrm{P}$ and ${ }^{33} \mathrm{P}$ in chlorine was plotted as a function of altitude (Figure 3.1). The altitudes or atmospheric depths, expressed in $\mathrm{g} / \mathrm{cm}^{2}$, were calculated using the polynomial fit of the altitude/pressure curve of the Manual of the ICAO standard atmosphere given by Lal (1991). The curve fits of the 
logarithm of the production rate of ${ }^{32} \mathrm{P}$ and ${ }^{33} \mathrm{P}$ yield slopes which allow the determination of the exponent and thus of the attenuation length. The production rates as a function of altitude can be approximated by the following relationship:

$$
\text { (3.4) } P=P_{0} \exp \left((1033-z) / L_{n}\right)
$$

where

$\mathrm{P}$ is the production rate at altitude $\mathrm{z}\left(\mathrm{g} / \mathrm{cm}^{2}\right)$.

$P_{0}$ is the production rate at sea level, i.e. $z=1033 \mathrm{~g} / \mathrm{cm}^{2}$.

$\mathrm{L}_{\mathrm{n}}$ : attenuation length of the production rate.

The logarithm of the production rates is thus simply approximated by:

$$
\text { (3.5) } \quad \operatorname{Ln} \mathrm{P}=\mathrm{Ln} \mathrm{P}_{0}+1033 / \mathrm{L}_{\mathrm{n}}-\mathrm{z} / \mathrm{L}_{\mathrm{n}}
$$

A value of $L_{n}=155 \pm 15 \mathrm{~g} / \mathrm{cm}^{2}$ is calculated for the attenuation length of the production rate of ${ }^{32} \mathrm{P}$. This value agrees well with the previously determined neutron attenuation length of $145 \mathrm{~g} / \mathrm{cm}^{2}$ at $40-50{ }^{0} \mathrm{~N}$ in the lower troposphere $(0-5 \mathrm{~km})$. The good agreement between the attenuation length of the production rate of ${ }^{32} \mathrm{P}$ and the previously estimated value of $145 \mathrm{~g} / \mathrm{cm}^{2}$ confirms that neutrons are the major cosmic rays inducing ${ }^{32} \mathrm{P}$ in chlorine.

For ${ }^{33} \mathrm{P}$ the least-squares fit of the logarithm of the production rate as a function of altitude gives an attenuation length of $195 \pm 50 \mathrm{~g} / \mathrm{cm}^{2}$. The errors on each individual production rate measurement of ${ }^{33} \mathrm{P}$ in $\mathrm{Cl}$ are large, which implies that the inverse of the slope of the fitted line is not precisely determined with only three measurements. In table 3.3, the production rates of ${ }^{32} \mathrm{P}$ and ${ }^{33} \mathrm{P}$ in $\mathrm{Cl}$ and $\mathrm{S}$ obtained in this study are compared with previous estimates. They differ form the results of Rama and Honda (1961), and Husain and Kuroda (1968), but the production rate of ${ }^{32} \mathrm{P}$ in $\mathrm{S}$ is in good agreement with the estimate of Mabuchi et al. (1971). 
Table 3.2. Production rates of ${ }^{32} \mathrm{P}$ and ${ }^{33} \mathrm{P}$ in $\mathrm{Cl}, \mathrm{S}$ and $\mathrm{K}$ targets at $\mathrm{l}^{\prime}$ Aiguille du Midi, Mount Washington and Woods Hole.

\begin{tabular}{|c|c|c|c|c|}
\hline \multirow[t]{2}{*}{$\begin{array}{l}\text { Sample, location, } \\
\text { weight, target, exposure time }\end{array}$} & \multirow[t]{2}{*}{ Target } & \multicolumn{2}{|c|}{$\begin{array}{l}\text { Production rates } \\
10^{-3} \text { atom } / \mathrm{min} / \mathrm{mol}\end{array}$} & \multirow{2}{*}{$\begin{array}{l}\text { Atom } \\
\text { ratio } \\
{ }^{33} \mathrm{P} /{ }^{32} \mathrm{P}\end{array}$} \\
\hline & & ${ }^{32} \mathrm{P}$ & ${ }^{33} \mathrm{P}$ & \\
\hline \multicolumn{5}{|l|}{ Woods Hole $\left(0,53^{0} \mathrm{~N}\right)$} \\
\hline \multicolumn{5}{|l|}{ Cl-WH* } \\
\hline $10 \mathrm{~kg}: \mathrm{NaCl}, \mathrm{KCl}, \mathrm{MgSO}_{4}, \mathrm{CaCl}_{2}$ & $\mathrm{Cl}$ & $3.0 \pm 0.6$ & $1.4 \pm 0.5$ & $0.5 \pm 0.2$ \\
\hline \multicolumn{5}{|l|}{$\left.\overline{\text { Mt. Washington }\left(1917 \mathrm{~m}, 55.7^{0}\right.} \mathrm{N}\right)$} \\
\hline \multicolumn{5}{|l|}{ Cl-MW } \\
\hline $\begin{array}{l}4.2 \mathrm{~kg}: \mathrm{NaCl} \\
\mathrm{Cl}_{4}-\mathrm{MW}\end{array}$ & $\mathrm{Cl}$ & $32 \pm 7$ & $7 \pm 2$ & $0.2 \pm 0.1$ \\
\hline $\begin{array}{l}6.4 \mathrm{~kg}: \mathrm{CCl}_{4} \\
\mathrm{~K}-\mathrm{MW}\end{array}$ & $\mathrm{Cl}$ & $10 \pm 1$ & $4 \pm 1$ & $0.4 \pm 0.1$ \\
\hline $\begin{array}{l}4.2 \mathrm{~kg} \text { of } \mathrm{KNO}_{3} \\
\text { S-MW }\end{array}$ & $\mathrm{K}$ & $10 \pm 3$ & n.d. & n.d. \\
\hline $1.9 \mathrm{~kg}$ of $\mathrm{MgSO}_{4}$ & S & $27 \pm 7$ & n.d. & n.d. \\
\hline $\begin{array}{l}\text { Aiguille du Midi }\left(3840 \mathrm{~m}, 47^{0} \mathrm{~N}\right. \\
\text { Exposure: } 82 \text { days } \\
\text { Cl-MA* }\end{array}$ & & & & \\
\hline $2.4 \mathrm{~kg}: \mathrm{NaCl}, \mathrm{KCl}, \mathrm{MgSO}_{4}, \mathrm{CaCl}_{2}$ & $\mathrm{Cl}$ & $37 \pm 4$ & $10 \pm 2$ & $0.27 \pm 0.06$ \\
\hline
\end{tabular}

* In these samples $\mathrm{Cl}$ is the overwhelmingly dominant target and thus the amount of target refers to $\mathrm{Cl}$.

n.d.: Not determined. 


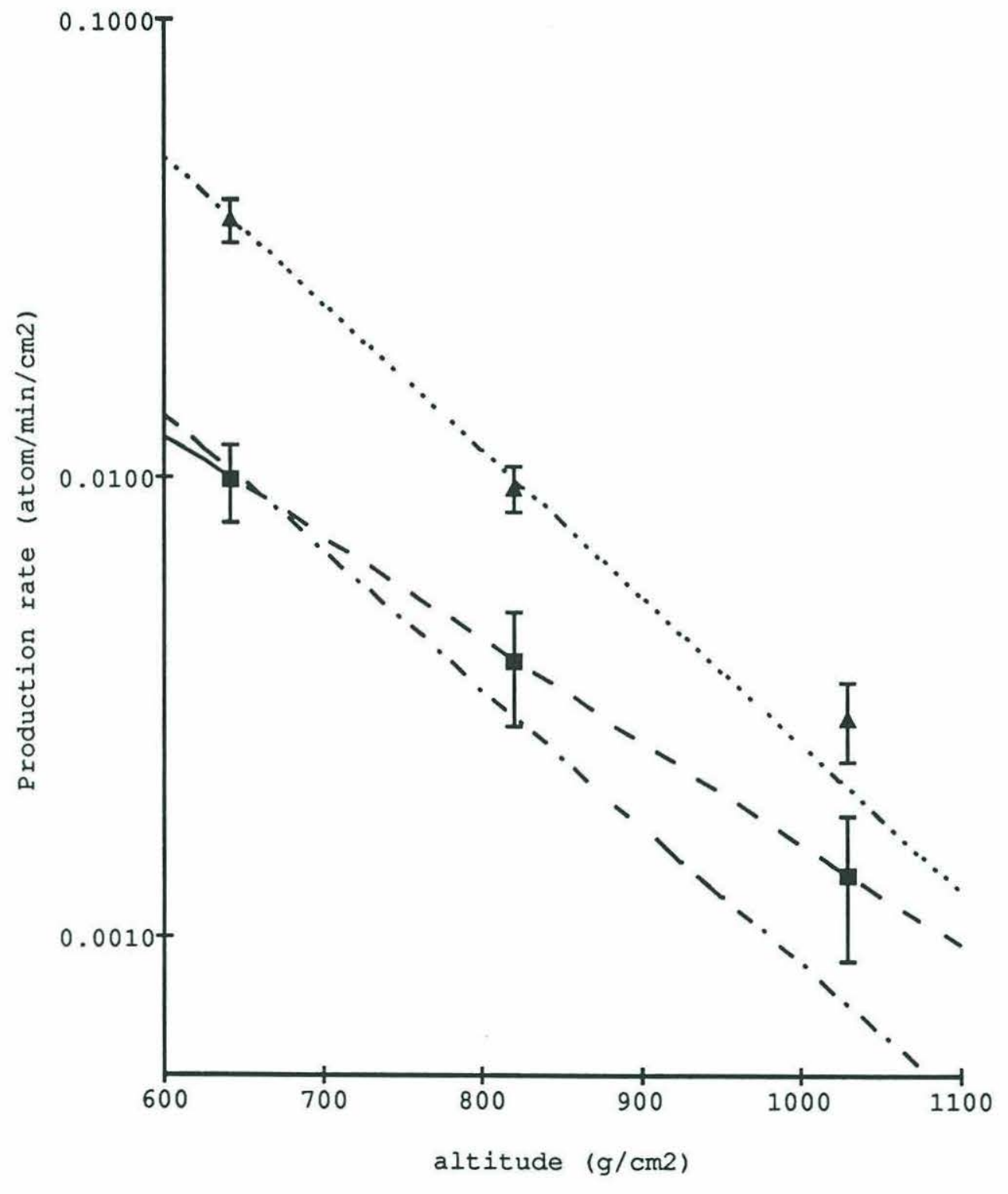

Figure 3.1. Logarithm of the production rates of ${ }^{32} \mathrm{P}$ and ${ }^{33} \mathrm{P}$ in chlorine target. The least-squares of the logarithm of the production rates are computed. 
Table 3.3. Comparison of published estimates of the production rates of ${ }^{32} \mathrm{P}$ and ${ }^{33} \mathrm{P}$ in $\mathrm{Cl}$ and $\mathrm{S}$ at sea level

\begin{tabular}{|c|c|c|c|c|}
\hline \multirow[t]{2}{*}{ Reference } & \multirow[t]{2}{*}{$\begin{array}{l}\text { Geomagnetic } \\
\text { latitude }\end{array}$} & \multirow[t]{2}{*}{ Target } & \multicolumn{2}{|c|}{$\begin{array}{l}\text { Production rate } \\
\text { atom } / \mathrm{min} / \mathrm{kg} \text { target }\end{array}$} \\
\hline & & & ${ }^{32} \mathrm{P}$ & ${ }^{33} \mathrm{P}$ \\
\hline \multicolumn{5}{|c|}{ Rama and Honda (1961) } \\
\hline & $44 N$ & $\mathrm{Cl}$ & $0.24 \pm 0.03$ & $0.09 \pm 0.04$ \\
\hline & $44 \mathrm{~N}$ & S & $0.52 \pm 0.06$ & n.d. \\
\hline \multicolumn{5}{|c|}{ Husain and Kuroda (1968) } \\
\hline & $49 N$ & $\mathrm{Cl}$ & $0.76 \pm 0.08$ & n.d. \\
\hline & $49 N$ & $S$ & $1.5 \pm 0.1$ & n.d. \\
\hline \multicolumn{5}{|c|}{ Mabuchi et al. (1971) } \\
\hline & $25 \mathrm{~N}$ & $S$ & $0.18 \pm 0.04$ & n.d. \\
\hline & $(44 N)^{*}$ & $S$ & $(0.20))^{*}$ & \\
\hline \multicolumn{5}{|l|}{ This work } \\
\hline & $47-55.7 \mathrm{~N}$ & $\mathrm{Cl}$ & $0.07 \pm 0.01$ & $0.026 \pm 0.007$ \\
\hline & $55.7 \mathrm{~N}$ & $S$ & $0.16 \pm 0.04$ & n.d. \\
\hline & $55.7 \mathrm{~N}$ & $\mathrm{~K}$ & $0.05 \pm 0.01$ & n.d. \\
\hline
\end{tabular}

n.d.: Not determined.

* Results extrapolated to $44^{\circ} \mathrm{N}$ by Mabuchi et al. (1971). 
To assess the relative importance of the in situ production rates of ${ }^{32} \mathrm{P}$ and ${ }^{33} \mathrm{P}$ in the upper ocean versus the wet deposition rates of ${ }^{32} \mathrm{P}$ and ${ }^{33} \mathrm{P}$ at Bermuda $\left(43.6^{\circ} \mathrm{N}\right)$, the measured production rates at the three sites were scaled to the same altitude (i.e., sea level) and to a geomagnetic latitude of $43.6{ }^{\circ} \mathrm{N}$. The altitude and latitude scaling were done using the polynomials of the nuclear disintegration rates given by Lal (1991). Linear interpolations of the coefficients were made to determine the particular polynomials for the latitudes of the study sites. The latitudinal variations turn out to be very small, and thus the latitudinal corrections to scale the production rates to $43.6{ }^{\circ} \mathrm{N}$ were small.

The production rates of ${ }^{32} \mathrm{P}$ and ${ }^{33} \mathrm{P}$ (in atom/min/mol) were then determined, taking into account the concentrations of the target in seawater. The production rates of ${ }^{32} \mathrm{P}$ and ${ }^{33} \mathrm{P}$ in the upper ocean (in atom/ $/ \mathrm{min} / \mathrm{cm}^{2}$ ) were then calculated by integrating from $0 \mathrm{~m}$ to infinity, the following relationship:

(3.6) $P_{z}=P_{0} \exp \left(-z / L_{n}\right)$, the integration gives: (3.7) $P=P_{0} L_{n}$

where

$\mathrm{P}$ is the integrated production rate in the upper ocean.

$\mathrm{P}_{\mathrm{z}}$ is the production rate at a depth $\mathrm{z}$ below sea level.

$P_{0}$ is the production rate at sea level, i.e. $z=0$.

$\mathrm{L}_{\mathrm{n}}$ : attenuation length of neutron in seawater.

The attenuation length of neutrons in seawater below the surface is somewhat different than the attenuation length above the surface. Authors have reported attenuation lengths of $155 \pm 15 \mathrm{~g} / \mathrm{cm}^{2}$ for the in situ production of cosmogenic nuclides in rocks exposed at the surface (Kurz, 1986; Lal, 1987; Brown et al., 1992). It is assumed in the calculation that the attenuation length of neutrons below the earth's surface is the same in seawater as in rocks. An average value of $155 \mathrm{~g} / \mathrm{cm}^{2}$ is chosen for the calculation. The results are presented in table 3.4. The in situ production rates of ${ }^{32} \mathrm{P}$ and ${ }^{33} \mathrm{P}$ in $\mathrm{Cl}, \mathrm{K}$ and $\mathrm{S}$ are then calculated by adding the production rates of ${ }^{32} \mathrm{P}$ and ${ }^{33} \mathrm{P}$ measured for each target. 
Unfortunately, the production rate of ${ }^{33} \mathrm{P}$ in $\mathrm{K}$ could not be determined because of the thickness of the source. The in situ production rates of ${ }^{32} \mathrm{P}$ and ${ }^{33} \mathrm{P}$ in the upper ocean at bermuda $\left(43.6^{\circ} \mathrm{N}\right)$ are thus determined to be $2.2 \pm 0.410^{-4}$ atom $/ \mathrm{cm}^{2} / \mathrm{min}$ for ${ }^{32} \mathrm{P}$ and $8 \pm$ $310^{-5}$ atom $/ \mathrm{cm}^{2} / \mathrm{min}$ for ${ }^{33} \mathrm{P}$. In table 3.5 , the in situ oceanic production rates of ${ }^{32} \mathrm{P}$ and ${ }^{33} \mathrm{P}$ at other latitudes are then computed, using the polynomials of the disintegration rates as scaling factors (Lal, 1991). These production rates are a factor of three lower than the mean in situ oceanic production rates estimated by Lal et al. (1988).

The length of the salt exposure experiments (July to September 1992) is examined with respect to the longer time record of the neutron flux to investigate time changes in the production rates. Figure 3.2 shows the neutron count rate given by the neutron monitor at the Mt. Washington Observatory since 1954. It is observed that 1991 corresponds to a year of minimum neutron flux in the 11-year solar cycle. Although the major variations in the neutron count rate are due to the 11-year cycle, there are nevertheless variations of up to $10 \%$ on time scales of 60-80 days (see years 1982 and 1991 in figure 3.2). Therefore the in situ production rates of ${ }^{32} \mathrm{P}$ and ${ }^{33} \mathrm{P}$ determined in 1992 on time scales of 64-80 days, are possibly offset from the mean of the low neutron flux period by $10 \%$. That correction will be made when the neutron data become available for 1992. The mean of the neutron flux varies by factors of $20-25 \%$ between a low and a high flux period of the 11-year cycle. It is thus expected that the production rates of radiophosphorus will also vary by $20-25 \%$ between a low and a high flux period. 
Table 3.4. In situ oceanic production rates of ${ }^{32} \mathrm{P}$ and ${ }^{33} \mathrm{P}$ in $\mathrm{Cl}, \mathrm{S}$ and $\mathrm{K}$ targets. The production rates are calculated for the upper ocean and geomagnetic latitude of Bermuda $\left(\lambda=43.6^{\circ} \mathrm{N}\right)$.

\begin{tabular}{lllc}
\hline Sample & Target & $\begin{array}{l}\text { Production rate } \\
\text { atom } / \mathrm{cm}^{2} / \mathrm{min}\end{array}$ \\
& & ${ }^{32} \mathrm{P}$ & ${ }^{33} \mathrm{P}$ \\
& & & \\
\hline Cl-WH & $\mathrm{Cl}$ & $2.4^{*} 10^{-4}$ & $1.1^{*} 10^{-4}$ \\
Cl-MW & $\mathrm{Cl}$ & $5.1^{*} 10^{-4}$ & $1.1^{*} 10^{-4}$ \\
Cl - MW & $\mathrm{Cl}$ & $1.6^{*} 10^{-4}$ & $0.6^{*} 10^{-4}$ \\
K-MW & $\mathrm{K}$ & $2.8^{*} 10^{-6}$ & n.d. \\
S-MW & $\mathrm{S}$ & $2.2^{*} 10^{-5}$ & n.d. \\
Cl-MA & $\mathrm{Cl}$ & $1.9^{*} 10^{-4}$ & $0.5^{*} 10^{-4}$ \\
& & & \\
\hline
\end{tabular}

n.d.: Not determined.

Table 3.5. In situ oceanic production rates of ${ }^{32} \mathrm{P}$ and ${ }^{33} \mathrm{P}$

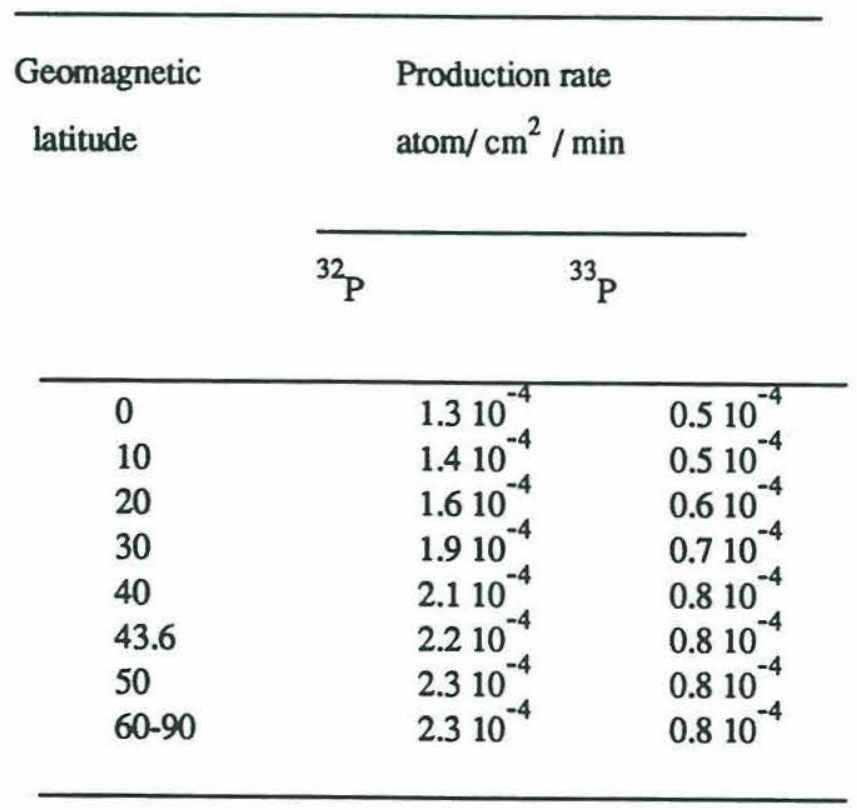




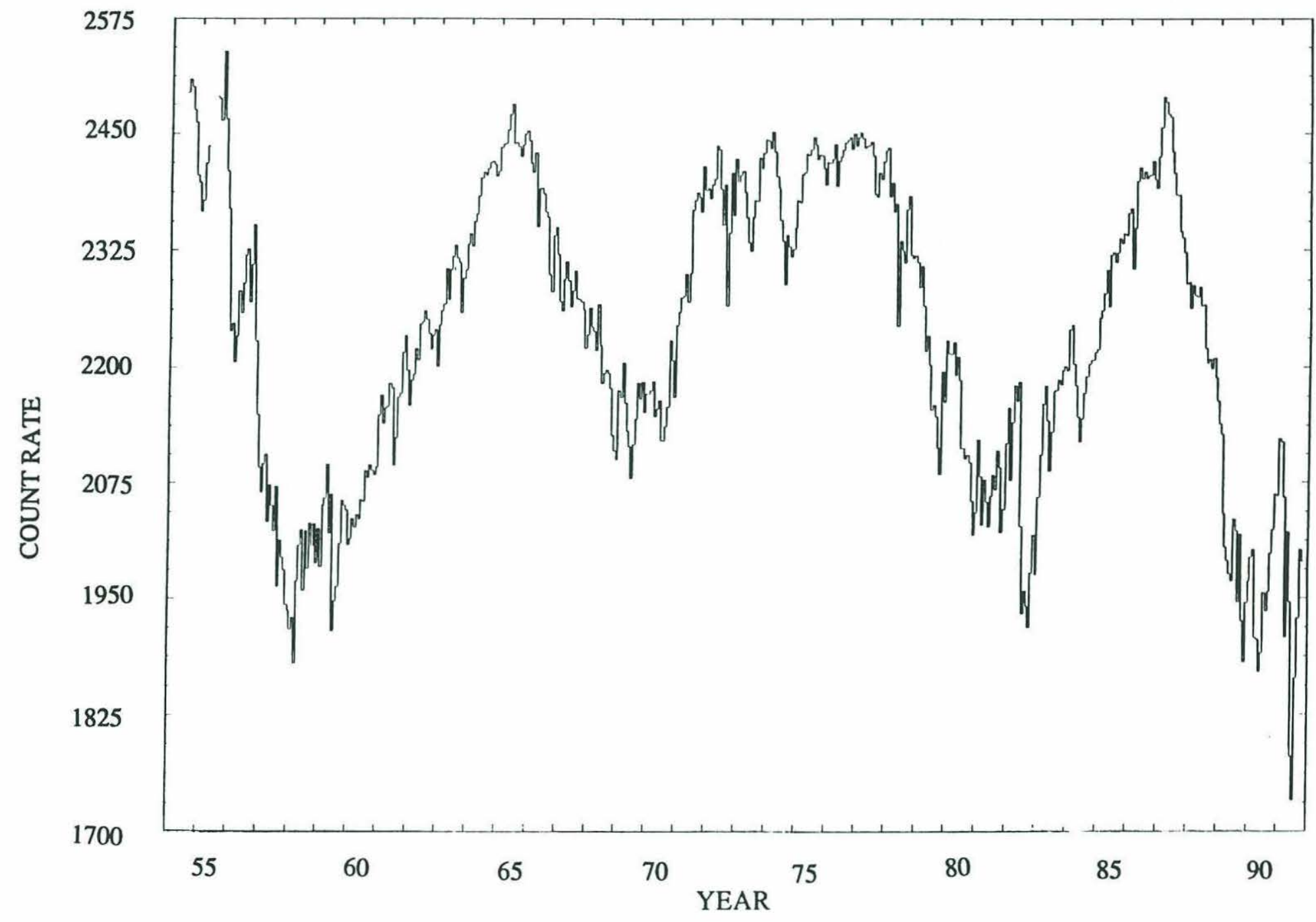

Figure 3.2. Forty-year record of the neutron count rate recorded by the neutron detector at the Mount Washington Observatory (from J. Lockwood). 


\section{CONCLUSION}

The total in situ production rates of ${ }^{32} \mathrm{P}$ and ${ }^{33} \mathrm{P}$ due to nucleonic spallation are estimated to be $2.5 \pm 0.410^{-4}$ atom $/ \mathrm{cm}^{2} / \mathrm{min}$ for ${ }^{32} \mathrm{P}$ and $8 \pm 310^{-5}$ atom $/ \mathrm{cm}^{2} / \mathrm{min}$ for ${ }^{33} \mathrm{P}$ at Bermuda $\left(43.6{ }^{0} \mathrm{~N}\right)$. These production rates are small compared to the annual wet deposition rates of $510^{-3}$ atom $/ \mathrm{cm}^{2} / \mathrm{min}$ for ${ }^{32} \mathrm{P}$ and $810^{-3}$ atom $/ \mathrm{cm}^{2} / \mathrm{min}$ for ${ }^{33} \mathrm{P}$ at Bermuda (5 and $1 \%$, respectively).

This investigation has not included the quantification of the production rates due to muons. The above production rates are thus lower limit estimates. It is known from previous studies that muons can contribute to the production rate of cosmogenic nuclides, but the contribution is only a fraction of the production rate due to neutrons, which is in turn a small fraction of the wet deposition rates. It is thus believed that the muon contribution does not significantly affect the conclusion that in situ production is small compared to wet deposition. There have been no studies of the muon production of ${ }^{32} \mathrm{P}$ and ${ }^{33} \mathrm{P}$ in $\mathrm{Cl}$, and that needs to be pursued to fully assess the importance of that process on the in situ production of ${ }^{32} \mathrm{P}$ and ${ }^{33} \mathrm{P}$. 


\section{Bibliography}

Bilokon, H., G. Cini Castagnoli, A. Castellina, B. D'Ettorre Piazzoli, G. Mannocchi, E. Meroni, P. Picchi, and S. Vernetto, 1989. Flux of the vertical negative muons stopping at depths 0.35-1000 hg/cm² . J. Geophys. Res., 94(B9):12,145-12,152.

Bhandari, N., J. Fruchter and J. Evans, 1969. Rates of production of ${ }^{24} \mathrm{Na}$ and ${ }^{28} \mathrm{Mg}$ in the atmosphere by cosmic radiation. Earth Planet. Sci. Lett., 7(1):89-92.

Brown, E.T., E.J. Brook, G.M. Raisbeck, F. Yiou, and M.D. Kurz, 1992. Effective attenuation lengths of cosmic rays producing ${ }^{10} \mathrm{Be}$ and ${ }^{26} \mathrm{Al}$ in quartz: implications for exposure age dating. Geophys. Res. Let., 19:369-372.

Hampel, W., J. Takagi, K. Sakamoto, and S. Tanaka, 1975. Measurements of muoninduced ${ }^{26} \mathrm{Al}$ in terrestrial silicate rock. J. Geophys. Res., 80:3757- .

Hess, W. N., W. Patterson and R. Wallace, 1959. Cosmic-ray-neutron energy spectrum. Phys. Rev., 116:445-457.

Husain, L. and P. K. Kuroda, 1968. Cosmic-ray-produced radioactivity in laboratory chemicals. J. inorg. nucl. chem., 30:1121-1124.

Kurz, M. D., 1986. In situ production of terrestrial cosmogenic ${ }^{3} \mathrm{He}$ and some applications to geochronology. Geochim. Cosmochim. Acta, 50:2855-2862.

Lal, D., 1991. Cosmic ray labeling of erosion surfaces: in situ nuclide production rates and erosion models. Earth Planet. Sci. Let., 104:424-439.

Lal, D., Y. Chung, T. Platt and T. Lee, 1988. Twin cosmogenic radiotracer studies of phosphorus recycling and chemical fluxes in the upper ocean. Limnol. Oceanogr., 33:1559-1567.

Lal, D., 1988. In situ produced cosmogenic isotopes in terrestrial rocks. Ann. Rev. Earth Planet. Sci., 16:335-388.

Lal, D., 1987. Production of ${ }^{3} \mathrm{He}$ in terrestrial rocks. Chem. Geol (Isotope Geoscience Section), 66:89-98.

Lal D. and B. Peters, 1967. Cosmic ray produced radioactivity on the earth, in Handbuch der Physik, vol. XLVI/2, Springer-verlag, new-York. 
Lal, D. J. R. Arnold, and M. Honda, 1960. Cosmic-ray production rates of ${ }^{7} \mathrm{Be}$ in oxygen, and ${ }^{32} \mathrm{P},{ }^{3} \mathrm{P}^{35} \mathrm{~S}$ in Argon at mountain altitudes. Phys. Rev., 118(6):16261632.

Lal D., 1958. Investigations of nuclear interactions produced by cosmic rays. Tata Institute of Fundamental Research, Bombay, 90p.

Lockwood, J.A., 1962. Intensity-time variations of the cosmic radiation. Am. J. Phys., 30:10-15.

Mabuchi, H. R. Gensho, Y. Wada, and H. Hamaguchi, 1971. Phosphorus-32 induced by atmospheric cosmic rays in laboratory chemicals. Geochem. J., 4:105-110.

Manual of the ICAO standard atmosphere, 2nd ed., International Civil Aviatory Organization, Montreal, Que., 1964.

Murphy, J. and J.P. Riley, 1962. A modified single solution method for the determination of phosphate in natural waters. Anal. Chim. Acta, 27:31-36.

Nakamura, Y., Mabuchi, H. and Hamaguchi, 1972. ${ }^{7}$ Be production from oxygen by atmospheric cosmic rays. Geochem. J., 6:43-47.

Nishiizumi, K., E. L. Winterer, C. P. Kohl, J. Klein, R. Middleton, D. Lal, and J. R. Arnold, 1989. Cosmic ray production rates of ${ }^{10} \mathrm{Be}$ and ${ }^{26} \mathrm{Al}$ in quartz from glacially polished rocks. J. Geophys. Res., 94(B12):17,907-17,915.

O'Brien, K, 1979. Secular variations in the production of cosmogenic isotopes in the earth's atmosphere. J. Geophys. Res., 84(A2):423-431.

Pomerantz, M. A., 1971. Cosmic rays, W. C. Michels (Ed.), Van Nostrand Reinhold Company.

Rama and M. Honda, 1961. Cosmic-ray-induced radioactivity in terrestrial materials. $J$. Geophys. Res., 66:3533-3539.

Rose, D. C., K. B. Fenton, J. Katzman and J. A. Simpson, 1956. Latitude effect of the cosmic ray nucleon and meson components at sea level from the Arctic to the Antarctic. Can. J. Phys., 34:968-984

Rossi, B., 1952. High Energy Particles, Prentice-Hall, New Jersey, N. Y., 569pp. 
Simpson, J. A. and W. C. Fagot, 1953. Properties of the low energy nucleonic component at large atmospheric depths. Phys. Rev., 90(6):1068-1072.

Tanaka, S., K. Sakamoto, J. Takagi, and M. Tsuchimoto, 1968. Search for aluminum 26 induced by cosmic-ray muons in terrestrial rocks. J. Geophys. Res., 73(10):3303-3309

Takagi, J. and S. Tanaka, 1968. Calculation of the production rate of radioactivity by cosmic rays at sea level. INSJ-110.

Winsberg, L., 1956. The production of ${ }^{39} \mathrm{Cl}$ in the lower atmosphere by cosmic radiation. Geochim. Cosmochim. Acta, 9:183-189.

Yamashita, M., L.D. Stephens, and H. Wade Patterson, 1966. Cosmic-ray produced neutrons at ground level: neutron production rate and flux distribution. J. Geophys. Res., 71(16):3817-3834.

Yokoyama, Y., J. Reyss and F. Guichard, 1977. Production of radionuclides by cosmic rays at mountain altitudes. Earth Planet. Sci. Lett., 36:44-50.

Zreda, M.G., F.M., Philips, D. Elmore, P.W. Kubik, P. Sharma and R.I. Dorn, 1991. Cosmogenic chlorine-36 production rates in terrestrial rocks. Earth Planet. Sci. Lett., 105:94-109. 
Chapter Four

\section{COSMOGENIC $^{32}$ P AND ${ }^{33}$ P RECYCLING \\ IN PLANKTON OFF BERMUDA}

\section{INTRODUCTION}

In spite of the tremendous potential of cosmogenic radioisotopes of phosphorus for tracing short-term processes involving phosphorus, their extremely low natural abundance in the marine environment has impeded their use in biogeochemistry. Early studies utilizing artificial ${ }^{32} \mathrm{P}$ took advantage of the release of the tracer from the water cooling system of nuclear reactors (Chakravarti, 1964). In a later study ${ }^{32} \mathrm{P}$ was released in a saltmarsh to trace the $\mathrm{P}$ cycle in that ecosystem (Pomeroy et al., 1967). It is only recently that the first measurements of naturally produced cosmogenic ${ }^{32} \mathrm{P}$ were obtained in the total dissolved phosphorus (TDP) pool (Lal et al., 1988; Lal and Lee, 1988, Lee et al., 1991), in the dissolved inorganic phosphorus (DIP) pool (Lee et al., 1992), and in plankton (Lal et al., 1988; Lal and Lee, 1988), opening new avenues for studying the $\mathrm{P}$ cycle in the environment. Although it is very desirable to utilize both radioisotopes, only four measurements of cosmogenic ${ }^{33} \mathrm{P}$ in seawater have been reported (Lal and Lee, 1988). 
The difficulty in measuring ${ }^{32} \mathrm{P}$ and ${ }^{33} \mathrm{P}$ is due both to their low activities in seawater and to the relatively large amount of stable phosphorus, which hinders detection of the radioisotopes, particularly the soft $\beta$-emitting ${ }^{33} \mathrm{P}$. All previously published data on ${ }^{32} \mathrm{P}$ in plankton were collected from eutrophic provinces of the ocean, and ${ }^{33} \mathrm{P}$ could hardly be detected because of self absorption in the source due to the large amount of stable P (Chapter One). In that respect the Sargasso Sea, with its low DIP and paticulate total phosphorus (PTP) concentrations, is an ideal ocean province to pursue a study of ${ }^{32} \mathrm{P}$ and, especially, ${ }^{33} \mathrm{P}$.

In this chapter, the activity ratio ${ }^{33} \mathrm{P} /{ }^{32} \mathrm{P}$ is used as a means of assessing the residence time of phosphorus in different size fractions of particulate matter and trophic position. The principle of the use of the activity ratio ${ }^{33} \mathrm{P} /{ }^{32} \mathrm{P}$ is that the ratio increases with time due to the differential radioactive decay rates of ${ }^{33} \mathrm{P}$ and ${ }^{32} \mathrm{P}$. An increase in the ratio in plankton relative to rain or total dissolved phosphorus can be interpreted as aging of the phosphorus in that plankton pool or in the pool from which it is derived, assuming that isotopic fractionation is small. Finally the in situ grazing rate of zooplankton is estimated from the specific activities of ${ }^{32} \mathrm{P}$ and ${ }^{33} \mathrm{P}$ in both suspended matter and plankton tows.

\section{BACKGROUND}

While there has been limited use of natural cosmogenic ${ }^{32} \mathrm{P}$ and ${ }^{33} \mathrm{P}$, tracer techniques have been applied extensively to study both marine and freshwater ecosystems. Uptake rates by phytoplankton and turnover times of $\mathrm{P}$ in plankton have been consequently determined in the marine system (Perry, 1976; Harrison et al., 1977; Perry and Eppley, 1981; Herbland, 1984; Sorokin, 1985; Harrison and Harris, 1986). The studies showed substantial recycling of phosphorus during the short incubation periods suggesting an underestimation of uptake rates by these methods (Harrison, 1983; 
Harrison and Harris, 1986). In addition, tracer techniques have been applied to the study of exchange rates between DIP, dissolved organic phosphorus (DOP) and PTP in seawater (Watt and Hayes, 1963). Assimilation efficiencies of $\mathrm{P}$ of single species of zooplankton or natural assemblages have been determined using ${ }^{32} \mathrm{P}$ in laboratotry experiments. Some of the studies have been reviewed by Corner and Davies (1971).

The Sargasso Sea is an oligotrophic oceanic province. Typically DIP concentrations in the upper ocean, as determined by the standard colorimetric method (Murphy and Riley, 1962; Koroleff, 1983), are below 20-30 nM (Boyle et al., 1986; Knap et al., 1991 and 1992; Michaels et al., 1992). With the recent improvement of analytical techniques, it has been possible to measure DIP concentrations as low as 1-2 nM at station S ( $\left.32^{0} 10^{\prime} \mathrm{N} ; 64^{\circ} 30^{\prime} \mathrm{W}\right)$ (Ormaza-Gonzalez, 1990). On average DIP concentrations are about $10 \mathrm{nM}$ while at station ALOHA in the central Pacific gyre, they are typically about $100 \mathrm{nM}$ in the upper ocean (Karl and Tien, 1992). Particulate total phosphorus (PTP) is also low, ranging from a few $\mathrm{nM}$ to $60 \mathrm{nM}$ in the Sargasso Sea and is typically around $10 \mathrm{nM}$ (Bishop et al., 1986a; Ormaza-Gonzalez, 1990; J. Ammerman, personal communication at BATS workshop 1992). Particulate nitrogen (PN) is also very low, ranging up to $0.5 \mu \mathrm{M}$ (Altabet, 1989; Knap et al., 1992). While DIP and PTP pools have similar sizes, DOP is by far the major pool of P at BATS station $\left(31^{\circ} 50^{\prime} \mathrm{N}, 64^{\circ} 10^{\prime}\right.$ W) and at station S, with typical concentrations of 100-250 nM (Ormaza-Gonzalez, 1990; J. Ammerman, personal communication at BATS workshop 1992).

Despite the importance of $\mathrm{P}$ in the ocean, the study of the $\mathrm{P}$ cycle has been neglected in favor of $\mathrm{C}$ and $\mathrm{N}$, partly because of the difficulties of conventional tracer techniques, measurement and sampling techniques, and the perception by biologists that $\mathrm{N}$ is the limiting nutrient in the ocean (Eppley et al., 1973; Eppley and Peterson, 1979; Goldman et al., 1979; Perry and Eppley, 1981; McCarthy and Carpenter, 1983). 
Phosphorus is an essential element for living organisms and is regarded by geochemists as the ultimate nutrient limiting productivity in the ocean because of nitrogen fixation (Redfield, 1958; Redfield et al., 1963; Broecker and Peng, 1982; Smith 1984; Smith and Atkinson, 1984; Fanning, 1989). In addition, very few studies have succeeded in quantifying the flux of phosphorus to the deep ocean due to large uncertainties in the $\mathrm{C} / \mathrm{P}$ ratio in sinking particulate matter. The observed ratios, i.e $150-900$, are found to be generally higher than the predicted ratio of $106 / 1$ by Redfield or of $127 / 1$ predicted by Peng and Broecker (Bogdanov and Shaposhnikova, 1971; Bishop et al., 1977; Knauer et al., 1979; Bishop et al., 1980; Knauer and Martin, 1981; Bishop et al., 1986b; Martin et al., 1987; Liebezeit, 1991). Phosphorus recycling in the upper ocean appears to be more efficient than cycling of carbon and nitrogen. It is also suggested by the high release of P relative to N during remineralization of both particles (Vaccaro, 1963; Grill and Richards, 1964; Harrison, 1980) and organic matter (Jackson and Williams, 1985; Smith et al., 1985; Smith et al., 1986; Orrett and Karl, 1987). In addition, $\mathrm{P}$ is released rapidly from biogenic particles upon collection (Collier and Edmond, 1984; Collier, 1991). Overall it is not clear whether the high $\mathrm{C} / \mathrm{P}$ ratios measured in sinking particles are meaningful features, i.e. faster recycling of $\mathrm{P}$ than $\mathrm{N}$ or $\mathrm{C}$, or artifacts of collection, i.e. loss due to cell lysis.

\section{RESULTS AND DISCUSSION}

A seasonal study of the distributions of ${ }^{32} \mathrm{P}$ and ${ }^{33} \mathrm{P}$ in different particulate fractions was pursued in the mixed layer at the U.S. JGOFS Bermuda Atlantic Timeseries Study (BATS) site $\left(31^{\circ} 50^{\prime} \mathrm{N}, 64^{\circ} 10^{\prime} \mathrm{W}\right), 80 \mathrm{~km}$ southeast of Bermuda, during 1991 and 1992.

The specific activities of ${ }^{32} \mathrm{P}$ (i.e., $\left.{ }^{32} \mathrm{P} / \mathrm{P}\right)$ and ${ }^{33} \mathrm{P}\left(\right.$ i.e., $\left.{ }^{33} \mathrm{P} / \mathrm{P}\right)$ were determined in surface suspended matter in July and November 1991 and in February and April 
1992 (Figure 4.1) and in suspended matter collected at three depths in April 1992 (Figures 4.2 and 4.3). The activity ratios ${ }^{33} \mathrm{P} /{ }^{32} \mathrm{P}$ were derived for surface and depthintegrated plankton tows, for surface suspended matter (Figures 4.4a to $4.4 \mathrm{e}$ and 4.5 ) and for the depth profile of ${ }^{33} \mathrm{P} /{ }^{2} \mathrm{P}$ in suspended matter in April 1992 (Figure 4.6). The samples were collected during 6 cruises on R/V Weatherbird II and R/V Endeavor at the BATS site. The results for 4-5 March, 29 April-1 May, 15-19 July (BATS 34) and 11-15 November (BATS 38) of 1991 and for 24-26 February (BATS 41A) and 12-27 April (EN 235) of 1992 are presented in tables 4.1-4.6. The samples collected in March and May do not correspond to BATS cruises, and hydrographic data from the closest BATS (BATS 29A and BATS 31) cruises are presented in figures 4.7 and 4.8. The hydrographic data for BATS 34, 38 and 41A are presented in figures 4.9, 4.10 and 4.11. For the Endeavor cruise (EN 235) $\mathrm{T}$ and $\mathrm{NO}_{3}$ profiles are presented in figures 4.12a and 4.12b for April 25 .

Suspended particulate matter was typically collected by filtering 2,000 to 7,000 liters of water through Millipore filters ( 3 or $8 \mu \mathrm{m}$ mesh size). Presumably, particles smaller than 3 or $8 \mu \mathrm{m}$ were collected as well because clogging occurred rapidly during filtration. The Millipore filters were changed as soon as the flow rate started to decrease about every hour. Large particles were harvested with plankton nets $(67,150,300$ and $500 \mu \mathrm{m}$ mesh size). These large particles contained macrozooplankton and also large phytoplanktonic species, such as cyanobacteria (Trichodesmium). An attempt was made to determine ${ }^{32} \mathrm{P}$ and ${ }^{33} \mathrm{P}$ on large particles collected by filtering $5,000 \mathrm{\ell}$ of water through a 53- $\mu \mathrm{m}$ Nitex filter in February 1992. The amount of $\mathrm{P}$ on the Nitex filter was very low (i.e., $0.3 \mathrm{nM}$ ) preventing analysis of ${ }^{32} \mathrm{P}$ and ${ }^{33} \mathrm{P}$. In April 92, comparison was made between PTP for a surface sample collected on GF/F $(0.7 \mu \mathrm{m})$ and on Millipore (3 $\mu \mathrm{m}$ mesh size). It was found that $20 \%$ of the suspended particles $>0.7 \mu \mathrm{m}$ were in the fraction 0.7-3 $\mu \mathrm{m}$. This percentage is a lower limit estimate, because particles smaller than $3 \mu \mathrm{m}$ were probably collected on the $3-\mu \mathrm{m}$ filter due to clogging. 


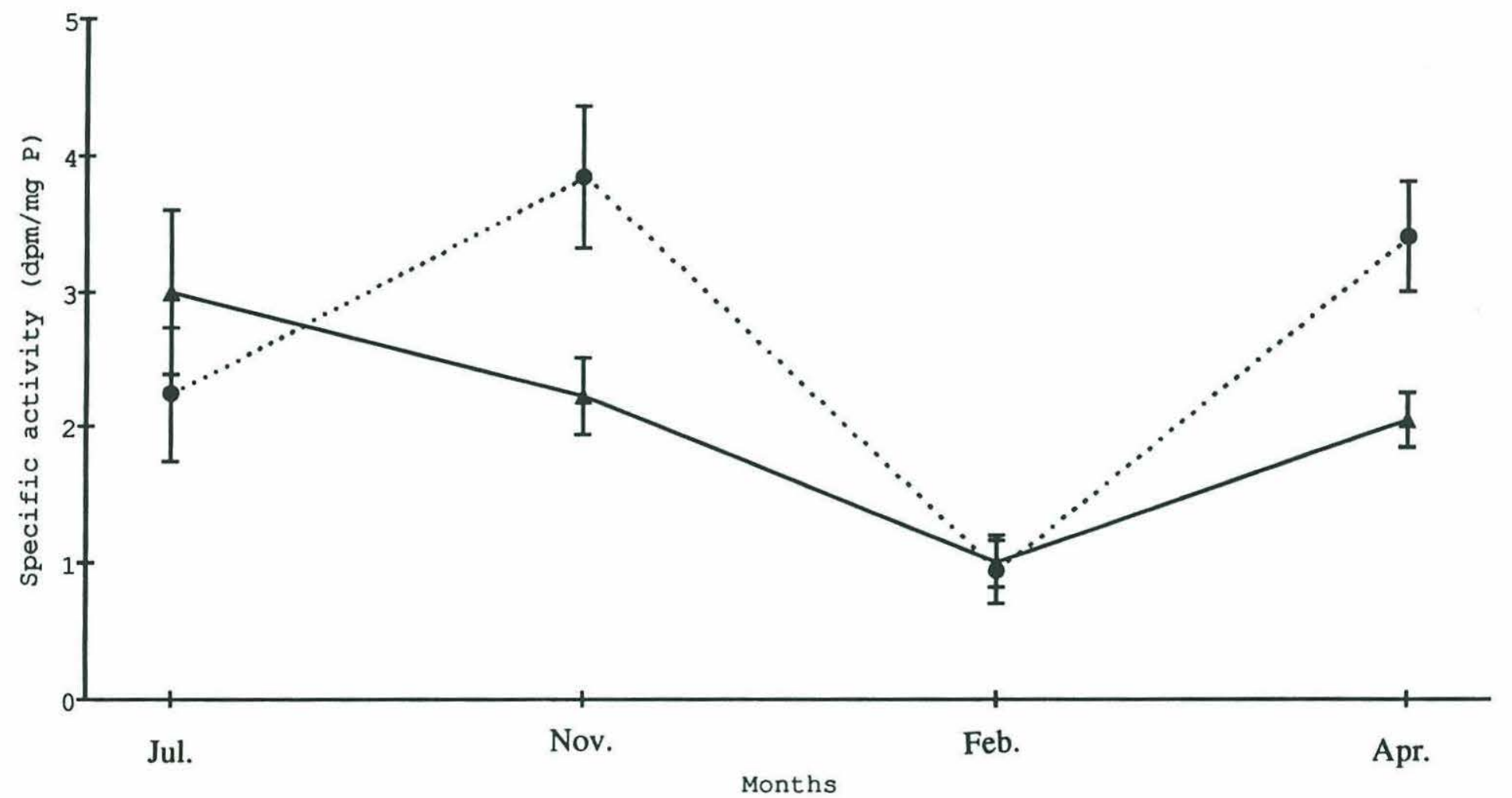

Figure 4.1. Specific activities of ${ }^{32} \mathrm{P}$ and ${ }^{33} \mathrm{P}(\mathrm{dpm} / \mathrm{mg} \mathrm{P})$ in surface suspended particles $(>3 \mu \mathrm{m}$ or $>8 \mu \mathrm{m}$ ) during 15-19 July 1991, 11-15 November 1991, 24-26 February 1992 and 25-26 April 1992 at BATS station. 
${ }^{32} \mathrm{P}(\mathrm{dpm} / \mathrm{mg} \mathrm{P})$

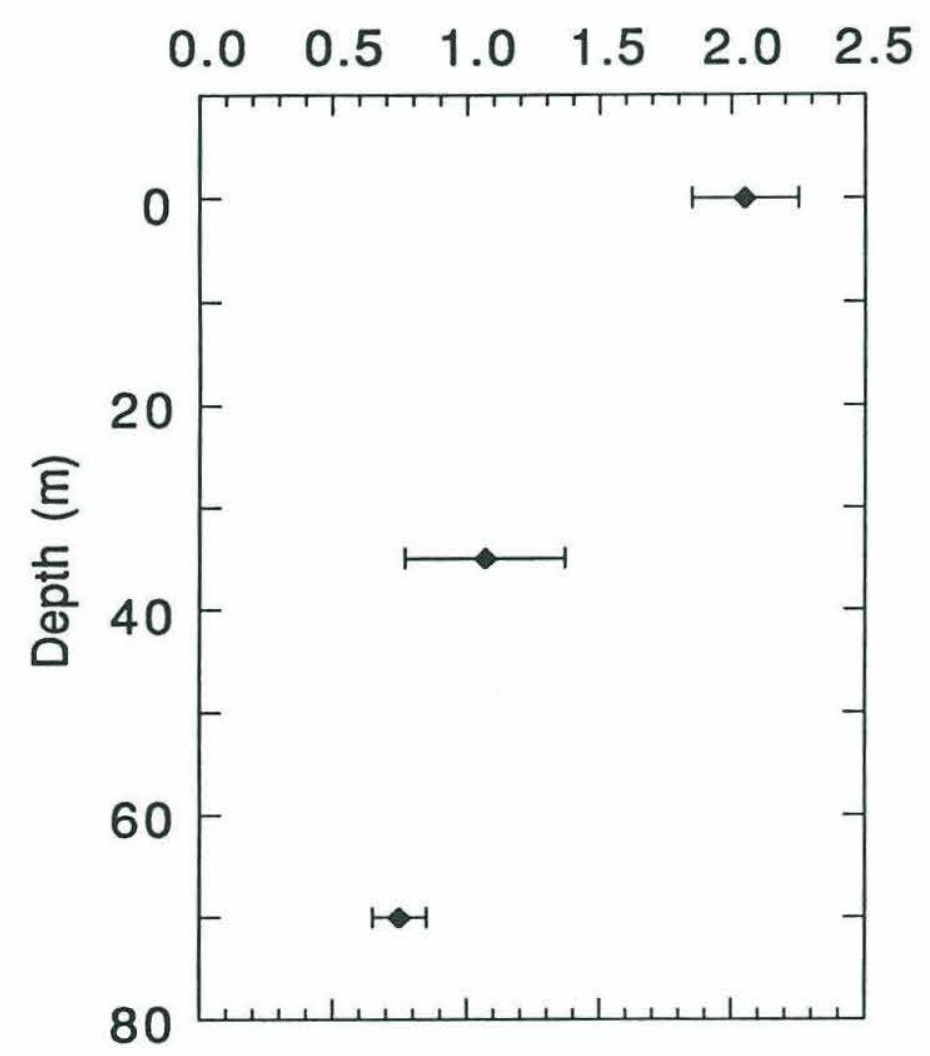

EN 235, 25-26 April 92

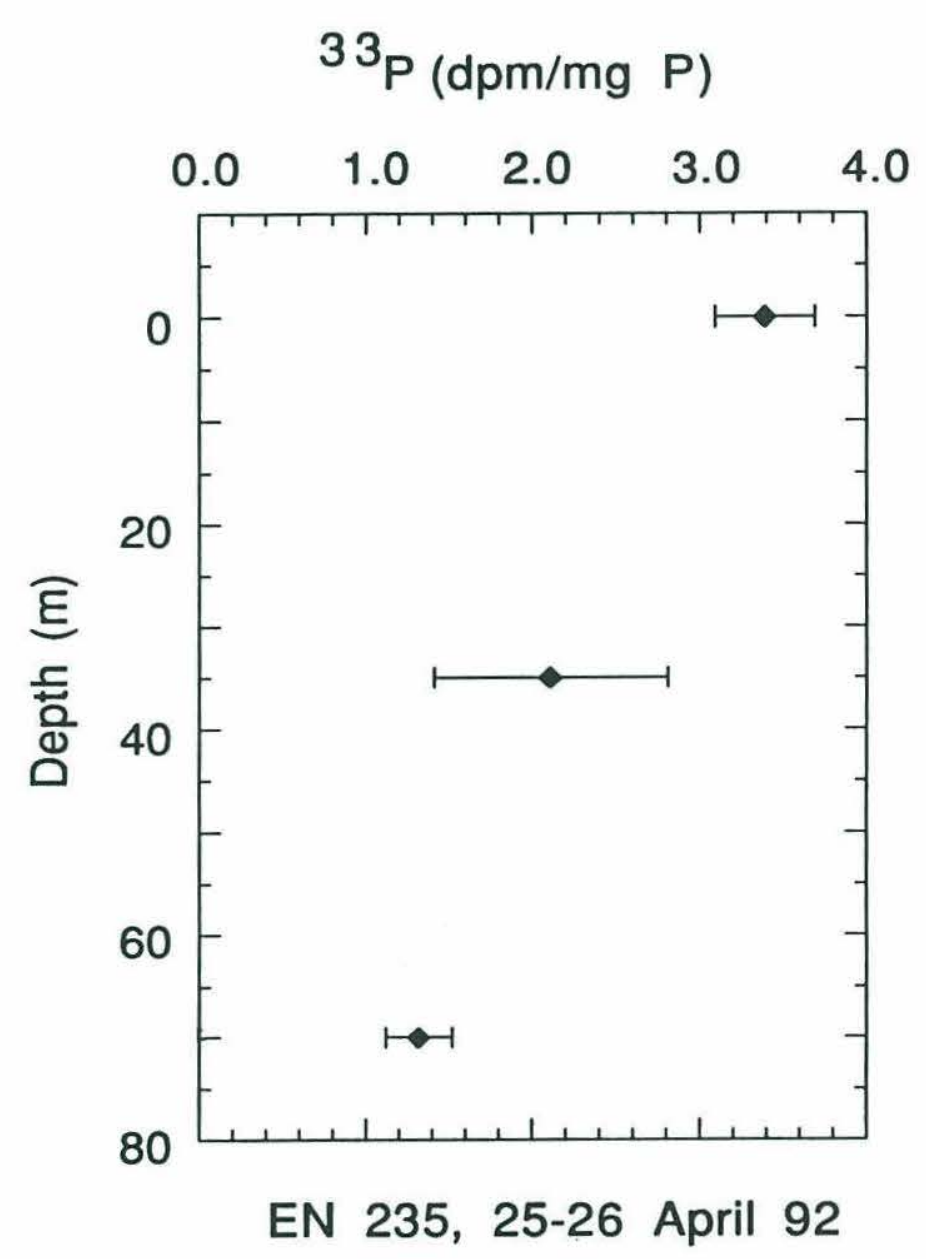

Figure 4.2. Profile of ${ }^{32} \mathrm{P}$ specific activity (dpm/mg P) in suspended particles $(>3 \mu \mathrm{m})$ during EN 235, 25-26 April 1992 at BATS station.

Figure 4.3. Profile of ${ }^{33} \mathrm{P}$ specific activity (dpm/mg P) in suspended particles $(>3 \mu \mathrm{m})$ during EN 235, 25-26 April 1992 at the BATS station. 

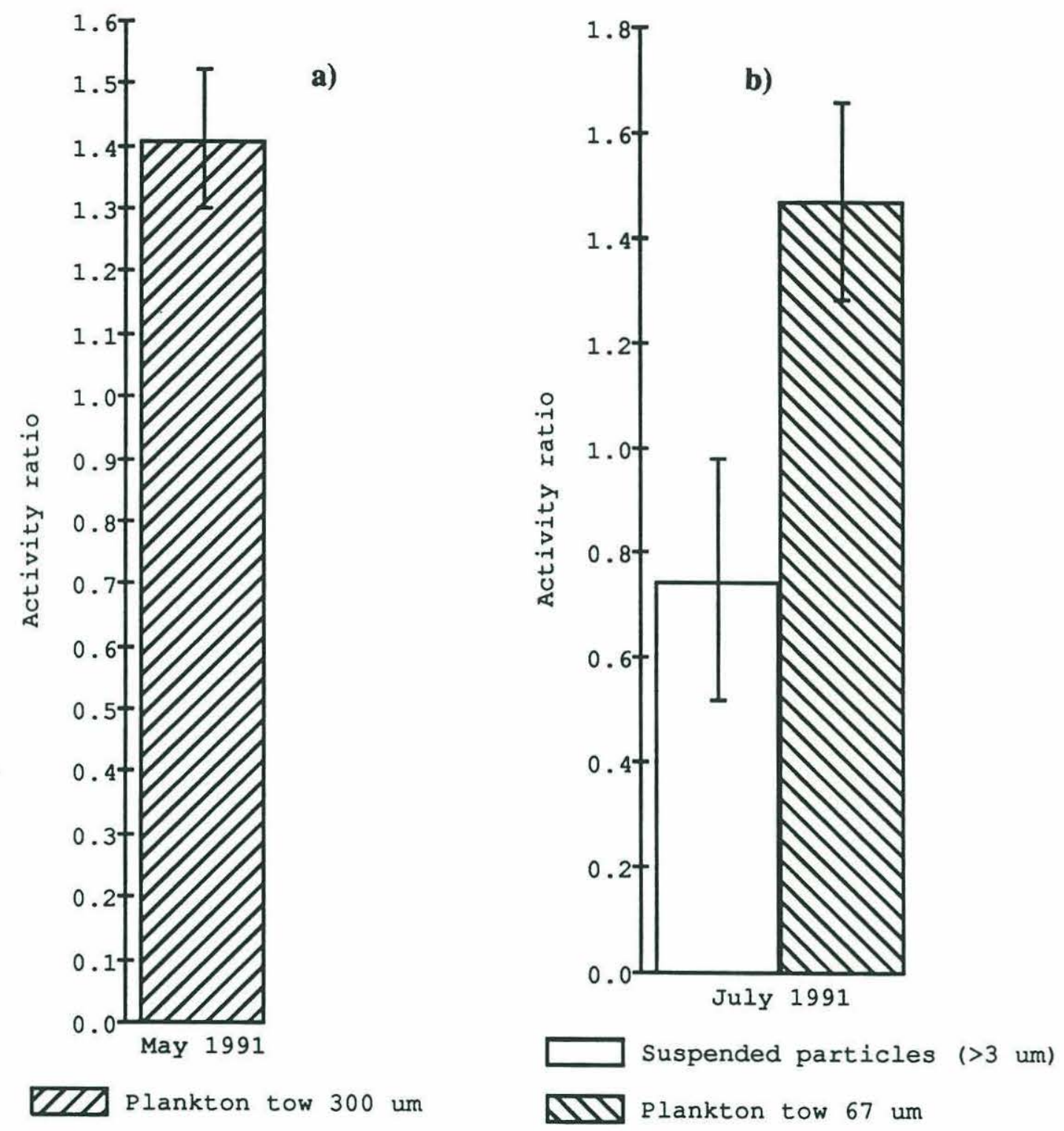

Figures 4.4.a, b. Activity ratio of ${ }^{33} \mathrm{P} /{ }^{32} \mathrm{P}$ in suspended particles and plankton tows $(67,300 \mu \mathrm{m}$ mesh size) during May and July 1991 at BATS station 


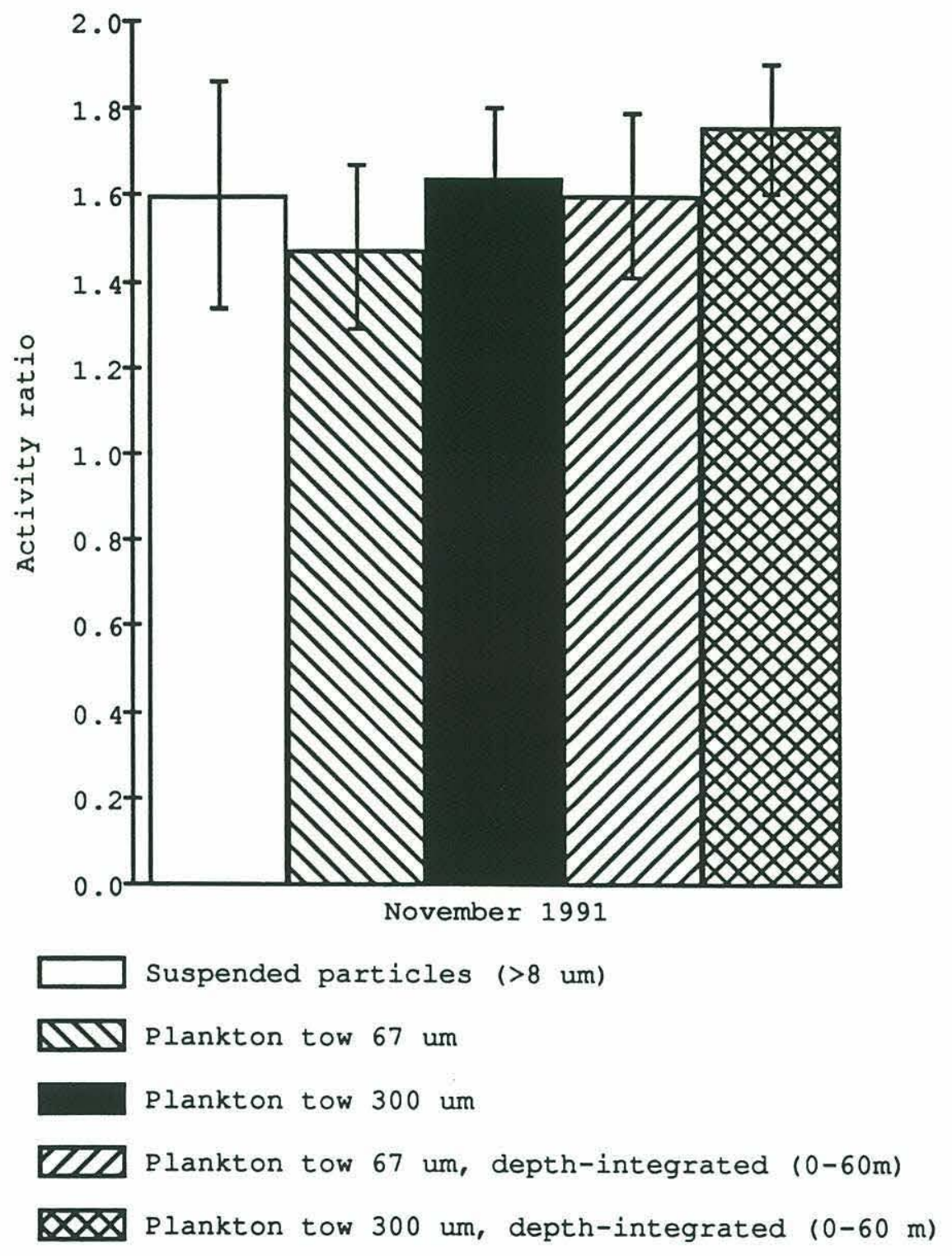

Figure 4.4.c. Activity ratio of ${ }^{33} \mathrm{P} /{ }^{32} \mathrm{P}$ in suspended particles and plankton tows (67, $300 \mu \mathrm{m}$ mesh size) during November 1991 at BATS station 

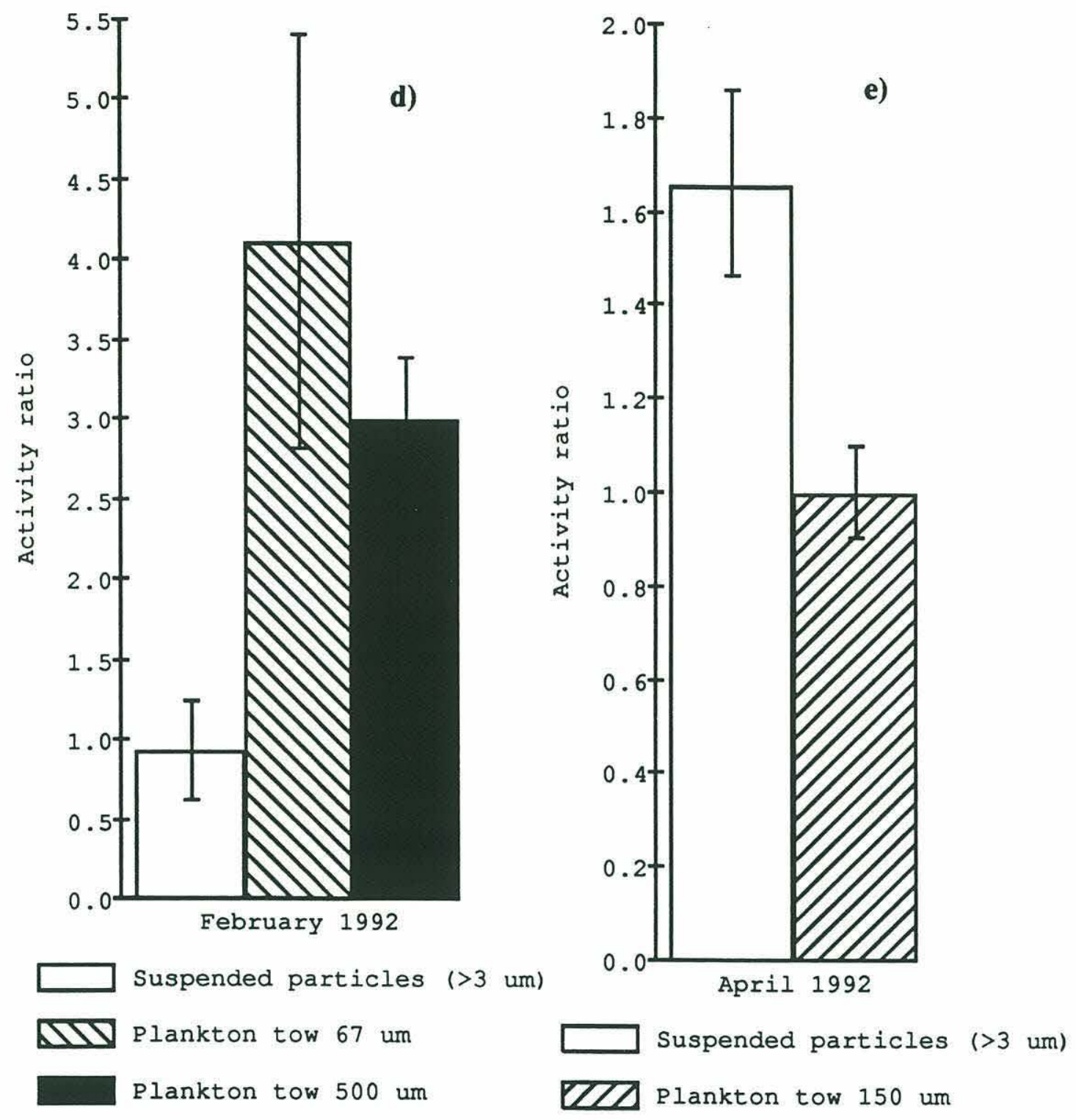

Figures 4.4.d, e. Activity ratio of ${ }^{33} \mathrm{P} /{ }^{32} \mathrm{P}$ in suspended particles and plankton tows (67, 150, $500 \mu \mathrm{m}$-mesh size) during d) February and e) April 1992 at BATS station. 


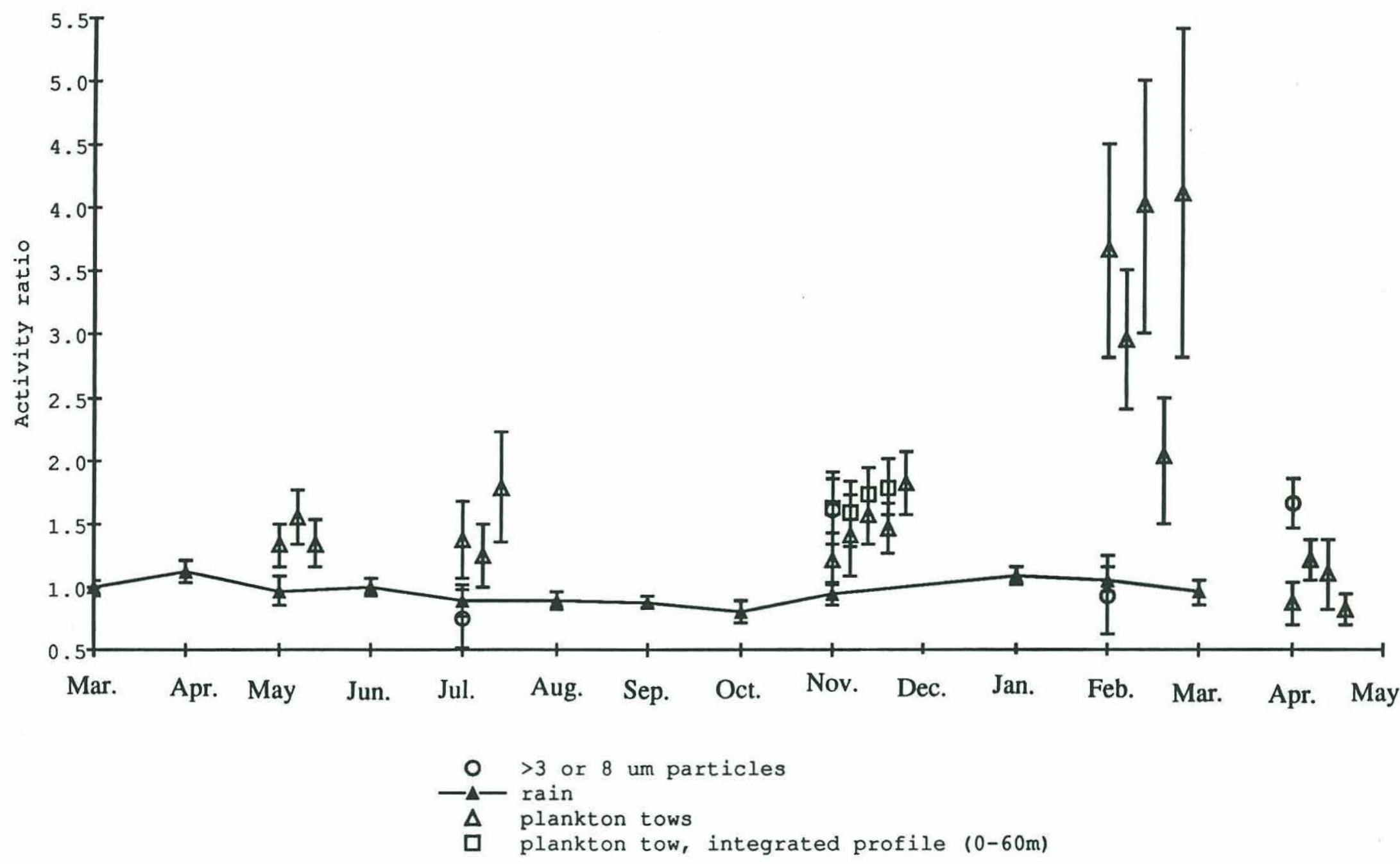

Figure 4.5. Monthly activity ratio ${ }^{33} \mathrm{P} / 2 \mathrm{P}$ in rainwater from March 1991 to March 1992, and activity ratio in surface suspended particles and plankton tows for May, July and November 1991, and February and April 1992. 


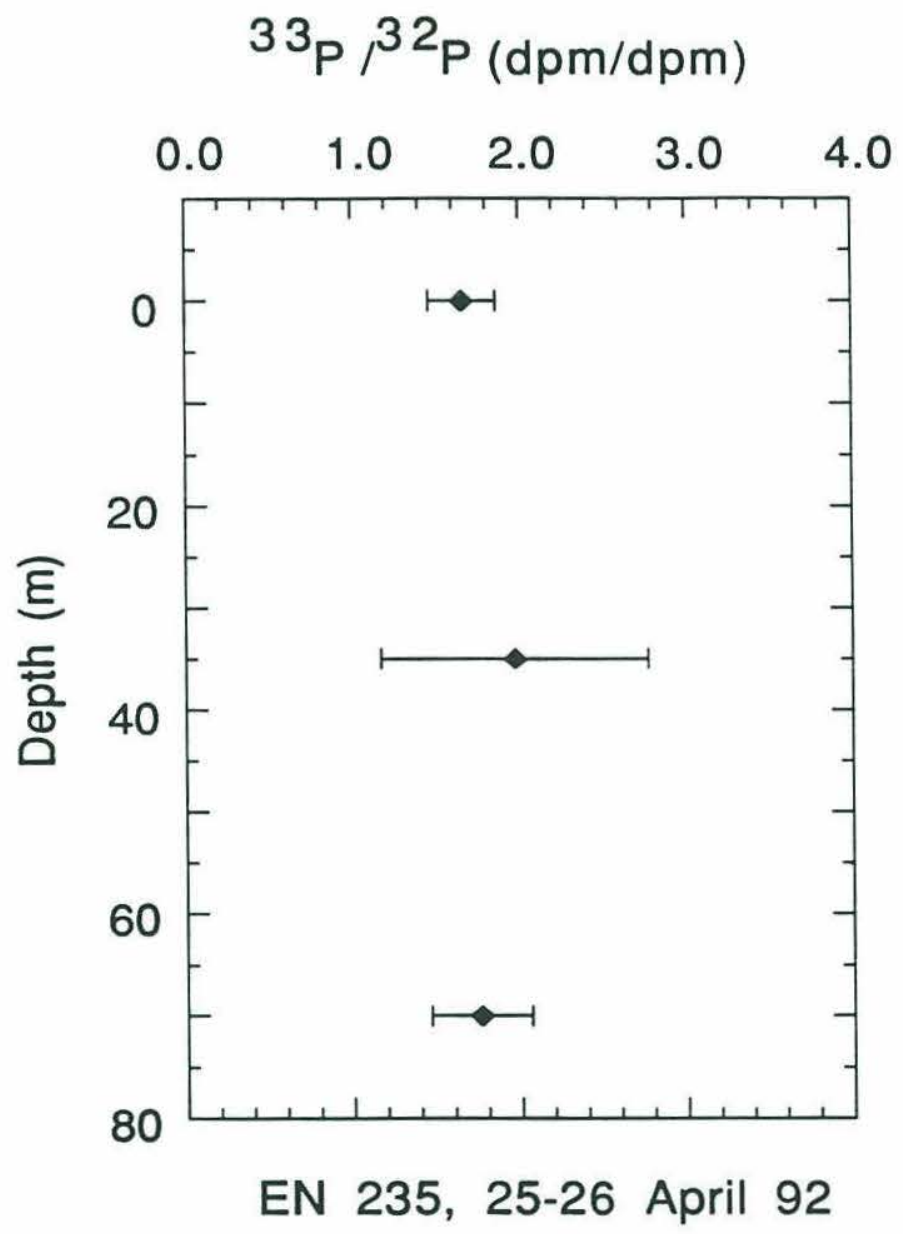

Figure 4.6. Profile of the activity ratio ${ }^{33} \mathrm{P} /{ }^{32} \mathrm{P}$ in suspended particles $(>3 \mu \mathrm{m})$ during EN 235, 25-26 April 1992, at BATS station. 
Both ${ }^{32} \mathrm{P}$ and ${ }^{33} \mathrm{P}$ were measured in suspended particles and plankton tows for the first time. Our ability to determine both isotopes, as explained before, is due mainly to the very low stable P concentrations in the Sargasso Sea. As expected, the specific activities in the particulate matter are one or two orders of magnitude higher than those encountered in the South California Bight, in the Celtic Sea and in the Bedford Basin (Lal et al., 1988; Lal and Lee, 1988).

The major features of the data set that will be discussed and interpreted are: (1) the specific activities in suspended particles are highest in November 1991; (2) the ratio ${ }^{3{ }^{3}} \mathrm{P} /{ }^{3}{ }^{2} \mathrm{P}$ in plankton tows, which is either equal to or significantly higher than the ratio in rain, is highest in February 1992; and (3) the phosphorus radioisotopes were not homogeneously distributed in zooplankton in March 1991, allowing a labile and a refractory pool to be identified. In addition, the residence time of $\mathrm{P}$ in macrozooplankton and the in situ grazing rate and defecation rate of zooplankton are estimated.

\section{1- Specific activities of ${ }^{32} \mathrm{P}$ and ${ }^{33} \mathrm{P}$}

The specific activities range from 1 to $3 \mathrm{dpm} / \mathrm{mg} \mathrm{P}$ for ${ }^{32} \mathrm{P}$ and ${ }^{33} \mathrm{P}$ in the suspended matter and, from 0.3 to $3 \mathrm{dpm} / \mathrm{mg} \mathrm{P}$ for ${ }^{32} \mathrm{P}$ and 0.9 to $5 \mathrm{dpm} / \mathrm{mg} \mathrm{P}$ for ${ }^{3}{ }^{3} \mathrm{P}$ in plankton tows (Tables 4.1 to 4.6). The activities in suspended particles were usually 0.3$0.9 \mathrm{dpm} / \mathrm{m}^{3}$ for ${ }^{32} \mathrm{P}$ and $0.3-1.3 \mathrm{dpm} / \mathrm{m}^{3}$ for ${ }^{33} \mathrm{P}$ (Table 4.7). PTP concentrations (collected on the 3 or $8-\mu \mathrm{m}$ filter) were found to range from 7 to $19 \mathrm{nM}$ and average 10 $\mathrm{nM}$ (Table 4.7). This is in agreement with the few existing measurements of PTP (filters of $0.45 \mu \mathrm{m}$ mesh size) at Hydrostation S and at BATS (Ormaza-Gonzalez, 1990; J. Ammerman, personal communication at BATS workshop 1992) suggesting that the Millipore 3 and $8-\mu \mathrm{m}$ filters collected particles smaller than their nominal pore sizes. The highest specific activities were obtained in November 1991, with values ranging from 2 to $5 \mathrm{dpm} / \mathrm{mg} \mathrm{P}$ for ${ }^{32} \mathrm{P}$ and 3 to $6 \mathrm{dpm} / \mathrm{mg} \mathrm{P}$ for ${ }^{3}{ }^{3} \mathrm{P}$ (Table 4.4). More typical values 
for the period sampled are around 0.2-1 dpm/mg P (Tables 4.2, 4.3, 4.5 and 4.6). In April 1992, three-point depth profiles of ${ }^{32} \mathrm{P}$ and ${ }^{33} \mathrm{P}$ in suspended particulate matter were obtained, and both show similar exponential decrease with depth (Figures 4.2 and 4.3). The specific activities observed at BATS, in suspended matter and plankton tows, are one or two orders of magnitude higher than the specific activities of ${ }^{32} \mathrm{P}$ in plankton tows reported previously (Lal et al. 1988; Lal and Lee 1988). The authors observed specific activities of ${ }^{32} \mathrm{P}$ ranging from 0.02 to $0.2 \mathrm{dpm} / \mathrm{mg} \mathrm{P}$ in the Bedford Basin and from 0.01 to $0.1 \mathrm{dpm} / \mathrm{mg} \mathrm{P}$ in the California Bight. The higher specific activities observed in the Sargasso Sea are due to the extremely low DIP concentrations, typically below the detection limit of the molybdenum blue method, i.e., 20-30 $\mathrm{nM}$ and as low as 1-2 nM (OrmazaGonzalez, 1990). In contrast, the DIP concentrations in the California Bight are 0.3 to 2 $\mu \mathrm{M}$ (Lee et al., 1991).

Off Bermuda, the major features of the upper 250 meters are; (1) the breakdown of the seasonal thermocline in January/February; (2) the productivity peak in March/mid-April following the deep winter mixing event; and (3) the development of the seasonal thermocline from April to the fall (Schroeder and Stommel, 1969; Menzel and Ryther, 1960, 1961; Michaels et al., 1992). During the period of development of the seasonal thermocline, new production is usually very low. In the absence of removal processes (vertical mixing at the base of the mixed layer and net export of particulate matter out of the mixed layer), the activities of ${ }^{32} \mathrm{P}$ and ${ }^{33} \mathrm{P}$ in TDP build up in the mixed layer. At steady state the activities can be simply determined from the balance between the supply and the decay of the inventories of ${ }^{32} \mathrm{P}$ and ${ }^{33} \mathrm{P}$. Accumulations of ${ }^{210} \mathrm{~Pb}$ and trace metals in the mixed layer have been observed in the summer off Bermuda (Boyle et al., 1986; Jickells et al., 1990). The high specific activities, i.e., 2 to 4 $\mathrm{dpm} / \mathrm{mg} \mathrm{P}$ for ${ }^{32} \mathrm{P}$ and 3 to $6 \mathrm{dpm} / \mathrm{mgP}$ for ${ }^{33} \mathrm{P}$, encountered in suspended particles and plankton tows in mid-November might be in part due to the accumulation of ${ }^{32} \mathrm{P}$ and 
${ }^{3} 3 \mathrm{P}$ in the mixed layer. In July 1991, February 1992 (BATS 34, 41A) and April 1992 (EN 235), the specific activities of ${ }^{32} \mathrm{P}$ and ${ }^{33} \mathrm{P}$ in suspended particles in the mixed layer were lower, because they were controlled more by vertical mixing and/or new production than by radioactive decay. In February 1992 (BATS 41A), the mixed layer depth was $210 \mathrm{~m}$ (Figure $4.11 \mathrm{a}$ ) and $\mathrm{PO}_{4}$ was detectable at $40 \mathrm{~m}$ and below by the molybdenum blue method (Figure $4.11 \mathrm{~b}$ ). These conditions imply both supply of stable $\mathrm{P}$ into the phosphate-depleted upper ocean and loss of radiophosphorus from the upper ocean, leading thus to lowest specific activities. In April 1992 (EN 235) the specific activities of both ${ }^{32} \mathrm{P}$ and ${ }^{33} \mathrm{P}$ were highest at the surface and decreased with depth (Figures 4.2, 4.3). April 1992 corresponded to the onset of stratification, with the seasonal thermocline forming and being destroyed on time-scales of a few days during the 12-day long cruise EN 235. The profiles of the specific activities of ${ }^{32} \mathrm{P}$ and ${ }^{33} \mathrm{P}$ reflect these phenomena integrated over a few weeks and thus reflect the decrease with depth observed in the timeaverage T profiles during the EN 235 cruise.

\section{2- Activity ratio ${ }^{33} \mathrm{P} /{ }^{32} \mathrm{P}$ in plankton}

In this section qualitative interpretations of the activity ratio ${ }^{33} \mathrm{P} /{ }^{32} \mathrm{P}$ will be given, while in sections 4 and 5 simple models will be developed to give quantitative interpretations. The activity ratios ${ }^{33} \mathrm{P} /{ }^{32} \mathrm{P}$ measured in suspended particles and in plankton tows are found always to be either equal to or higher than the ratio in rain, which averages 0.96 on an annual basis (Figure 4.5). This is explained by an increase with time of the ratio ${ }^{33} \mathrm{P} /{ }^{32} \mathrm{P}$ due to the differential decay rates of ${ }^{32} \mathrm{P}(14.3 \mathrm{~d})$ and ${ }^{33} \mathrm{P}(25.3 \mathrm{~d})$. The ratio is expected to increase in higher trophic levels relative to the ratio in rain because the doubling time of plankton, to a first approximation, is positively correlated with the particle size and ranges from hours for phytoplankton to hundreds of days for certain species of zooplankton (Sheldon et al., 1972; Tranter, 1976). 
The turnover time of $\mathrm{P}$ deduced from the time-dependent curve of the ratio ${ }^{3{ }^{3}} \mathrm{P} /{ }^{3}{ }^{2} \mathrm{P}$ in zooplankton is model-dependent. Two end-member models will be developed for zooplankton in section four. The first model predicts that the ratio increases with time until the activities of ${ }^{33} \mathrm{P}$ and ${ }^{32} \mathrm{P}$ reach a steady state, at which time the curve reaches a plateau. This end-member model represents a situation where zooplankton behave as an "open system", continuously grazing on phytoplankton and regenerating a fraction of that food. The other end-member model represents the case where zooplankton is behaving as a "closed system", neither grazing or regenarating P. This second model predicts that the ratio will increase exponentially with time.

In May 1991 the activity ratio ${ }^{33} \mathrm{P} /{ }^{32} \mathrm{P}$ in plankton tow $(>300 \mu \mathrm{m})$ averaged 1.4. This ratio is significantly higher than the average ratio of $1.02 \pm 0.03$ in rain. In July 1991 the activity ratio in surface suspended particles ( $>3 \mu \mathrm{m}$; presumed to be mostly phytoplankton) was $0.75 \pm 0.2$ (Figure 4.5 ). That is lower than the activity ratio of $1.5 \pm 0.3$ in the plankton tow ( $>67 \mu \mathrm{m}$; presumed to be mostly macrozooplankton). This observation indicates a measurable aging of $\mathrm{P}$ in macrozooplankton relative to phytoplankton. In contrast, the activity ratio in suspended particles is, within the errors, identical to the ratio in rain. The similarity of the ratios suggests that suspended particles, presumably phytoplanktonic in origin, have a very short P turnover time, estimated to be less than a few days, which is consistent with the doubling time of phytoplankton, i.e., hours to days (Sheldon et al., 1972). Furthermore, Harrison and Harris (1986) estimated a turnover time of $\mathrm{P}$ in phytoplankton on the order of 1-2 days in the Sargasso Sea. As pointed out by the authors, the tracer technique used for the estimation tends to underestimate the uptake rates, and it is likely that the turnover time of $\mathrm{P}$ is even shorter than 1-2 days.

In November 1991, there was no difference in the activity ratios of 1.6 between the surface suspended particles $(>8 \mu \mathrm{m})$ and the surface plankton tows collected with 
either a 67 or $300 \mu \mathrm{m}$ mesh net (Figure 4.4c). The ratio was also 1.6 in the depthintegrated ( 0 to $60 \mathrm{~m}$ ) plankton tows collected with nets of mesh size $67 \mu \mathrm{m}$ and $300 \mu \mathrm{m}$. The ratio of 1.6 in the surface suspended particulate sample can be explained in part by the accumulation of ${ }^{32} \mathrm{P}$ and ${ }^{33} \mathrm{P}$ in the shallow mixed layer from June to the fall. In other words, ${ }^{32} \mathrm{P}$ and ${ }^{33} \mathrm{P}$ are being supplied in a ratio of 0.9-1.0 from June to November (150 days) and are being removed mostly by decay from the mixed layer. Similar conclusions were derived for ${ }^{210} \mathrm{~Pb}$ at station $\mathrm{S}$ where accumulation of ${ }^{210} \mathrm{~Pb}$ was found throughout the June-September period (Boyle et al., 1986). Similarly, some trace elements accumulate in the shallow mixed layer during the summer months (Jickells et al., 1990). In November, Trichodesmium (blue-green algae) was found in abundance in two tows and was present in all the tows $(>67 \mu \mathrm{m}$ and $>300 \mu \mathrm{m})$. Trichodesmium, presumably, has a very short turnover time of P like other phytoplankton, and their presence might account for the similarity of the ratios in plankton tows and in suspended matter.

In February 1992 (BATS 41A) the activity ratio was $0.9 \pm 0.3$ in suspended particles $(>3 \mu \mathrm{m})$ and was on average $3.3 \pm 0.5$ in plankton tows ( $>67 \mu \mathrm{m}$ and $>500 \mu \mathrm{m})$, as seen in figure 4.5. There were no significant differences between the ratios in the 67$\mu \mathrm{m}$ plankton tow and the ratio in the $500-\mu \mathrm{m}$ plankton tow (Figure $4.4 \mathrm{~d}$ ). In an attempt to separate species of zooplankton, material from a large tow was poured into a container filled with surface seawater, and the fast sinking fraction was separated from the rest of the tow which consists of mostly radiolarians. The samples were referred to as Z500-B1 and Z500-B2 (fast sinking large particles) and Z500-T (rest of the tow) (Table 4.5). Those two samples did not exhibit different ratios, suggesting a homogeneous residence time of $\mathrm{P}$ in the different species and types of zooplankton. The most striking feature of the February cruise, compared to the other cruises, was the great difference in the activity 
ratio in the two size-fractions (Figure 4.5). This observation suggests that macrozooplankton was quite old, with low turnover times, relative to phytoplankton and that part or all of the $\mathrm{P}$ in zooplankton was not being exchanged with external sources of $\mathrm{P}$. This can be explained if the grazing activity of the animals had partially shut down during the winter, leading to considerable decay of ${ }^{32} \mathrm{P}$ and ${ }^{33} \mathrm{P}$ already present in zooplankton. It would explain the high ratios of 3 or 4 measured in macrozooplankton while the primary producers exhibit ratios of only 0.9 . It is possible that the plankton collected in February 1992 in $67 \mu \mathrm{m}$ and $500 \mu \mathrm{m}$ mesh size nets were large interzonal migrants living in the mesopelagic zone (Longhurst and Harrison, 1988).

In April 1992 an opposite trend was found. The activity ratio in the suspended particles $(>3 \mu \mathrm{m})$ averaged $1.7 \pm 0.2$, while the plankton tows $(>150 \mu \mathrm{m})$ exhibited ratios of $1.0 \pm 0.2$ on average. No significant difference was found between the activity ratio in night and day plankton tows Z150-N and Z150-D (Table 4.6), and both had ratios lower than suspended particles. It suggests that possibly a fraction of the suspended particle pool consisted at that time of detritus with a slow turnover time of P. Detritus could possibly originate from old wintertime zooplankton producing particles via excretion or ejection of fecal matter. If this is the case, a simple calculation with two end-member mixing terms (February and April terms) shows that a fraction of 1 to $10 \%$ of wintertime zooplankton organic matter characterized by activity ratios ${ }^{33} \mathrm{P} /{ }^{32} \mathrm{P}$ of 3-4 released in the suspended particles could increase the ratio in the suspended pool to 1.7 in April. Then the question is why the ratio is as low as 1 in the plank on tows, 1 being, within the error of the measurements the ratio in rain. The ratio in plankton tows was 1.0, suggesting very rapid turnover times of $\mathrm{P}$ on time scales of less than a day. In April 1992, BATS 42B (11 April) showed maximum $\mathrm{Chl}$ a, indicating the occurrence of the spring bloom. Peak concentrations in the pigments (fucoxanthine, diadinoxanthine and diatoxanthine) were observed during that cruise as well, possibly indicating the presence of abundant 
diatoms during the bloom. It is hypothesized that large diatoms might have been present in the surface tow of 25 April (EN 235), giving rise to the observed low ${ }^{33} \mathrm{P} /{ }^{32} \mathrm{P}$ ratios.

\section{3- Labile and refractory $P$ in zooplankton}

The zooplankton analysed in March 1991 revealed that radioisotopes of $\mathrm{P}$ were not homogeneously distributed in zooplankton, and two operationally-defined P compartments were identified (Table 4.1). Freshly collected plankton tows were left in surface seawater at $4{ }^{\circ} \mathrm{C}$ for a few days in the dark. A large amount of phosphate (about $50 \%$ of the total amount of $\mathrm{P}$ ) was released into solution during storage and was detectable with the standard molybdenum blue method (Murphy and Riley, 1962). The amount released was far greater than typical phosphate concentrations in the surface waters (i.e., $<20-30$ $\mathrm{nM}$ ). The three samples were filtered through $\mathrm{GF} / \mathrm{F}$, and the filtrates were combined. Phosphate was extracted on alumina and processed as explained in Chapter One. The analysis of the filtrate revealed that the activity ratio ${ }^{33} \mathrm{P} /{ }^{32} \mathrm{P}$ in the combined three samples is $1.7 \pm 0.3$. That ratio is significantly higher than the ratio in the rain. Two of the fractions remaining after leaching had very high ratios. One sample exhibits a ratio as high as 18 , indicating a very long residence time of $\mathrm{P}$ in the refractory pool. The errors on the determination of the ratio in the 3 refractory fractions were large because of the extremely low count rate of ${ }^{32} \mathrm{P}$ in those samples (almost undetectable in Z67-3). It is thus clear that those samples were particularily old, and even if the precision of the ratio determination is not good, the slope of the total net count rate is a qualitative indication of a very high fraction of ${ }^{33} \mathrm{P}$ in the sample. The experiment was repeated in February 1992 and April 1992. In February, unfortunately, the filtrate was lost during processing. The refractory fraction exhibited an activity ratio of $3.7 \pm 0.8$ which was not very different from the ratios observed in the bulk of the other tows, suggesting that the filtrate or labile fraction had a ratio similar to $2-4$. This result indicates that zooplankton had slow $\mathrm{P}$ turnover times. In April 1992, both the filtrate and the refractory fractions were analysed 
(Table 4.6). The filtrate was coprecipitated with $\mathrm{Fe}(\mathrm{OH})_{3}$ and further purified with the procedure described in Chapter One. The amounts of stable $\mathrm{PO}_{4}$ in each subsample Z150-R and Z150-L were identical within the $2 \%$ analytical error of the colorimetric method, indicating that the two subsamples are of equal size in terms of stable P. The activity ratios ${ }^{33} \mathrm{P} /{ }^{3} \mathrm{P}$ of both samples were, within the $1 \sigma$ error, identical to the average activity ratio in rain, suggesting very fast turnover of $P$ in the plankton present in the tows. This result can be explained by the probable presence of diatoms in the tows during the spring bloom (April 1992).

The difference in the ratios in the operationally defined labile and refractory fractions observed in March 1991 suggests that zooplankton encompassed two compartments of phosphorus, one labile and one refractory. Two distinct pools of $\mathrm{P}$ have been found previously, characterized as labile and stable, with very different $P$ turnover times, i.e. 0.4 days and 13 days, respectively (Conover et al., 1961). Also it has been shown that zooplankton have the ability to store $\mathrm{P}$ as fat in the males and in the reproductive system in the females (Corner and Davies, 1971). The ratio of $1.7 \pm 0.3$ observed in the labile pool suggests that $\mathrm{P}$ turns over on a time scale of a few days to a week. That pool of $\mathrm{P}$ is probably the labile pool of $\mathrm{P}$ identified in earlier plankton studies which showed substantial and rapid release of $\mathrm{P}$ subsequent to the collection of plankton tows (Collier, 1984). It also appears that $\mathrm{P}$ is excreted efficiently by zooplankton relative to nitrogen, while nitrogen is enriched in fecal pellets and thus in sinking particles (Howard, 1988), suggesting that there is a pool of labile P.

The operationally-defined refractory pool of P might contain (1) phospholipids, which are ubiquitous in the membranes of organisms (Wefer et al., 1982; Cembella et al., 1984); (2) phosphonates (Cembella and Antia, 1986; Liebezeit, 1991), or (3) nucleic acids (Holm-Hansen, 1966). The labile pool is likely to be partly composed of (1) phosphate monoesters, like AMP, ADP and ATP, which are very important $\mathrm{P}$ compounds in the energy system of cells; (2) $\mathrm{PO}_{4}$ groups which are end-products of many enzymatic 
reactions (Westheimer, 1987); and (3) $\mathrm{PO}_{4}$ present in the guts of the animals. Characterization of the $\mathrm{P}$ compounds in a single species of zooplankton has been pursued by Corner (1973), and the P compounds found were an acid-soluble fraction (50\%), phospholipids, nucleic acids and phosphoproteins (phosphate ester).

In April 1992, no significant difference was found between the easily leachable fraction and the remaining, supposedly more refractory, fraction. Both fractions had low ${ }^{3}{ }^{3} \mathrm{P} /{ }^{3} 2 \mathrm{P}$ ratios, suggesting rapid turnover of $\mathrm{P}$. April corresponded to the spring bloom period with high $\mathrm{Chl} \mathrm{a}$ in the euphotic zone. The ratio in zooplankton suggests that zooplankton was regenerating $\mathrm{P}$ at high rates. It is consistent with Corner and Davis's (1971) study, which showed a direct link between food availability and increased excretion of $\mathrm{N}$ and $\mathrm{P}$ by zooplankton.

\section{4- Residence time of $P$ and grazing rates of macrozooplankton}

In this section, I quantify the residence time of $\mathrm{P}$ in macrozooplankton, based on the activity ratios ${ }^{33} \mathrm{P} /{ }^{32} \mathrm{P}$ measured in suspended particles and plankton tows when the tows were dominated by zooplankton. As a consequence, the grazing rate can be derived from the specific activities of ${ }^{32} \mathrm{P}$ and ${ }^{33} \mathrm{P}$ in phyto- and zooplankton. The calculation of the residence time is model-dependent. The simplest model that is examined is a steady-state model describing the mass balances of ${ }^{32} \mathrm{P}$ and ${ }^{33} \mathrm{P}$ in zooplankton. The mass balance for ${ }^{32} \mathrm{P}$ in zooplankton is given by the following equation:

$$
\text { (4.1) } \mathrm{g}\left(\left(^{32} \mathrm{P}\right)_{\mathrm{p}}=\lambda_{32}\left({ }^{32} \mathrm{P}\right)_{\mathrm{z}}+\mathrm{r}\left({ }^{32} \mathrm{P}\right)_{\mathrm{z}}+\mathrm{s}\left({ }^{32} \mathrm{P}\right)_{\mathrm{z}}\right.
$$

where $\quad\left({ }^{32} \mathrm{P}\right)_{\mathrm{p}}$ : concentration of ${ }^{32} \mathrm{P}$ in phytoplankton $\left(\mathrm{dpm} / \mathrm{m}^{3}\right)$;

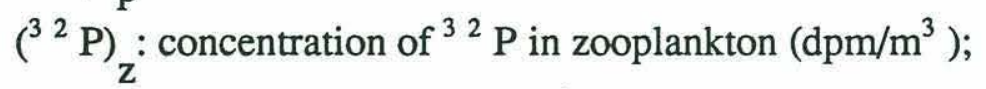

$\lambda_{32}$ : decay constant of ${ }^{32} \mathrm{P}\left(\mathrm{s}^{-1}\right)$;

g: zooplankton grazing rate $\left(\mathrm{s}^{-1}\right)$; 
r: regeneration rate of $\mathrm{P}$ from zooplankton $\left(\mathrm{s}^{-1}\right)$;

s: removal rate of $\mathrm{P}$ by zooplanktonic sinking particles (fecal pellets and matter, molts, etc...), $\mathrm{s}^{-1}$.

A similar equation is written for ${ }^{33} \mathrm{P}$. It is assumed in equation (4.1) that zooplankton acquire ${ }^{32} \mathrm{P}$ and ${ }^{33} \mathrm{P}$ from the grazing of phytoplankton and assimilate the isotopes in the proportions occurring in phytoplankton. Thus the activity ratio ${ }^{33} \mathrm{P} /{ }^{32} \mathrm{P}$ in zooplankton is the following:

Where

$$
\text { (4.2) } \quad R_{z}=R_{p}\left(\lambda_{32}+r+s\right) /\left(\lambda_{33}+r+s\right)
$$

$$
\begin{aligned}
& \mathrm{R}_{\mathrm{z}}=\left({ }^{33} \mathrm{P}\right) /\left({ }^{32} \mathrm{P}\right) \mathrm{z} \text { : activity ratio }{ }^{33} \mathrm{P} /{ }^{32} \mathrm{P} \text { in zooplankton } \\
& \mathrm{R}_{\mathrm{p}}=\left({ }^{33} \mathrm{P}\right) /\left({ }^{32} \mathrm{P}\right)_{\mathrm{p}}: \text { activity ratio }{ }^{33} \mathrm{P} / \mathrm{j}^{2} \mathrm{P} \text { in phytoplankton }
\end{aligned}
$$

From equation (4.2) one can calculate $\mathrm{r}+\mathrm{s}$ as follows:

$$
\text { (4.3) } \mathrm{r}+\mathrm{s}=\left(\lambda_{32}-\lambda_{33} * \mathrm{R}_{\mathrm{z}} / \mathrm{R}_{\mathrm{p}}\right) /\left(\mathrm{R}_{\mathrm{Z}} / \mathrm{R}_{\mathrm{p}}-1\right)
$$

This model predicts that the ratio in zooplankton ranges from $R_{p}$ to a maximum value of $1.77 R_{p}$ according to the magnitude of $r$ and $s$ relative to $\lambda_{32}$ and $\lambda_{33}$. The residence time of $\mathrm{P}$ in zooplankton, $\tau$, is then simply derived as follows:

$$
\text { (4.4) } \tau=1 /(\mathrm{r}+\mathrm{s})
$$

From equation (4.1) one can calculate the grazing rate as follows:

(4.5) $\mathrm{g}=\left({ }^{32} \mathrm{P}\right)_{\mathrm{z}} /\left({ }^{32} \mathrm{P}\right)_{\mathrm{p}}\left(\lambda_{32}+1 / \tau\right)$ and,

(4.6) $\mathrm{g}=\left({ }^{3} \mathrm{P}\right)_{\mathrm{z}} /\left({ }^{3}{ }^{3} \mathrm{P}\right)_{\mathrm{p}}\left(\lambda_{33}+1 / \tau\right)$

In July, the average activity ratio in zooplankton was $1.31 \pm 0.19$. I did not include the high value of $1.79 \pm 0.44$ in the calculation of the average because that high ratio was measured less precisely than the two others (Table 4.3). The measured activity ratio of $0.75 \pm 0.23$ in the suspended particles was found to be, within the error, similar to the ratio in the rain (Figure 4.5). The average activity ratio in rain for the three months that preceded the July 1991 cruise (BATS 34) was $0.92 \pm 0.04$. Therefore a value of 0.92 , was chosen for the activity ratio in suspended particles. A residence time of $\tau=45_{-37}^{+85}$ 
days is estimated for the plankton tow in July 1991, assumed to be mostly composed of macrozooplankton. This residence time is similar to the estimated residence times of $\mathrm{P}$ in zooplankton of 30-40 days or more in the California Bight (Lal et al., 1988). The estimated $\tau$ is also within the range of turnover times of single species of zooplankton which have been estimated previously based on the ratio of the production rate to the biomass. The results of some of these studies are summarized by Tranter (1976) and Sheldon et al. (1972). The turnover time of zooplankton ranges from a few days to hundreds of days and is to a first approximation positively correlated with the diameter of the particles (Sheldon et al., 1972). Large boreal species exhibited turnover times of about 100 days, while temperate smaller species had turnover times of about 10 days.

In suspended particles, the specific activities were $2.99 \pm 0.50 \mathrm{dpm} / \mathrm{mg} P$ for ${ }^{32} \mathrm{P}$ and and $2.24 \pm 0.52 \mathrm{dpm} / \mathrm{mg} \mathrm{P}$ for ${ }^{33} \mathrm{P}$. In macrozooplankton, the specific activities were $0.90 \pm 0.07 \mathrm{dpm} / \mathrm{mg} P$ for ${ }^{32} \mathrm{P}$ and $1.21 \pm 0.14 \mathrm{dpm} / \mathrm{mg} \mathrm{P}$ for ${ }^{33} \mathrm{P}$. Grazing rates of $0.021 \pm 0.006 \mathrm{~d}^{-1}$ for ${ }^{32} \mathrm{P}$ and $0.027 \pm 0.009 \mathrm{~d}^{-1}$ for ${ }^{33} \mathrm{P}$ were determined utilizing equations (4.5) and (4.6); or an average grazing rate of $0.024 \pm 0.006 \mathrm{~d}^{-1}$. Particulate organic carbon (POC) concentrations yield a value of $30 \mu \mathrm{g} \mathrm{C} / \ell$ in the $150-\mathrm{m}$ euphotic zone, for BATS 34 (15-19 July 1991). An integrated value of $4,500 \mathrm{mg} \mathrm{C} / \mathrm{m}^{2}$ was calculated for the euphotic zone for that cruise. The flux of carbon grazed by macrozooplankton was thus estimated to be $110 \pm 30 \mathrm{mg} \mathrm{C} / \mathrm{m}^{2} / \mathrm{d}$. In July 1991 primary productivity was $500 \mathrm{mg} \mathrm{C} / \mathrm{m}^{2} / \mathrm{d}$ at BATS station (Michaels et al., 1992); thus the estimated grazing flux corresponded to $20 \pm 5 \%$ of primary productivity. This result is within the range of the percent of primary productivity grazed by a copepod community on the outer shelf off Long Island (Dagg and Turner, 1982) and on the outer and mid shelf of the Bering Sea (Dagg et al., 1982).

Assuming that zooplankton have assimilation efficiencies ranging from 30 to $70 \%$ (Angel, 1984; Dagg et al., 1982), I estimate a flux of 30 to $80 \mathrm{mg} \mathrm{C} / \mathrm{m}^{2} / \mathrm{d}$ out of the euphotic zone due to defecation of zooplankton in July 1991. Although assimilation 
efficiencies of zooplankton vary with the constituent and the food type (Corner and Davies, 1971), $70 \%$ is often considered to be a reasonable assimilation efficiency (Angel 1984; Dagg et al., 1982). In that case, I estimate that $30 \pm 10 \mathrm{mg} \mathrm{C} / \mathrm{m}^{2} / \mathrm{d}$ leaves the euphotic zone by defecation of zooplankton. This second estimate is in very good agreement with the flux of particulate carbon of $35 \mathrm{mg} \mathrm{C} / \mathrm{m}^{2} / \mathrm{d}$, determined by sediment traps deployed at $150 \mathrm{~m}$ at BATS station in July 1991 (Michaels et al., 1992). If the sediment trap flux is accurate my results suggest that fecal pellets or fecal matter constitute a major component of the particulate flux in the upper ocean at BATS. It has been recognized that fecal material is a major source of particulate matter in the ocean (Pomeroy and Diebel, 1980; Fowler and Knauer, 1986; Small et al., 1987), and some studies have shown that it made up the bulk of the particulate flux in certain areas like the Panama Basin and the equatorial Atlantic Ocean (Bishop et al., 1977; Bishop et al., 1986b).

In May 1991 the ratio ${ }^{33} \mathrm{P} /{ }^{32} \mathrm{P}$ in plankton tows was $1.4 \pm 0.1$. The ratio in the suspended particles was not measured. It is suggested from figure 3.5 that the ratio in suspended particles must range from a minimum value of 1.0 , the ratio in rain, to a maximum of 1.4, the ratio in the plankton tows. If a ratio of $1.02 \pm 0.03$ is assumed (the average ratio in the rain in the spring), a residence time of $40_{-17}^{+30}$ days is estimated for May 1991. This estimate is in agreement with previous estimates made in the California Bight (Lal et al., 1988) and consistent with turnover times of various species of zooplankton (Sheldon et al., 1972 and Tranter, 1976).

In November 1991 the ratios in both suspended matter and zooplankton were the same. Therefore a lower estimate of a few days was estimated for the residence time of $\mathrm{P}$ in plankton. In November 1991, Trichodesmium was very abundant in two tows (i.e., Z67-10 and Z300-10) and was present in all the tows. The presence of 
Trichodesmium in the tows might explain the similarity of the ratios between the suspended matter and the plankton tows in November 1991.

In February 1992, the activity ratio in suspended matter was $0.93 \pm 0.3$ and, on average, about $3.3 \pm 0.5$ in plankton tows. The previous end-member model can not explain the high ratios observed in plankton tows. It can only account for ratios in zooplankton ranging from $0.9-1.0$ to $1.5-1.8$. An extreme scenario is presented in which zooplankton acquire P early in their growth cycle and store it. Radiophosphorus would decay as zooplankton, assumed to be a "closed system", become older. The ratio can be predicted by the following relationship:

$$
\text { (4.7) } \mathrm{R}_{\mathrm{z}}=\mathrm{R}_{\mathrm{p}} \exp \left(\left(\lambda_{32}-\lambda_{33}\right) \tau\right)
$$

The residence time given by equation (4.7) represents the age of zooplankton. Equation (4.7) yields a residence time of $P$ in zooplankton of $60 \pm 12$ days for February 1992. It means that for two months prior to the cruise (December and January) radiophosphorus in zooplankton was decaying without significant exchange with the environment. In winter, when food is scarce, feeding activities are likely to be reduced, and zooplankton are likely to retain phosphorus. This is consistent with the evidence of a direct link between food availability and excretion (Corner and Davies, 1971). The residence time of 60 days is probably an upper limit, because it is unlikely that zooplankton were completely isolated from the environment for two months.

\section{5- Mass balance of ${ }^{32} \mathrm{P}$ and ${ }^{33} \mathrm{P}$ in the euphotic zone}

In this section, the inventories of ${ }^{32} \mathrm{P}$ and ${ }^{33} \mathrm{P}$ in the suspended particles are determined. The decay of the inventories in suspended matter is then compared to the wet deposition rates. For most of the cruises, except April 1992, the depth profiles of the activities of ${ }^{32} \mathrm{P}$ and ${ }^{33} \mathrm{P}$ in suspended matter were not obtained. The profiles of ${ }^{32} \mathrm{P}$ 
and ${ }^{33} \mathrm{P}$ in suspended particles for April 1992 (Figure 4.2 and 4.3) were fitted with empirical exponential functions given as follows:

$$
\begin{aligned}
& \text { (4.8) }{ }^{32} \mathrm{P}=1.00 \exp (-\mathrm{z} / 67.7) \\
& \text { (4.9) }{ }^{33} \mathrm{P}=1.68 \exp (-\mathrm{z} / 74.2)
\end{aligned}
$$

Where

$$
\left({ }^{3}{ }^{2} \mathrm{P}\right)_{\mathrm{z}=0}=1.00 \mathrm{dpm} / \mathrm{m}^{3} \text { and }\left({ }^{3}{ }^{3} \mathrm{P}\right)_{\mathrm{z}=0}=1.68 \mathrm{dpm} / \mathrm{m}^{3}
$$

Each exponential was then integrated from the surface to $150 \mathrm{~m}$, the depth of the euphotic zone, to calculate the activities in the euphotic zone. It is observed that the depth profiles of the specific activities of ${ }^{32} \mathrm{P}$ and ${ }^{33} \mathrm{P}$ in suspended particles have decreasing trends with depth which are very similar to one another and similar to the $\mathrm{T}$ profile (Figure 4.12 a). For July 1991 and November 1992 (BATS 34 and 38), I assumed that ${ }^{32} \mathrm{P}$ and ${ }^{33} \mathrm{P}$ activities in suspended matter at any depth in the mixed layer were identical to the activities at the surface. I also assumed that the activities of ${ }^{32} \mathrm{P}$ and ${ }^{33} \mathrm{P}$ in suspended matter, below the mixed layer, decreased exponentially. In February 1992 (BATS 41A) there was intense vertical mixing within the upper $250 \mathrm{~m}$ of the ocean and constant activities of ${ }^{32} \mathrm{P}$ and ${ }^{33} \mathrm{P}$ in the mixed layer $(210 \mathrm{~m})$ could not be assumed. No inventory computation was pursued for that cruise. The inventories of ${ }^{32} \mathrm{P}$ and ${ }^{33} \mathrm{P}$ in the euphotic zone are reported in table 4.8 for July 1991, November 1991, and April 1992.

The inventories of ${ }^{32} \mathrm{P}$ and ${ }^{33} \mathrm{P}$ in suspended particles are then compared to the amount of ${ }^{32} \mathrm{P}$ and ${ }^{33} \mathrm{P}$ delivered by precipitation. The wet deposition rates of ${ }^{32} \mathrm{P}$ and ${ }^{33} \mathrm{P}$ can depart significantly from the annual average rates by factors of up to three. The deposition rates were computed from the average activities and rainfall rates over a period of three months preceding the cruises. Three months, or four times the half-life of the longer-lived radiophosphorus isotope, corresponded to the period prior to which the activities of ${ }^{32} \mathrm{P}$ and ${ }^{33} \mathrm{P}$ in rain could not remain detectable in particulate matter at the 
time of sampling. Since May 1991 was such a dry month, it was assumed as a first approximation that events prior to June 1991 would not be detectable in mid-July 1991 (BATS 34) and were thus not taken into account in the calculation. For April 1992 (EN 235 ) the wet deposition rates used are the annual averages since no rain data were collected after March 26, 1992 (one month before the sampling time). The wet deposition rates of ${ }^{32} \mathrm{P}$ and ${ }^{33} \mathrm{P}$ so computed are listed in table 4.8.

The differences between the wet deposition rates and the decay of the inventories of ${ }^{32} \mathrm{P}$ and ${ }^{33} \mathrm{P}$ are computed (Table 4.8). It is found that the decays of the inventories of ${ }^{32} \mathrm{P}$ and ${ }^{33} \mathrm{P}$ in suspended particles are in balance with the wet deposition rates of ${ }^{32} \mathrm{P}$ and ${ }^{33} \mathrm{P}$ in July 1991, November 1991, and April 1992 in the euphotic zone. This result suggests that, (1) removal of ${ }^{32} \mathrm{P}$ and ${ }^{33} \mathrm{P}$ onto sinking particles (new production) and removal due to vertical mixing at the base of the euphotic zone must be very small, and (2) most of the inventories of ${ }^{32} \mathrm{P}$ and ${ }^{33} \mathrm{P}$ are in the suspended particles. The balance between the deposition rates of ${ }^{32} \mathrm{P}$ and ${ }^{33} \mathrm{P}$ and the decays of the inventories indicates that the residence time of $\mathrm{P}$ in the euphotic zone must be longer than 4 or 5 half-lives of ${ }^{32} \mathrm{P}$ and ${ }^{33} \mathrm{P}$ or about 100 days. The estimated lower limit for the residence time is consistent with the range of 0.7 to 2 years estimated by OrmazaGonzalez (1990).

The results indicate that ${ }^{32} \mathrm{P}$ and ${ }^{33} \mathrm{P}$ inventories must be very low in the dissolved pools of P, i.e. DIP and DOP. These findings contrast with previous studies in the Southern California Bight showing that most of the inventory of ${ }^{32} \mathrm{P}$ is in the TDP (Lal and Lee, 1988; Lal et al., 1988). In the Southern California Bight, DIP is usually the major pool of dissolved $\mathrm{P}$ with a range of concentartions of 0.1 to $2 \mu \mathrm{M}$ while DOP ranges from 0.1 to $0.8 \mu \mathrm{M}$ (Lee et al., 1991; Lee et al., 1992). These values of DOP are consistent with the DOP range in the Pacific ocean, i.e. 0.1-0.4 $\mu \mathrm{M}$ (Orrett and Karl, 1987; Jackson and William, 1985; Ridal and Moore, 1992). In contrast, at Hydrostation S, DIP is a very small pool with concentrations ranging from below $1 \mathrm{nM}$ to $30 \mathrm{nM}$, 
while DOP is the major dissolved pool of phosphorus with 100-250 nM P (OrmazaGonzalez, 1990). The DOP values found off Bermuda are also consistent with the values found by Ridal and Moore (1990) in a Gulf Stream station. If most of the inventories of ${ }^{32} \mathrm{P}$ and ${ }^{33} \mathrm{P}$ are in PTP at BATS station, as indicated by the mass balance, then it suggests that the residence time of $\mathrm{P}$ in DOP is long relative to the half-lives of ${ }^{32} \mathrm{P}$ and ${ }^{33} \mathrm{P}$. A lower limit for the residence time of $\mathrm{P}$ is estimated to be four or five times the half-life of ${ }^{33} \mathrm{P}$, i.e., $100-120$ days. These estimates agree with previous studies which showed that only a small fraction of the ${ }^{32} \mathrm{P}$ activity was found in DOP, i.e., $<0-0.09$ $\mathrm{dpm} / \mathrm{m}^{3}$ (Lee et al., 1992), leading the authors to conclude that the mean time period of DOP utilization is much longer than 6 weeks in the Southern California Bight.

Cosmogenic ${ }^{32} \mathrm{P}$ and ${ }^{33} \mathrm{P}$ studies give a somewhat different picture of DOP availability than previous studies, because they allow computation of rates and turnover times. There is evidence that DOP is a labile pool, more so than DON (Jackson and Williams, 1985; Smith et al., 1986, Smith et al., 1985; Orrett and Karl, 1987) and that all DOP is available to the microbiological community in the subarctic Pacific (Ridal and Moore, 1992). In addition, it has been well documented that marine bacteria and phytoplankton have evolved cell-surface enzymes that are capable of cleaving organic $\mathrm{P}$ compounds (Perry, 1972; Azam and Hodson, 1977; Cembella et al., 1984; Ammerman and Azam, 1985; Rivkin and Swift, 1985). One of these enzymes, alkaline phosphatase, has been detected at Hydrostation $\mathrm{S}$ in activities high enough possibly to hydrolyse all the DOP present in the euphotic zone (Ormaza-Gonzalez, 1990). The important question regarding the role of DOP in contributing to phytoplankton growth and new production is the rate of turnover of DOP. Cosmogenic ${ }^{32} \mathrm{P}$ and ${ }^{33} \mathrm{P}$ provide insight regarding that question on time scales of days to weeks. 
Table 4.7. Activities of ${ }^{32} \mathrm{P},{ }^{33} \mathrm{P}$ and concentrations of $\mathrm{P}$ in suspended matter $(>3-8 \mu \mathrm{m})$ at BATS station.

\begin{tabular}{|c|c|c|c|c|c|c|}
\hline Sample & Cruise & $\begin{array}{l}\text { Initial } \\
\text { amount of } \\
\text { P in the } \\
\text { sample } \\
\text { mg P }\end{array}$ & $\begin{array}{c}\text { Volume } \\
\text { of water } \\
\text { pumped } \\
\ell\end{array}$ & $\begin{array}{l}\text { Stable P } \\
\text { suspended } \\
\text { matter } \\
\mathrm{nM}\end{array}$ & $\begin{array}{l}{ }^{32} \mathrm{P} \\
\mathrm{dpm} / \mathrm{m}^{3}\end{array}$ & $\begin{array}{l}{ }^{33} \mathrm{P} \\
\mathrm{dpm} / \mathrm{m}^{3}\end{array}$ \\
\hline M1 & BATS 34 & $0.64 \pm 0.01$ & $2,230 \pm 30$ & $9.2 \pm 0.3$ & 0.86 & 0.64 \\
\hline M-S1 & BATS 38 & $1.08 \pm 0.02$ & $3,970 \pm 10$ & $8.8 \pm 0.2$ & 0.55 & 0.89 \\
\hline M-S2 & BATS 38 & $0.78 \pm 0.01$ & $3,040 \pm 40$ & $8.3 \pm 0.2$ & 0.62 & 1.13 \\
\hline M2 & BATS41A & $1.48 \pm 0.03$ & $5,100 \pm 25$ & $9.4 \pm 0.2$ & 0.29 & 0.27 \\
\hline M-0 & EN 235 & $2.93 \pm 0.06$ & $7,400 \pm 150$ & $12 . \underline{8}+0.5$ & 0.81 & 1.34 \\
\hline M-35 & EN 235 & $3.01 \pm 0.06$ & $5,360 \pm 40$ & $18.1 \pm 0.9$ & 0.60 & 1.18 \\
\hline M-70 & EN 235 & $3.22 \pm 0.06$ & $5,520 \pm 80$ & $19 \pm 1$ & 0.44 & 0.77 \\
\hline
\end{tabular}

Table 4.8. Activities (A), wet deposition rates $(\mathrm{W})$ and radioactive decay $(\lambda \mathrm{A})$ of ${ }^{32} \mathrm{P}$ and ${ }^{33} \mathrm{P}$, and differences between the wet deposition rates and the decay of ${ }^{32} \mathrm{P}$ and ${ }^{33} \mathrm{P}$ (i.e., $\left.\mathrm{W}-\lambda \mathrm{A}\right)$ in the euphotic zone.

\begin{tabular}{|c|c|c|c|c|c|c|c|c|}
\hline \multirow{2}{*}{\multicolumn{2}{|c|}{$\begin{array}{l}\text { Cruise } \\
\qquad{ }^{32} \mathrm{~A}\end{array}$}} & \multicolumn{5}{|c|}{$\lambda \mathrm{A}$} & \multicolumn{2}{|c|}{$\mathrm{W}-\lambda \mathrm{A}$} \\
\hline & & $\mathrm{dpm} / \mathrm{m}^{2}$ & $\mathrm{dpm} / \mathrm{m}^{2} / \mathrm{d}$ & $\begin{array}{l}{ }^{33} \mathrm{~W} \\
{ }^{2} / \mathrm{d}\end{array}$ & $\begin{array}{l}{ }^{32} \mathrm{P} \\
\mathrm{dpm}\end{array}$ & $\begin{array}{l}{ }^{33} \mathrm{P} \\
/ \mathrm{d}\end{array}$ & $\begin{array}{l}{ }^{32} \mathrm{P} \\
\mathrm{d}\end{array}$ & $\begin{array}{l}{ }^{33} \mathrm{P} \\
\mathrm{m}^{2} / \mathrm{d}\end{array}$ \\
\hline TS 34 & 45 & 36.4 & $1.7 \pm 0.3$ & $1.4 \pm 0.3$ & 2. & 1.0 & 0 & 0 \\
\hline TS 38 & 47 & 72.9 & $2.5 \pm 0.5$ & $2.2 \pm 0.4$ & 2. & 2.0 & 0 & 0 \\
\hline 235 & 61 & 108 & $2.4 \pm 0.4$ & $2.2 \pm 0.4$ & 3 & 3.0 & 0 & 0 \\
\hline
\end{tabular}




\section{CONCLUSIONS}

The specific activities ${ }^{32} \mathrm{P}$ and ${ }^{33} \mathrm{P}$ and the activity ratio ${ }^{33} \mathrm{P} /{ }^{32} \mathrm{P}$ in rainwater, suspended particles and plankton tows allowed determination of the in situ turnover time of $\mathrm{P}$ in macrozooplankton and the in situ grazing rates. The turnover time of $P$ in macrozooplankton was found to range from 40 days to 60 days at BATS station. In some cruises, the plankton tows were presumably dominated by large phytoplanktonic species as evidenced by the low ratios. The estimated turnover times of $\mathrm{P}$ in plankton tows are consistent with the estimates of doubling times of species of zooplankton.

An in situ grazing rate of $0.024 \pm 0.006 \mathrm{~d}^{-1}$ was determined, and it was estimated that $30 \pm 10 \mathrm{mg} \mathrm{C} / \mathrm{m}^{2} / \mathrm{d}$ left the euphotic zone by zooplankton defecation in July 1991 at BATS. The estimated particulate flux matchs the bulk of the particulate carbon flux determined by sediment traps deployed at $150 \mathrm{~m}$ at BATS, suggesting that zooplankton fecal matter made up the bulk of the particulate flux at BATS.

The decay of the inventories of ${ }^{32} \mathrm{P}$ and ${ }^{33} \mathrm{P}$ in suspended particles was found to balance the input of ${ }^{32} \mathrm{P}$ and ${ }^{33} \mathrm{P}$ by precipitation, suggesting that turnover of DOP, which is the major pool of dissolved $\mathrm{P}$, is long relative to the half-lives of ${ }^{32} \mathrm{P}$ and ${ }^{33} \mathrm{P}$. 

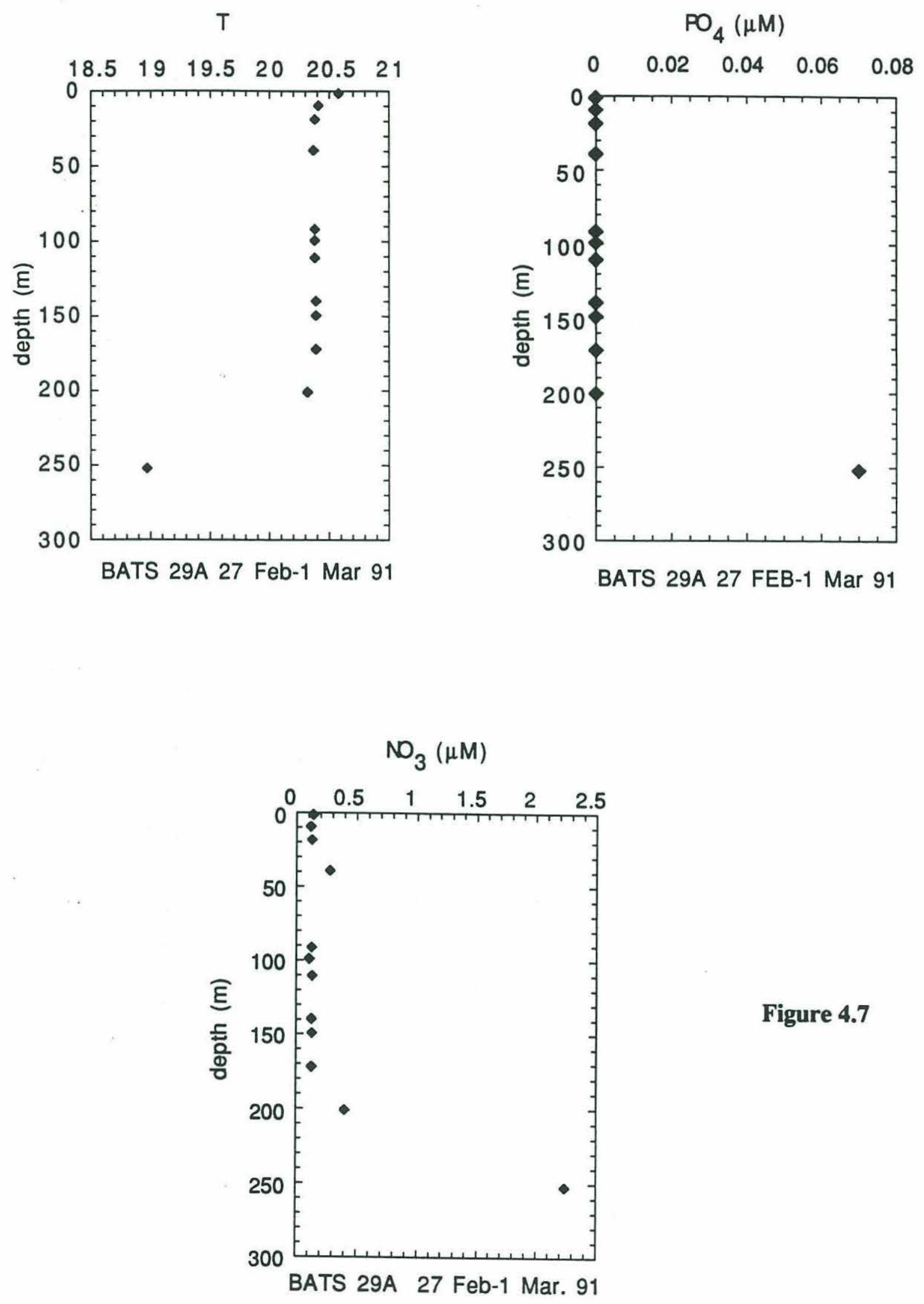

Figure 4.7 

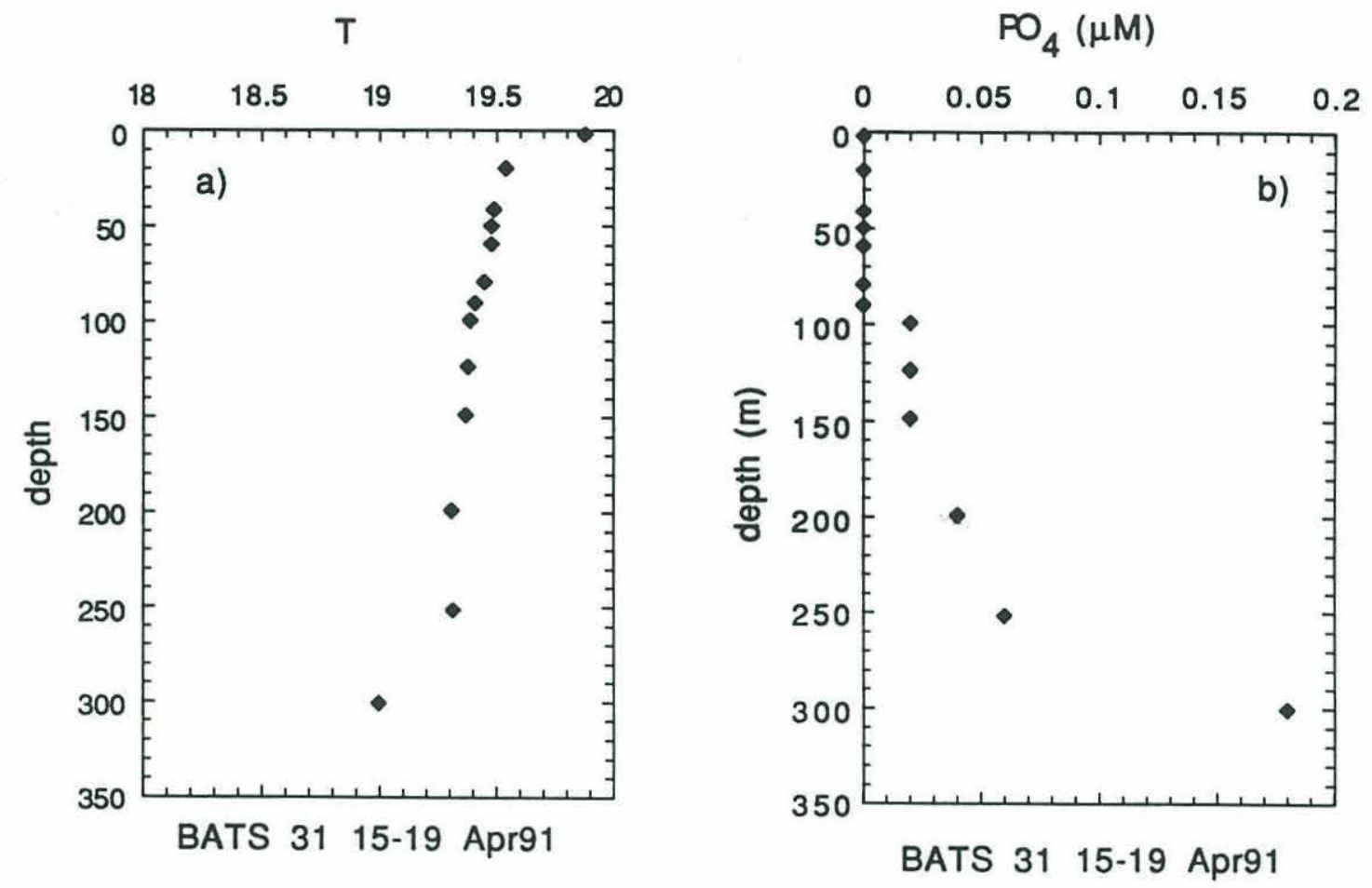

Figure 4.8

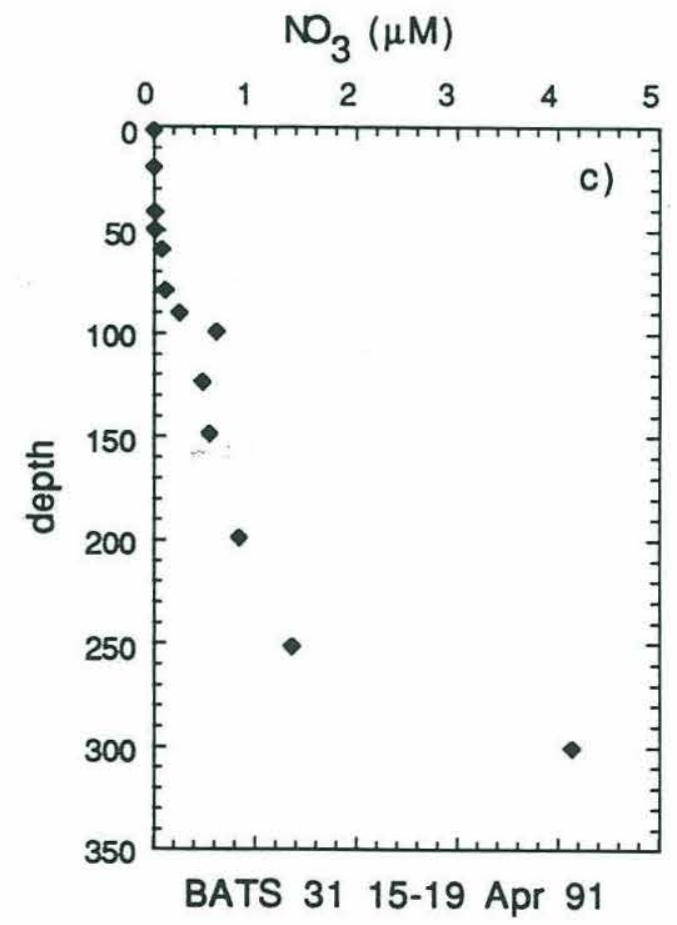



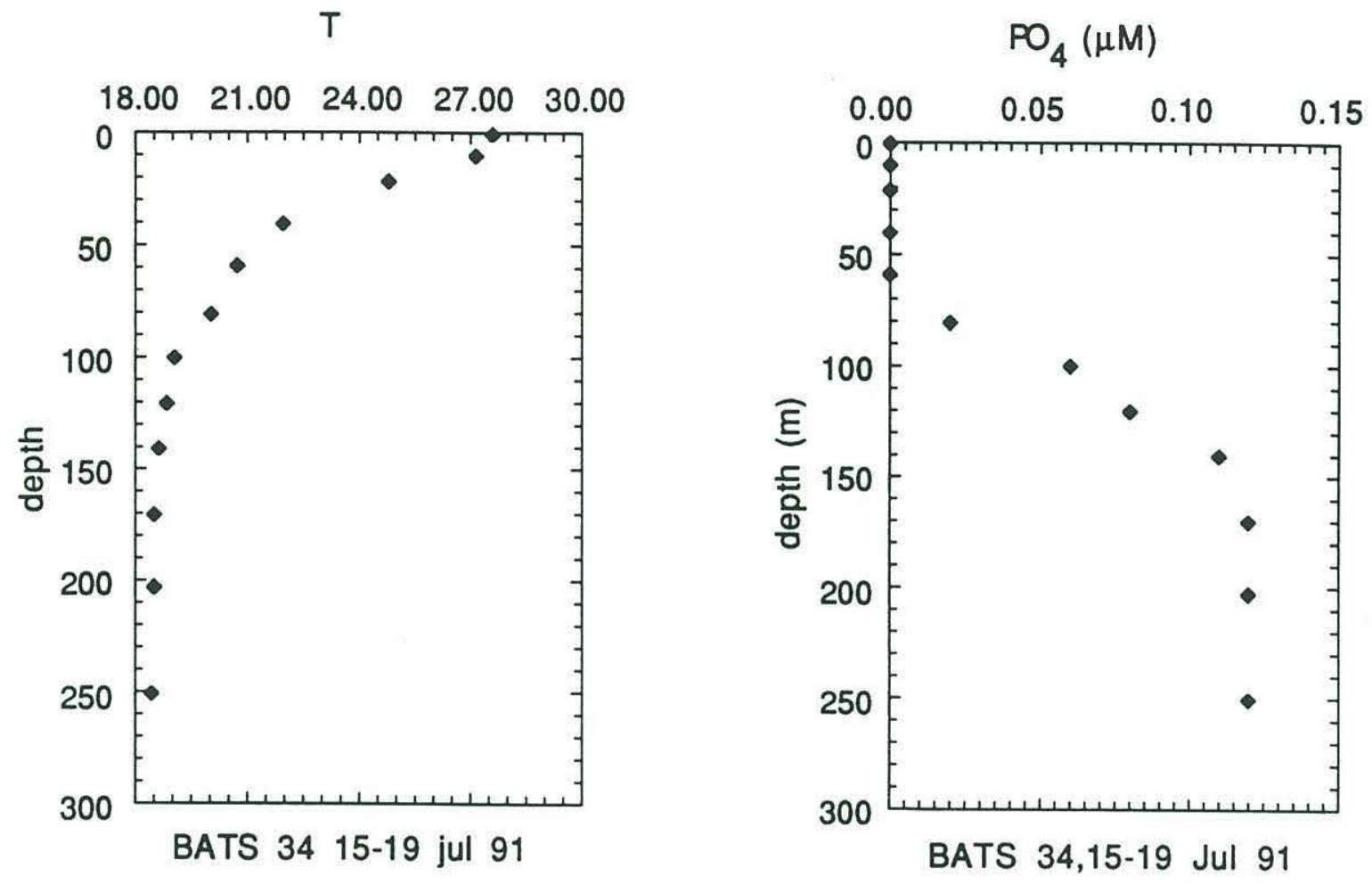

Figure 4.9
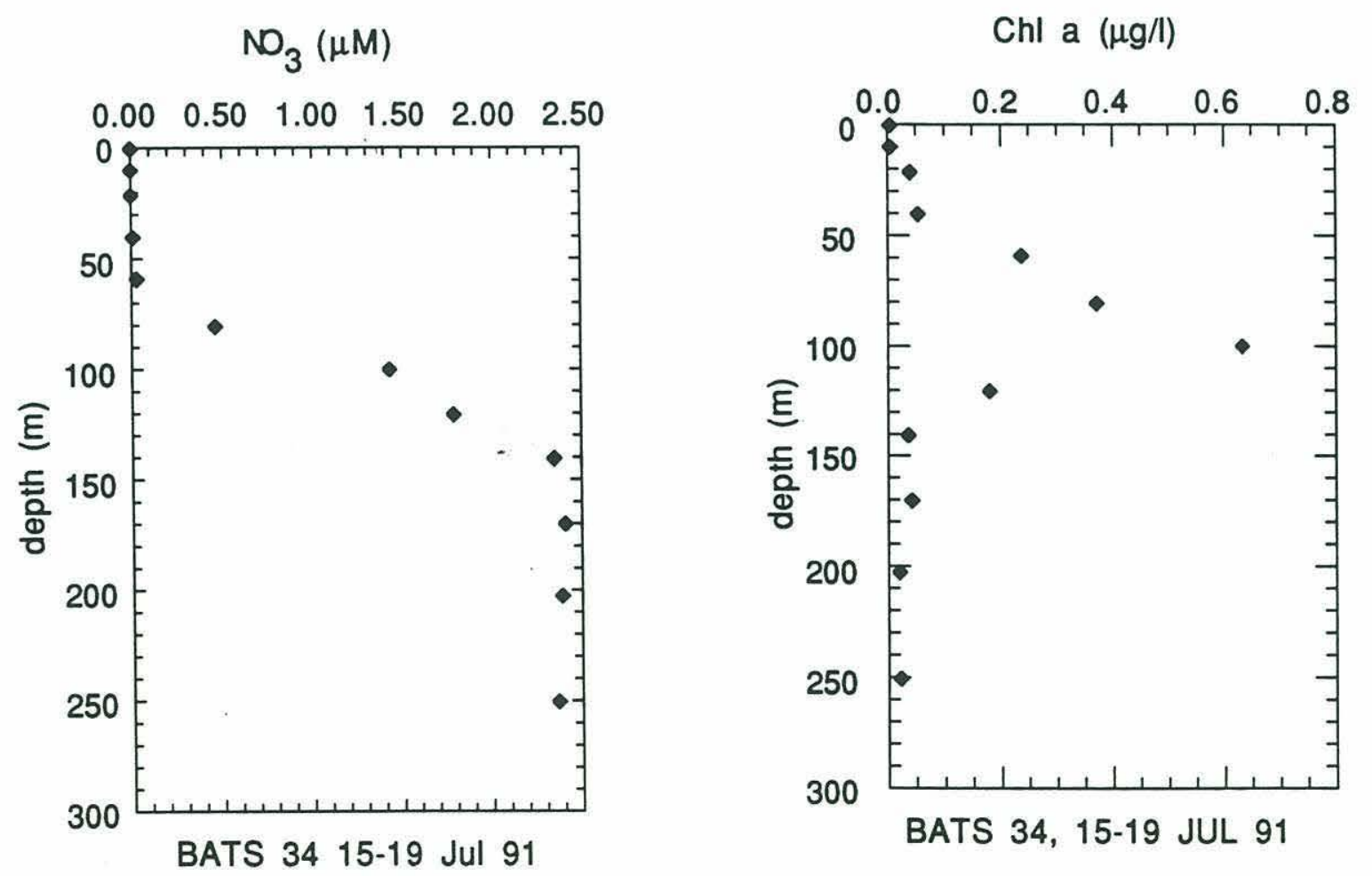

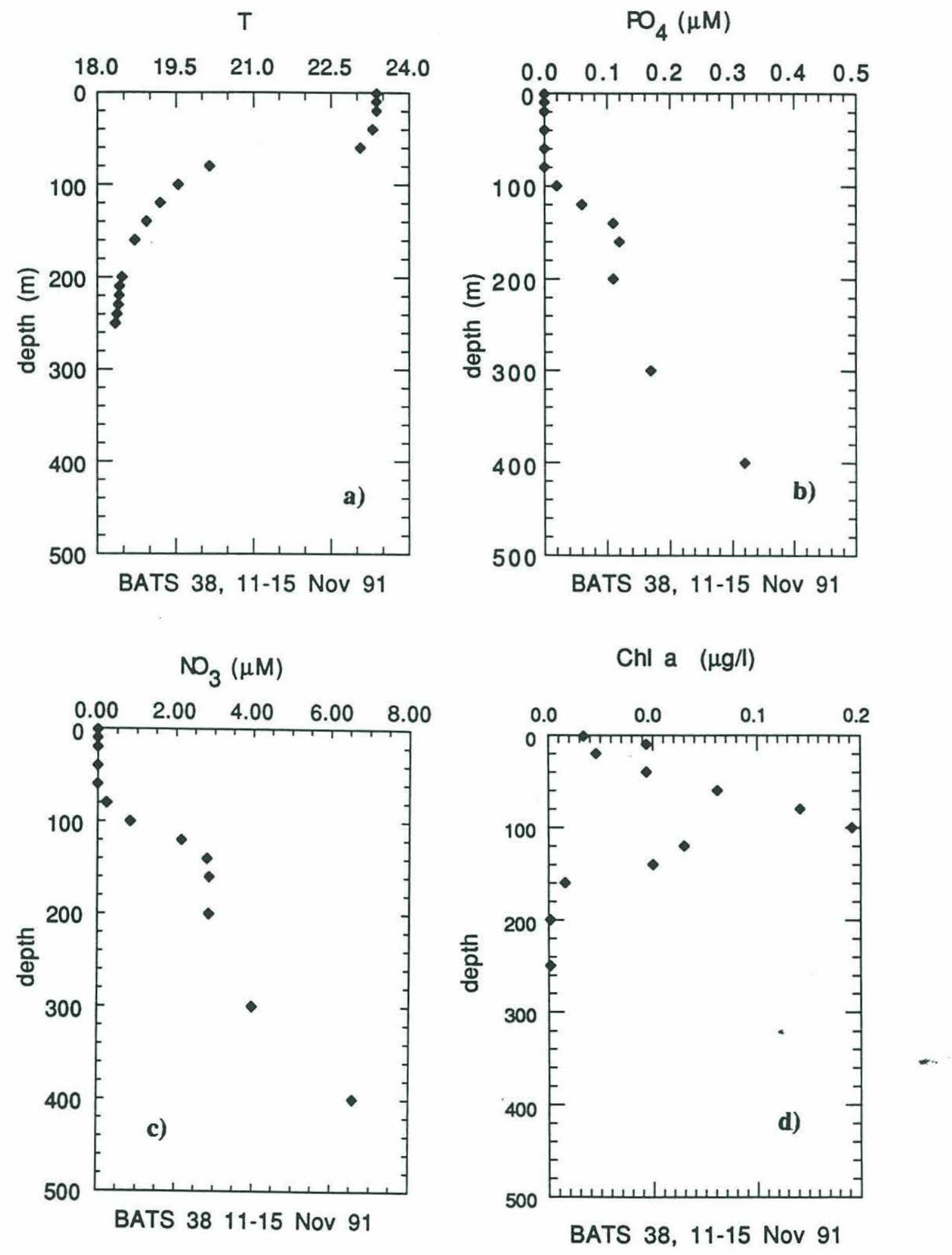

Figure 4.10 

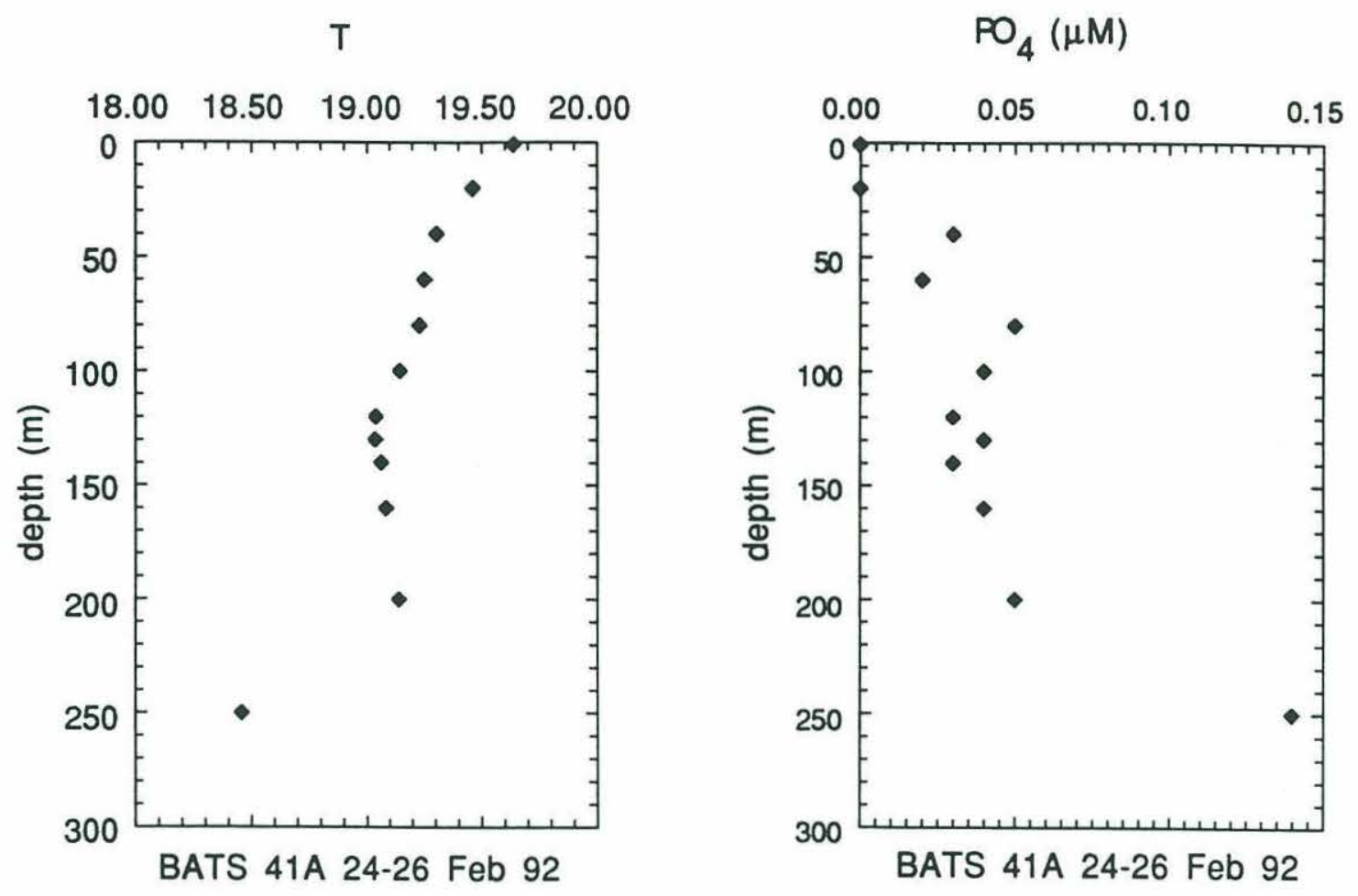

Figure 4.11
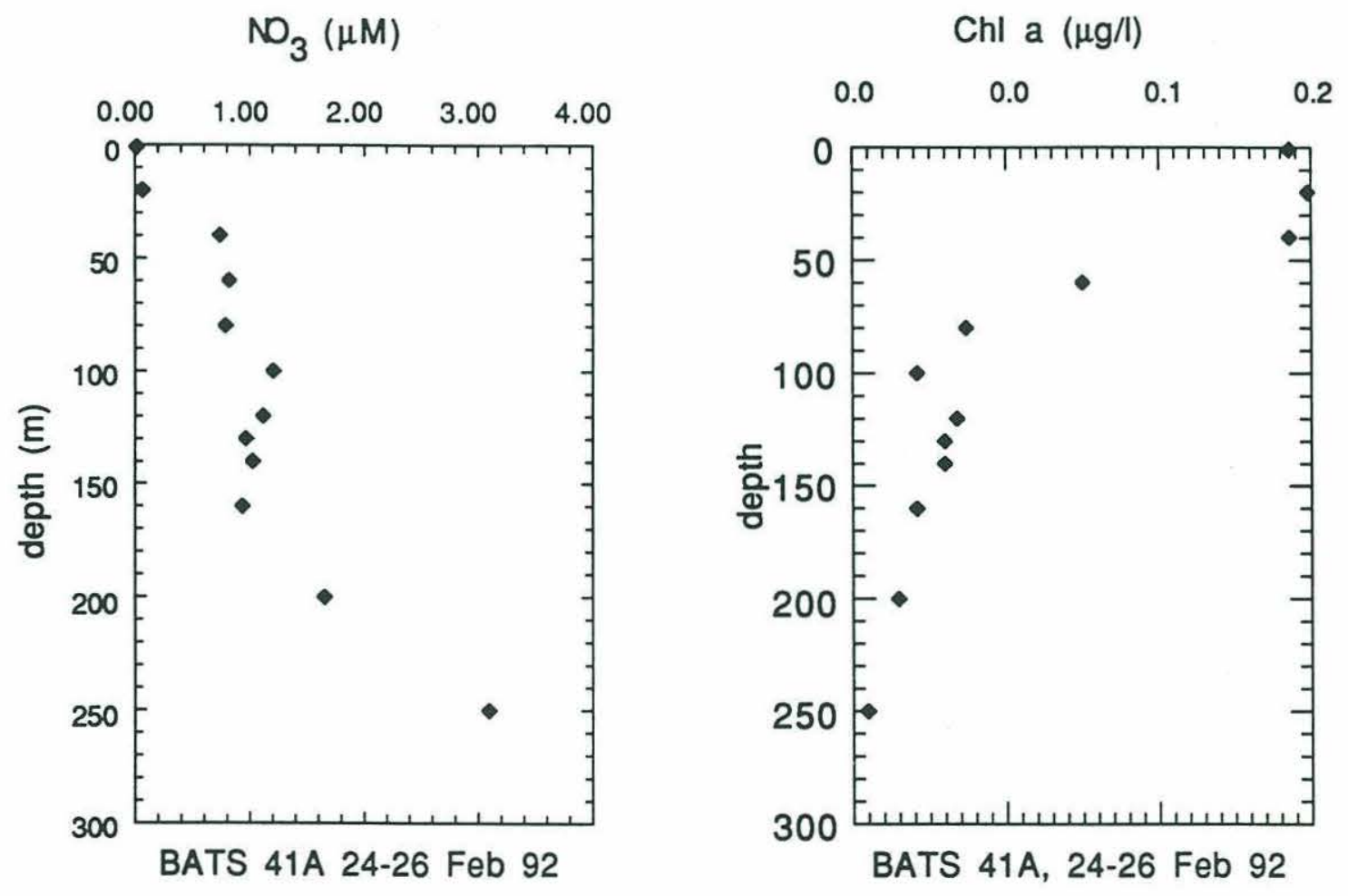


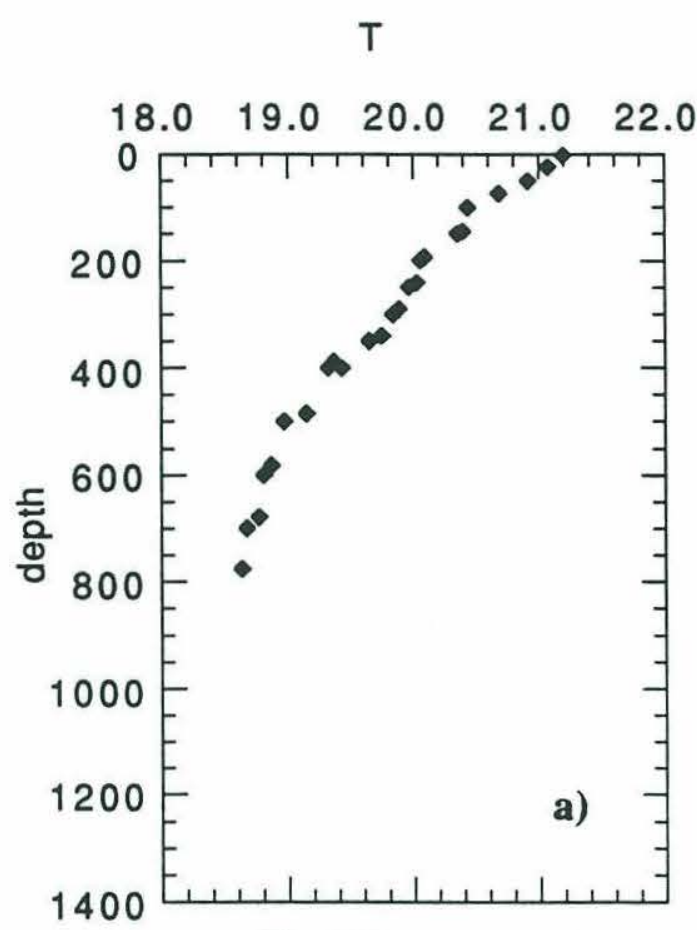

EN 235, 23 Apr 92

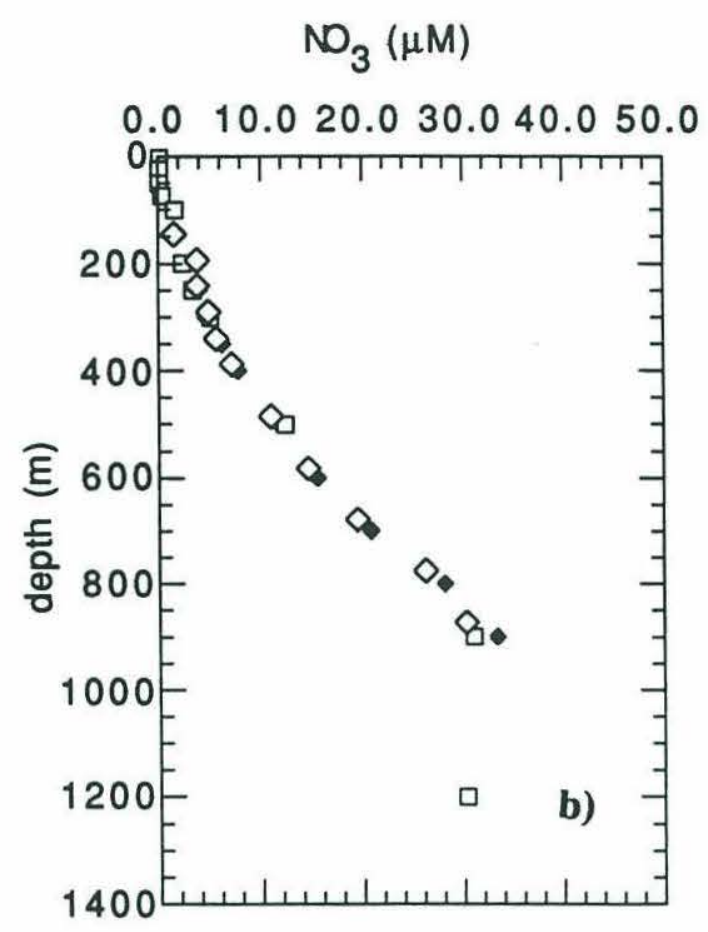

EN 235, 23-26 Apr 92

Figure 4.12 
Table 4.1. Specific activities of ${ }^{32} \mathrm{P}$ and ${ }^{33} \mathrm{P}$ and activity ratio ${ }^{33} \mathrm{P} /{ }^{32} \mathrm{P}$ in plankton tows collected with a 67- $\mu \mathrm{m}$ plankton net in March 1991.

\begin{tabular}{|c|c|c|c|c|c|c|c|}
\hline Sample & Date & Depth & Type & $\begin{array}{l}\text { Amount of } \\
\text { stable P } \\
\text { mg P }\end{array}$ & $\begin{array}{l}\text { Specific } \\
\text { activity } \\
\text { of }{ }^{32} \mathrm{P} \\
\mathrm{dpm} / \mathrm{mg} \mathrm{P}\end{array}$ & $\begin{array}{l}\text { Specific } \\
\text { activity } \\
\text { of }{ }^{33} \mathrm{P} \\
\mathrm{dpm} / \mathrm{mg} \mathrm{P}\end{array}$ & $\begin{array}{l}\text { Ratio } \\
{ }^{3}{ }^{3} \mathrm{P}^{3}{ }^{2} \mathrm{P} \\
\text { dpm/dpm }\end{array}$ \\
\hline $\mathrm{L}+$ & $3 / 4 / 91$ & surface & tow & I & 1 & 1 & $1.7 \pm 0.5$ \\
\hline Z67-R1* & $3 / 4 / 91$ & surface & tow & $0.99 \pm 0.02$ & $1.30 \pm 0.35$ & $5.2 \pm 1.2$ & $4.0 \pm 1.2$ \\
\hline Z67-R2* & $3 / 4 / 91$ & surface & tow & $1.09 \pm 0.02$ & $1.7 \pm 0.9$ & $1.12 \pm 0.30$ & $0.67 \pm 0.19$ \\
\hline Z67-R3* & $3 / 4 / 91$ & surface & tow & $0.90 \pm 0.02$ & $0.30 \pm 0.65$ & $7.5 \pm 1.1$ & $18.7 \pm 12.5$ \\
\hline Z67 & $3 / 31 / 91$ & surface & tow & $1.66 \pm 0.03$ & $0.81 \pm 0.09$ & $0.49 \pm 0.08$ & $0.61 \pm 0.16$ \\
\hline
\end{tabular}

+: labile fraction of the three tows combined. The initial amount of phosphate is not known, thus making it impossible to determine the yield in that sample.

*: refractory fractions.

Table 4.2. Specific activities of ${ }^{32} \mathrm{P}$ and ${ }^{33} \mathrm{P}$ and activity ratio ${ }^{33} \mathrm{P} /{ }^{32} \mathrm{P}$ in plankton tows collected with a $300-\mu \mathrm{m}$ mesh net in 29 April- 1 May. The samples are triplicates from the same tow.

\begin{tabular}{|c|c|c|c|c|c|c|c|}
\hline Sample & Date & Depth & Type & $\begin{array}{l}\text { Amount of } \\
\text { stable P } \\
\text { mg P }\end{array}$ & $\begin{array}{l}\text { Specific } \\
\text { activity } \\
\text { of }{ }^{32} \mathrm{P} \\
\mathrm{dpm} / \mathrm{mg} \mathrm{P}\end{array}$ & $\begin{array}{l}\text { Specific } \\
\text { activity } \\
\text { of }{ }^{3}{ }^{3} \mathrm{P} \\
\mathrm{dpm} / \mathrm{mg} \mathrm{P}\end{array}$ & $\begin{array}{l}{ }^{\text {Ratio }}{ }^{3} \mathrm{P}^{3}{ }^{2} \mathrm{P} \\
\text { dpm/dpm }\end{array}$ \\
\hline $\mathrm{Z} 300-2$ & $5 / 1 / 91$ & surface & night tow & $2.57 \pm 0.05$ & $0.79 \pm 0.07$ & $1.05 \pm 0.13$ & $1.33 \pm 0.17$ \\
\hline Z300-3 & $5 / 1 / 91$ & surface & night tow & $4.74 \pm 0.09$ & $0.71 \pm 0.07$ & $1.10 \pm 0.11$ & $1.55 \pm 0.22$ \\
\hline Z300-4 & $5 / 1 / 91$ & surafce & night tow & $6.01 \pm 0.12$ & $0.67 \pm 0.07$ & $0.90 \pm 0.12$ & $1.34 \pm 0.19$ \\
\hline
\end{tabular}


Table 4.3. Specific activities of ${ }^{32} \mathrm{P}$ and ${ }^{33} \mathrm{P}$ and activity ratio ${ }^{33} \mathrm{P}^{32} \mathrm{P}$ in suspended particles $(>8$ $\mu \mathrm{m})$ and in plankton tows (67- $\mu \mathrm{m}$ mesh size net) collected during BATS 34, 15-19 July 1991.

\begin{tabular}{|c|c|c|c|c|c|c|c|}
\hline Sample & Date & Depth & Type & $\begin{array}{l}\text { Amount of } \\
\text { stable P } \\
\text { mg P }\end{array}$ & $\begin{array}{l}\text { Specific } \\
\text { activity } \\
\text { of }{ }^{32} \mathrm{P} \\
\mathrm{dpm} / \mathrm{mg} \mathrm{P}\end{array}$ & $\begin{array}{l}\text { Specific } \\
\text { activity } \\
\text { of }{ }^{33} \mathrm{P} \\
\mathrm{dpm} / \mathrm{mg} \mathrm{P}\end{array}$ & $\begin{array}{l}{ }^{3{ }^{3}} \mathrm{P}^{3}{ }^{2} \mathrm{P} \\
\text { dpm/dpm }\end{array}$ \\
\hline M1 & $7 / 16 / 91$ & surface & pump & $0.64 \pm 0.01$ & $2.99 \pm 0.50$ & $2.24 \pm 0.52$ & $0.75 \pm 0.23$ \\
\hline Z67-10* & $7 / 18 / 91$ & surface & night tow & $3.10 \pm 0.06$ & $0.96 \pm 0.11$ & $1.32 \pm 0.21$ & $1.37 \pm 0.30$ \\
\hline Z67-11* & $7 / 18 / 91$ & surface & night tow & $3.10 \pm 0.06$ & $0.87 \pm 0.13$ & $1.09 \pm 0.22$ & $1.25 \pm 0.25$ \\
\hline Z67-12* & $7 / 18 / 91$ & surface & night tow & $1.27 \pm 0.03$ & $0.89 \pm 0.12$ & $1.59 \pm 0.30$ & $1.79 \pm 0.44$ \\
\hline Sg-1+ & $7 / 16 / 91$ & surface & macroalgae & $3.22 \pm 0.06$ & $1.68 \pm 0.24$ & $2.58 \pm 0.42$ & $1.55 \pm 0.37$ \\
\hline $\mathrm{Sg}-2+$ & $7 / 16 / 91$ & surface & macroalgae & $2.14 \pm 0.04$ & $2.67 \pm 0.35$ & $3.53 \pm 0.42$ & $1.32 \pm 0.22$ \\
\hline
\end{tabular}

*: triplicates of the same tow.

+ : duplicates of a sample of sargassum.

Table 4.4. Specific activities of ${ }^{32} \mathrm{P}$ and ${ }^{33} \mathrm{P}$ and activity ratio ${ }^{33} \mathrm{P} /{ }^{32} \mathrm{P}$ in plankton tows and suspended particulate $(>3 \mu \mathrm{m}$ ) samples collected during BATS 38, 11-15 November 1991. Z67 and $\mathrm{Z} 300$ refer to plankton tows collected with a $67-\mu \mathrm{m}$ and $300-\mu \mathrm{m}$ plankton net respectively. Each tow is split in two samples except Z67-10. Z300-10 contained Trichodesmium and marine snow mostly.

\begin{tabular}{llllllll}
\hline Sample & Date & Depth & Type & $\begin{array}{l}\text { Amount of } \\
\text { stable P } \\
\mathrm{mg} \mathrm{P}\end{array}$ & $\begin{array}{l}\text { Specific } \\
\text { activity } \\
\text { of }{ }^{32} \mathrm{P} \\
\text { dpm/mg P }\end{array}$ & $\begin{array}{l}\text { Specific } \\
\text { activity } \\
\text { of }{ }^{33} \mathrm{P} \\
\text { dpm/mg P }\end{array}$ & dpm/dpm \\
\hline M-S1 & $11 / 12 / 91$ & surface & pump & $1.08 \pm 0.02$ & $2.04 \pm 0.19$ & $3.27 \pm 0.52$ & $1.60 \pm 0.26$ \\
M-S2 & $11 / 14 / 91$ & surface & pump & $0.78 \pm 0.01$ & $2.42 \pm 0.57$ & $4.4 \pm 1.0$ & $1.84 \pm 0.90$ \\
Z67-10 & $11 / 12 / 91$ & surface & night tow & $1.24 \pm 0.02$ & $3.84 \pm 0.38$ & $4.71 \pm 0.67$ & $1.22 \pm 0.21$ \\
Z67-20* & $11 / 14 / 91$ & $0-60 \mathrm{~m}$ & day tow & $2.84 \pm 0.06$ & $2.19 \pm 0.28$ & $3.56 \pm 0.56$ & $1.62 \pm 0.29$ \\
Z67-21* & $11 / 14 / 91$ & $0-60 \mathrm{~m}$ & day tow & $1.95 \pm 0.04$ & $3.58 \pm 0.51$ & $5.67 \pm 0.88$ & $1.58 \pm 0.26$ \\
Z67-30 & $11 / 14 / 91$ & surface & night tow & $2.08 \pm 0.04$ & $3.35 \pm 0.52$ & $4.69 \pm 0.67$ & $1.40 \pm 0.32$ \\
Z67-31 & $11 / 14 / 91$ & surface & night tow & $3.12 \pm 0.06$ & $2.00 \pm 0.31$ & $3.12 \pm 0.41$ & $1.56 \pm 0.22$ \\
Z300-10 & $11 / 12 / 91$ & surface & night tow & $3.24 \pm 0.06$ & $2.75 \pm 0.38$ & $4.00 \pm 0.65$ & $1.46 \pm 0.20$ \\
Z300-11 & $11 / 12 / 91$ & surface & night tow & $2.16 \pm 0.04$ & $2.85 \pm 0.43$ & $5.20 \pm 0.76$ & $1.82 \pm 0.25$ \\
Z300-20* $11 / 14 / 91$ & $0-60 \mathrm{~m}$ & day tow & $3.15 \pm 0.06$ & $2.48 \pm 0.37$ & $4.30 \pm 0.65$ & $1.73 \pm 0.22$ \\
Z300-21** & $11 / 14 / 91$ & $0-60 \mathrm{~m}$ & day tow & $3.15 \pm 0.06$ & $2.77 \pm 0.43$ & $4.95 \pm 0.73$ & $1.79 \pm 0.22$
\end{tabular}

*: tows collected by continually yo-yoing the net on the hydrowire from 0 to the base of the mixed layer at $60 \mathrm{~m}$. 
Table 4.5. Specific activities of ${ }^{32} \mathrm{P}$ and ${ }^{33} \mathrm{P}$ and activity ratio ${ }^{33} \mathrm{P}^{32} \mathrm{P}$ in plankton and suspended particles $(>3 \mu \mathrm{m})$ in samples collected during BATS 41A, 24-25 February 1992. Z500 and $\mathrm{Z} 67$ refer to samples collected with plankton nets of mesh size $500-\mu \mathrm{m}$ and $67-\mu \mathrm{m}$ respectively. One of the Z500 was separated into two fractions Z500-T and Z500-B. Z500-T is the fraction that stayed suspended in seawater. It contained mostly radiolarians. Z Z500-B is the fraction that sank and contained mostly marine snow and crustacians (Z500-B1 and Z500-B2 are duplicates). Z500-R is the refractory fraction of a tow, the labile fraction was lost during processing.

\begin{tabular}{|c|c|c|c|c|c|c|c|}
\hline Sample & Date & Depth & Type & $\begin{array}{l}\text { Amount of } \\
\text { stable P } \\
\text { mg P }\end{array}$ & $\begin{array}{l}\text { Specific } \\
\text { activity } \\
\text { of }{ }^{32} \mathrm{P} \\
\mathrm{dpm} / \mathrm{mg} \mathrm{P}\end{array}$ & $\begin{array}{l}\text { Specific } \\
\text { activity } \\
\text { of }{ }^{3}{ }^{3} \mathrm{P} \\
\mathrm{dpm} / \mathrm{mg} \mathrm{P}\end{array}$ & ${ }^{33} \mathrm{P}^{32} \mathrm{P}$ \\
\hline M2 & $02 / 25 / 92$ & surface & pump & $1.48 \pm 0.03$ & $1.01 \pm 0.19$ & $0.94 \pm 0.23$ & $0.93 \pm 0.31$ \\
\hline Z500-R & $02 / 25 / 92$ & surface & night tow & $1.77 \pm 0.04$ & $0.34 \pm 0.05$ & $1.25 \pm 0.23$ & $3.66 \pm 0.84$ \\
\hline Z500-B1 & $02 / 25 / 92$ & surface & night tow & $3.49 \pm 0.07$ & $0.39 \pm 0.04$ & $1.16 \pm 0.18$ & $2.95 \pm 0.55$ \\
\hline $\mathrm{Z} 500-\mathrm{B} 2$ & $02 / 25 / 92$ & surface & night tow & $3.49 \pm 0.07$ & $0.34 \pm 0.05$ & $1.36 \pm 0.23$ & $4.0 \pm \overline{1} .0$ \\
\hline Z500-T & $02 / 25 / 92$ & surface & night tow & $2.16 \pm 0.04$ & $0.49 \pm 0.09$ & $0.99 \pm 0.25$ & $2.03 \pm 0.51$ \\
\hline Z67-1 & $02 / 25 / 92$ & surface & night tow & $2.04 \pm 0.04$ & $0.34 \pm 0.06$ & $1.41 \pm 0.38$ & $4.1 \pm 1.3$ \\
\hline Z67-2 & $02 / 25 / 92$ & surface & day tow & $1.37 \pm 0.03$ & $0.21 \pm 0.08$ & $1.36 \pm 0.65$ & $6.5 \pm 4.8$ \\
\hline
\end{tabular}

Table 4.6. Specific activities of ${ }^{32} \mathrm{P}$ and ${ }^{33} \mathrm{P}$ and activity ratio ${ }^{33} \mathrm{P}^{32} \mathrm{P}$ in suspended particles $(>3 \mu \mathrm{m})$ and in plankton tows collected during EN 235 in April 1992 at BATS station. Z150 refer to a tow collected with a $150 \mu \mathrm{m}$ net. $\mathrm{Z} 150-\mathrm{L}$ and $\mathrm{R}$ refer to the labile and refractory fractions.

\begin{tabular}{|c|c|c|c|c|c|c|c|}
\hline Sample & Date & Depth & Type & $\begin{array}{l}\text { Initial } \\
\text { amount of } \\
\text { stable P } \\
\text { mg P }\end{array}$ & $\begin{array}{l}\text { Specific } \\
\text { activity } \\
\text { of }{ }^{32} \mathrm{P} \\
\mathrm{dpm} / \mathrm{mg} \mathrm{P}\end{array}$ & $\begin{array}{l}\text { Specific } \\
\text { activity } \\
\text { of }{ }^{3}{ }^{3} \mathrm{P} \\
\mathrm{dpm} / \mathrm{mg} \mathrm{P}\end{array}$ & $\begin{array}{l}\text { Ratio } \\
{ }^{3}{ }^{3} \mathrm{P}^{3}{ }^{2} \mathrm{P} \\
\text { dpm/dpm }\end{array}$ \\
\hline M-0 & $4 / 25 / 92$ & surface & pump & $2.93 \pm 0.06$ & $2.05 \pm 0.20$ & $3.39 \pm 0.45$ & $1.66 \pm 0.20$ \\
\hline M-35 & $4 / 25 / 92$ & $35 \mathrm{~m}$ & pump & $3.01 \pm 0.06$ & $1.07 \pm 0.31$ & $2.11 \pm 0.79$ & $1.97 \pm 0.81$ \\
\hline M-70 & $4 / 25 / 92$ & $70 \mathrm{~m}$ & pump & $3.22 \pm 0.06$ & $0.75 \pm 0.12$ & $1.32 \pm 0.25$ & $1.76 \pm 0.30$ \\
\hline $\mathrm{Z} 150-\mathrm{N} 1$ & $4 / 26 / 92$ & surface & night tow & $3.87 \pm 0.07$ & $1.25 \pm 0.26$ & $1.09 \pm 0.23$ & $0.87 \pm 0.17$ \\
\hline Z150-D1 & $4 / 26 / 92$ & surface & day tow & $3.88 \pm 0.07$ & $1.37 \pm 0.18$ & $1.66 \pm 0.21$ & $1.21 \pm 0.16$ \\
\hline Z150-L & $4 / 26 / 92$ & surface & night tow & $4.06 \pm 0.08$ & $0.84 \pm 0.08$ & $0.93 \pm 0.11$ & $1.10 \pm 0.28$ \\
\hline Z150-R & $4 / 26 / 92$ & surface & night tow & $3.33 \pm 0.06$ & $0.72 \pm 0.08$ & $0.58 \pm 0.08$ & $0.82 \pm 0.13$ \\
\hline
\end{tabular}




\section{Bibliography}

Altabet, M.A., 1989. A time-series study of the vertical structure of nitrogen and particle dynamics in the Sargasso Sea. Limnol. Oceanogr., 34(7):1185-1201.

Ammerman, J.W., and F. Azam, 1985. Bacterial 5'-nucleotidase in acquatic ecosystems: a novel meachanism of phosphorus regeneration. Science, 227:1338-1340.

Angel, M.V., 1984. Detrital organic fluxes through pelagic ecosystems. In: Flows of energy and materials in marine ecosystems, Fasham, M.J.R. (ed.). Plenum Press, N.Y. pp 475-516.

Azam, F., and R.E. Hodson., 1977. Dissolved ATP in the sea and its utilization by marine bacteria. Nature, 267:696-698.

Bishop, J.K.B., M.H. Conte, P.H. Wiebe, M.R. Roman, and C. Langdon, 1986a. Particulate matter production and consumption in the deep mixed layers: observations in a warm-core ring. Deep Sea Res. 33:1813-1841.

Bishop, J.K.B., J.C. Stepien, and P.H. Wiebe, 1986b. Particulate matter distributions, chemistry and flux in the Panama Basin: response to environmental forcing. Prog. Oceanogr. 17:1-59.

Bishop, J.K., R.W. Collier, D.R. Ketten, and J.M. Edmond., 1980. The chemistry, biology, and vertical flux of particulate matter from the upper $1500 \mathrm{~m}$ of the Panama Basin. Deep Sea Res., 27A:615-640.

Bishop, J.K., J.M. Edmond, D.R. Ketten, M.P. Bacon, and W.B. Silker, 1977. The chemistry, biology, and vertical flux of particulate matter from the upper $400 \mathrm{~m}$ of the equatorial Atlantic Ocean. Deep Sea Res., 24:511-548.

Bogdanov, Y.A. and M.G. Shaposhnikova, 1971. Content of suspended organic matter in the tropical Pacific. Oceanol., 11:563-567.

Boyle, E.A., S.D. Chapnick, G.T. Shen, and M.P. Bacon, 1986. Temporal variability of lead in the western North Atlantic. J. Geophys. Res., 91(C7):8573-8593.

Broecker, W.S. and T.H. Peng, 1982. Tracers in the Sea, Lamont-Doherty Geological Observatory, Columbia University, Palisades, N.Y., 690pp. 
Buesseler, K.O., 1991. Do upper-ocean sediment traps provide an accurate record of particle flux? Nature, 353:420-423.

Cembella, A.D. and N.J. Antia, 1986. The determination of phosphonates in seawater by fractionation of the total phosphorus. Mar. Chem., 19:205-210.

Cembella, A.D., N.J. Antia, and P.J. Harrison, 1984. The utilization of inorganic and organic phosphorus compounds as nutrients by eukaryotic microalgae: a multidisciplinary perspective: part I. CRC Critical Reviews in Microbiology, 20:317-391.

Chakravarti, D., G.B. Lewis, R.F. Palumbo, and A.H. Seymour, 1964. Analyses of radionuclides of biological interest in Pacific Waters. Nature, 203:571-573.

Collier, R. W., 1991. Analysis of particulate matter collected by sediment traps and from sediment cores. In: Marine Particles: Analysis and characterization, D. Hurd and D. Spencer (Ed), Geophysical Monograph Series, American Geophysical Union, pp235.

Collier, R.W., and J.M. Edmond, 1984. The trace element geochemistry of marine biogenic particulate matter. Prog. Oceanogr., 13:113-199.

Conover, R.J., Marshall, S.M., and A.P. Orr, 1961. On the biology of Calanus finmarchicus. XII. The phosphorus cycle: excretion, egg production, autolysis. The turnover of phosphorus by Calanus finmarchicus. J. Mar. Biol. Ass. U.K., 41:463-488.

Corner, E.D.S, 1973. Phosphorus in marine zooplankton. Water Res., 7:93-110.

Corner, E.D.S. and A.G. Davis, 1971. Plankton as a factor in the nitrogen and phosphorus cycles in the sea. Adv. Mar. Biol., 9:101-204.

Dagg, M.J. and J.T. Turner, 1982. The impact of copepod grazing on the phytoplankton of Georges Bank and the New York Bight. Can. J. Fish. Aquat. Sci., 39:979-990.

Dagg, M.J., J. Vidal, T.E. Whitledge, R.L. Iverson, and J.J. Goering, 1982. The feeding, respiration, and excretion of zooplankton in the Bering Sea during a spring bloom. Deep Sea Res., 29:45-63.

Eppley, R.W., and B.J. Peterson, 1979. Particulate organic matter flux and planktonic new production in the deep ocean. Nature, 282:677-680. 
Eppley, R.W., E.H. Renger, E.L. Venrick, and M.M. Mullin, 1973. A study of plankton dynamics and nutrient cycling in the central gyre of the North Pacific Ocean. Limnol. Oceanogr., 18:534-551.

Fanning, K.A., 1989. Influence of atmospheric pollution on nutrient limitation in the ocean. Nature, 339:460-

Fowler, S.W. and G.A. Knauer, 1986. Role of large particles in the transport of elements and organic compounds through the oceanic water column. Prog. Oceanogr. 16:147-194.

Goldman, J.C., J.J. McCarthy, and D.G. Peavey, 1979. Growth rate influence on the chemical composition of phytoplankton in oceanic waters. Nature, 278:210-215.

Grill, E.V., and F.A. Richards, 1964. Nutrient regeneration from phytoplankton decomposing in seawater. J. Mar. Res., 25:51-69.

Harrison, W.G., and L.R. Harris, 1986. Isotope-dilution and its effects on measurements of nitrogen and phosphorus uptake by oceanic microplankton. Mar. Ecol. Prog. Ser., 27:253-261.

Harrison, W.G., 1983. Uptake and recycling of soluble reactive phosphorus by marine microplankton. Mar. Ecol. Prog. Ser., 10:127-135.

Harrison, W.G., 1980. Nutrient regeneration and primary productivity in the sea. In: Primary Productivity in the Sea, P. Falkowski (ed.), Plenum Press, N.Y., pp433-460.

Harrison, W.G., F. Azam, E.H. Renger and, R.W. Eppley, 1977. Some experiments on phosphate assimilation by coastal marine plankton. Mar. Biol., 40:9-18.

Herbland, A., 1984. Phosphate uptake in the euphotic layer of Equatorial Atlantic Ocean. Methodological observations and ecological significance. Oceanogr. trop., 19:25-40.

Holm-Hansen, O., J.D.H. Strickland, and P.M. Williams, 1966. A detailed anslysis of biologically important substances in a profile off Southern California. Limnol. Oceanogr., 11:548-561.

Howard, R.W., 1988. Nutrient limitation of net primary production in marine ecosystems. Ann. Rev. Ecol., 19:89-110.

Jackson, G.A. and P.M. Williams, 1985. Importance of dissolved organic and phosphorus to biological nutrient cycling. Deep Sea Res., 32:223-235. 
Jickells, T.D., W.G. Deuser, and R.A. Belastock, 1990. Temporal variations in the concentrations of some particulate elements in the surface waters of the Sargasso Sea and their relationship to deep-sea fluxes. Mar. Chem., 29:203-219.

Karl, D.M., R. Letelier, D.V. Hebel, D.F. Bird, and C.D. Winn, 1992. Trichodesmium blooms and new nitrogen in the North Pacific Gyre. In: Biology and ecology of diazotrophic marine organisms: Trichodesmium and other species, E.J. Carpenter, D.G. Capone and J.G. Rueter (eds.), Kluwer Academic Publishers, pp1-19.

Karl, D.M. and G. Tien, 1992. Magic: a sensitive and precise method for measuring dissolved phosphorus in aquatic environments. Limnol. Oceanogr., 37:105-116.

Koroleff, F., 1983. Determination of phosphorus. In: Methods of Seawater Analysis; K. Grasshoff, M. Ehrhard and K. Kremling (eds.). 2nd Edn., Verlag Chemie, Weinheim, pp125-135.

Knap, A. H., Michaels, A.F., R.L. Dow, R.J. Johnson, K. Gundersen, J. Sorensen, and A. Close, M. Hammer, G.A. Knauer, S.E. Lohrenz, V.A. Asper, M. Tuel, H Ducklow, H. Quinby, P. Brewer, and R. Bidigare, 1992. U.S. Joint Global Ocean Flux Study, Bermuda Atlantic Time-series Study. BATS Data Report B-2, 1992.

Knap, A.H., Michaels, A.F., R.L. Dow, R.J. Johnson, K. Gundersen, G.A. Knauer, S.E. Lohrenz, V.A. Asper, M. Tuel, H Ducklow, H. Quinby, and P. Brewer 1992. U.S. Joint Global Ocean Flux Study, Bermuda Atlantic Time-series Study. BATS Data Report B1A, 1991.

Knauer, G.A., and J.H. Martin, 1981. Phosphorus-cadmium cycling in the northeast Pacific waters. J. of Mar. Res., 39:65-77.

Knauer, G. A., J.H. Martin and K. Bruland, 1979. Fluxes of particulate carbon, nitrogen, and phosphorus in the upper water column of the northeast Pacific. Deep Sea Res., 26A:97-108.

Lal, D., and T. Lee, 1988, Cosmogenic ${ }^{32} \mathrm{P}$ and ${ }^{33} \mathrm{P}$ used as tracers to study phosphorus recycling in the ocean. Nature, 333:752-754.

Lal, D., Chung, Y., Platt, T., and T. Lee, 1988, Twin cosmogenic radiotracer studies of phosphorus cycling and chemical fluxes in the upper ocean. Limnol. Oceanogr., 33:15591567. 
Longhurst, A.R., and W.G. Harrison, 1988. Vertical nitrogen flux from the oceanic photic zone by diel migrant zooplankton and nekton. Deep Sea Res., 35:881-889.

Lee, T., E. Barg, and D. Lal, 1991. Studies of vertical mixing in the Southern California Bight using cosmogenic radionuclides ${ }^{3}{ }^{2} \mathrm{P}$ and ${ }^{7} \mathrm{Be}$, Limnol. Oceanogr., 36:1044-1053.

Lee, T., E. Barg, and D. Lal, 1992. Techniques for extraction of dissolved inorganic and organic phophorus from large volumes of seawater. Anal. Chim. Acta, 260:113-121.

Liebezeit, G., 1991. Analytical phosphorus fractionation of sediment trap material. Mar. Chem. 33:61-69.

Martin, J.H., G.A. Knauer, D.M. Karl and W.W. Broenkow, 1987. Vertex: carbon cycling in the northeast Pacific. Deep Sea Res., 34:267-285.

McCarthy, J.J., and E.J. Carpenter, 1983. Nitrogen cycling in the near-surface waters of the open ocean. In: Nitrogen in the marine environment, E.J. Carpenter and D.G. Capone (eds.) Academic, pp 487-512.

Menzel, D.W., and J.H. Ryther, 1961. Annual variations in primary production of the Sargasso Sea off Bermuda. Deep Sea Res., 7:282-288.

Menzel, D.W., and J.H. Ryther, 1960. The annual cycle of primary production in the Sargasso Sea. Deep Sea Res., 6:341-365.

Michaels, A.F., A.H. Knap, R.L. Dow, K. Gundersen, R.J. Johnson, J. Sorensen, A. Close, G.A. Knauer, S.E. Lohrenz, V.A. Asper, M.D. Tuel, and R. Bidigare, 1993. Ocean time-series measurements off Bermuda: The first two years of US JGOFS Bermuda Atlantic Time-series Study. Deep Sea Res., in press.

Murphy, J., and J.P. Riley, 1962. A modified single solution method for the determination of phosphate in natural waters. Anal. Chim. Acta, 27:31-36.

Ormaza-Gonzalez, F.I., 1990. Phosphorus in estuarine and oligotrophic ocean waters: analytical and biogeochemical studies. Ph.D Thesis. University of Southampton, U.K., 346pp.

Orrett, K., and D.M. Karl. 1987. Dissolved organic phosphorus production in surface seawaters. Limnol. Oceanogr., 32:383-395. 
Peng, T., and W. Broecker, 1987. C/P ratios in marine detritus. Global Biogeochem. Cycles, 1(2):155-161.

Perry, M.J., and R. W. Eppley, 1981. Phosphate uptake by phytoplankton in the central North Pacific Ocean. Deep Sea Res., 28A:39-49.

Perry, M.J., 1976. Phosphate utilization by an oceanic diatom in phosphorus-limited chemostat culture and in the oligotrophic waters of the central North Pacific. Limnol. Oceanogr., 21:88-107.

Perry, M.J., 1972. Alkaline phosphatase activity in subtropical central North Pacific waters using a sensitive fluorometric method. Mar. Biol., 15:113-119.

Pomeroy, L.R., and D. Diebel, 1980. Aggregation of organic matter by pelagic tunicates. Limnol. Oceanogr., 25:643-652.

Pomeroy, L.R.; E.P. Odum, R.E.. Johannes, and B. Roffman, 1967. Flux of ${ }^{32} \mathrm{P}$ and ${ }^{65} \mathrm{Zn}$ through a salt-marsh ecosystem. In: Disposal of radioactive waste into seas, oceans and surface waters, IAEA, Vienna, pp 177-188.

Redfield, A.C., Ketchum, B.H., and F.A. Richards, 1963. The influence of organisms on the composition of sea-water. In: The Sea, M. N. Hill (ed.), vol 2., Wiley (Interscience), N.Y., pp 26-27.

Redfield, A.C., 1958. The biological control of chemical factors in the environment. Am. Sci. 46:205-222.

Ridal, J.J., and R.M. Moore, 1992. Dissolved organic phosphorus concentrations in the NE subarctic Pacific Ocean. Limnol. Oceanogr., 37:1067-1075.

Ridal, J.J., and R.M. Moore, 1990. A re-examination of the measurement of dissolved organic phosphorus in seawater. Mar. Chem., 29:19-31.

Rivkin, R.B., and E. Swift, 1985. characterization of alkaline phosphatase and organic phosphorus utilization in the oceanic dinoflagellates Pyrocystis noctiluca. Mar. Biol., 61:1-8.

Schroeder, E., and H. Stommel, 1969. How representative is the series of Panulirus stations of monthly mean conditions off Bermuda? Progr. Oceanogr. 5:31-40. 
Sheldon, R.W., A. Prakash, and W.H. Sutcliffe, 1972. The size distribution of particles in the ocean. Limnol. Oceanogr. 17:327-340.

Small, L.F., G.A. Knauer, and M.D. Tuel, 1987. The role of sinking fecal pellets in stratified euphotic zones. Deep Sea Res., 34:1705-1712.

Smith, R.E., W.G. Harrison, and L. Harris, 1985. Phosphorus exchange in marine microplankton communities near Hawaii. Mar. Biol., 86:75-84.

Smith, S.V., W.J. Kimmerer, and T.W. Walsh, 1986. Vertical flux and biogeochemical turnover regulate nutrient limitation of net organic production in the North Pacific Gyre. Limnol. Oceanogr., 31(1):161-167.

Smith, S.V., 1984. Phosphorus versus nitrogen limitation in the marine environment. Limnol. Oceanogr., 29(6):1149-1160.

Smith, S.V., and M.J. Atkinson, 1984. Phosphorus limitation of net production in a confined aquatic ecosystem. Nature, 307:626-627.

Sorokin, Y.I., 1985. Phosphorus metabolism in planktonic communities of the eastern tropical Pacific Ocean. Mar. Ecol. - Prog. Ser., 27:87-97.

Tranter, D.J., 1976. Herbivore Production. In: The Ecology of the Seas, D.H. Cushing and J.J. Walsh (eds.), W.S. Sauders Co., Toronto, pp 186-224.

Vaccaro, R.F., 1963. Available nitrogen and phosphorus and the biochemical cycle in the Atlantic off New England. J. Mar. Res., 21:284-301.

Watt, W.D., and R.F. Hayes, 1963. Tracer study of the phosphorus cycle in sea water. Limnol. Oceanogr., 8:267-285.

Wefer, G.E., W. Suess, W. Balzer, G. Liebezeit, P.J. Muller, C.A. Ungerer, and W. Zenk, 1982. Fluxes of biogenic components from sediment trap deployment in circumpolar waters of the Drake Passage. Nature, 299:145-147.

Westheimer, F.H., 1987. Why nature chose phosphates. Science, 235:1173-1178. 


\section{CONCLUSIONS}

\section{PRESENT FINDINGS}

The wet deposition rates of ${ }^{32} \mathrm{P}$ and ${ }^{33} \mathrm{P}$ at Bermuda were determined to be $510^{-3}$ atom $/ \mathrm{cm}^{2} / \mathrm{min}$ for ${ }^{32} \mathrm{P}$ and $810^{-3}$ atom $/ \mathrm{cm}^{2} / \mathrm{min}$ for ${ }^{33} \mathrm{P}$. The activity ratio ${ }^{33} \mathrm{P} /{ }^{32} \mathrm{P}$ delivered in rainwater was found to be close to 0.96 throughout the year (March 1991 to March 1992). The study of ${ }^{33} \mathrm{P}$ and ${ }^{32} \mathrm{P}$ in rainwater showed that the ratio ${ }^{33} \mathrm{P} /{ }^{2} \mathrm{P}$ is a powerful tracer of atmospheric processes. The variations in the ratio ${ }^{33} \mathrm{P} /{ }^{32} \mathrm{P}$ can be utilized to determine the residence time of tropospheric aerosols. A residence time of 27 days was found. The ratio exhibits variations that are probably seasonal due to seasonal changes in stratospheric input and/or seasonal changes in mixing between the lower and upper troposphere.

The study of ${ }^{32} \mathrm{P}$ and ${ }^{33} \mathrm{P}$ in $\mathrm{Cl}, \mathrm{K}$ and $\mathrm{S}$ targets has allowed the determination of the in situ production rates of ${ }^{32} \cdot \mathrm{P}$ and ${ }^{33} \mathrm{P}$ in the upper ocean due to neutrons at all latitudes. The production rates were estimated to be $2.510^{-4}$ atom $/ \mathrm{cm}^{2} / \mathrm{min}$ for ${ }^{32} \mathrm{P}$ and $810^{-5}$ atom $/ \mathrm{cm}^{2} / \mathrm{min}$ for ${ }^{33} \mathrm{P}$ at Bermuda. In situ production was found to account for $5 \%$ for ${ }^{32} \mathrm{P}$ and $1 \%$ for ${ }^{33} \mathrm{P}$ of the wet deposition rates.

The combined study of the sources of ${ }^{32} \mathrm{P}$ and ${ }^{33} \mathrm{P}$ to the ocean and the distribution of ${ }^{32} \mathrm{P}$ and ${ }^{33} \mathrm{P}$ in suspended particles and plankton allowed the determination of the turnover time of $\mathrm{P}$ in zooplankton. Residence times of $\mathrm{P}$ of 40 to 60 days were found in zooplankton, based on the activity ratio ${ }^{33} \mathrm{P} /{ }^{32} \mathrm{P}$ in rainwater, suspended matter and plankton.

Grazing rates of $0.024 \mathrm{~d}^{-1}$ were determined, and it was estimated that $30 \pm 10$ $\mathrm{mg} \mathrm{C} / \mathrm{m}^{2} / \mathrm{d}$ leaves the euphotic zone at BATS as fecal matter or pellets. The estimated 
carbon flux suggests that fecal pellets and matter make up the bulk of the particulate flux at BATS.

Inventory calculations of ${ }^{32} \mathrm{P}$ and ${ }^{33} \mathrm{P}$ in the euphotic zone suggest that most of the activities of ${ }^{32} \mathrm{P}$ and ${ }^{33} \mathrm{P}$ delivered by rain are found in the suspended matter. It suggests that DOP, which is the major pool of P at BATS, is turning over slowly relative to the half-lives of ${ }^{32} \mathrm{P}$ and ${ }^{33} \mathrm{P}$.

\section{FUTURE WORK}

The study of ${ }^{32} \mathrm{P}$ and ${ }^{33} \mathrm{P}$ in rainwater has indicated the complexities involved in the interpretation of the ratio in rainwater. The study has shown the potential usefulness of cosmogenic ${ }^{32} \mathrm{P}$ and ${ }^{33} \mathrm{P}$ and investigations could be done in the following areas:

1- The tropospheric production rates of ${ }^{32} \mathrm{P}$ and ${ }^{33} \mathrm{P}$ need to be better known in order to determine the residence times more accurately. It is especially important in the case of cosmogenic ${ }^{32} \mathrm{P}$ and ${ }^{33} \mathrm{P}$, since the expected range of ratios is small $\left(\mathrm{R}_{0}\right.$ to $\left.\mathrm{R}_{0} * 1.77\right)$ due to the similarity in the half-lives.

2- The vertical profiles of ${ }^{32} \mathrm{P}$ and ${ }^{33} \mathrm{P}$ in sub-micrometer aerosols in the troposphere should be determined. One of the assumptions of the model of residence time is that the troposphere is well mixed. There is evidence that this assumption is incorrect and the discord should be assessed.

3- Another way of investigating the extent of mixing in the troposphere, particularly with respect to mixing between the stratosphere and the troposphere, is to study ${ }^{7} \mathrm{Be},{ }^{32} \mathrm{P}$ and ${ }^{33} \mathrm{P}$ in rainwater. The observed ratios ${ }^{7} \mathrm{Be} /{ }^{32} \mathrm{P}$ and ${ }^{33} \mathrm{P} /{ }^{32} \mathrm{P}$ can possibly be used as 
tracers of mixing by comparison with the expected ratios ${ }^{7} \mathrm{Be} /{ }^{32} \mathrm{P}$ and ${ }^{33} \mathrm{P} /{ }^{32} \mathrm{P}$, assuming no mixing.

4- The efficiency of the removal of sub-micrometer aerosols during washout needs to be determined. The model of residence time relied on the assumption that the efficiency is $100 \%$ and that needs to be assessed.

The study of ${ }^{32} \mathrm{P}$ and ${ }^{33} \mathrm{P}$ in marine particulate matter has indicated the usefulness of these tracers for studying zooplankton dynamics. Investigations could be pursued in the following areas.

1- Depth profiles of ${ }^{32} \mathrm{P}$ and ${ }^{33} \mathrm{P}$ in DIP, DOP and suspended particles need to be measured to assess correctly the inventories of ${ }^{32} \mathrm{P}$ and ${ }^{33} \mathrm{P}$ in the mixed layer and in the euphotic zone.

2- One of the most important questions with respect to phosphorus cycling in the upper ocean concerns the availability of DOP to phytoplankton. The ratio ${ }^{33} \mathrm{P} /{ }^{32} \mathrm{P}$ in DOP can be used as an indicator of the lability of DOP by providing a means of estimating the residence time of $\mathrm{P}$ in DOP.

3- An important question in the cycle of $\mathrm{P}$ is the extent of remineralization of $\mathrm{P}$ in sinking particles below the euphotic zone. The ratio ${ }^{33} \mathrm{P} / 2 \mathrm{P}$ in sinking particles at different depths can provide estimates of the regeneration rates of $\mathrm{P}$ from sinking particles. 


\section{Appendix A}

Table A.1. Total net count rates $\left(\mathrm{N}_{\mathrm{H}}\right)$ and count rates with absorber $\left(\mathrm{N}_{\text {) }}\right)$ for the rain samples collected at Woods Hole (first three rows) and at Bermuda during 1990, 1991 and 1992.

\begin{tabular}{|c|c|c|c|c|}
\hline \multirow[t]{3}{*}{$\begin{array}{l}\text { Sample } \\
\text { date }\end{array}$} & \multicolumn{3}{|c|}{$\begin{array}{l}\text { Total net count rate } \\
\text { of }{ }^{32} \mathrm{P} \text { and }{ }^{33} \mathrm{P}\end{array}$} & \multirow{3}{*}{$\begin{array}{c}\text { Net count rate } \\
\text { of }{ }^{32} \mathrm{P}_{\text {and }}^{33} \mathrm{P} \\
\text { with absorber } \\
\mathrm{N}_{\mathrm{a}} \\
\mathrm{b} \\
\text { in } \mathrm{cpm}\end{array}$} \\
\hline & \multicolumn{2}{|r|}{$\mathrm{N}_{\mathrm{t}}$} & \multirow[b]{2}{*}{$\begin{array}{l}\tau \\
\mathrm{d}\end{array}$} & \\
\hline & $\begin{array}{l}\mathrm{a} \\
\mathrm{cpm}\end{array}$ & $\begin{array}{c}\alpha \\
1 / d\end{array}$ & & \\
\hline 27-Dec-90 & $13.34 \pm 0.07$ & $0.0430 \pm 0.0005$ & 16.1 & $6.42 \pm 0.03$ \\
\hline 16-Jan-91 & $4.33 \pm 0.041$ & $0.0424 \pm 0.0008$ & 16.3 & $2.12 \pm 0.02$ \\
\hline 21-Apr-91 & $4.44 \pm 0.07$ & $0.041 \pm 0.001$ & 16.9 & $2.33 \pm 0.06$ \\
\hline 5-Mar-91 & $3.49 \pm 0.09$ & $0.0402 \pm 0.002$ & 17.3 & $1.95 \pm 0.05$ \\
\hline 10-Mar-91 & $13.74 \pm 0.1$ & $0.0441 \pm 0.0008$ & 15.7 & $6.55 \pm 0.08$ \\
\hline 10-Mar-91 & $16.97 \pm 0.2$ & $0.043 \pm 0.001$ & 16.1 & $8.30 \pm 0.20$ \\
\hline 20-Apr-91 & $13.24 \pm 0.1$ & $0.0411 \pm 0.0009$ & 16.9 & $6.59 \pm 0.09$ \\
\hline 20-Apr-91 & $20.06 \pm 0.2$ & $0.0415 \pm 0.0008$ & 16.7 & $9.59 \pm 0.06$ \\
\hline 22-Apr-91 & $9.27 \pm 0.1$ & $0.044 \pm 0.001$ & 15.7 & $4.32 \pm 0.07$ \\
\hline 22-Apr-91 & $3.51 \pm 0.1$ & $0.045 \pm 0.001$ & 15.4 & $1.78 \pm 0.03$ \\
\hline 1-May-91 & $8.60 \pm 0.3$ & $0.042 \pm 0.003$ & 16.5 & $4.32 \pm 0.06$ \\
\hline 11-jun-91 & $2.12 \pm 0.07$ & $0.046 \pm 0.003$ & 15.1 & $1.23 \pm 0.02$ \\
\hline 11-Jun-91 & $1.78 \pm 0.08$ & $0.044 \pm 0.005$ & 15.8 & $0.91 \pm 0.02$ \\
\hline 20-Jun-91 & $5.75 \pm 0.06$ & $0.044 \pm 0.001$ & 15.8 & $2.69 \pm 0.03$ \\
\hline 27-Jun-91 & $2.66 \pm 0.06$ & $0.043 \pm 0.002$ & 16.1 & $1.24 \pm 0.01$ \\
\hline 7-Jul-91 & $6.53 \pm 0.2$ & $0.040 \pm 0.001$ & 17.3 & $3.01 \pm 0.06$ \\
\hline 8-Jul-91 & $1.89 \pm 0.05$ & $0.043 \pm 0.002$ & 16.1 & $0.80 \pm 0.06$ \\
\hline 18-Jul-91 & $7.15 \pm 0.1$ & $0.041 \overline{6} \pm 0.0008$ & 16.7 & $3.16 \pm 0.06$ \\
\hline 19-Jul-91 & $6.95 \pm 0.1$ & $0.042 \pm 0.001$ & 16.5 & $3.27 \pm 0.07$ \\
\hline 7-Aug-91 & $6.38 \pm 0.1$ & $0.040 \pm 0.001$ & 17.3 & $3.06 \pm 0.04$ \\
\hline 26-Aug-91 & $9.13 \pm 0.09$ & $0.041 \pm 0.0007$ & 16.9 & $4.18 \pm 0.03$ \\
\hline 6-Sep-91 & $4.65 \pm 0.2$ & $0.041 \pm 0.009$ & 16.9 & $2.34 \pm 0.04$ \\
\hline 11-Sep-91 & $5.86 \pm 0.07$ & $0.042 \pm 0.0009$ & 16.5 & $2.87 \pm 0.03$ \\
\hline 14-Sep-91* & $0.77 \pm 0.04$ & 0.044 & 15.8 & $0.32 \pm 0.02$ \\
\hline 16-Sep-91 & $2.18 \pm 0.04$ & $0.041 \pm 0.002$ & 16.9 & $1.08 \pm 0.03$ \\
\hline 29-Sep-91 & $5.37 \pm 0.05$ & $0.042 \pm 0.001$ & 16.5 & $2.59 \pm 0.05$ \\
\hline 28-Oct-91 & $10.3 \overline{2}+0.2$ & $0.044 \pm 0.001$ & 15.8 & $5.63 \pm 0.09$ \\
\hline 28-Oct-91 & $3.33 \pm 0.1$ & $0.042 \pm 0.006$ & 16.5 & $1.98 \pm 0.05$ \\
\hline 7-Nov-91 & $5.56 \pm 0.1$ & $0.047 \pm 0.002$ & 14.7 & $2.53 \pm 0.04$ \\
\hline 17-Nov-91 & $12.01 \pm 0.2$ & $0.040 \pm 0.002$ & 17.3 & $6.02 \pm 0.09$ \\
\hline 16-Jan-92 & $1.90 \pm 0.04$ & $0.042 \pm 0.002$ & 16.5 & $0.94 \pm 0.02$ \\
\hline 21-Jan-92 & $17.44 \pm 0.08$ & $0.0416 \pm 0.0005$ & 16.7 & $7.71 \pm 0.04$ \\
\hline 25-Jan-92 & $6.63 \pm 0.1$ & $0.040 \pm 0.002$ & 17.3 & $3.28 \pm 0.06$ \\
\hline
\end{tabular}




$\begin{array}{lllll}\text { 31-Jan-92 } & 8.36 \pm 0.2 & 0.039 \pm 0.004 & 17.8 & 4.03 \pm 0.04 \\ \text { 2-Feb-92 } & 5.05 \pm 0.07 & 0.046 \pm 0.002 & 15.1 & 2.50 \pm 0.02 \\ \text { 14-Feb-92 } & 6.95 \pm 0.10 & 0.042 \pm 0.001 & 16.5 & 3.18 \pm 0.06 \\ \text { 17-Mar-92* } & 1.27 \pm 0.06 & 0.044 & 15.8 & 0.68 \pm 0.02 \\ \text { 26-Mar-92 } & 7.53 \pm 0.2 & 0.042 \pm 0.002 & 16.5 & 3.47 \pm 0.18 \\ \text { 26-Mar-92* } & 3.57 \pm 0.06 & 0.044 & 15.8 & 1.79 \pm 0.04\end{array}$

The net count rate with absorber $\mathrm{Na}$ and without absorber $\mathrm{Nt}$ are fitted by the following relationships: $\mathrm{N}_{\mathrm{t}}=\mathrm{a}^{*} \exp (-\alpha * \mathrm{t})$ and $\mathrm{N}_{2}=\mathrm{b}^{*} \exp (-\ln 2 * \mathrm{t} / 14.28)$

$\tau=\ln 2 \% \alpha, \tau$ is the apparent hall-life of the total activity of ${ }^{32} \mathrm{P}$ and ${ }^{33} \mathrm{P}$. The parameters $\mathrm{a}, \alpha$ and $\mathrm{b}$ resulting from the least-squares fit are given with the standard errors.

* The fit of the total net count rate gave a slope corresponding to $\tau<14.3$ days. A slope of 0.044 was imposed instead for the fit. 
Table A.2. Net count rates of the source with absorber $\left(\mathrm{N}_{\mathrm{a}}\right)$ and without $\left(\mathrm{N}_{\mathrm{t}}\right)$ as a function of time for the particle samples collected at the Bermuda Atlantic Time-series (BATS) station in 1991 and 1992.

\begin{tabular}{|c|c|c|c|c|c|}
\hline & \multirow[t]{2}{*}{ Sample } & \multicolumn{2}{|c|}{$\begin{array}{l}\text { Net count rate Net count } \\
\text { of }{ }^{32} \mathrm{P} \text { and }{ }^{33} \mathrm{P}\end{array}$} & \multirow{2}{*}{$\begin{array}{l}\text { first } \\
\text { rate with } \\
\text { absorber } \\
\mathrm{N}_{\mathrm{a}} \\
\mathrm{b}\end{array}$} & \multirow[t]{2}{*}{$\begin{array}{l}\text { day of } \\
\text { counting }\end{array}$} \\
\hline & & a & $\alpha$ & & \\
\hline $\begin{array}{l}\text { March } \\
1991\end{array}$ & $\begin{array}{l}\mathrm{L} \\
\mathrm{Z67-1R} \\
\mathrm{Z67-2R} \\
\mathrm{Z67-3R} \\
\mathrm{Z67-4}\end{array}$ & $\begin{array}{l}0.57 \pm 0.01 \\
1.25 \pm 0.03 \\
0.77 \pm 0.04 \\
1.18 \pm 0.03 \\
0.61 \pm 0.03\end{array}$ & $\begin{array}{l}0.042 \pm 0.003 \\
0.024 \pm 0.002 \\
0.039 \pm 0.004 \\
0.017 \pm 0.001 \\
0.040 \pm 0.005\end{array}$ & $\begin{array}{l}0.36 \pm 0.03 \\
0.45 \pm 0.04 \\
0.56 \pm 0.05 \\
0.36 \pm 0.04 \\
0.46 \pm 0.02\end{array}$ & $\begin{array}{l}3 / 9 / 91 \\
3 / 11 / 91 \\
3 / 11 / 91 \\
3 / 10 / 91 \\
4 / 6 / 91\end{array}$ \\
\hline $\begin{array}{l}\text { May } \\
1991\end{array}$ & $\begin{array}{l}Z 300-2 \\
Z 300-3 \\
Z 300-4\end{array}$ & $\begin{array}{l}0.99 \pm 0.04 \\
1.73 \pm 0.04 \\
1.62 \pm 0.03\end{array}$ & $\begin{array}{l}0.035 \pm 0.005 \\
0.049 \pm 0.004 \\
0.048 \pm 0.004\end{array}$ & $\begin{array}{l}0.58 \pm 0.02 \\
1.02 \pm 0.02 \\
1.00 \pm 0.02\end{array}$ & $\begin{array}{l}5 / 5 / 91 \\
5 / 5 / 91 \\
5 / 5 / 91\end{array}$ \\
\hline $\begin{array}{l}\text { July } \\
1991\end{array}$ & $\begin{array}{l}\text { M1 } \\
\text { Z67-10 } \\
\text { Z67-11 } \\
\mathrm{Z67-12} \\
\mathrm{Sg}-1 \\
\mathrm{Sg}-2\end{array}$ & $\begin{array}{l}0.43 \pm 0.02 \\
1.50 \pm 0.07 \\
1.50 \pm 0.04 \\
0.71 \pm 0.03 \\
1.96 \pm 0.1 \\
2.58 \pm 0.04\end{array}$ & $\begin{array}{l}0.060 \pm 0.004 \\
0.036 \pm 0.005 \\
0.043 \pm 0.003 \\
0.054 \pm 0.005 \\
0.032 \pm 0.004 \\
0.043 \pm 0.001\end{array}$ & $\begin{array}{l}0.30 \pm 0.03 \\
0.88 \pm 0.04 \\
0.87 \pm 0.03 \\
0.34 \pm 0.02 \\
1.12 \pm 0.06 \\
1.22 \pm 0.03\end{array}$ & $\begin{array}{l}7 / 23 / 91 \\
7 / 23 / 91 \\
7 / 23 / 91 \\
7 / 23 / 91 \\
7 / 23 / 91 \\
7 / 24 / 91\end{array}$ \\
\hline $\begin{array}{l}\text { Nov. } \\
1991\end{array}$ & $\begin{array}{l}\text { M-S1 } \\
\text { M-S2 } \\
\text { Z67-10 } \\
\text { Z67-20 } \\
\text { Z67-21 } \\
Z 67-30 \\
Z 67-31 \\
Z 300-10 \\
Z 300-11 \\
Z 300-20 \\
Z 300-21\end{array}$ & $\begin{array}{l}1.01 \pm 0.04 \\
1.00 \pm 0.07 \\
1.89 \pm 0.05 \\
3.12 \pm 0.2 \\
3.58 \pm 0.11 \\
3.64 \pm 0.03 \\
2.10 \pm 0.06 \\
3.95 \pm 0.06 \\
3.45 \pm 0.09 \\
5.01 \pm 0.10 \\
4.19 \pm 0.11\end{array}$ & $\begin{array}{l}0.047 \pm 0.005 \\
0.047 \pm 0.005 \\
0.042 \pm 0.003 \\
0.042 \pm 0.02 \\
0.048 \pm 0.003 \\
0.050 \pm 0.002 \\
0.042 \pm 0.003 \\
0.040 \pm 0.001 \\
0.046 \pm 0.002 \\
0.046 \pm 0.002 \\
0.044 \pm 0.002\end{array}$ & $\begin{array}{l}0.53 \pm 0.01 \\
0.57 \pm 0.10 \\
1.00 \pm 0.03 \\
1.63 \pm 0.03 \\
1.87 \pm 0.05 \\
2.14 \pm 0.16 \\
1.03 \pm 0.02 \\
1.94 \pm 0.03 \\
1.45 \pm 0.02 \\
2.42 \pm 0.04 \\
2.11 \pm 0.03\end{array}$ & $\begin{array}{l}11 / 19 / 91 \\
11 / 18 / 91 \\
11 / 19 / 91 \\
11 / 18 / 91 \\
11 / 21 / 91 \\
11 / 18 / 91 \\
11 / 25 / 91 \\
11 / 21 / 91 \\
11 / 19 / 91 \\
11 / 20 / 91 \\
11 / 20 / 91\end{array}$ \\
\hline
\end{tabular}




\begin{tabular}{llllll} 
& M2 & $0.57 \pm 0.04$ & $0.045 \pm 0.005$ & $0.35 \pm 0.03$ & $3 / 2 / 92$ \\
& Z500-R & $0.44 \pm 0.02$ & $0.074 \pm 0.005$ & $0.19 \pm 0.02$ & $3 / 1 / 92$ \\
Feb. & Z500-B1 & $1.06 \pm 0.05$ & $0.055 \pm 0.005$ & $0.52 \pm 0.01$ & $2 / 28 / 92$ \\
1992 & Z500-B2 & $0.99 \pm 0.04$ & $0.059 \pm 0.004$ & $0.43 \pm 0.03$ & $2 / 29 / 92$ \\
& Z500-T & $0.56 \pm 0.03$ & $0.050 \pm 0.005$ & $0.29 \pm 0.02$ & $2 / 28 / 92$ \\
& Z67-1 & $0.58 \pm 0.05$ & $0.084 \pm 0.01$ & $0.19 \pm 0.02$ & $2 / 28 / 92$ \\
& Z67-2 & $0.27 \pm 0.03$ & $0.10 \pm 0.05$ & $0.06 \pm 0.02$ & $2 / 28 / 92$ \\
& & & & & \\
\hline & M-0 & $2.33 \pm 0.05$ & $0.039 \pm 0.001$ & $1.29 \pm 0.01$ & $5 / 1 / 92$ \\
& M-35 & $0.58 \pm 0.02$ & $0.048 \pm 0.004$ & $0.30 \pm 0.01$ & $5 / 11 / 92$ \\
April & M-70 & $0.71 \pm 0.02$ & $0.051 \pm 0.002$ & $0.42 \pm 0.02$ & $5 / 1 / 92$ \\
& Z150-N1 & $1.42 \pm 0.04$ & $0.044 \pm 0.002$ & $0.93 \pm 0.04$ & $5 / 2 / 92$ \\
& Z150-D1 & $2.02 \pm 0.04$ & $0.043 \pm 0.001$ & $1.16 \pm 0.02$ & $5 / 3 / 92$ \\
& Z150-L & $1.23 \pm 0.03$ & $0.040 \pm 0.002$ & $0.77 \pm 0.07$ & $5 / 4 / 92$ \\
& Z150-R & $0.84 \pm 0.02$ & $0.028 \pm 0.001$ & $0.58 \pm 0.01$ & $5 / 1 / 92$ \\
& & & & &
\end{tabular}

$N_{t}(t)$ and $N_{a}(t)$ are fitted with exponential functions using a least-squares method. The equations used for the fit are the following:

$$
\begin{aligned}
& \mathrm{N}_{\mathrm{t}}=\mathrm{a} * \exp \left(-\alpha^{*} \mathrm{t}\right) \\
& \mathrm{N}_{\mathrm{a}}=\mathrm{b} * \exp (-\ln 2 * \mathrm{t} / 14.28)
\end{aligned}
$$

The parameters $\mathrm{a}, \alpha$ and $\mathrm{b}$ and their standard errors are given. 
Table A.3. Thickness (d), yield (Y), the counting efficiencies $\left({ }^{33} \varepsilon\right)$, volume of rain water (V) and net count rates at the time of collection $\left({ }^{32} \mathrm{~N}\right.$ and ${ }^{33} \mathrm{~N}$ ) of rain samples collected at Woods Hole (first 3 rows) and at Bermuda. The counting efficiency of ${ }^{32} \mathrm{P}$ is $49 \pm 2 \%$ for all thicknesses encountered.

\begin{tabular}{|c|c|c|c|c|c|c|}
\hline $\begin{array}{l}\text { Sample } \\
\text { date }\end{array}$ & $\begin{array}{l}\mathrm{d} \\
\mathrm{mg} / \mathrm{cm}^{2}\end{array}$ & $\begin{array}{l}\mathrm{Y} \\
\%\end{array}$ & ${ }_{\%}^{33} \varepsilon$ & $\begin{array}{l}{ }^{32} \mathrm{~N} \\
\mathrm{cpm}\end{array}$ & ${ }_{\mathrm{cpm}}^{33} \mathrm{~N}$ & $\begin{array}{l}\text { V } \\
\ell\end{array}$ \\
\hline 27-Dec-90 & $4.50 \pm 0.05$ & $50 \pm 2$ & $18.9 \pm 0.8$ & $10.30 \pm 0.05$ & $4.81 \pm 0.04$ & $52 \pm 1$ \\
\hline 16-Jan-91 & $2.50 \pm 0.03$ & $30 \pm 1$ & $21.7 \pm 0.9$ & $3.72 \pm 0.03$ & $2.05 \pm 0.04$ & $62 \pm 1$ \\
\hline 21-Apr-91 & $1.29 \pm 0.01$ & $14 \pm 1$ & $23.6 \pm 0.9$ & $3.78 \pm 0.10$ & $1.48 \pm 0.07$ & $62 \pm 1$ \\
\hline 05-Mar-91 & $1.80 \pm 0.05$ & $39 \pm 2$ & $22.8 \pm 0.9$ & $2.91 \pm 0.08$ & $1.23 \pm 0.06$ & $37 \pm 2$ \\
\hline 10-Mar-91 & $1.89 \pm 0.02$ & $20 \pm 1$ & $22.6 \pm 0.9$ & $11.65 \pm 0.15$ & $5.93 \pm 0.11$ & $62 \pm 2$ \\
\hline 10-Mar-91 & $1.16 \pm 0.01$ & $14 \pm 1$ & $23.8 \pm 1.0$ & $14.70 \pm 0.32$ & $6.24 \pm 0.06$ & $62 \pm 2$ \\
\hline 20-Mar-91 & $3.40 \pm 0.03$ & $38 \pm 2$ & $20.4 \pm 0.8$ & $11.7 \pm 0.23$ & $5.27 \pm 0.12$ & $60 \pm 1$ \\
\hline 20-Mar-91 & $3.49 \pm 0.03$ & $39 \pm 2$ & $20.2 \pm 0.8$ & $17.79 \pm 0.14$ & $7.97 \pm 0.14$ & $60 \pm 1$ \\
\hline 22-Apr-91 & $2.13 \pm 0.02$ & $24 \pm 1$ & $22.3 \pm 0.9$ & $7.29 \pm 0.09$ & $3.45 \pm 0.09$ & $61 \pm 1$ \\
\hline 22-Apr-91 & $1.44 \pm 0.01$ & $16 \pm 1$ & $23.5 \pm 1.0$ & $2.60 \pm 0.03$ & $1.52 \pm 0.07$ & $60 \pm 1$ \\
\hline 01-May-91 & $4.22 \pm 0.04$ & $41 \pm 2$ & $19.3 \pm 0.8$ & $8.04 \pm 0.11$ & $3.06 \pm 0.15$ & $53 \pm 1$ \\
\hline 11-Jun-91 & $2.05 \pm 0.02$ & $19 \pm 1$ & $22.4 \pm 0.9$ & $3.38 \pm 0.06$ & $1.47 \pm 0.06$ & $60 \pm 2$ \\
\hline 11-Jun-91 & $2.27 \pm 0.02$ & $21 \pm 1$ & $22.0 \pm 0.9$ & $2.39 \pm 0.06$ & $0.83 \pm 0.06$ & $61 \pm 2$ \\
\hline 20-Jun-91 & $4.84 \pm 0.05$ & $54 \pm 2$ & $18.5 \pm 0.8$ & $6.17 \pm 0.06$ & $2.57 \pm 0.05$ & $40 \pm 1$ \\
\hline 27-Jun-91 & $3.47 \pm 0.03$ & $40 \pm 2$ & $20.0 \pm 0.9$ & $5.90 \pm 0.04$ & $2.46 \pm 0.06$ & $62 \pm 1$ \\
\hline 07-Jul-91 & $4.80 \pm 0.05$ & $54 \pm 2$ & $18.5 \pm 0.8$ & $22.9 \pm 0.55$ & $6.10 \pm 0.32$ & $62 \pm 1$ \\
\hline 08-Jul-91 & $2.53 \pm 0.03$ & $25 \pm 1$ & $21.7 \pm 0.9$ & $9.95 \pm 0.07$ & $2.9 \pm 0.13$ & $62 \pm 1$ \\
\hline 18-Jul-91 & $5.45 \pm 0.05$ & $61 \pm 2$ & $17.8 \pm 0.8$ & $13.0 \pm 0.21$ & $4.9 \pm 0.22$ & $62 \pm 1$ \\
\hline 19-Jul-91 & $4.87 \pm 0.05$ & $55 \pm 2$ & $18.4 \pm 0.8$ & $6.49 \pm 0.11$ & $2.82 \pm 0.09$ & $40 \pm 1$ \\
\hline 07-Aug-91 & $4.20 \pm 0.04$ & $47 \pm 2$ & $19.3 \pm 0.9$ & $10.9 \pm 0.27$ & $3.5 \pm 0.13$ & $45 \pm 1$ \\
\hline 26-Aug-91 & $4.80 \pm 0.05$ & $54 \pm 2$ & $18.5 \pm 0.9$ & $12.57 \pm 0.08$ & $4.62 \pm 0.08$ & $61 \pm 2$ \\
\hline 05-Sep-91 & $2.22 \pm 0.02$ & $24 \pm 1$ & $22.1 \pm 0.9$ & $7.48 \pm 0.13$ & $2.51 \pm 0.12$ & $61 \pm 2$ \\
\hline 11-Sep-91 & $3.31 \pm 0.03$ & $36 \pm 2$ & $20.5 \pm 0.9$ & $7.12 \pm 0.06$ & $2.62 \pm 0.05$ & $60 \pm 2$ \\
\hline 14-Sep-91 & $5.24 \pm 0.05$ & $59 \pm 2$ & $18.0 \pm 0.8$ & $4.74 \pm 0.05$ & $1.74 \pm 0.09$ & $62 \pm 2$ \\
\hline 16-Sep-91 & $4.53 \pm 0.05$ & $51 \pm 2$ & $18.9 \pm 0.9$ & $13.55 \pm 0.06$ & $4.19 \pm 0.07$ & $60 \pm 1$ \\
\hline 29-Sep-91 & $4.95 \pm 0.05$ & $56 \pm 2$ & $18.4 \pm 0.8$ & $6.42 \pm 0.14$ & $2.48 \pm 0.07$ & $50 \pm 1$ \\
\hline 28-Oct-91 & $4.76 \pm 0.05$ & $53 \pm 2$ & $18.6 \pm 0.8$ & $12.8 \pm 0.23$ & $3.8 \pm 0.12$ & $62 \pm 1$ \\
\hline
\end{tabular}




\begin{tabular}{lllllll} 
28-Oct-91 & $4.55 \pm 0.05$ & $51 \pm 2$ & $18.8 \pm 0.8$ & $3.9 \pm 0.12$ & $1.25 \pm 0.09$ & $60 \pm 1$ \\
6/7-Nov-91 & $4.84 \pm 0.05$ & $54 \pm 2$ & $18.5 \pm 0.8$ & $10.2 \pm 0.2$ & $3.8 \pm 0.1$ & $49 \pm 1$ \\
17-Nov-91 & $4.95 \pm 0.05$ & $55 \pm 2$ & $18.4 \pm 0.8$ & $14.25 \pm 0.2$ & $4.9 \pm 0.2$ & $60 \pm 1$ \\
16-Jan-92 & $2.58 \pm 0.03$ & $29 \pm 1$ & $21.6 \pm 0.9$ & $2.77 \pm 0.05$ & $1.22 \pm 0.05$ & $62 \pm 2$ \\
21-Jan-92 & $5.00 \pm 0.05$ & $56 \pm 2$ & $18.3 \pm 0.8$ & $21.1 \pm 0.2$ & $8.90 \pm 0.1$ & $61 \pm 2$ \\
25-Jan-92 & $6.00 \pm 0.06$ & $67 \pm 2$ & $17.1 \pm 0.8$ & $7.05 \pm 0.1$ & $2.66 \pm 0.09$ & $60 \pm 1$ \\
31-Jan-92 & $5.62 \pm 0.06$ & $63 \pm 2$ & $17.5 \pm 0.8$ & $9.55 \pm 0.09$ & $3.73 \pm 0.1$ & $46 \pm 2$ \\
02-Feb-92 & $6.05 \pm 0.06$ & $68 \pm 2$ & $17.1 \pm 0.8$ & $5.18 \pm 0.05$ & $2.18 \pm 0.0$ & $61 \pm 1$ \\
14-Feb-92 & $4.44 \pm 0.04$ & $49 \pm 2$ & $19.0 \pm 0.9$ & $10.3 \pm 0.2$ & $3.7 \pm 0.1$ & $62 \pm 2$ \\
17-Mar-92 & $4.10 \pm 0.04$ & $46 \pm 2$ & $19.4 \pm 0.9$ & $2.12 \pm 0.06$ & $0.79 \pm 0.06$ & $62 \pm 2$ \\
26-Mar-92 & $4.67 \pm 0.04$ & $52 \pm 2$ & $18.7 \pm 0.8$ & $8.61 \pm 0.4$ & $3.36 \pm 0.2$ & $62 \pm 2$ \\
26-Mar-92 & $2.45 \pm 0.03$ & $27 \pm 2$ & $21.7 \pm 0.9$ & $4.05 \pm 0.09$ & $1.66 \pm 0.06$ & $46 \pm 2$ \\
& & & & & & \\
\hline
\end{tabular}

Table A.4. Thickness (d), yield (Y), counting efficiencies $\left({ }^{32} \varepsilon\right.$ and $\left.{ }^{33} \varepsilon\right)$ and net count rates at the time of collection $\left({ }^{32} \mathrm{~N}\right.$ and $\left.{ }^{33} \mathrm{~N}\right)$ in plankton tow samples collected with a $67-\mu \mathrm{m}$ plankton net in March 1991.

\begin{tabular}{|c|c|c|c|c|c|c|c|c|c|}
\hline Sample & date & depth & type & $\underset{\mathrm{mg} / \mathrm{cm}^{2}}{\mathrm{~d}}$ & $\begin{array}{l}\mathrm{Y} \\
\%\end{array}$ & $\begin{array}{c}32 \\
\%\end{array}$ & $\begin{array}{c}{ }^{33} \varepsilon \\
\%\end{array}$ & $\begin{array}{l}{ }^{32} \mathrm{~N} \\
\mathrm{cpm}\end{array}$ & $\begin{array}{l}{ }^{33} \mathrm{~N} \\
\mathrm{cpm}\end{array}$ \\
\hline$L^{*}$ & $3 / 4 / 91$ & Surface & tow & $2.86 \pm 0.03$ & I & 49 & $21.1 \pm 1.8$ & $0.37 \pm 0.03$ & $0.27 \pm 0.01$ \\
\hline Z67-R1+ & $3 / 4 / 91$ & Surface & tow & $3.59 \pm 0.04$ & 92 & 49 & $20.0 \pm 1.8$ & $0.58 \pm 0.05$ & $0.96 \pm 0.10$ \\
\hline Z67-R2+ & $3 / 4 / 91$ & Surface & tow & $3.84 \pm 0.05$ & 89 & 49 & $19.8 \pm 1.8$ & $0.79 \pm 0.04$ & $0.22 \pm 0.03$ \\
\hline Z67-R3+ & $3 / 4 / 91$ & Surface & tow & $3.28 \pm 0.04$ & 91 & 49 & $20.5 \pm 1.8$ & $0.12 \pm 0.08$ & $1.25 \pm 0.13$ \\
\hline $\mathrm{Z} 67$ & $3 / 31 / 91$ & Surface & tow & $5.93 \pm 0.06$ & 95 & 49 & $17.2 \pm 1.8$ & $0.63 \pm 0.02$ & $0.13 \pm 0.01$ \\
\hline
\end{tabular}

+ Operationally defined refractory fractions of three individual tows.

* Labile fractions of all three tows combined. 
Table A.5. Thickness (d), yield (Y), counting efficiencies $\left({ }^{32} \varepsilon\right.$ and $\left.{ }^{33} \varepsilon\right)$ and net count rates at the time of collection $\left({ }^{32} \mathrm{~N}\right.$ and $\left.{ }^{33} \mathrm{~N}\right)$ in plankton tows collected with a $300-\mu \mathrm{m}$ net on 29 April-1 May 1991. The samples are triplicates from the same tow.

\begin{tabular}{|c|c|c|c|c|c|c|c|c|c|}
\hline Sample & Date & Depth & Type & $\underset{\mathrm{mg} / \mathrm{cm}^{2}}{\mathrm{~d}}$ & $\begin{array}{l}\mathrm{Y} \\
\%\end{array}$ & ${ }_{\%}^{32} \varepsilon$ & ${ }_{\%}^{33} \varepsilon$ & $\begin{array}{l}{ }^{32} \mathrm{~N} \\
\mathrm{cpm}\end{array}$ & $\begin{array}{l}{ }^{33} \mathrm{~N} \\
\mathrm{cpm}\end{array}$ \\
\hline $\mathrm{Z} 300-2$ & $5 / 1 / 91$ & Surface & night tow & $5.93 \pm 0.1$ & 77 & 49 & $17.2 \pm 0.8$ & $0.77 \pm 0.01$ & $0.36 \pm 0.01$ \\
\hline Z300-3 & $5 / 1 / 91$ & Surface & night tow & $13.1 \pm 0.3$ & 90 & 47 & $11.4 \pm 0.5$ & $1.43 \pm 0.03$ & $0.54 \pm 0.02$ \\
\hline$Z 300-4$ & $5 / 1 / 91$ & Surface & night tow & $13.7 \pm 0.3$ & 74 & 47 & $11.0 \pm 0.4$ & $1.41 \pm 0.02$ & $0.44 \pm 0.02$ \\
\hline
\end{tabular}

Table A.6. Thickness (d), yield (Y), counting efficiencies $\left({ }^{32} \varepsilon\right.$ and $\left.{ }^{33} \varepsilon\right)$ and net count rates at the time of collection $\left({ }^{32} \mathrm{~N}\right.$ and $\left.{ }^{33} \mathrm{~N}\right)$ in suspended particles and in plankton tows collected with a $67-\mu \mathrm{m}$ net during BATS 34, 15-19 July 1991.

\begin{tabular}{|c|c|c|c|c|c|c|c|c|c|}
\hline Sample & date & depth & type & $\underset{\mathrm{mg} / \mathrm{cm}^{2}}{\mathrm{~d}}$ & $\begin{array}{l}\mathrm{Y} \\
\%\end{array}$ & ${ }_{\%}^{32} \varepsilon$ & $\begin{array}{c}{ }^{33} \varepsilon \\
\%\end{array}$ & $\begin{array}{l}{ }^{32} \mathrm{~N} \\
\mathrm{cpm}\end{array}$ & $\begin{array}{l}{ }^{33} \mathrm{~N} \\
\mathrm{cpm}\end{array}$ \\
\hline M1 & $7 / 16 / 91$ & surface & pump & $2.18 \pm 0.02$ & 48 & 49 & $22.1 \pm 0.9$ & $0.45 \pm 0.04$ & $0.15 \pm 0.02$ \\
\hline Z67-10* & * 7/18/91 & Surface & night tow & $8.29 \pm 0.08$ & 87 & 48 & $14.9 \pm 0.5$ & $1.24 \pm 0.06$ & $0.53 \pm 0.05$ \\
\hline Z67-11* & * $7 / 18 / 91$ & Surface & night tow & $7.33 \pm 0.07$ & 82 & 48 & $15.8 \pm 0.6$ & $1.07 \pm 0.04$ & $0.44 \pm 0.03$ \\
\hline Z67-12* & * $7 / 18 / 91$ & Surface & night tow & $3.87 \pm 0.04$ & 87 & 49 & $19.7 \pm 0.8$ & $0.48 \pm 0.03$ & $0.35 \pm 0.03$ \\
\hline Sg-1+ & $7 / 16 / 91$ & Surface & macroalgae & $7.84 \pm 0.08$ & 78 & 48 & $15.3 \pm 0.5$ & $2.01 \pm 0.10$ & $0.99 \pm 0.1$ \\
\hline $\mathrm{Sg}-2+$ & $7 / 16 / 91$ & Surface & macroalgae & $6.93 \pm 0.07$ & 87 & 48 & $16.2 \pm 0.6$ & $2.38 \pm 0.07$ & $1.07 \pm 0.05$ \\
\hline
\end{tabular}

* Triplicates of a plankton tow.

+ Duplicates of a sample of sargassum. 
Table A.7. Thickness (d), yield (Y), counting efficiencies $\left(^{32} \varepsilon\right.$ and $\left.{ }^{33} \varepsilon\right)$ and net count rates at the time of collection $\left(^{32} \mathrm{~N}\right.$ and $\left.{ }^{33} \mathrm{~N}\right)$ in plankton tow and suspended particulate samples (3- $\mu \mathrm{m}$ mesh size) collected during BATS 38, 11-15 November 1991. Z67 and Z300 refer to plankton tows collected with a $67-\mu \mathrm{m}$ and $300-\mu \mathrm{m}$ plankton net. Each tow was split in two except Z67-10.

\begin{tabular}{llllllllll}
\hline Sample & date & depth & type & $\begin{array}{c}\mathrm{d} \\
\mathrm{mg} / \mathrm{cm}^{2}\end{array}$ & $\begin{array}{c}\mathrm{Y}^{32} \\
\%\end{array}$ & $\begin{array}{c}{ }^{33} \varepsilon \\
\%\end{array}$ & $\begin{array}{l}{ }^{32} \mathrm{~N} \\
\mathrm{cpm}\end{array}$ & $\begin{array}{c}{ }^{3} \mathrm{~N} \\
\mathrm{cpm}\end{array}$ \\
\hline $\mathrm{M}-\mathrm{S} 1$ & $11 / 12 / 91$ & surface & pump & $2.62 \pm 0.03$ & 6949 & $21.5 \pm 0.9$ & $0.75 \pm 0.02$ & $0.53 \pm 0.03$ \\
$\mathrm{M}-\mathrm{S} 2$ & $11 / 14 / 91$ & surface & pump & $3.31 \pm 0.03$ & 68 & 49 & $20.5 \pm 0.8$ & $0.63 \pm 0.11$ & $0.48 \pm 0.12$ \\
$\mathrm{Z67-10}$ & $11 / 12 / 91$ & surface & night tow & $2.91 \pm 0.03$ & 67 & 49 & $21.1 \pm 0.8$ & $1.56 \pm 0.05$ & $0.83 \pm 0.05$ \\
$\mathrm{Z67-20*}$ & $11 / 14 / 91$ & $0-60 \mathrm{~m}$ & day tow & $7.76 \pm 0.08$ & 8348 & $15.4 \pm 0.6$ & $2.32 \pm 0.04$ & $1.21 \pm 0.14$ \\
$\mathrm{Z67-21*}$ & $11 / 14 / 91$ & $0-60 \mathrm{~m}$ & day tow & $7.45 \pm 0.07$ & 9048 & $15.7 \pm 0.6$ & $3.02 \pm 0.09$ & $1.56 \pm 0.09$ \\
Z67-30 & $11 / 14 / 91$ & surface & night tow & $9.95 \pm 0.12$ & 9647 & $13.5 \pm 0.5$ & $2.95 \pm 0.2$ & $1.18 \pm 0.12$ \\
Z67-31 & $11 / 14 / 91$ & surface & night tow & $5.09 \pm 0.05$ & 6648 & $18.2 \pm 0.7$ & $1.97 \pm 0.04$ & $1.16 \pm 0.05$ \\
Z300-10 & $11 / 12 / 91$ & surface & night tow & $10.8 \pm 0.13$ & 9547 & $13.0 \pm 0.5$ & $3.97 \pm 0.07$ & $1.60 \pm 0.05$ \\
Z300-11 & $11 / 12 / 91$ & surface & night tow & $6.47 \pm 0.06$ & 9148 & $16.6 \pm 0.7$ & $2.69 \pm 0.04$ & $1.70 \pm 0.07$ \\
Z300-20* $11 / 14 / 91$ & $0-60 \mathrm{~m}$ & day tow & $8.62 \pm 0.09$ & 9548 & $14.6 \pm 0.5$ & $3.56 \pm 0.05$ & $1.88 \pm 0.07$ \\
Z300-21* & $11 / 14 / 91$ & $0-60 \mathrm{~m}$ & day tow & $8.24 \pm 0.08$ & 7948 & $14.9 \pm 0.5$ & $3.31 \pm 0.04$ & $1.84 \pm 0.07$
\end{tabular}

*: tows collected by yoyoing the net on the hydrowire from 0 to the base of the mixed-layer at $60 \mathrm{~m}$.

Table A.8. Thickness (d), yield (Y), counting efficiencies $\left({ }^{32} \varepsilon\right.$ and $\left.{ }^{33} \varepsilon\right)$ and net count rates at the time of collection $\left({ }^{32} \mathrm{~N}\right.$ and ${ }^{33} \mathrm{~N}$ ) in plankton tows and suspended particulate samples (Millipore $3 \mu \mathrm{m}$ ) samples collected during BATS 41A, 24-25 February 1992. Z500 and Z67 refer to samples collected with plankton nets of mesh size $500 \mu \mathrm{m}$ and $67 \mu \mathrm{m}$ respectively. One of the $\mathrm{Z} 500$ was separated into two fractions Z500-T and Z500-B. Z500-T is the fraction that stayed suspended in seawater. Z500-B is the fraction that sank. Z500-B1 and Z500-B2 are duplicates. Z500-R is the refractory fraction of a tow, the labile fraction was lost during processing.

\begin{tabular}{|c|c|c|c|c|c|c|c|c|c|}
\hline Sample & date & depth & type & $\underset{\mathrm{mg} / \mathrm{cm}^{2}}{\mathrm{~d}}$ & $\begin{array}{l}\mathrm{Y} \\
\%\end{array}$ & ${ }_{\%}^{32} \varepsilon$ & $\begin{array}{c}{ }^{33} \varepsilon \\
\varepsilon\end{array}$ & $\begin{array}{l}{ }^{32} \mathrm{~N} \\
\mathrm{cpm}\end{array}$ & $\begin{array}{l}{ }^{33} \mathrm{~N} \\
\mathrm{cpm}\end{array}$ \\
\hline M2 & $02 / 25 / 92$ & surf. & pump & $3.64 \pm 0.04$ & 70 & 49 & $20.0 \pm 0.8$ & $0.51 \pm 0.05$ & $0.19 \pm 0.03$ \\
\hline Z500-R & $02 / 25 / 92$ & surf. & night tow & $4.44 \pm 0.04$ & 71 & 49 & $19.0 \pm 0.8$ & $0.21 \pm 0.01$ & $0.30 \pm 0.04$ \\
\hline Z500-B1 & $02 / 25 / 92$ & surf. & night tow & $9.40 \pm 0.09$ & 94 & 47 & $13.9 \pm 0.5$ & $0.61 \pm 0.02$ & $0.53 \pm 0.03$ \\
\hline $\mathrm{Z} 500-\mathrm{B} 2$ & $02 / 25 / 92$ & surf. & night tow & $10.0 \pm 0.1$ & 93 & 47 & $13.5 \pm 0.4$ & $0.51 \pm 0.04$ & $0.59 \pm 0.06$ \\
\hline Z500-T & $02 / 25 / 92$ & surf. & night tow & $5.20 \pm 0.05$ & 73 & 48 & $15.3 \pm 0.5$ & $0.37 \pm 0.02$ & $0.24 \pm 0.03$ \\
\hline Z67-1 & $02 / 25 / 92$ & surf. & night tow & $4.82 \pm 0.05$ & 72 & 48 & $18.5 \pm 0.7$ & $0.24 \pm 0.02$ & $0.38 \pm 0.07$ \\
\hline Z67-2 & $02 / 25 / 92$ & surf. & day tow & $2.51 \pm 0.03$ & 52 & 49 & $21.7 \pm 0.9$ & $0.07 \pm 0.02$ & $0.21 \pm 0.08$ \\
\hline
\end{tabular}


Table A.9. Thickness (d), yield $(\mathrm{Y})$, counting efficiencies $\left({ }^{32} \varepsilon\right.$ and $\left.{ }^{33} \varepsilon\right)$ and net count rates at the time of collection $\left({ }^{32} \mathrm{~N}\right.$ and $\left.{ }^{33} \mathrm{~N}\right)$ in suspended particles and in plankton tows collected during EN 235 in April 1992 at BATS station. Z150 refer to a tow collected with a $150-\mu \mathrm{m}$ net. Z150-L and R refer to the labile and refractory fractions.

\begin{tabular}{|c|c|c|c|c|c|c|c|c|c|}
\hline Sample & Date & depth & type & $\underset{\mathrm{mg} / \mathrm{cm}^{2}}{\mathrm{~d}}$ & $\begin{array}{l}\mathrm{Y} \\
\%\end{array}$ & ${ }_{\%}^{32} \varepsilon$ & ${ }_{\%}^{33} \varepsilon$ & $\begin{array}{l}32 \mathrm{~N} \\
\mathrm{cpm}\end{array}$ & $\begin{array}{l}{ }^{33} \mathrm{~N} \\
\mathrm{cpm}\end{array}$ \\
\hline M-0 & $4 / 25 / 92$ & surf. & pump & $5.75 \pm 0.06$ & 63 & 48 & $17.4 \pm 0.7$ & $1.81 \pm 0.02$ & $1.09 \pm 0.03$ \\
\hline M-35 & $4 / 25 / 92$ & $35 \mathrm{~m}$ & pump & $3.58 \pm 0.04$ & 36 & 49 & $20.1 \pm 0.9$ & $0.57 \pm 0.11$ & $0.46 \pm 0.12$ \\
\hline M-70 & $4 / 25 / 92$ & $70 \mathrm{~m}$ & pump & $4.65 \pm 0.05$ & 44 & 49 & $18.7 \pm 0.7$ & $0.52 \pm 0.02$ & $0.35 \pm 0.02$ \\
\hline Z150-N1 & $4 / 26 / 92$ & surf. & night tow & $7.00 \pm 0.07$ & 59 & 48 & $16.1 \pm 0.7$ & $1.37 \pm 0.06$ & $0.40 \pm 0.03$ \\
\hline Z150-D1 & $4 / 26 / 92$ & surf. & day tow & $8.27 \pm 0.08$ & 74 & 48 & $14.9 \pm 0.5$ & $1.89 \pm 0.03$ & $0.71 \pm 0.03$ \\
\hline Z150-L & $4 / 26 / 92$ & surf. & night tow & $8.93 \pm 0.09$ & 76 & 48 & $14.3 \pm 0.5$ & $1.25 \pm 0.12$ & $0.41 \pm 0.04$ \\
\hline Z150-R & $4 / 26 / 92$ & surf. & night tow & $6.49 \pm 0.06$ & 68 & 48 & $16.6 \pm 0.7$ & $0.78 \pm 0.02$ & $0.22 \pm 0.01$ \\
\hline
\end{tabular}

Table A.10. Thickness (d), yield (Y), counting efficiencies $\left({ }^{32} \varepsilon\right.$ and $\left.{ }^{33} \varepsilon\right)$ and net count rates at the time of collection $\left(^{32} \mathrm{~N}\right.$ and $\left.{ }^{33} \mathrm{~N}\right)$ of the samples exposed to cosmic rays in Woods Hole $\left(53^{0} \mathrm{~N}\right)$, Mt. Washington $\left(55.7^{\circ} \mathrm{N}\right)$ and l' Aiguille du Midi $\left(47^{\circ} \mathrm{N}\right)$.

\begin{tabular}{|c|c|c|c|c|c|c|c|c|}
\hline Sample & site & $\begin{array}{l}\text { target } \\
\text { element }\end{array}$ & $\underset{\mathrm{mg} / \mathrm{cm}^{2}}{2}$ & $\begin{array}{l}\mathrm{Y} \\
\%\end{array}$ & ${ }_{\%}^{33} \varepsilon$ & $\begin{array}{c}32 \\
\%\end{array}$ & $\begin{array}{l}{ }^{32} \mathrm{~N} \\
\mathrm{cpm}\end{array}$ & $\begin{array}{l}{ }^{33} \mathrm{~N} \\
\mathrm{cpm}\end{array}$ \\
\hline Cl-WH & Woods Hole & $\mathrm{Cl}$ & 3.62 & 81 & 20 & 49 & $0.21 \pm 0.03$ & $0.034 \pm 0.008$ \\
\hline Cl-MW & Mt. Washington & $\mathrm{Cl}$ & 2.18 & 50 & 22 & 49 & $0.55 \pm 0.09$ & $0.045 \pm 0.01$ \\
\hline $\mathrm{Cl}_{4}-\mathrm{MW}$ & Mt. Washington & $\mathrm{Cl}$ & 2.05 & 48 & 22 & 49 & $0.36 \pm 0.02$ & $0.060 \pm 0.01$ \\
\hline K-MW* & Mt. Washington & $\mathrm{K}$ & 9.89 & 90 & 1 & 47 & $0.16 \pm 0.03$ & I \\
\hline S-MW* & Mt. Washington & S & 11.9 & 80 & 1 & 47 & $0.15 \pm 0.03$ & I \\
\hline $\mathrm{Cl}-\mathrm{AM}$ & Aiguille du Midi & $\mathrm{Cl}$ & 3.93 & 78 & 19.6 & 49 & $0.50 \pm 0.03$ & $0.049 \pm 0.004$ \\
\hline
\end{tabular}

* The activity of ${ }^{33} \mathrm{P}$ could not be detected in that sample. 